\title{
SMART SILVER TOWNS: PROSPECTS AND CHALLENGES
}

\author{
SUNG JUN KIM
}

Submitted in total fulfilment of the requirements of the degree of Doctor of Philosophy

December 2017

Faculty of Architecture, Building and Planning

The University of Melbourne 


\begin{abstract}
Korea is facing challenges related to the rapid increase in the aging population combined with minus population growth, and the country is projected to be an aged society within a few years. Further, there has been remarkable growth in information and communication technology (ICT) and the Internet of Things (IoT), which has led to smart-technology-friendly environments at the country and individual levels.

The first apartments were introduced in Korea around five decades ago, and more than half of the country's population now dwell in high-rise and high-density apartment complexes. This enables intensive smart technologies to be directly applied to living environments.
\end{abstract}

The aging population, ICT development, government strategic planning and the high-rise living environment have led to the rise of silver towns, which are high-rise buildings that are integrated with smart technology and facilities to support seniors' independent living.

However, although silver towns are increasingly being conceived, designed and marketed as smart living environments for the elderly, research has not explored the elderly perspective regarding the changes caused by smart technology embedded within these silver towns.

Thus, this research aims to investigate emergent patterns in the design and use of silver towns from the elderly perspective. Data are collected from selected silver towns, including the first development and recently built silver towns, to obtain insights about these developments from the elderly perspective, and to understand the prospects and challenges for future silver towns and smart technologies. 
To correspond with research questions, both qualitative and quantitative methods, i.e., intensive interview, survey and site observation, are used to collect data and data analysis through five selected silver towns.

The research firstly explored current status of newly applied smart technologies in unique elderly living environment, i.e., silver town, from the elderly residents' understanding. It examined the emergent patterns in design and use of silver towns from the senior residents' usage patterns and acceptance of smart technologies embedded in selected silver towns.

The understanding of senior residents' experience and preference regarding smart technologies integrated in silver town provides a design guideline for upcoming development of elderly-centred living environment. In addition, it also supports a selection guideline for future silver town residents. 


\section{Declaration}

This is to certify that:

i) the thesis comprises only my original work towards the degree of Doctor of Philosophy except where indicated in the Preface

ii) due acknowledgement has been made in the text to all other material used

iii) the thesis is fewer than 100,000 words in length, exclusive of tables, maps, bibliographies and appendices.

Signed: On: 15 December 2017 


\section{Acknowledgements}

I can do everything through him who gives me strength (Philippians 4:21).

My humble tribute to the only GOD.

In memory of the late Professor Bharat Dave.

My sincere gratitude to Dr. Peter Raisbeck.

My deepest gratitude to my dearly beloved family.

My late father Keun Hyuck Kim.

My mother Jung Sook Kim.

My sister NaYoung Kim.

My brother-in-law Michael Andrew Wachovec.

My cousin Jimin Kim Wachovec. 


\section{Table of Contents}

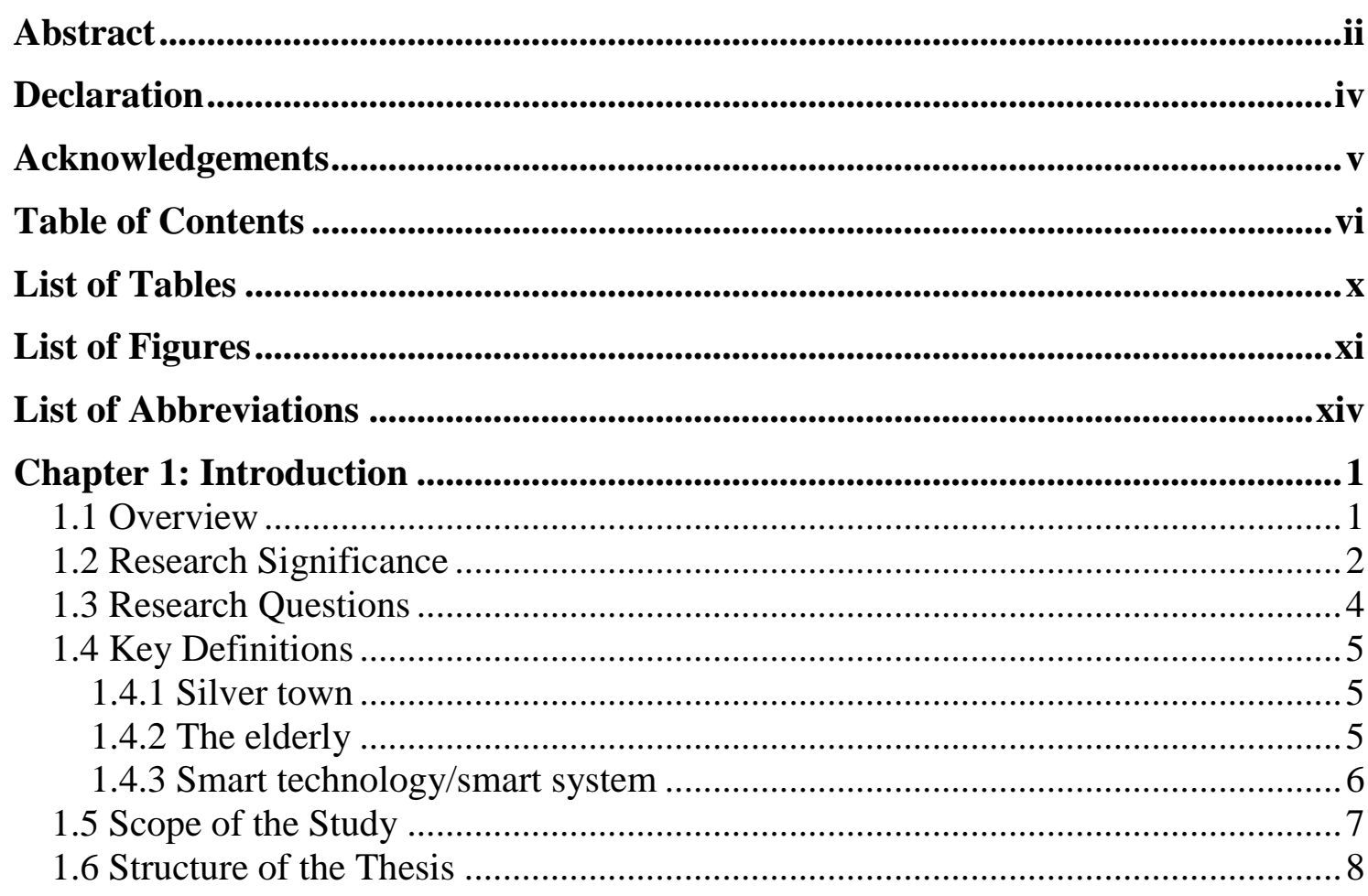

Chapter 2: Research Background ...........................................................................11

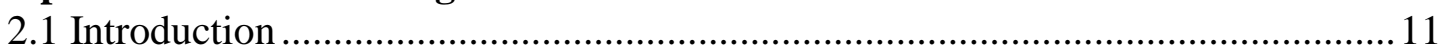

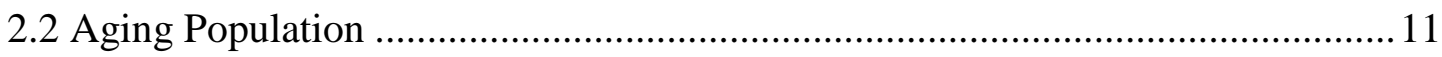

2.2.1 Comparative trends of aging population ................................................... 11

2.2.2 Aging index/population structure/median age ......................................... 13

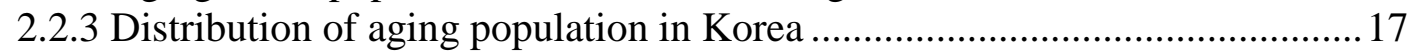

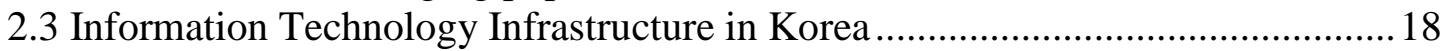

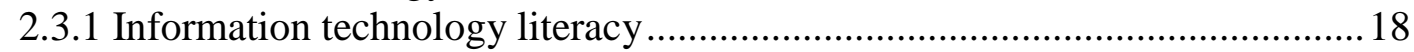

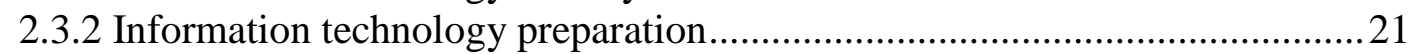

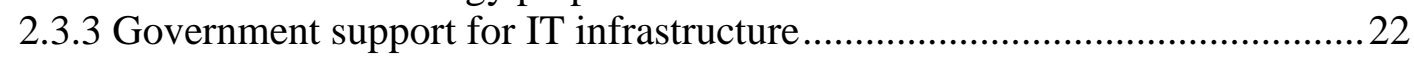

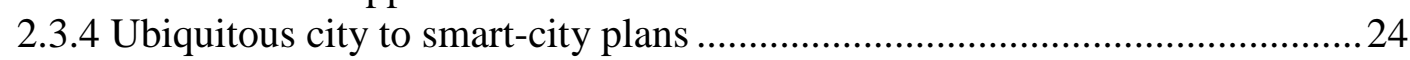

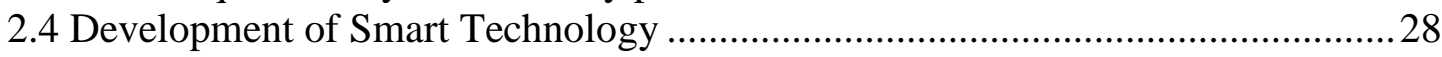

2.5 Transition from Traditional House to Apartments .............................................. 34

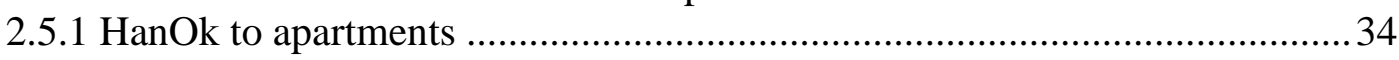

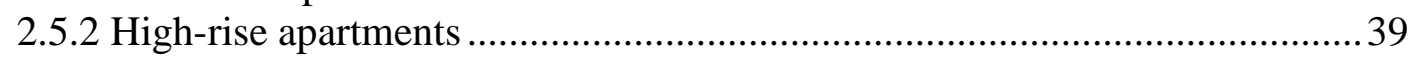

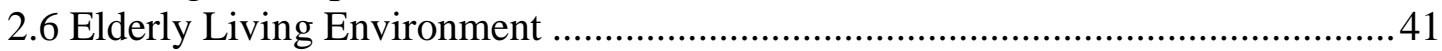

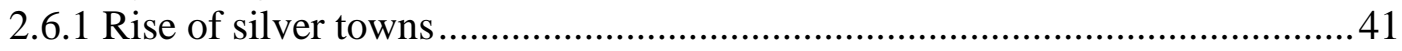

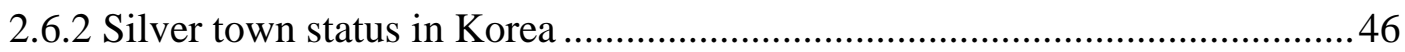

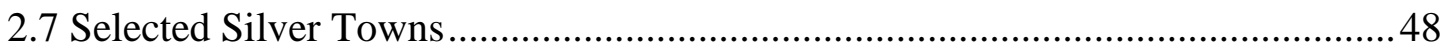

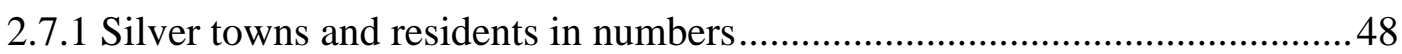

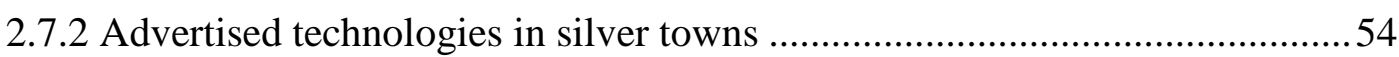

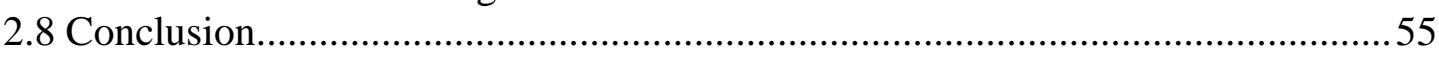

Chapter 3: Previous Research and Research Design..................................................57

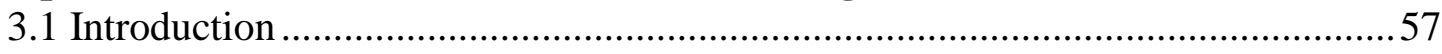

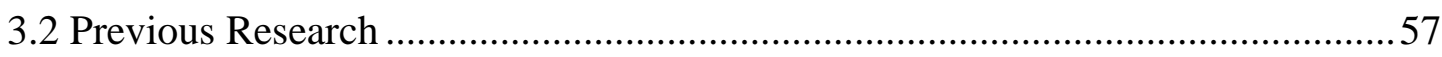

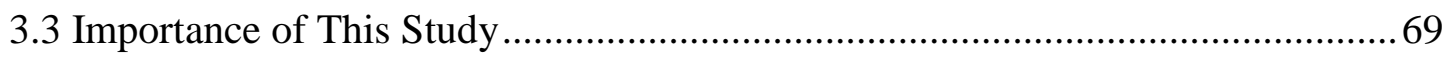




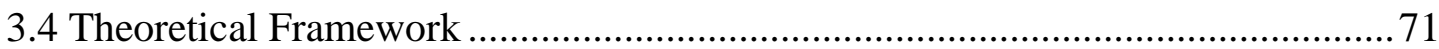

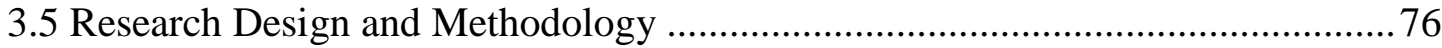

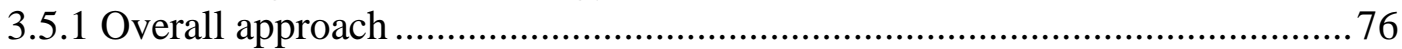

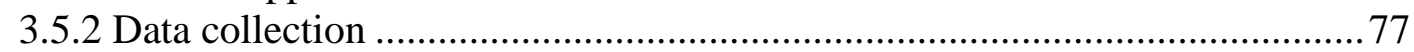

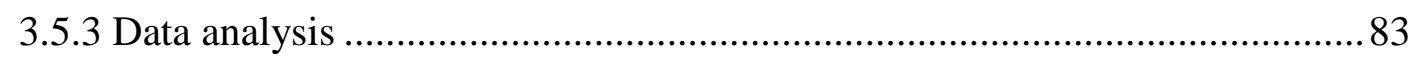

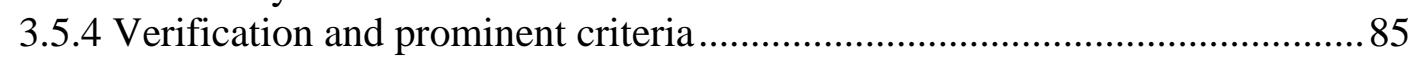

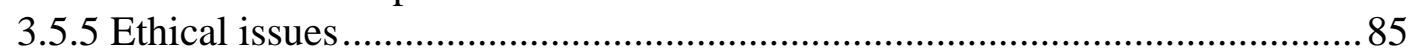

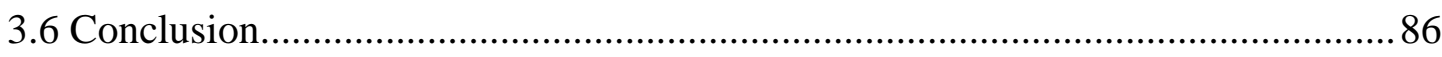

Chapter 4: Elderly in Selected Silver Towns ........................................................88

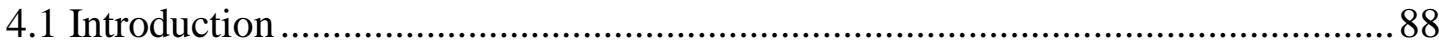

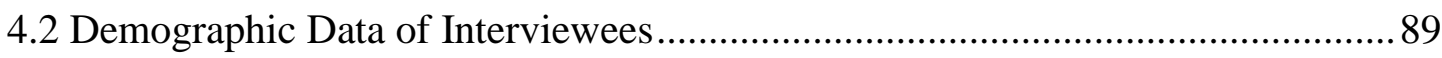

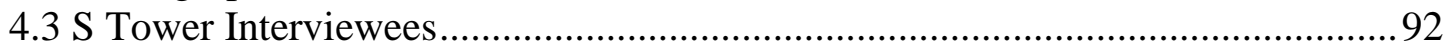

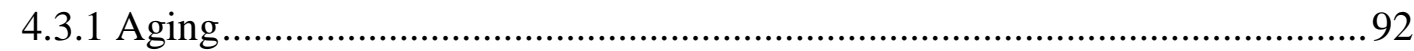

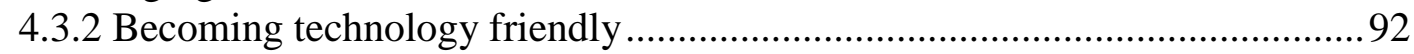

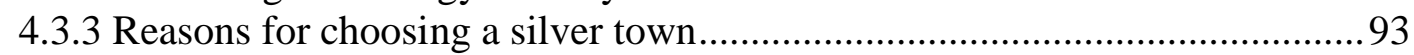

4.3.4 Non-residents' perceptions of silver towns............................................... 95

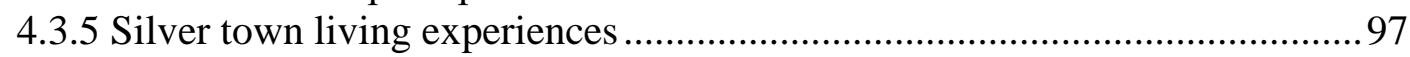

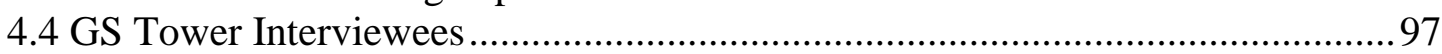

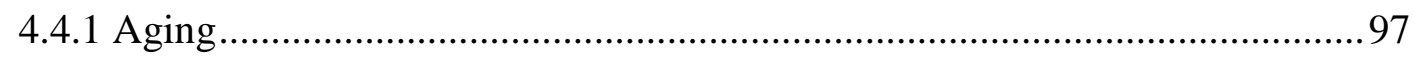

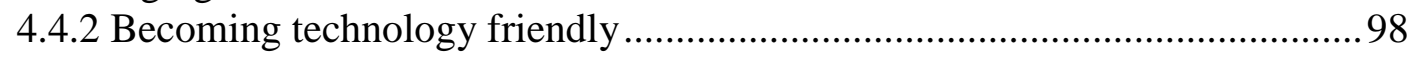

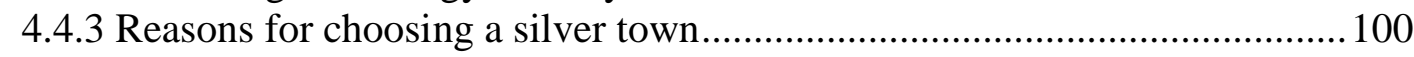

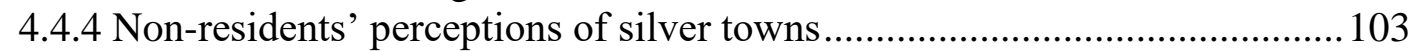

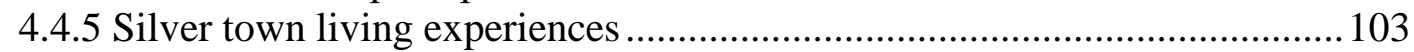

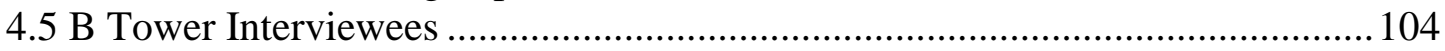

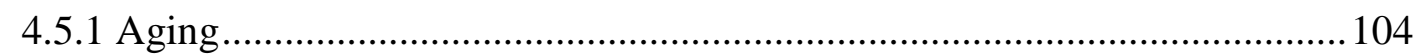

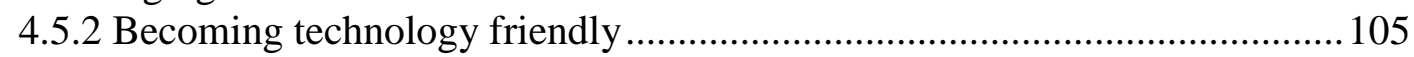

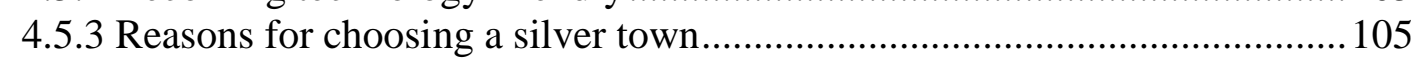

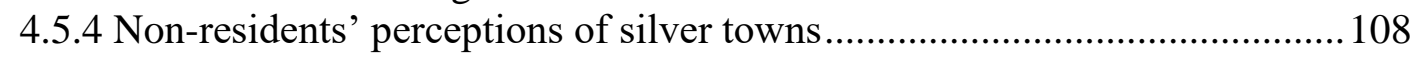

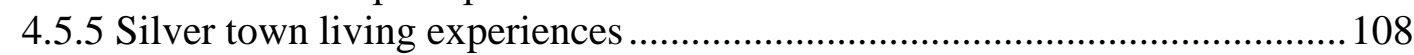

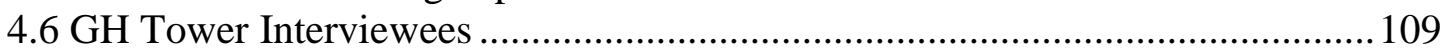

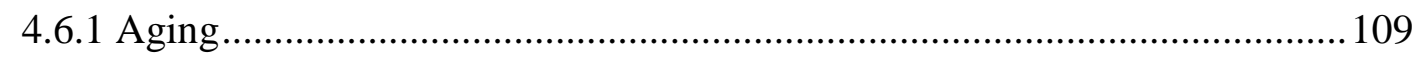

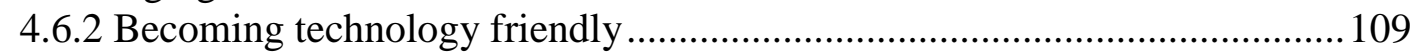

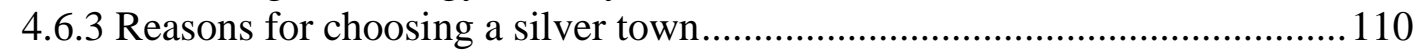

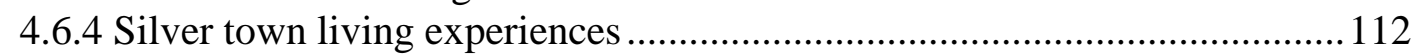

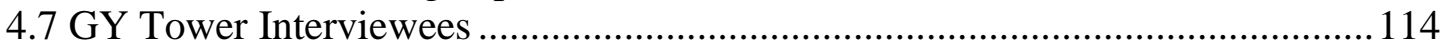

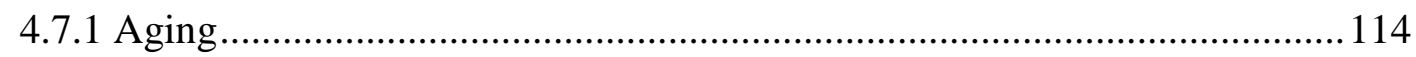

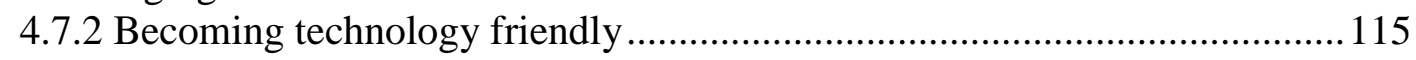

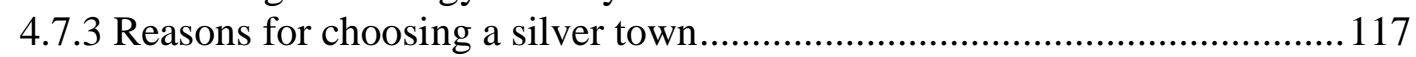

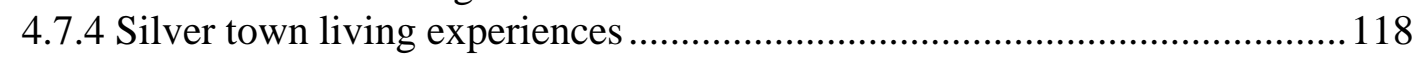

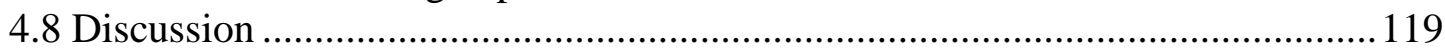

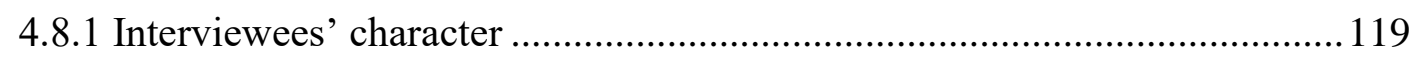

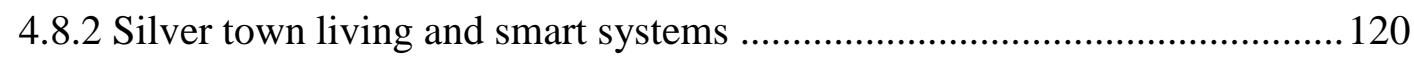

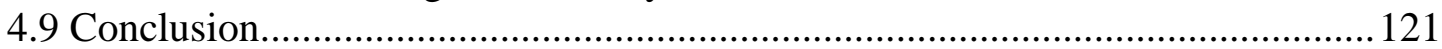

Chapter 5: Applied Smart Technology from the Perspective of Senior

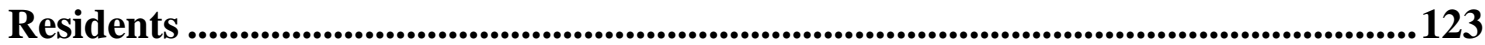

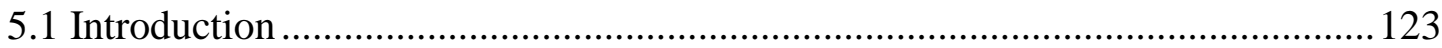

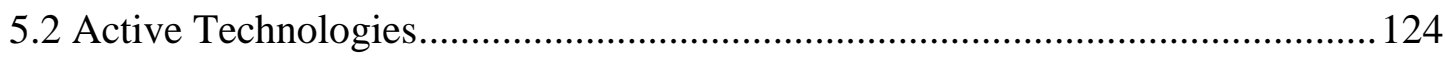

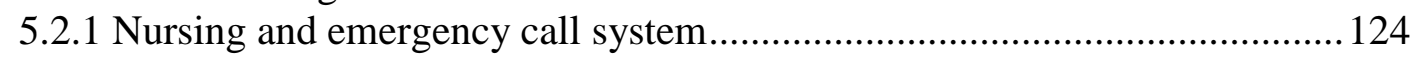

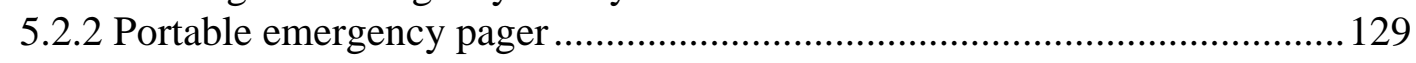




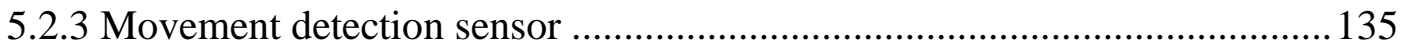

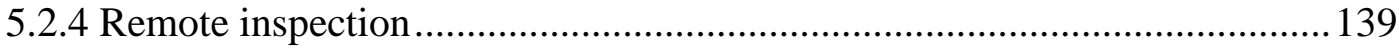

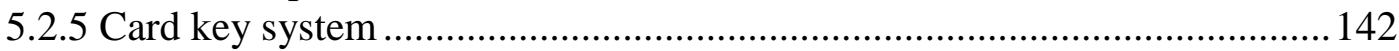

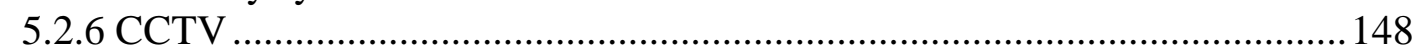

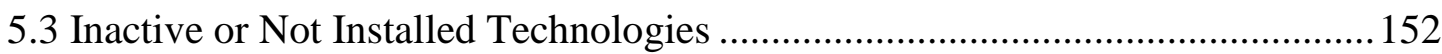

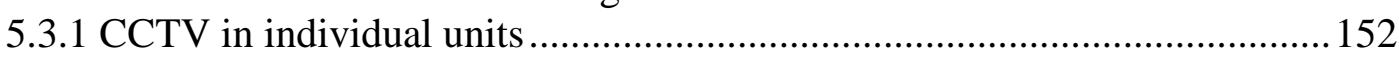

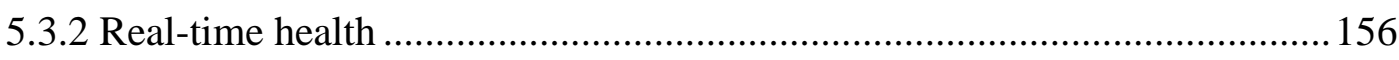

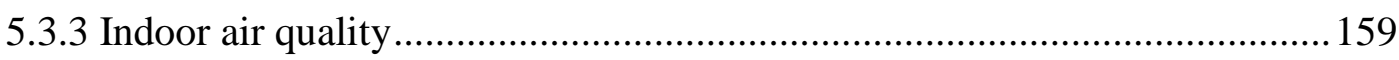

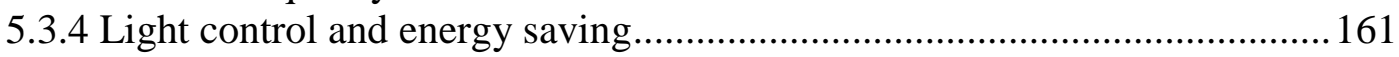

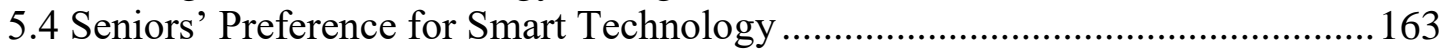

5.5 Experience After Usage of Smart Systems ....................................................... 166

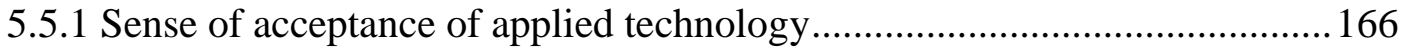

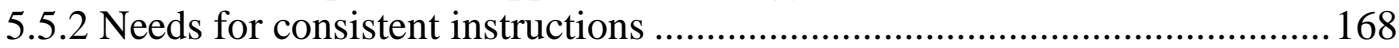

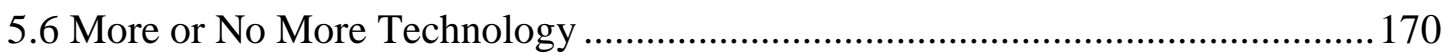

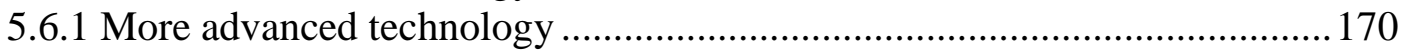

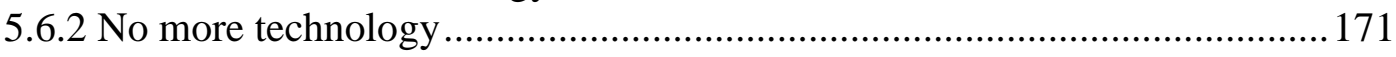

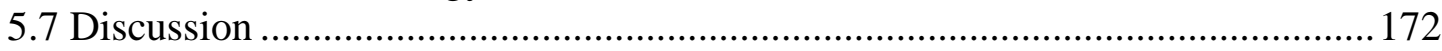

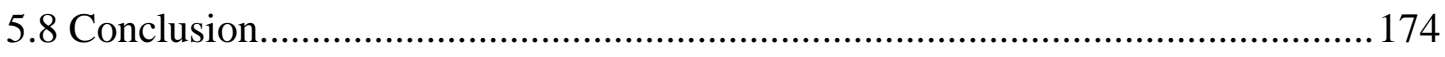

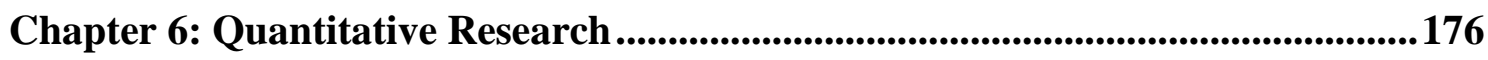

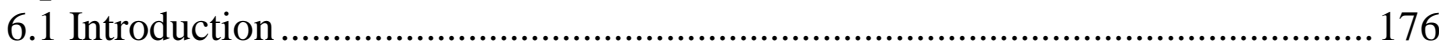

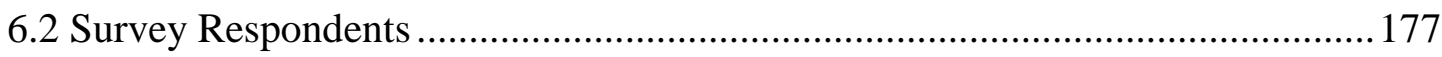

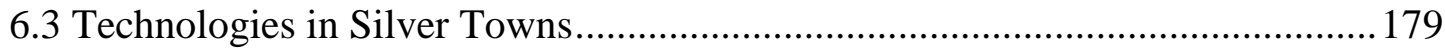

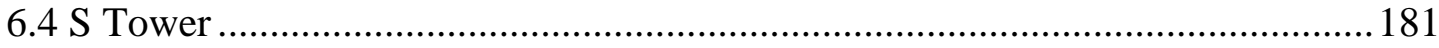

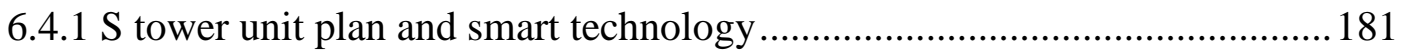

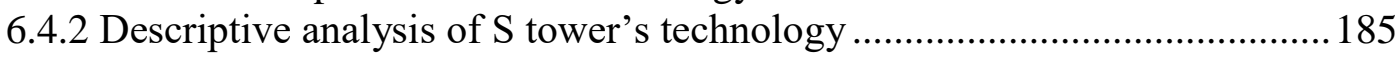

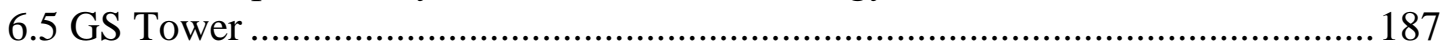

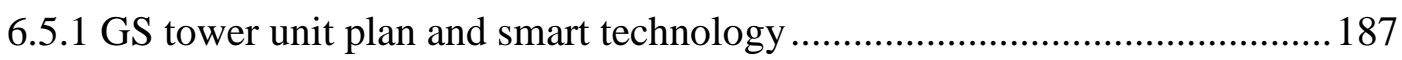

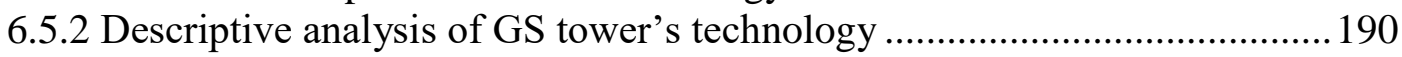

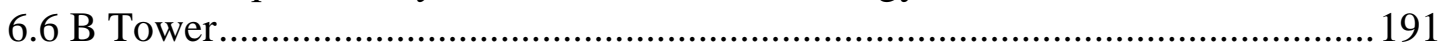

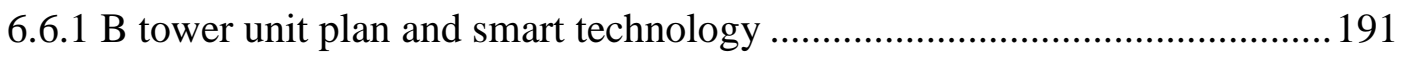

6.6.2 Descriptive analysis of B tower's technology .............................................. 194

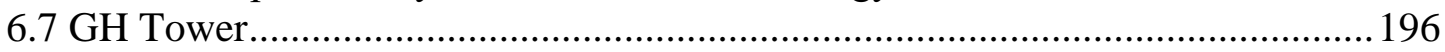

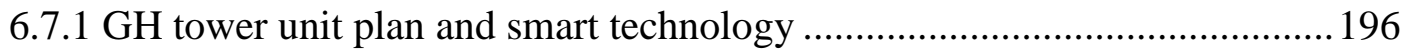

6.7.2 Descriptive analysis of GH tower's technology .....................................201

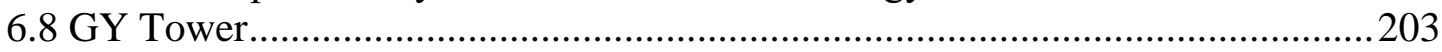

6.8.1 GY tower unit plan and smart technology ..............................................203

6.8.2 Descriptive analysis of GY tower's technology .....................................209

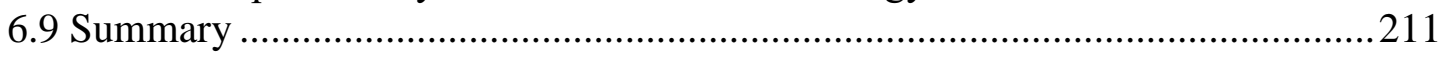

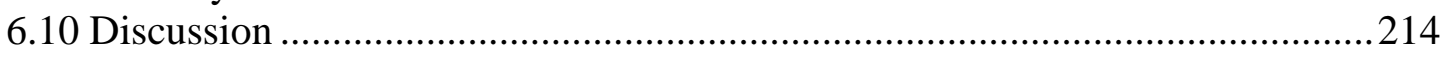

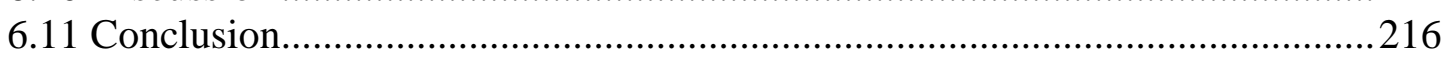

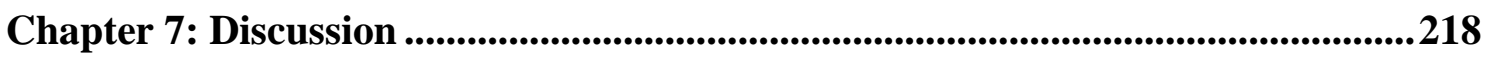

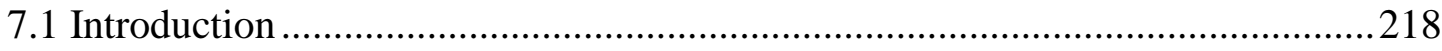

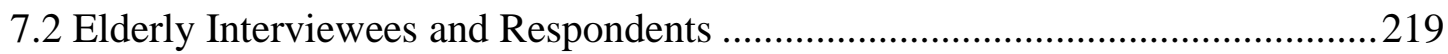

7.3 Range and Intended Purpose of Smart Technologies ........................................220

7.4 Intended Purpose of Smart Technologies ........................................................221

7.4.1 Nursing and emergency call—active technology .......................................221

7.4.2 Movement detection sensor — active technology ....................................223

7.4.3 Portable emergency pager — active technology.......................................225

7.4.4 Card key_active technology ............................................................. 228 


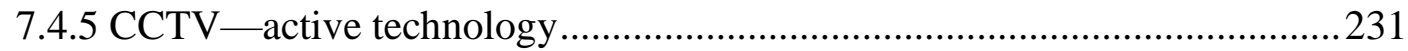

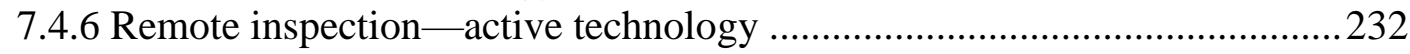

7.4.7 System-related monitors — active technology .........................................2233

7.4.8 Real-time health checks_-installed then currently inactive technology ......235

7.4.9 CCTV inside — installed then currently inactive technology ......................237

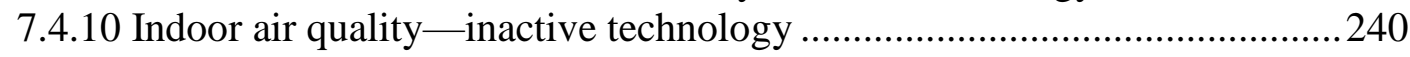

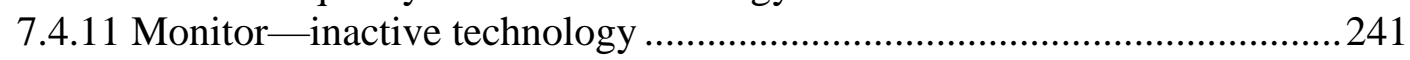

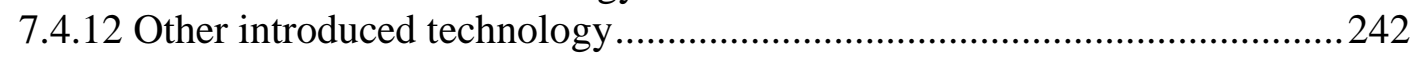

7.5 Usage Patterns and Acceptance of Smart Technologies ....................................243

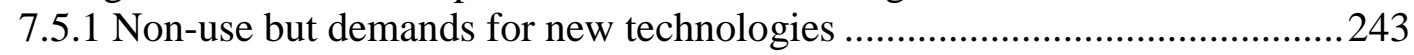

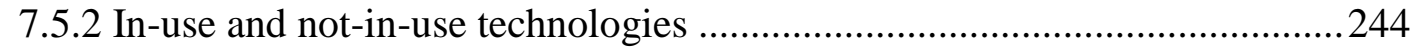

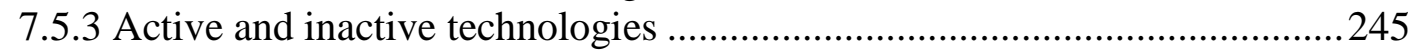

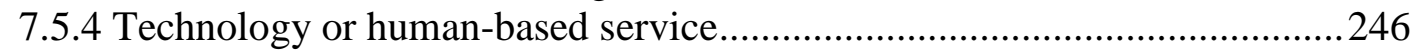

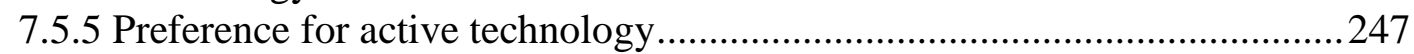

7.6 Usage Patterns and Design Changes in Space ................................................... 249

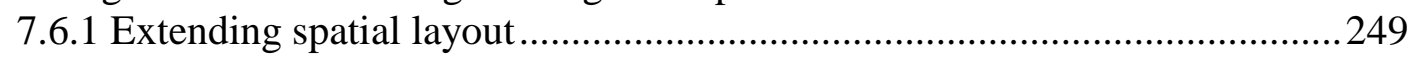

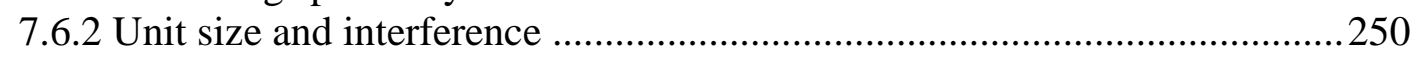

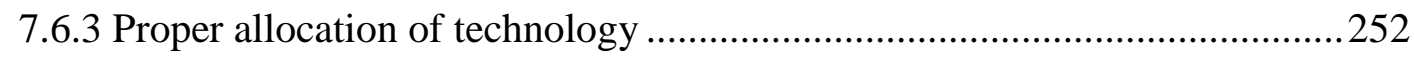

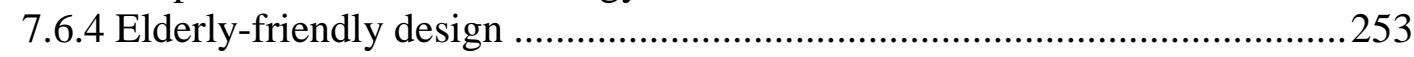

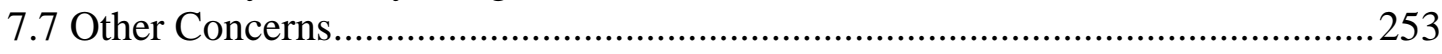

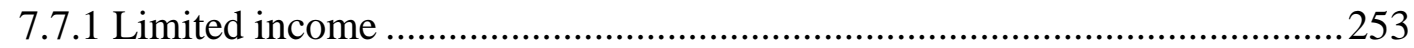

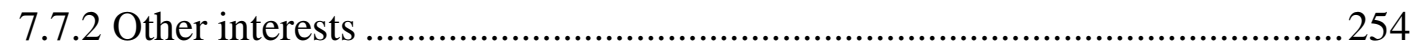

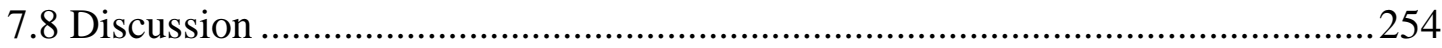

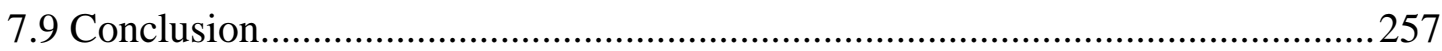

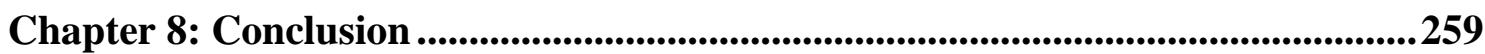

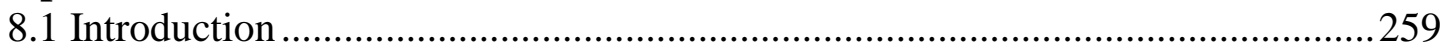

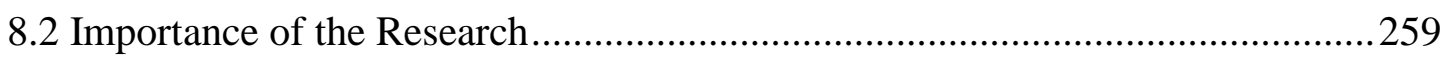

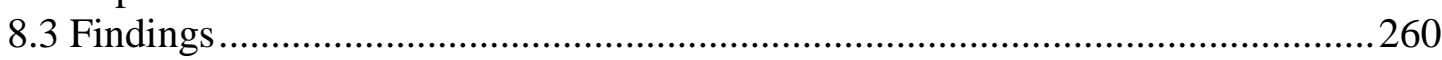

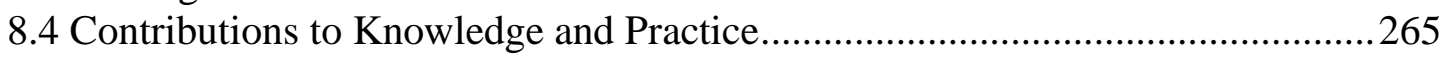

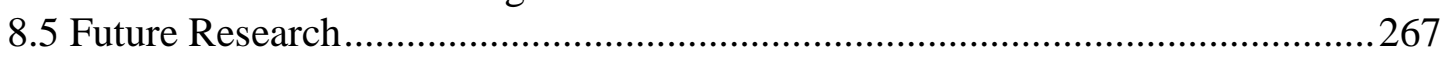

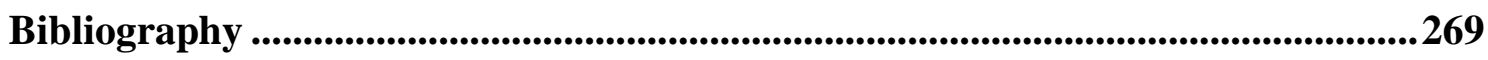

Appendices .........................................................................................................................................2287

Appendix 1. Interview Questions for Elderly_English .................................28

Appendix 2. Interview Questions for Elderly_Korean ...................................2290

Appendix 3. Interview Questions for Developers_English............................. 294

Appendix 4. Interview Questions for Developers-Korean ..............................296

Appendix 5. Survey Questionnaires for Elderly_English................................299

Appendix 6. Survey Questionnaires for Elderly_Korean...................................309 


\section{List of Tables}

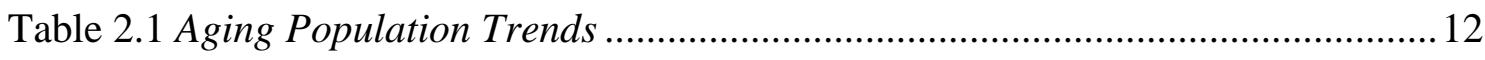

Table 2.2 Population Growth, 2010-2060 (\%) ........................................................... 13

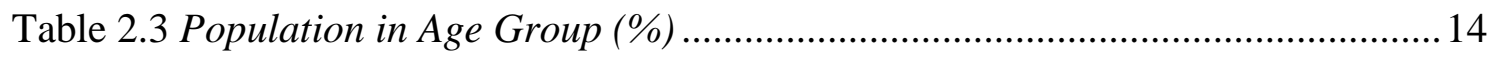

Table 2.4 Population in Select Age Group (\%)........................................................... 15

Table 2.5 Aging Dependency and Aged-Child Ratio (\%)............................................. 16

Table 2.6 Countries with the Oldest Populations: 2015, 2030, 2050 ............................. 16

Table 2.7 Internet Users and Penetration in Selected Countries in the Asia-Pacific

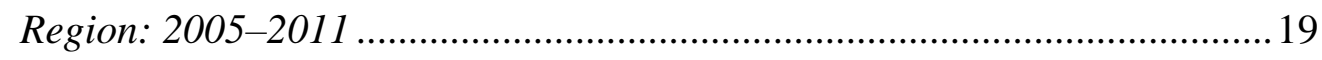

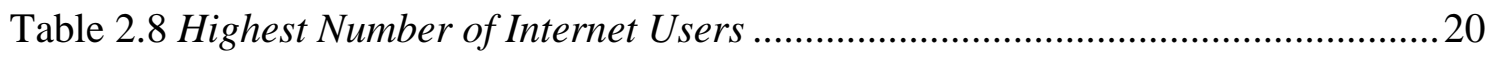

Table 2.9 Average Connection Speed and Broadband Adoption....................................20

Table 2.10 PC Ownership in Households ...................................................................... 21

Table 2.11 Status of Number of Floors of Apartments ....................................................... 40

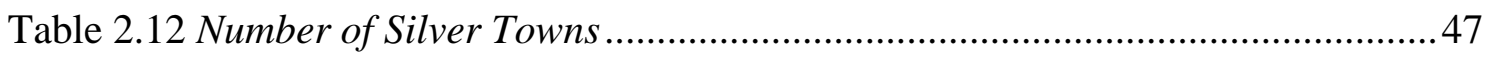

Table 2.13 Smart Technologies in Selected Silver Towns...............................................54

Table 6.1 Average Age and Average Dwelling Period of Selected Silver Town

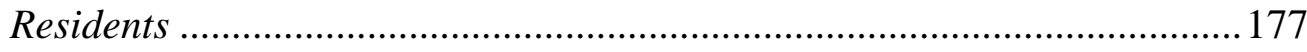

Table 6.2 Gender and Spousal Status of Selected Silver Town Residents .................... 178

Table 6.3 Education Level of Selected Silver Town Residents...................................... 178

Table 6.4 Smart Technologies in Selected Silver Towns ............................................. 180

Table 6.5 Survey Respondents for Active Technology in S Tower (People/\%)............. 185

Table 6.6 Survey Respondents for Active Technology in GS Tower (People/\%).......... 190

Table 6.7 Survey Respondents for Active Technology in B Tower (People/\%) ........... 194

Table 6.8 Survey Respondents for Active Technology in GH Tower (People/\%) ..........201

Table 6.9 Survey Respondents for Active Technology in GY Tower (People/\%)..........209 


\section{List of Figures}

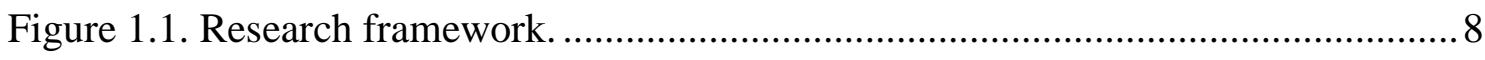

Figure 2.1. Number of years for percentage of population ........................................ 13

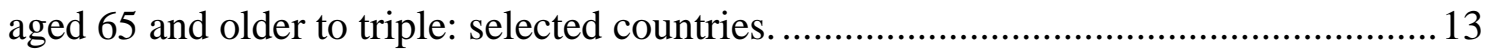

Figure 2.2. Countries with total dependency ratio (per 100 of working age population). 15

Figure 2.3. Distribution of population in metropolitan cities and provinces of Korea... 17

Figure 2.4. Aging index by metropolitan cities and provinces of Korea. ....................... 18

Figure 2.5. Internet penetration rate and PC ownership rate in households. .................. 22

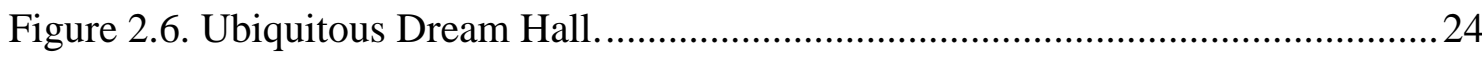

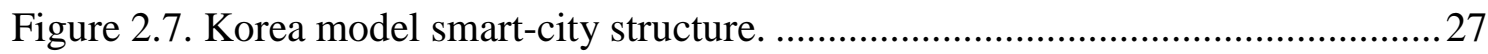

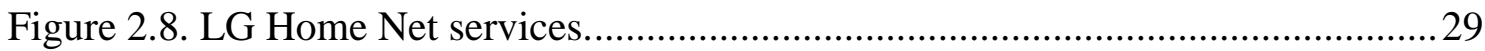

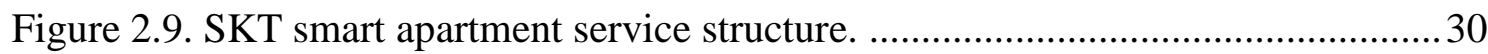

Figure 2.10. Mireaseum-Seongnam Senior Complex............................................ 31

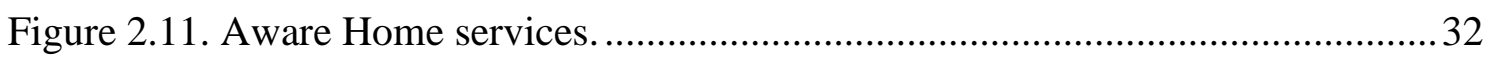

Figure 2.12. MIT PlaceLab example and Oatfield Estates' tracking system................. 33

Figure 2.13. Transition from traditional Korean-style house to apartments."..................36

Figure 2.14. Ideal method of living expenses. .......................................................... 43

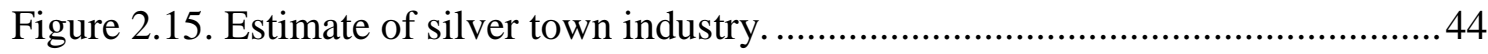

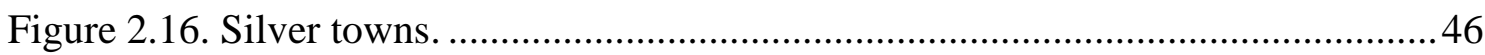

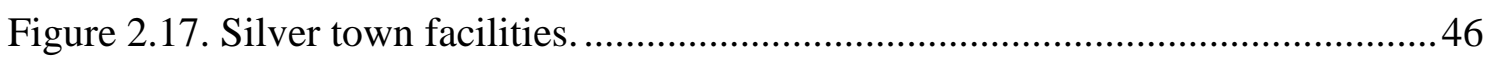

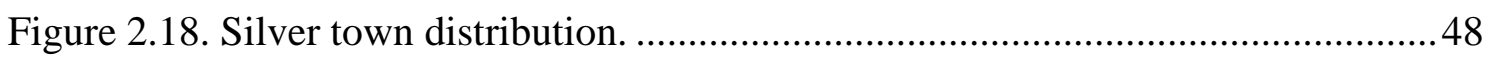

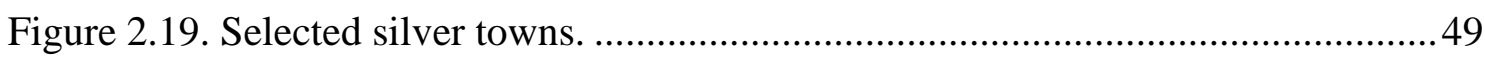

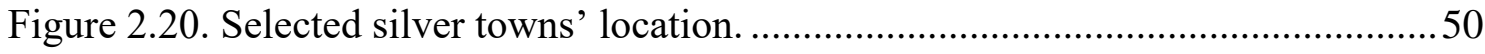

Figure 2.21. Years of construction of silver towns................................................... 51

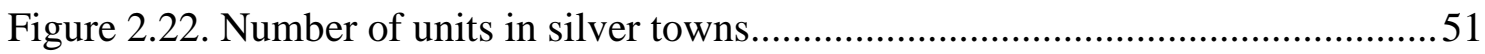

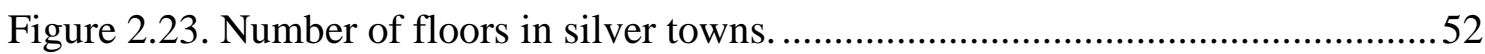

Figure 2.24. Silver town facilities (swimming pool, golf range, pool tables, fitness)....52

Figure 2.25. Silver town facilities (computer, library, cinema, karaoke). ......................53

Figure 2.26. Silver town facilities (walk, lobby, communal restaurant, nursing unit)....53

Figure 2.27. Installed and active technologies in each silver town..............................55

Figure 3.1. Technology acceptance model (Davis, 1989).......................................... 72 
Figure 3.2. Unified theory of acceptance and use of technology (Venkatesh et al., 2003).

Figure 3.3. Senior technology acceptance model (Chen et al., 2014).......................... 74

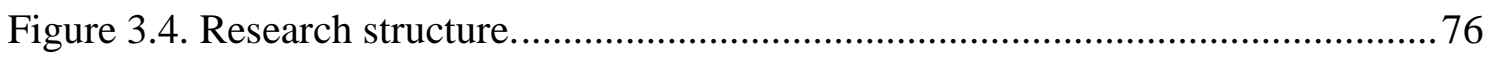

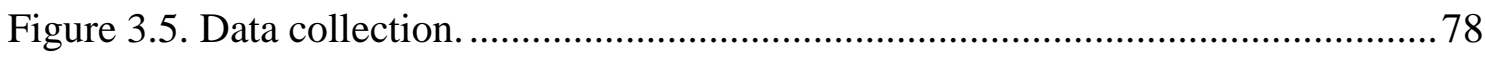

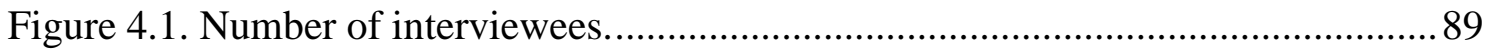

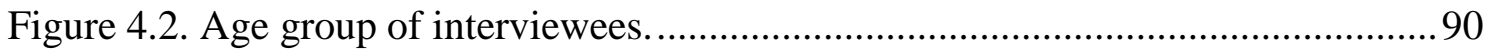

Figure 4.3. Residence period of interviewees. ............................................................ 91

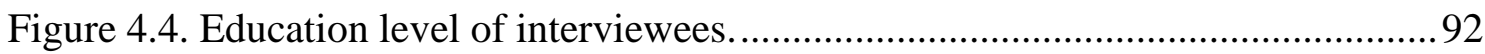

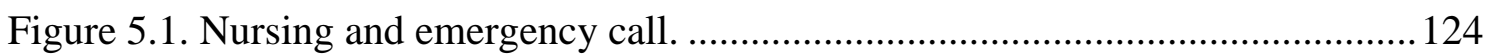

Figure 5.2. Patterns of use of nursing and emergency call. ....................................... 127

Figure 5.3. Portable emergency pager.................................................................. 129

Figure 5.4. Patterns of use of portable emergency pager............................................ 131

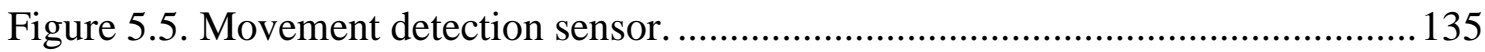

Figure 5.6. Patterns of use-movement detection sensor. ......................................... 137

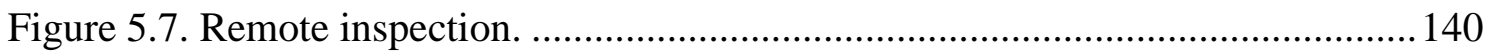

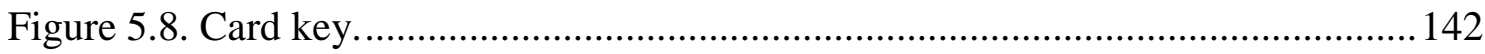

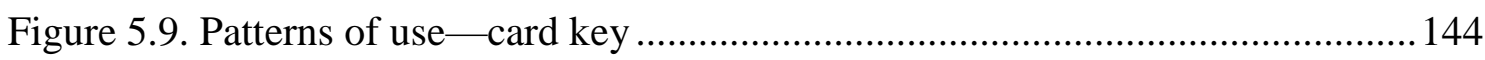

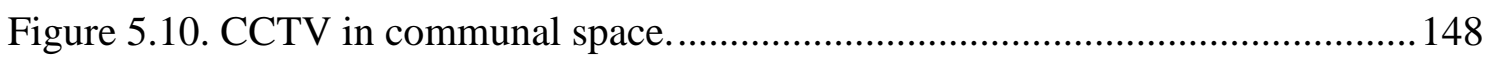

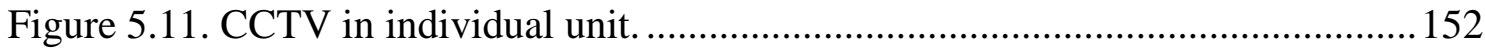

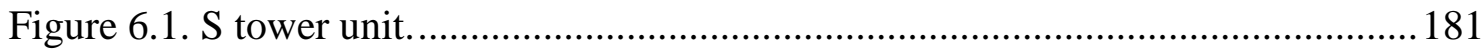

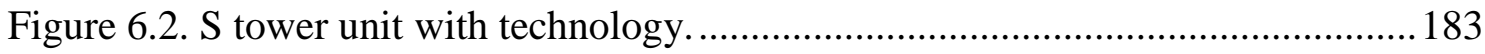

Figure 6.3. Survey respondents' active technology in S tower.................................... 186

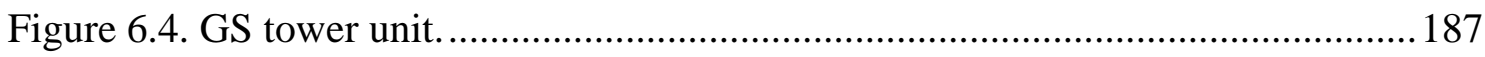

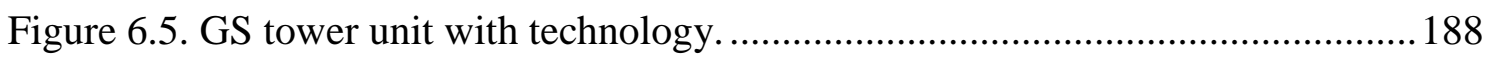

Figure 6.6. Survey respondents for active technology in GS tower........................... 191

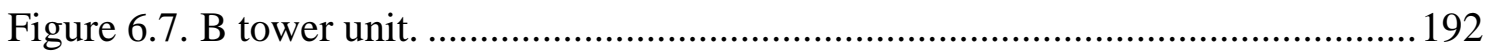

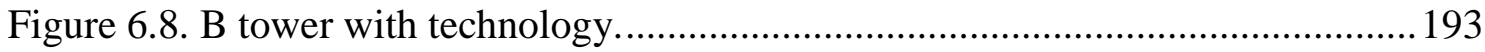

Figure 6.9. Survey respondents for active technology in B tower............................... 196

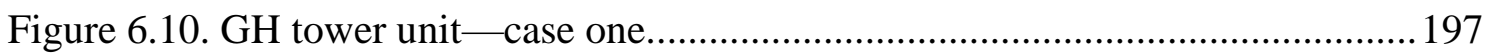

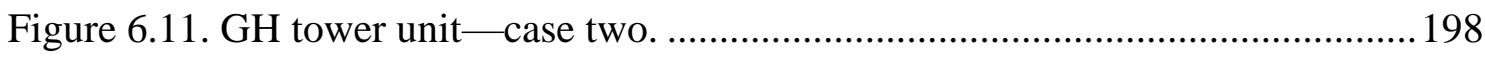

Figure 6.12. GH tower unit with technology...................................................... 199

Figure 6.13. Survey respondents for active technology in GH tower........................202

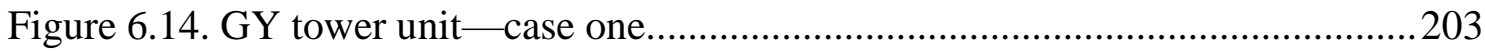




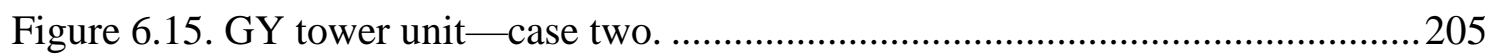

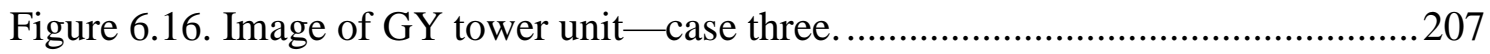

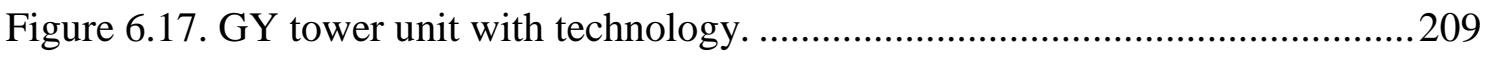

Figure 6.18. Survey respondents for active technology in GY tower.........................210 


\section{List of Abbreviations}

ICT Information and communication technology

ICU Intensive Care Unit

IoT Internet of Things

IPv4 Internet Protocol version 4

IT Information technology

KNSO Korea National Statistical Office

LDK Living, Dining, Kitchen

LK Living, Kitchen

NTT Nippon Telegraph and Telephone Corporation

PC Personal computer

R\&D Research and development

RFID Radio Frequency Identification

SKT SK Telecom

SPSS Statistical Package for the Social Sciences

TAM Technology Acceptance Model

UK United Kingdom

US United States

USN Ubiquitous Sensor Network

UTAUT Unified theory of acceptance and use of technology 


\section{Chapter 1: Introduction}

\subsection{Overview}

In Korea, the recent rise of silver housing, i.e., residential developments for the aged, combined with smart technologies has been underpinned by a confluence of social and technological changes. There has been a significant increase in Korea's aging population compared with other countries. As a result of the rapid increase in the aging population and negative population growth, it is predicted that more than $14 \%$ of the total population will be aged 65 years or more within 19 years. Therefore, deficiencies in housing for the elderly has become an area of increasing interest among researchers.

In addition, information and communication technology (ICT), which is supported by the Korean government, has been rapidly developing. As a result, Korea has created an ICT-friendly environment and has become a frontrunner in the industry. Further, ubiquitous city plans to smart-city plans are targeted for the next move as a strategic industry by the government which enables fulfilment of ICT development.

A shortage of land combined with the introduction of apartment buildings has led to high-rise living environments. The transition from detached house dwellings to apartment living was made within a period of four decades, and more than half of the population now resides in high-rise apartment complexes.

A rapidly aging population and a lack of facilities for the aged have led to recent developments in Korea in the form of silver towers, which are high-rise apartment buildings that are conceived, designed and marketed as smart living environments for the elderly. These developments have been occurring against the backdrop of developments in ICT, in which Korea has invested heavily in recent decades. 


\subsection{Research Significance}

In the past five decades, a combination of increasing urbanisation in Korea and the population concentration in high-density urban $\operatorname{areas}^{1}$ has led to the development of high-rise living environments. ${ }^{2}$ Moreover, as a result of high land prices and a shortage of land, most of the population has moved to live in high-rise apartment buildings. In addition, Korea has the fastest-growing aging population, ${ }^{3,4}$ with older people living alone $^{5}$ in high-rise buildings integrated with smart technology. Further, the government and the technology industry have increasingly been encouraging the adoption of technology as a nationwide strategic plan and as a way of supporting those

1 Hahn, J 1998, Residential differentiation and the structure of housing provision: a case study of Seoul, Korea, 1960-1990, doctoral thesis, University of Wisconsin-Madison.

2 Kim, J \& Choe, S 1997, Seoul: the making of a metropolis, John Wiley \& Sons, England.

3 Korea National Statistical Office 2007, Statistics on the aged, viewed July 2008, http://www.nso.go.kr/eng2006/e01__0000/e01b_0000/e01ba_0000/e01ba_0000.html.

4 Choi, U \& Lee, S 2006, 'A case study on the spatial organization in public areas of silver town', Journal of the Korean Housing Association, vol. 17, no. 2, p. 151.

5 Korea National Statistical Office 2006, Open 2008: result of the 2005 population and housing census, http://www.nso.go.kr/eng2006/e01__0000/e01b_0000/e01ba_0000/e01ba_0000.html. 
changes. ${ }^{6,7,8,9}$ Lastly, most Koreans —including the aging population-are increasingly receptive to the use of information and communication technologies. ${ }^{10}$

These mutually reinforcing changes have encouraged the development of technology integration into high-rise living environments for elderly people who live independently. These silver towns are unique to Korea (i.e., this term is only used in Korea). While retirement communities in Australia, the US and Europe are generally low-rise and low-density communities, silver towns in Korea have been developed in the form of high-rise and high-density buildings that are integrated with smart technologies. Further, the silver town industry is growing and is expected to result in trillion US dollar markets. ${ }^{11,12}$ Thus, silver towns receive public attention and constitute significant social and economic issues. As a result, the phenomenon of silver towns in Korea is qualitatively different from other places and therefore requires further research. Previous research by other researchers has not examined the effects of technology integrated into silver town developments on aged living environments from

6 Yun, K, Lee, H \& Lim, S 2002, The growth of broadband internet connections in South Korea: contributing factors, working paper, Asia/Pacific Research Center, Stanford University.

7 Kim, Y 2007, 'Understanding of U-CITY', Construction Engineering/Ssang Yong, vol. 45, winter, pp. 25-28.

8 Korean Communications Commission, Dynamic IT Korea, viewed August 2008, http://www.dynamicitkorea.org/policy/itKorea.jsp.

9 'The core strategy of IT-839 is making “ubiquitous" environment' 2006, Digital Daily_Internet News, 2 August, viewed June 2008, http://www.ddaily.co.kr/news/news_view.php?uid=7702.

10 Yun, K, Lee, H \& Lim, S 2002, The growth of broadband internet connections in South Korea: contributing factors, working paper, Asia/Pacific Research Center, Stanford University.

11 Korean Association of Senior Industry, viewed July 2008, http://www.kasinet.or.kr.

12 Korea Institute for Health and Social Affairs, viewed August 2008, http://www.kihasa.re.kr/html/jsp/. 
the perspective of the elderly, what the elderly think of these technologies, the extent to which they adopt and find these technologies useful, how they use and interact with these technologies, and the types of changes they lead to in the aged spatial environment in silver towns. This research aims to fill these gaps in the literature.

\subsection{Research Questions}

Recent developments of silver towns integrated with smart technologies in Korea have demonstrated a growing need for and acceptance of high-rise, high-density neighbourhoods that focus on the elderly living environment and population. Although some existing studies have compared developments in aged housing in Korea with similar environments in Japan and the United States (US), no existing in-depth studies have analysed the introduction and adoption of smart technologies in silver housing in Korea from the perspective of elderly residents.

The broad aim of this research is to examine how smart technologies integrated into elderly living environments - generally referred to as silver towns - in Korea have influenced spatial and living patterns from the perspective of elderly residents.

The main research question for this study is: 'What are the emergent patterns in the design and use of silver towns integrated with smart technologies from the elderly perspective?'

This research question will be answered by collecting and analysing data from selected smart technologies that have recently been integrated into silver town developments in Korea. This will identify:

- the range and intended purposes of smart technologies that have been introduced the perspective of elderly residents

- patterns of use of smart devices and technologies

- changes in spatial layouts resulting from the use of new technologies. 
Another point likely to emerge from the investigation relates to the aspects of spatial design and technology that need to be different for elderly people.

\subsection{Key Definitions}

\subsubsection{Silver town}

The term 'silver town' is used only in Korea; 'silver' refers to the grey hair colour of the elderly, and the town is where people live and work. In other countries, these environments are generally known as retirement communities or assisted living. Silver towns include, or are affiliated with, leisure facilities, a general hospital and a community centre to support elderly living. ${ }^{13}$ In this research, 'silver town' is used interchangeably with 'silver tower', because the silver towns selected for this study are high-rise buildings that comprise a residential section, which accommodates hundreds of elderly residents, as well as other support facilities, such as an on-site clinic, a fitness centre and a communal dining room.

\subsubsection{The elderly}

The Oxford Living Dictionary ${ }^{14}$ defines 'elderly' as a person who is old or aging. Merriam-Webster ${ }^{15}$ defines 'elderly' as a person who is past middle age or has a characteristic of later life. Further, it includes terms such as 'aged', 'aging', 'ancient', 'old', 'senior', and 'long-lived'. ${ }^{16}$ In this study, terms such as 'elderly', 'senior' and

13 'Silver town' n.d., Terminology Dictionary of Urban Planning of Seoul, viewed June 2017, http://terms.naver.com/entry.nhn?docId=1826417\&cid=42151\&categoryId=42151.

14 'Elderly’ n.d., Oxford Living Dictionary, viewed June 2015,

https://en.oxforddictionaries.com/definition/elderly.

15 'Elderly’ n.d., Mirriam-Webster, viewed June 2015,

https://www.merriam-webster.com/dictionary/elderly.

16 'Elderly’ n.d., Mirriam-Webster, viewed June 2015,

https://www.merriam-webster.com/thesaurus/elderly. 
'old generation' are used in Chapters $4-8$ to refer to elderly residents in silver towns aged 60 years or older. In addition, a condition of residing in a silver town is that elderly residents must not have a serious disability; they must be able to maintain independent living, even if they require a small amount of medical assistance. ${ }^{17}$

\subsubsection{Smart technology/smart system}

According to IGI Global, smart technologies include sensors, databases and wireless access that work collaboratively to sense, adapt to and provide for users within the environment. These smart technologies are currently found in housing designs for the elderly. ${ }^{18}$ Smart systems incorporate sensing, actuation and control functions to describe and analyse a situation and make decisions based on the available data in a predictive or adaptive manner, thereby performing smart actions. In most cases, the 'smartness' of the system can be attributed to autonomous operations based on closed loop control, energy efficiency and networking capabilities. ${ }^{19}$ In this study, the terms 'technology' and 'devices' are used in Chapters 4-8 to describe technologies embedded in silver town by developers to support elderly residents' independent living. Applied smart technologies or systems are categorised as care-related, environmental-controlrelated, security-related and systems in public areas. For example, nursing and emergency call systems and movement detection sensors enable residents to contact on-

17 'Enforcement regulation of the elderly welfare act' viewed Aug. 2017, http://www.law.go.kr/lsInfoP.do?lsiSeq=178901\#0000

18 'Smart Technology’ n.d., IGI Global, viewed June 2017, https://www.igi-

global.com/dictionary/smart-technology/38186.

19 'Smart system' 2017, Wikipedia, The Free Encyclopedia, viewed June 2017,

https://en.wikipedia.org/wiki/Smart_system. 
site staff members or nurses in the event of an emergency. Further, card keys are used to control energy supply and access to residents' units and other facilities in silver towns.

\subsection{Scope of the Study}

Encouraged by the Korean government's strategy ${ }^{20}$ and infrastructure development plans, ${ }^{21}$ the broadband Internet business has grown rapidly in Korea, ${ }^{22}$ and smart technologies are increasingly being integrated into living environments for the elderly. This phenomenon not only makes older adults technology-ready, but it also influences changes in these environments. This study examines how the integration of smart technologies into silver towns affects aged living from the perspective of the elderly. Hence, this research is aware of current trends in smart technology supporting the elderly and silver town developments in Korea and elsewhere as part of the research background, but it does not focus on the development of smart technology per se or whether it is desirable in the design of living environments for the elderly.

To identify and analyse changes in the aged living space embedded with smart technology from the perspective of the elderly, it is necessary to understand the range and intended purposes of the technology integrated into silver towns. More importantly, this research aims to understand which smart technologies the elderly use and why. This is complemented by an understanding of the spatial changes in living environments for the elderly resulting from the integration of smart technologies in silver towns.

20 'The core strategy of IT-839 is making “ubiquitous" environment' 2006, Digital Daily_Internet News, 2 August, viewed June 2008, http://www.ddaily.co.kr/news/news_view.php?uid=7702.

21 Kim, Y 2007, 'Understanding of U-CITY', Construction Engineering/Ssang Yong, vol. 45, winter, pp. $25-28$.

22 Yun, K, Lee, H \& Lim, S 2002, The growth of broadband internet connections in South Korea: contributing factors, working paper, Asia/Pacific Research Center, Stanford University. 


\subsection{Structure of the Thesis}

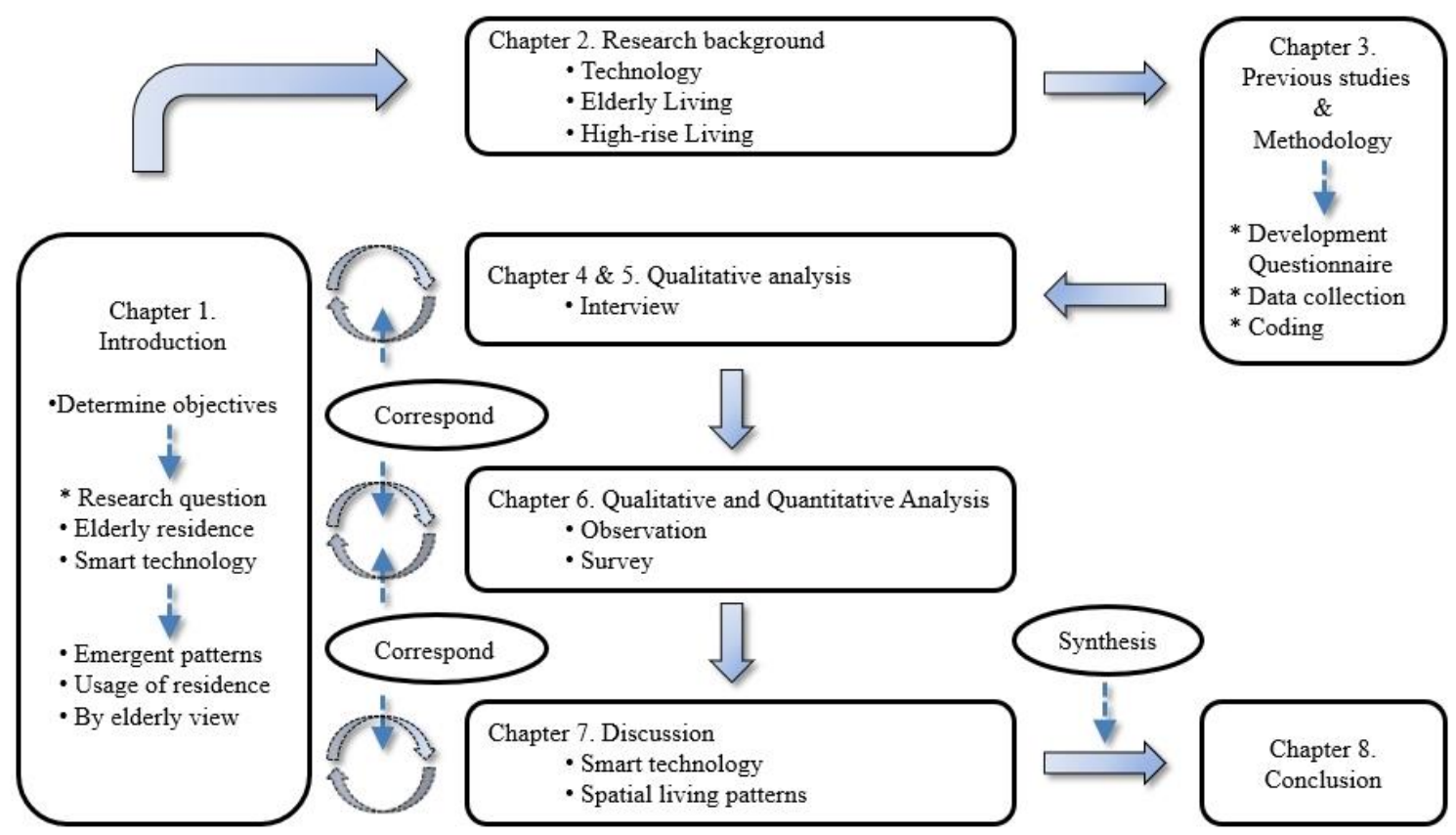

Figure 1.1. Research framework.

Chapter 1 outlines the thesis. It presents the initial research background and significant issues leading to the research questions, which aim to understand patterns of design and use relating to the new type of elderly living environment integrated with smart systems from the elderly perspective. The research framework illustrates the steps conducted in the research, the scope of the study and its limitations. Lastly, the chapter defines important terms that are used in the study.

Chapter 2 introduces the research background and the issue of the rapid increase in Korea's aging population. It examines how information technology development has combined with the government's strategic planning to make Korea a frontrunner in ICT. The chapter discusses how the country has rapidly changed from traditional detached house dwellings to high-rise living environments embedded with supportive smart technology. It examines the new type of elderly living environment — that is, silver towns embedded with smart technologies - from the elderly perspective. 
Chapter 3 reviews previous research into silver towns. Further, it demonstrates the theoretical background and framework to analyse collected data from intensive interviews, surveys and site observations. These research methods aim to gather information by interacting with the elderly residents and analysing the information to answer the research questions.

Chapter 4 contains the first part of the qualitative analysis of the interviews with the elderly residents. It provides demographic data of the interviewees to provide an understanding of their character and their attitude towards modern technology and its development. It then analyses specific smart technologies integrated into silver towns. In addition, it examines the elderly residents' understanding of and experiences with silver towns integrated with smart technology to comprehend the design and use of the elderly-only living environment.

Chapter 5 presents the second part of the qualitative analysis, which targets introduced technologies from the elderly perspective. Advertised technologies are narrowed down to applied technologies to provide an understanding of the range of technologies available in silver towns. The applied technologies are classified into care, environment control, security and public-related technology, which are then divided into active, inactive and not installed. Each technology is explored from the perspective of the elderly residents, followed by that of the developers. Moreover, it examines the most and least important technologies from the elderly perspective, and whether there are more demands on additional technological support in silver towns for current and the next silver town development from the seniors' understanding.

Chapter 6 presents the quantitative analysis of the surveys and site observations to support the analysis of the interviews. It presents demographic data of the elderly participants from the selected silver towns, and it introduces the smart technologies in 
terms of residents' awareness, frequency of use and satisfaction. The site observations illustrate how the residents interact with their new living environment and how the smart technologies are used in individual units.

Chapter 7 presents the intersectional findings of the data analysis using three different methods to understand the elderly perspective of changes in the design and use of their new living environment, which is integrated with smart technologies. Moreover, it discusses issues arising from the introduced technologies from the elderly perspective. It also presents developers' opinions as subsidiary information.

Chapter 8 summarises the research findings regarding Korea's elderly society, silver towns as a new type of living environment, supportive smart technologies and silver towns integrated with smart technology systems. It discusses contributions in terms of theory, practical field and knowledge. The chapter concludes with a discussion of the limitations of the study and directions for future research. 


\section{Chapter 2: Research Background}

\subsection{Introduction}

In Korea, the development of smart homes for the elderly has been underpinned by three connected phenomena. First, aging population trends verify the need for elderly- only living environments. Second, ICT, which is a strong field in Korea, is supported by the government's strategy to establish smart environments throughout the country. Lastly, traditional detached houses are changing to high-rise, high-density living environments, which are relatively well suited for the application of smart technologies.

The proceeding chapter 2 provides background on the key aspects that explain the significant effects on the emerging elderly-only living environment. Aging population trends and IT infrastructure were illustrated, as well as government policies. Moreover, it demonstrated a general understanding of the transition from traditional houses to high-rise, high-density living environments in Korea.

This chapter discusses the status of the senior industry and the development of selected silver towns in Korea.

\subsection{Aging Population}

\subsubsection{Comparative trends of aging population}

The Korea National Statistical Office (KNSO) defines an aging society as one in which $7 \%-14 \%$ of the total population is aged 65 years or more. Statistical data released by the KNSO in July $2007^{23}$ show that Korea's aging population increased to $9.9 \%$ from $5.1 \%$ in 1990 . Thus, Korea is an aging society. Further, Korea will become an

23 Korea National Statistical Office 2007, Statistics on the aged, viewed July 2010, http://www.nso.go.kr. 
aged society by 2019 , with more than $14 \%$ of the population aged 65 years or more, and a post-aged society by 2026, with more than $20 \%$ aged 65 years or more. Compared with other developed countries, Korea will become an aged society within a brief period, as illustrated in Table 2.1. ${ }^{24}$

Table 2.1 Aging Population Trends

\begin{tabular}{lcccc}
\hline & France & US & Japan & Korea \\
\hline Period from aging society to aged society & 115 & 71 & 24 & 19 \\
Year of being an aging society (7\%-14\%) & 1864 & 1942 & 1970 & 2000 \\
Year of being aged society (14\%-20\%) & 1979 & 2013 & 1994 & 2019 \\
\hline
\end{tabular}

Source: KNSO

A report published by the US Census Bureau in $2016^{25}$ also shows how fast Korea will become an aged society, with more than $14 \%$ of the elderly population aged 65 or more. In contrast, Japan has been an aged society since 2007, whereas other countries that are expected to become aged societies in the future include the United Kingdom (UK; predicted to become an aged society in more than 50 years), France (more than 40 years) and the US and Australia (around 20 years). Thus, there is a large disparity between Korea and other countries (see Figure 2.1).

24 Choi, U \& Lee, S 2006, 'A case study on the spatial organization in public areas of silver town', Journal of the Korean Housing Association, vol. 17, no. 2, p. 151.

25 He, W, Goodkind, D \& Kowa, P 2016, An aging world: 2015-international population reports, United States Census Bureau, Washington DC. 


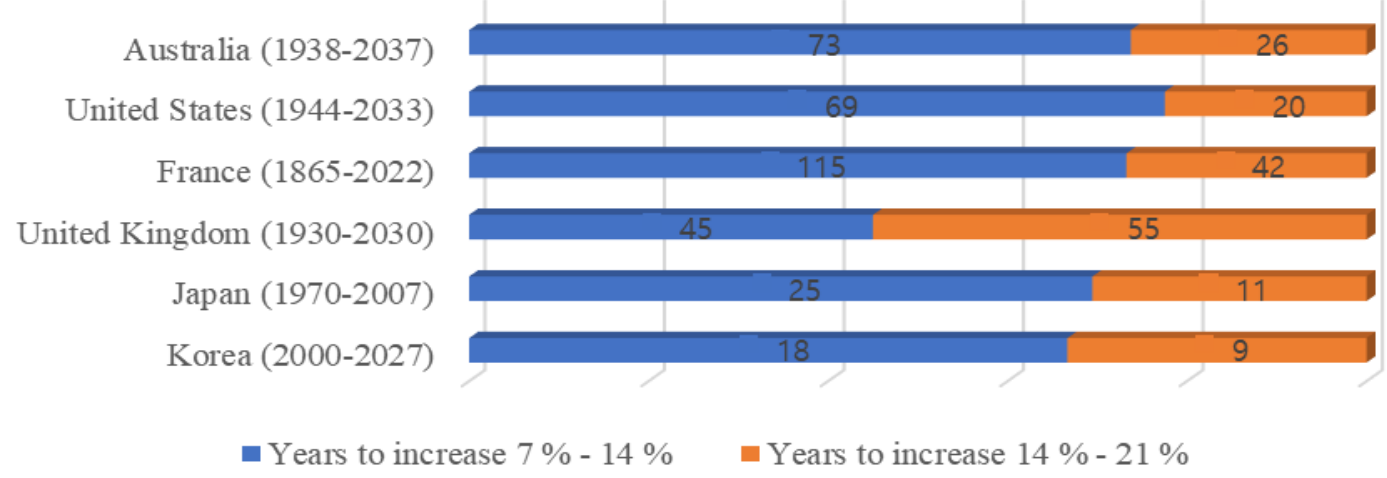

Figure 2.1. Number of years for percentage of population aged 65 and older to triple: selected countries. ${ }^{26}$

\subsubsection{Aging index/population structure/median age}

Table $2.2^{27}$ shows that Korea will experience negative population growth of -0.104 in 2030-2035 and -1.071 in 2060-2065. In contrast, the other countries-except for Japan, which shows negative growth in all periods - will experience growth during these periods. This is an important criterion for forecasting Korea's population flows.

Table 2.2 Population Growth, 2010-2060 (\%)

\begin{tabular}{lcccccc}
\hline & Korea & Japan & Britain & France & US & Australia \\
\hline 2010-2015 & 0.484 & -0.073 & 0.603 & 0.511 & 0.852 & 1.325 \\
$2030-2035$ & -0.104 & -0.483 & 0.360 & 0.338 & 0.610 & 0.745 \\
$2060-2065$ & -1.071 & -0.517 & 0.076 & 0.207 & 0.410 & 0.317 \\
\hline
\end{tabular}

Table $2.3^{28}$ shows Korea's population structure with the negative population growth. The proportion of Korea's population aged 65 years or more will increase dramatically from $11.0 \%$ in 2010 to $40.1 \%$ in 2060 , whereas other countries will have

26 He, W, Goodkind, D \& Kowa, P 2016, An aging world: 2015-international population reports, United States Census Bureau, Washington DC.

27 Korea National Statistical Office 2011, Future population prospects: 2010-2060.

28 Korea National Statistical Office 2011, Future population prospects: 2010-2060. 
around $25 \%$ of their population aged 65 or more. Further, the US Census Bureau indicates that, of the rapid-aging Asian countries, Japan will have the oldest population until 2050, followed by Korea, Hong Kong and Taiwan. At this point, 35.9\% of Korea's population will be aged 65 or more. Korea's elderly population was younger than that of the US in 2015 , but it is projected to be older by $2050 .{ }^{29}$ Thus, Korea will become a hyper-aged society.

Table 2.3 Population in Age Group (\%)

\begin{tabular}{lcccccc}
\hline & \multicolumn{2}{c}{2010} & \multicolumn{2}{c}{2030} & \multicolumn{2}{c}{2060} \\
\cline { 2 - 7 } & $15-64$ & $65+$ & $15-64$ & $65+$ & $15-64$ & $65+$ \\
\hline Korea & 72.8 & 11.0 & 63.1 & 24.3 & 49.7 & 40.1 \\
Japan & 64.0 & 22.7 & 57.3 & 30.3 & 51.1 & 35.1 \\
Britain & 66.0 & 16.6 & 61.3 & 21.1 & 57.7 & 25.1 \\
France & 64.8 & 16.8 & 59.4 & 23.1 & 57.5 & 25.0 \\
US & 66.9 & 13.1 & 61.0 & 19.9 & 59.5 & 21.9 \\
Australia & 67.6 & 13.4 & 61.8 & 19.5 & 57.6 & 24.6 \\
\hline
\end{tabular}

Table $2.4^{30}$ shows that the $80+$ population in Korea will increase sixfold between 2015 and 2100. There were 370,000 people aged 85 and over in Korea in 2010 ( $0.7 \%$ of the total population), and this is expected to rise to $4,480,000$ by 2060 $(10.2 \%)$. This represents a tenfold increase in five decades. ${ }^{31}$ According to these data,

29 He, W, Goodkind, D \& Kowa, P 2016, An aging world: 2015-international population reports, United States Census Bureau, Washington DC.

30 United Nations, Department of Economic and Social Affairs, Population Division 2015, World population prospects: The 2010 revision-key findings and advance tables. United Nations, NY.

31 Korea National Statistical Office 2011, Future population prospects: 2010-2060. 
Korea will become a post-aged society in a shorter amount of time than any other country.

Table 2.4 Population in Select Age Group (\%)

\begin{tabular}{lcccccc}
\hline & \multicolumn{2}{c}{2015} & \multicolumn{2}{c}{2050} & \multicolumn{2}{c}{2100} \\
\cline { 2 - 7 } & $60+$ & $80+$ & $60+$ & $80+$ & $60+$ & $80+$ \\
\hline Korea & 18.5 & 2.8 & 41.5 & 13.9 & 41.6 & 17.7 \\
Japan & 33.1 & 7.8 & 42.5 & 15.1 & 40.9 & 18.5 \\
Britain & 23.0 & 4.7 & 30.7 & 9.7 & 35.1 & 13.7 \\
France & 25.1 & 6.1 & 31.8 & 11.1 & 35.9 & 14.7 \\
US & 20.7 & 3.8 & 27.9 & 8.3 & 32.6 & 11.5 \\
Australia & 20.4 & 3.9 & 28.3 & 8.3 & 34.8 & 13.8 \\
\hline
\end{tabular}

Another way to examine Korea's decreasing total population and increasing elderly population is to use the total dependency ratio, which shows that there will be fewer people of working age. Figure 2.2 shows a sharp upward trend between 2010 and 2060 (from 37.3 to 101.0), while other countries will experience a steady increase.

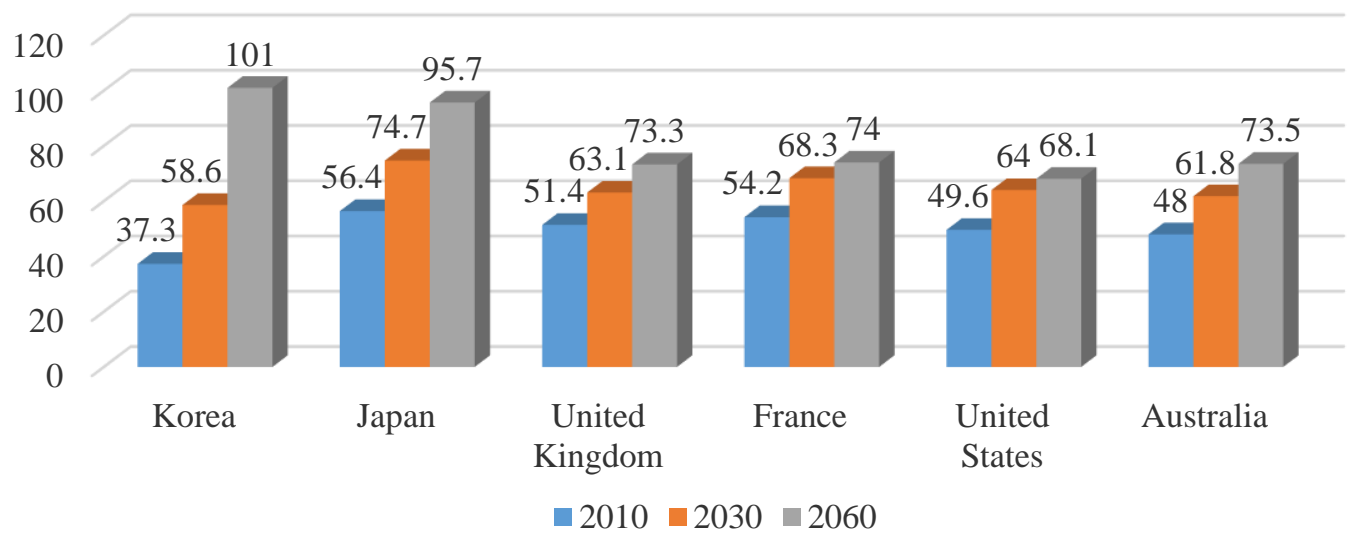

Figure 2.2. Countries with total dependency ratio (per 100 of working age population).

Table 2.5 presents further evidence that Korea will experience an unhealthy population structure using the aged-child ratio or aging index, which is the ratio of the aged population to children aged under 15. A higher number represents a larger elderly 
population. A number of 30 or more represents an aged society (aging index $=($ number of population aged over 65/number of population aged under 15) x 100). In 2005, the aging index was 47.3 , but this is expected to dramatically increase to 213.8 in 2030 and 429.3 in 2050; thus, Korea will become a post-aged society in 2030. The aging dependency ratio (number of population aged over 65/number of population aged 1564) was 12.6 in 2005 and is expected to show an upward trend to 37.7 and 72.0 in 2030 and 2050 respectively because of increased life expectancy.

Table 2.5 Aging Dependency and Aged-Child Ratio (\%)

\begin{tabular}{lcccc}
\hline & 2005 & 2020 & 2030 & 2050 \\
\hline Aging dependency ratio (over 65/age 15-64) & 12.6 & 21.7 & 37.7 & 72 \\
Aged-child ratio (over 65/under 15) x 100 & 47.3 & 125.9 & 213.8 & 429.3 \\
\hline
\end{tabular}

Source: KNSO

Median age also shows a dramatic increase due to the low fertility rate and extended life expectancy. In 2015, Korea did not appear in the list of the top ten oldest countries. In 2030, a median age of 47.5 will make Korea the tenth-oldest country in the world, and by 2050 , it is expected to be the oldest country, with a median age of 53.9, followed by Japan, Singapore, China, Hong Kong and Greece. ${ }^{32}$

Table 2.6 Countries with the Oldest Populations: 2015, 2030, 2050

\begin{tabular}{llllll}
\hline \multicolumn{2}{c}{2015} & \multicolumn{2}{c}{2030} & \multicolumn{2}{c}{2050} \\
$\begin{array}{l}\text { Country of } \\
\text { area (rank) }\end{array}$ & $\begin{array}{l}\text { Median age } \\
\text { (years) }\end{array}$ & $\begin{array}{l}\text { Country of } \\
\text { area (rank) }\end{array}$ & $\begin{array}{l}\text { Median age } \\
\text { (years) }\end{array}$ & $\begin{array}{l}\text { Country of } \\
\text { area (rank)* }\end{array}$ & $\begin{array}{l}\text { Median age } \\
\text { (years) }\end{array}$ \\
\hline Japan (1) & 46.5 & Japan (1) & 51.5 & Korea (2) & 53.9 \\
Germany (2) & 46.2 & Italy (2) & 50.8 & Japan (3) & 53.3 \\
Italy (4) & 45.9 & Spain (4) & 50.1 & Singapore (5) & 53.0 \\
\hline
\end{tabular}

32 United Nations, Department of Economic and Social Affairs, Population Division 2015, World population prospects: the 2010 revision — key findings and advance tables. United Nations, NY. 


\begin{tabular}{lclclc}
\hline Greece (6) & 43.6 & $\begin{array}{l}\text { China, Hong } \\
\text { Kong (6) }\end{array}$ & 48.6 & $\begin{array}{l}\text { China, Hong } \\
\text { Kong (6) }\end{array}$ & 52.7 \\
$\begin{array}{l}\text { China, Hong } \\
\text { Kong (9) }\end{array}$ & 43.2 & Germany (7) & 48.6 & Greece (8) & 52.3 \\
Spain (10) & 43.2 & Korea (10) & 47.5 & Poland (10) & 51.8 \\
\hline
\end{tabular}

* Ranked first in 2050 in 'other non-specified areas'.

\subsubsection{Distribution of aging population in Korea ${ }^{33}$}

To gain a better understanding of the silver town phenomenon, it is important to know where the elderly population resides.

Figure 2.3 presents the distribution ratio of the population, the population aged under 65 and the population aged 65 and over in metropolitan cities and provinces in Korea. In 2017 , approximately $44 \%$ of the total population $(22,459,049$ of $51,446,201$ people) and $43 \%$ of the aging population $(3,049,682$ of $7,075,518)$ lived in the national capital region, including Seoul, Incheon and Gyeonggi-do. Thus, many people tend to live in the capital region, where the aged population is also focused.
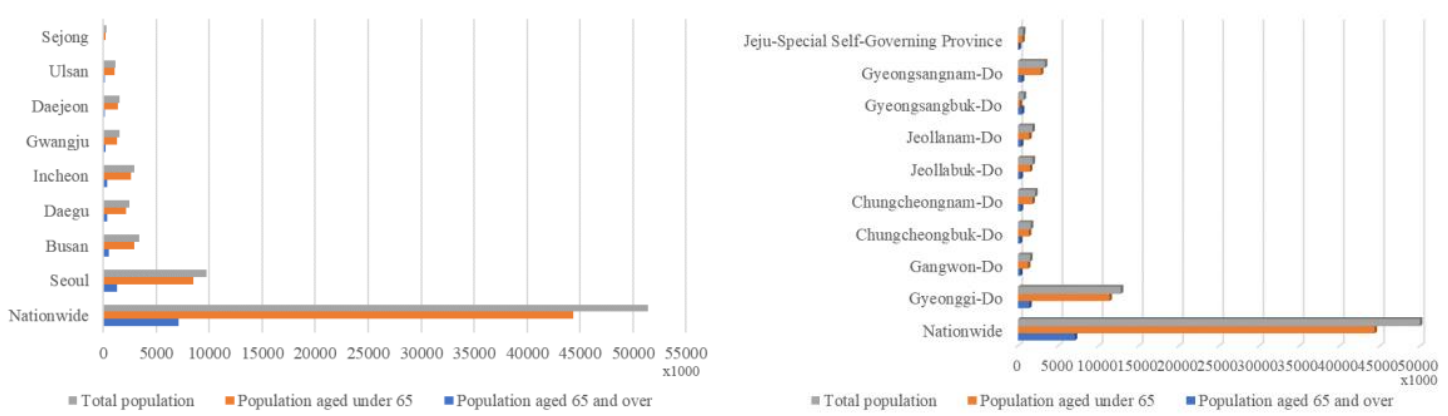

Figure 2.3. Distribution of population in metropolitan cities and provinces of Korea.

33 Korean Statistical Information Service, Future Population Prospect 2013-2040, viewed august 2016, http://kosis.kr/statHtml/statHtml.do?orgId=101\&tblId=DT_1BPB002\&vw_cd=MT_OTITLE\&list_id=M T_CTITLE_E_3\&scrId=\&seqNo=\&lang_mode=ko\&obj_var_id=\&itm_id=\&conn_path=E1\#. 
The aging index of the metropolitan cities and provinces in 2017 shows that there is a high index number nationwide, which causes aging issues not only in the capital region, but also in other cities and provinces. Busan, Gangwon-Do and Jeollanam-Do have high index numbers of 138, 145 and 151 respectively (see Figure 2.4).
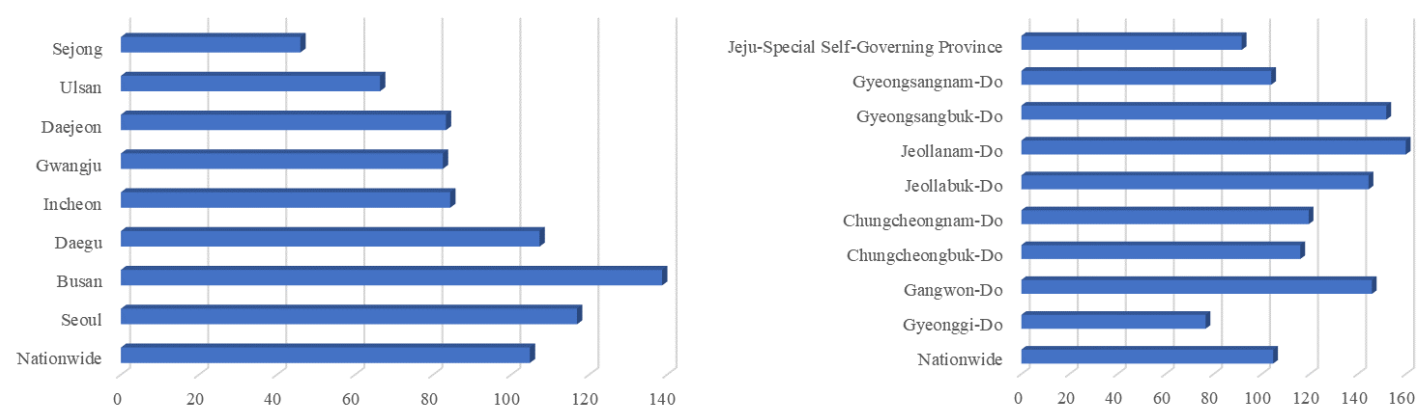

Figure 2.4. Aging index by metropolitan cities and provinces of Korea.

\subsection{Information Technology Infrastructure in Korea}

\subsubsection{Information technology literacy}

Supported by the government's strategy and infrastructure development plans, the broadband Internet business has grown rapidly in Korea. A number of factors explain why the Internet industry has grown significantly in Korea in the past decade.

First, the government deregulated the telecommunications industry and provided tax benefits, which created fierce competition in the market. Second, in 2000, the Ministry of Information and Communications created the 'Ten Million People Internet Education' project, which mainly targeted housewives and the elderly. Third, Internet personal computer (PC) Bahngs, which are similar to Internet cafés, played an important role in providing high-speed Internet to users of all ages. Fourth, competitive enthusiasm for children's education created a need for people to catch up with their neighbours by subscribing to high-speed Internet at home. Lastly, apartment complexes classified by the Cyber Building Certificate system introduced by the government in 
1997 made it relatively easy to install broadband services because the system provides a standard for buildings with a capacity for high-speed telecommunications traffic. ${ }^{34}$

In 2007, eMarketer published a report regarding Internet users' data and Internet penetration in selected countries. ${ }^{35}$ Korea ranked top in the Asia-Pacific region, with $72.7 \%$ of the population having access to the Internet. It is estimated that this will increase to $77.3 \%$ in 2011. Japan ranked second (69.9\%), followed by Australia (66.7\%), with these rates expected to rise to $75.1 \%$ and $72.5 \%$, respectively, in 2011 .

Table 2.7 Internet Users and Penetration in Selected Countries in the Asia-Pacific Region: $2005-2011$

\begin{tabular}{lllllll}
\hline & \multicolumn{2}{c}{2007} & \multicolumn{2}{c}{2009} & \multicolumn{2}{c}{2011} \\
& $\begin{array}{l}\text { Internet } \\
\text { users } \\
\text { (million) }\end{array}$ & $\begin{array}{l}\text { \% of } \\
\text { population }\end{array}$ & $\begin{array}{l}\text { Internet } \\
\text { users } \\
\text { (million) }\end{array}$ & $\begin{array}{l}\text { \% of } \\
\text { population }\end{array}$ & $\begin{array}{l}\text { Internet } \\
\text { users } \\
\text { (million) }\end{array}$ & $\begin{array}{l}\% \text { of } \\
\text { population }\end{array}$ \\
\hline Australia & 13.6 & $66.7 \%$ & 14.4 & $69.2 \%$ & 15.3 & $72.5 \%$ \\
China & 156.2 & $11.8 \%$ & 206.6 & $15.4 \%$ & 245.5 & $28.1 \%$ \\
Japan & 89.1 & $69.9 \%$ & 92.5 & $72.7 \%$ & 95.4 & $75.1 \%$ \\
Korea & 35.6 & $72.7 \%$ & 37.2 & $75.3 \%$ & 38.4 & $77.3 \%$ \\
\hline
\end{tabular}

The recent report provides more significant data to verify widespread Internet connections in Korea. According to a report on the number of Internet users around the world, ${ }^{36}$ China was ranked first (721 million users), the US was third (286 million), the UK was eleventh (60 million) and Korea was eighteenth (45 million). However, in

34 Yun, K, Lee, H \& Lim, S 2002, The growth of broadband internet connections in South Korea: contributing factors, working paper, Asia/Pacific Research Center, Stanford University.

35 eMarketer 2007, Internet users and penetration in select countries in the Asia-Pacific Region, 20052011, viewed August 2008, http://www.emarketer.com/SiteSearch.aspx?pageNum=15\&arg=Korea. 36 Internet World Stats 2016, Top 20 countries with the highest number of internet users, viewed November 2016, http://www.internetworldstats.com/top20.htm. 
terms of the percentage of Internet penetration, Korea ranked second (92.1\%) and China dropped to fourteenth place $(52.3 \%)$.

Table 2.8 Highest Number of Internet Users ${ }^{37}$

\begin{tabular}{lcc}
\hline Country & Internet users (30 June 2016) (rank) & Internet penetration (rank) \\
\hline UK & $60,273,385(11)$ & $93.5 \%(1)$ \\
Korea & $45,314,248(18)$ & $92.1 \%(2)$ \\
Japan & $115,111,595(5)$ & $91.0 \%(3)$ \\
US & $286,942,362(3)$ & $88.6 \%(5)$ \\
China & $721,434,547(1)$ & $52.3 \%(14)$ \\
\hline
\end{tabular}

Akamai's report for the first quarter of 2017 compared the average connection speed of the Internet (Internet Protocol version 4 [IPv4]) and broadband adoption (IPv4) in different speeds (Mbps) by country and region. Table 2.9 shows that South Korea is ranked first for both Internet connection speed and broadband adoption, followed by European and Asian countries. This is further evidence of Korea's well-structured ICT infrastructure and high accessibility to the Internet environment.

Table 2.9 Average Connection Speed and Broadband Adoption ${ }^{38}$

\begin{tabular}{lcccc}
\hline & $\begin{array}{c}\text { Average connection } \\
\text { speed, Mbps (Ranking) }\end{array}$ & $\begin{array}{c}\text { \% above 10Mbps } \\
\text { (Ranking) }\end{array}$ & $\begin{array}{c}\% \text { above 15Mbps } \\
\text { (Ranking) }\end{array}$ & $\begin{array}{c}\text { above 25Mbps } \\
\text { (Ranking) }\end{array}$ \\
\hline Global & 7.2 & 45 & 28 & 12 \\
South Korea & $28.6(1)$ & $85(1)$ & $69(1)$ & $40(1)$ \\
Norway & $23.5(2)$ & $69(9)$ & $54(3)$ & $34(2)$ \\
Hong Kong & $21.9(4)$ & $71(6)$ & $54(4)$ & $28(4)$ \\
Switzerland & $21.7(5)$ & $75(2)$ & $56(2)$ & $26(5)$
\end{tabular}

37 Internet World Stats 2016, Top 20 countries with the highest number of internet users, viewed November 2016, http://www.internetworldstats.com/top20.htm.

38 Akamai 2017, Q1 2017 state of the internet, viewed June 2017, https://www.akamai.com/us/en/about/our-thinking/state-of-the-internet-report/global-state-of-theinternet-security-ddos-attack-reports.jsp. 
Japan

$20.2(8)$

$73(3)$

$52(5)$

$25(8)$

US

$18.7(10)$

$48(8)$

$21(10)$

\subsubsection{Information technology preparation}

Turning to domestic data for Korea, $93.3 \%$ of the population aged 40-50 owned a PC and $55.1 \%$ of the population aged over 50 owned a computer by 2006 . The rate of PC ownership increased by $2.5 \%$ between 2006 and 2007. This is significant because the current middle-aged population, which will become the aging population in a few decades, are already regular users of information services and are likely to expect access to similar services in the future. ${ }^{39}$

Table 2.10 PC Ownership in Households

\begin{tabular}{lcl}
\hline & 2006 & 2007 \\
\hline Total & $79.4 \%$ & $80.0 \%$ \\
Aged 20 & $92.4 \%$ & $94.8 \%$ \\
Aged 30 & $93.9 \%$ & $97.6 \%$ \\
Aged 40 & $93.3 \%$ & $95.4 \%$ \\
Aged over 50 & $55.1 \%$ & $57.6 \%$ \\
\hline
\end{tabular}

The Ministry of Science, ICT and Future Planning and the Korea Internet \& Security Agency published a study regarding the Internet penetration rate and PC ownership rate in households. It found that the Internet penetration rate increased from $79.8 \%$ in 2007 to $84.4 \%$ in 2015 , whereas the PC ownership rate decreased from $80.4 \%$

39 Korea Statistical Information Service 2016, Personal computer possession rate by household ages, viewed March 2016, http://kosis.kr/. 
in 2007 to $77.1 \%$ in 2015 (see Figure 2.5). The declining rate of ownership has been influenced by mobile phone use. ${ }^{40}$

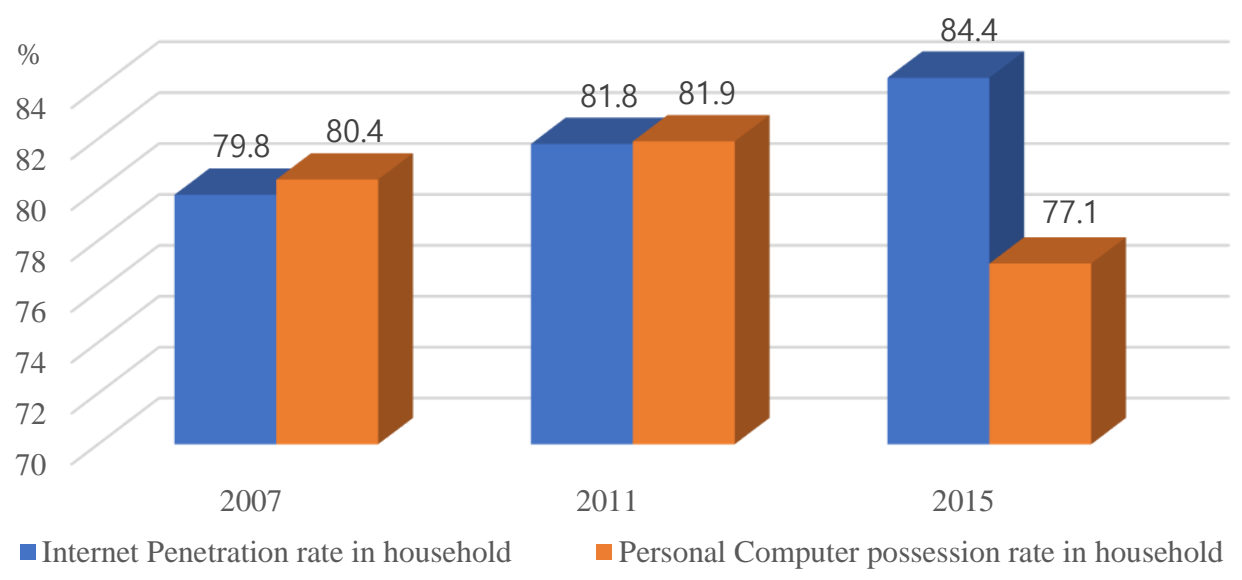

Figure 2.5. Internet penetration rate and PC ownership rate in households.

\subsubsection{Government support for IT infrastructure}

The Ministry of Information and Communication was established in 1994 and has successfully accelerated Korea's transition into an information society by providing mid-term and long-term visions for the national-level informationalisation process and building an intimate cooperation system with the private industry sector.

The Promotion of Informationalization plan was drawn up in 1996. Under this master plan, a series of new plans, strategies and visions were successively added: Cyber Korea 21 in 1999, u-Korea Vision 2006 in 2002 and Broadband IT Korea Vision 2007 in 2004, with each one updating competitive strategies and reflecting new technological and market demands.

40 Ministry of Science, ICT and Future Planning and Korea Internet \& Security Agency 2015, Survey on internet usage, viewed March 2016, http://www.index.go.kr/potal/main/EachDtlPageDetail.do?idx_cd=1345. 
In 2004, the ministry developed the u-Korea policy based on the IT839 strategy, which was a national development programme founded on the ICT industry's value chain development model. The policy was re-evaluated in 2006 to boost its strategies, and it was renamed u-IT839. It has become the roadmap for the evolution of ICT into ubiquitous technology. The implementation plan of u-IT839 comprises eight new services. Further, the plan adds up investment into the building of three essential networks. In addition, these networks will pave the way for the nine new sectors to grow quickly and create synergistic effects. ${ }^{41}$

There has been strong government support to actualise the u-IT839 strategy. First, the government was quick to remove legal and regulatory obstacles. Second, since 2001, the Korean government has been conducting a programme to help companies network themselves, based on an IT rental model, with the goal of boosting their competitiveness through informationalisation. As a result, small- and medium-sized ITrelated businesses have become stronger and more competitive. Third, there have been significant investments to build a broadband network infrastructure to be covered by a satellite Internet service. As a result, high-speed network access will become available throughout the country. Moreover, research and development (R\&D) investment by both the government and the private sector has increased over the past two decades. According to a report issued by the International Institute for Management Development in May 2005, Korea was ranked second in the world in the 'Scientific Infrastructure /Patent Productivity' category. ${ }^{42}$

41 National IT Industry Promotion Agency, U-IT839 Strategy, viewed May 2015, https://www.nipa.kr/cyber/historySub.it?value=history_2001_5.

42 Korean Communications Commission, Dynamic IT Korea, viewed August 2008, http://www.dynamicitkorea.org/policy/itKorea.jsp. 
Further, importantly, the government and the private sector are attempting to reduce the gap that is continuously widening between the information-rich and the information-poor. Opportunities to access information are typically limited to certain age groups and income groups. To further diffuse information about emerging services and technologies, the Ministry of Information and Communication supported the development of the 'Ubiquitous Dream Hall'43 in 2005, which enabled people to experience the future of digital life (see Figure 2.6). The Ubiquitous Dream Exhibition was built in the centre of Seoul by leading domestic IT companies such as KT, Samsung Electronics, LG Electronics, Sunkyoung Telecom (SKT) and LG Telecom, but the exhibition closed in July $2008 .^{44}$

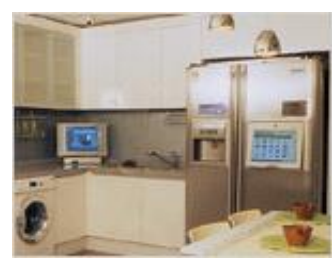

(a) Home network

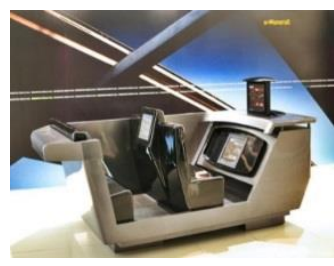

(c) Monorail

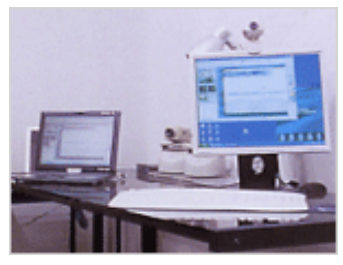

(b) Next generation network

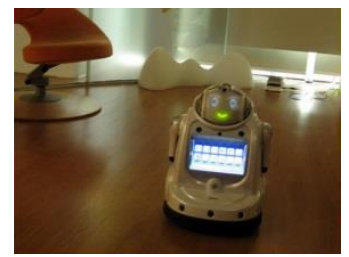

(d) Broadcasting robot

Figure 2.6. Ubiquitous Dream Hall.

\subsubsection{Ubiquitous city to smart-city plans}

In 2006, the Korean government developed U-City as an ambitious plan to encapsulate the vision of an advanced city in the twenty-first century. It integrates

43 Futurize Korea 2008, Ubiquitous dream hall, viewed 2008, http://futurize.tistory.com/80. 44 Futurize Korea 2008, Ubiquitous dream hall closed, viewed 2008, http://futurize.tistory.com/191. 
advanced information communication infrastructure and ubiquitous information services into urban spaces to increase convenience and quality of life, as well as safety and civil welfare based on systematic city management, and to create new businesses and innovate various city functions. ${ }^{45,46}$

Different ministries in the government have developed detailed plans and strategies to realise the U-City vision. Some of these plans include IT-839 and U-Korea by the Ministry of Information and Communication, the National Geographic Information System and Intelligent Transportation System by the Ministry of Construction and Transportation, and the Ubiquitous Computing Frontier Business by the Ministry of Science and Technology. ${ }^{47}$

U-City is predicted to solve traffic, poverty and environmental issues caused by urban sprawl centralised around metropolitan cities by applying smart technology. To extend the IT industry to the next level of development, Korea requires new IT growth combined with current telecommunication infrastructure and industry sources to compete with other countries. In addition, by supporting current infrastructure related to the IT industry, the development of U-City will create new markets and more opportunities for companies and service providers.

Moreover, local governments are preparing U-City construction plans to develop the capability of individual regions considering their own strengths and characteristics

45 Korea Ubiquitous City Association, Concept of U-City, viewed September 2015, http://www.ucta.or.kr/en/ucity/concept.php. 46 Kim, Y 2007, 'Understanding of U-City', Construction Engineering/Ssang Yong, vol. 45, winter, pp. $25-28$.

47 Uhm, J 2006, 'U-City strategy: discourses and visions for the realization of ubiquitous future city: from ideas to cases', in 2006 U-City International Symposium Proceedings, Housing and Urban Research Institute, pp. 186-196. 
(e.g., U-Port in Busan, Incheon, U-Tourism in Jeju and Gyeongju, U-Home and Healthcare in Bundang and Ilsan and U-Silvertown in Bundang and Jeju). ${ }^{48}$ Continuous development of U-City is in progress, and a number of exhibition centres enable people to experience the city or control centres in operation. For example, Paju established an exhibition centre to control traffic by closed-circuit television (CCTV), ${ }^{49}$ and Osan obtained satisfactory results in preventing crime when it opened a U-City control tower to provide better security in $2013 .^{50}$ Seongnam extended its service to not only control traffic, but also to protect public facilities, conserve the environment and support seniors living alone. ${ }^{51}$

Recent development trends have seen a transition from U-City plans to smartcity plans. U-city plans are more focused on technology intensive ways to implement of developed IT infrastructure, whereas smart-city plans are more user-friendly, with people benefiting from applied smart systems. Information released by the Ministry of Land, Infrastructure and Transport, combined with private companies, has led to the creation of smart cities as a new and sustainable engine of nationwide development (see Figure 2.7). ${ }^{52}$ Smart-city plans are designed for efficient management of the

48 Gyeonggi-do, Seongnam-si, Korea Land Corporation, Korea National Housing Corporation 2006, The construction scheme of U-City in Seongnam and Pankyo: summary of researches.

49 Pajuunjeong U-City, U-City exhibition center, viewed 2015, http://ucity.paju.go.kr/public/promote.html.

50 Ubiquitous Journal 2013, 'Opening of U-City control center at city of Osan’ Ubiquitous Journal web log post, 30 December, viewed 2014, http://blog.naver.com/ubsmart/90187400853.

51 Seongnam City, Seongnam U-City control center, viewed 2016, http://www.seongnam.go.kr/city/1000477/10349/contents.do.

52 Ministry of Land, Infrastructure and Transport 2016, Card news-leading the world by smart city, viewed August 2016, http://www.molit.go.kr/USR/NEWS/m_35045/dtl.jsp?lcmspage=1\&id=95077873. 
infrastructure already in place in the targeted city so that the infrastructures are integrated with ICT. For example, there are energy- and eco-related concerns related to water and air quality, as well as life conveniences such as education and culture, and infrastructure-related concerns such as transport and traffic. In addition, through increased $\mathrm{R} \& \mathrm{D}$ implementation, each city develops smart environments according to its available resources.

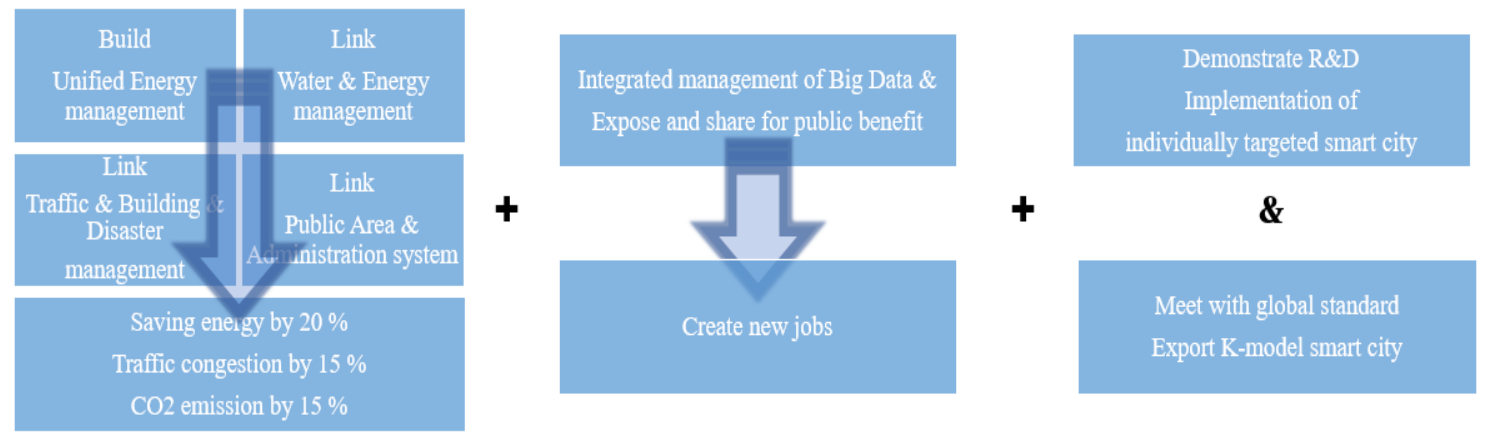

Figure 2.7. Korea model smart-city structure.

The smart-city plans were initiated by Song-do in $2003,{ }^{53,54}$ followed by GwangMyeong city, ${ }^{55}$ Sejong city ${ }^{56}$ and Busan, which is one of the leading and active

53 Songdo IBD, Smart city plan, viewed December 2010, http://songdoibd.tistory.com/1081.

54 'Incheon Songdo, smart city connected to ICT' 2017, SBS CNBC, 31 January, viewed February 2017, http://sbscnbc.sbs.co.kr/read.jsp?pmArticleId=10000844956.

55 Gwangmyeong City, Smart city strategy, viewed June 2017, http://www.gm.go.kr/pt/user/bbs/BD_selectBbs.do?q_bbsCode=2045\&q_bbscttSn=20170613142614327 56 'Sejong city to K-smart city’ 2017, Inews365, 2 February, viewed March 2017, http://www.inews365.com/news/article.html?no=480997. 
smart-city developments. ${ }^{57}$ The strategy and plans have been exported to cities in countries such as India and Kuwait. ${ }^{58,59}$

\subsection{Development of Smart Technology}

One response to the increasingly aging population and increasing population density has been the development of high-rise apartment complexes that integrate smart IT services. As Koreans are willing to embrace technology, a number of residential complexes have integrated smart technologies into silver towers, and a number of technology companies have heavily invested in the development of smart technology services that are specifically aimed at supporting the needs of the elderly.

Supported by the government's movement for the construction of IT infrastructure, smart home research in Korea has evolved and typically centres around a home network system that connects home appliances with one controller to support an integrated and controlled environment. However, the focus on the development of home network systems has typically been driven by technology, but not sufficiently from the users' perspective — especially elderly residents living in silver towers.

LG Dream Home 'HomeNet' is an example of a smart home prototype in Korea (see Figure 2.8). The project offers a 'HomeNet' solution for home appliances in eight different categories. For example, it supports the control of home appliances and wireless control for home tasking, energy meters for home management, networked

57 Busan IT Industry Promotion Agency, Global smart city, viewed August 2016, http://ksmartcity.kr/english/index.php.

58 Woo, JS 2017, 'Exporting Korea's smart city plan to India', MKNews, 7 April, viewed April 2017, http://news.mk.co.kr/newsRead.php?year=2017\&no=237281.

59 Song, J 2017, 'Korea’s smart city, exporting to Kuwait...construction begins in 2019', Weeklytoday, 4 April, viewed April 2017, http://www.weeklytoday.com/news/articleView.html?idxno=55548. 
home theatres for entertainment and fire alarms for safety. Other categories include controlling heating, cooling and the ventilation system for wellbeing, and a notification system for home delivery for community management and portals. This smart system has been integrated into many apartments built by GS E\&C Corporation as home solution. ${ }^{60}$

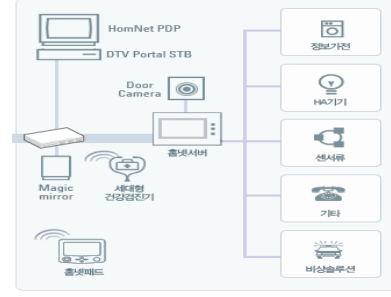

Home network solution

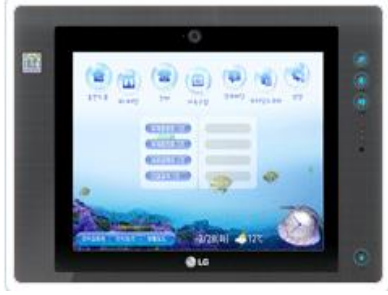

HomeNet screen

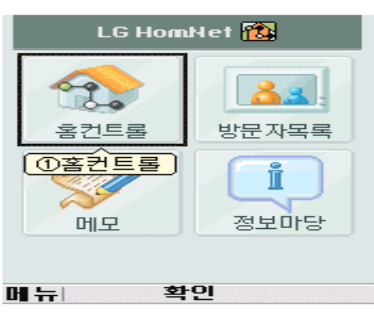

Mobile control

Figure 2.8. LG Home Net services.

Recently, these developed smart technologies began to be integrated into apartments. Daewoo construction affiliated with SKT (SK Telecom) to apply smart technology to help residents control their lights, heating systems and energy usage through an application on their mobile phone or tablet. Residents can monitor and manage their home environment from any location and at any time to create a customised environment. ${ }^{61}$

SKT is one of the leading companies in ICT development and the application of smart technology in residential buildings. SKT works closely with other specialist IT and electronic sectors to develop smart living environments. The smart technology that

60 Dream Home_LG, viewed September 2015, http://www.lghomnet.co.kr/.

61 Lee, S 2016, ‘Dongtan Daewoo Prugio’s city officetel apply SKT smart home service', Edaily, 10 October, viewed November 2016, http://www.edaily.co.kr/news/NewsRead.edy?SCD=JD31\&newsid=01997526612811608\&DCD=A0040 3\&OutLnkChk=Y. 
SKT is applying in apartment complexes is much more advanced and user-centred than its previous 'HomeNet' service. As shown in Figure 2.9, a mobile phone or tablet is connected to a smart home server, which connects to a server in the apartment complex. A control pad on the wall in each apartment is used to control each device or system. If the apartment complex does not have an installed server, the smart home server is directly connected to the home devices and systems to be controlled. Thus, residents can monitor and control their home environment from any location and at any time using smart technology.

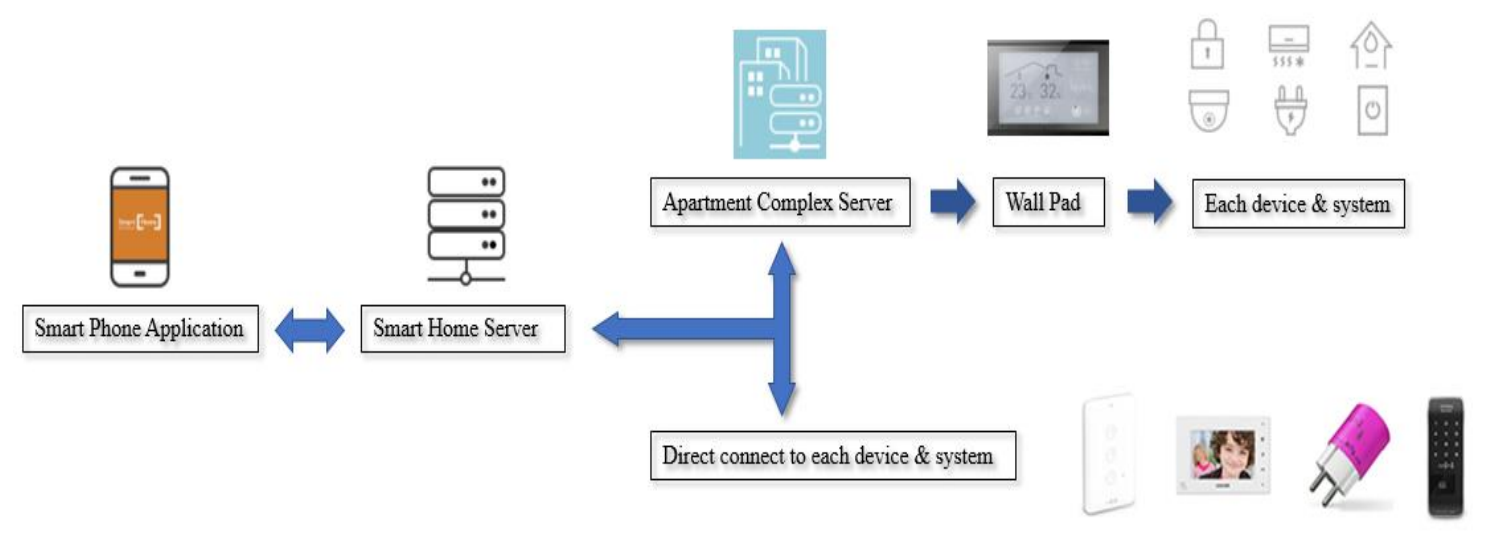

Figure 2.9. SKT smart apartment service structure. ${ }^{62}$

Although many smart technologies have been incorporated into people's living environments to support convenient and smart living, there has been limited technology application in general apartment complexes. In terms of smart technologies to support the elderly, silver simulation centres, ${ }^{63,64}$ which are funded by the local government and

62 SK Telecom, Smart home by SK telecom—smart apartment, viewed January 2017, https://www.sktsmarthome.com/html/apartment.html.

63 Cho, J \& Kim, M 2006, 'Study on space composition analysis of the local old age experience hall', Proceedings of Korean Institute of Interior Design, vol. 8, no. 1, pp. 173-178.

64 Lee, Y \& Suh, H 2005, 'A study on space formation of the senior simulation center', Proceedings of Korean Institute of Interior Design, vol. 14, no. 3, pp. 156-164. 
affiliated with the university research labs, function as testbeds for the smart home industry for the elderly. These centres research, develop and demonstrate elderlycentred design and provide interactive displays to enhance people's understanding and knowledge of new services. For example, based on active interactions, 'Miraeseum' has offered more opportunities for the elderly and other generations to experience these facilities since 2008 (see Figure 2.10). In addition, the elderly conduct seminars and workshops in simulation centres for communication purposes. Further, the centre has worked with a research lab, and the local government has supported further development and changes. ${ }^{65}$
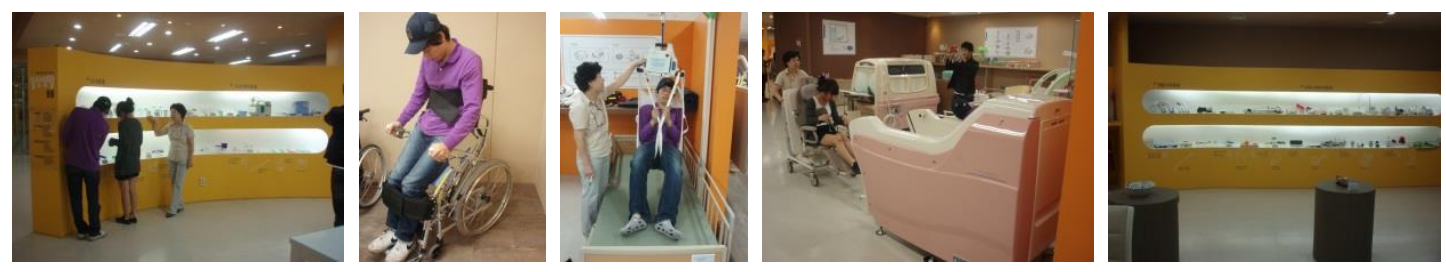

Figure 2.10. Mireaseum-Seongnam Senior Complex.

Many international corporations, research labs, institutions, governments and private developers have invested in smart technology $R \& D$ to assist the elderly population, and a number of service providers have improved smart technology devices. In Japan, developments in smart technology made by the private sector and major companies have been implemented in elderly homes. For instance, sensor-based devices that do not use cameras (because of privacy concerns), such as Z-Works, are designed to detect heart rates, movements, lighting, temperature and humidity. Further, they check the open and closed status of doors to monitor abnormal signs from older people and respond to emergencies. ${ }^{66}$ In another case from Japan, telecommunications company

65 Miraeseum Seongnam Senior Complex 2008, Miraeseum - Seongnam Senior Complex, viewed 2010, http://www.miraeseum.or.kr/.

66 Z-Works, viewed May 2016, http://z-works.co.jp/index_en.html. 
Nippon Telegraph and Telephone Corporation (NTT) launched a small robot that verbally interacts with elderly users and can check on their health status when users wear a compatible device. ${ }^{67}$

The R\&D of smart homes in Korea parallels similar efforts elsewhere in the world. Some of these examples are old, but they are still worth examining. In 1998, the 'Aware Home' ${ }^{68}$ research at Georgia Tech was supported by Hewlett-Packard, Intel, Motorola, Mitsubishi and the National Science Foundation (see Figure 2.11). The research aimed to monitor residents' movements in their living environments. Using 'the concept of human-like perception', the project aimed to develop various devices that could help the elderly and support the needs of the disabled and children with autism. Some of the services are intended for the aged population, making it easy to use devices and enable communication with other family members.

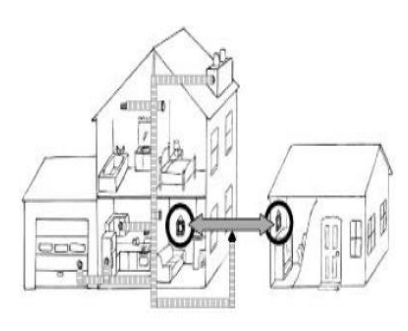

(a) Digital Family Portrait

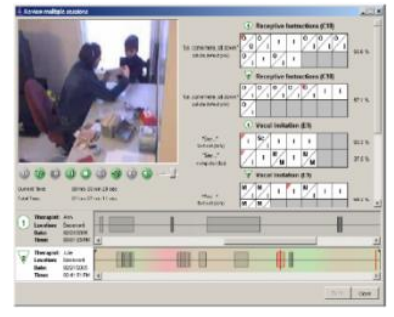

(b) Abrais

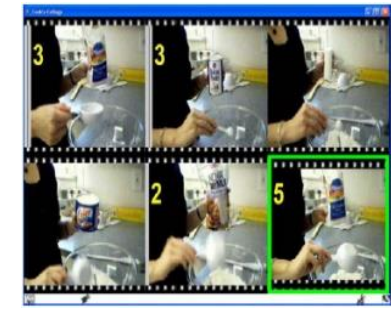

(c) Cook's Collage

Figure 2.11. Aware Home services.

'MIT PlaceLab'69 is supported by a consortium called 'Changing Places'. This research project aims to construct a digital interface that can control appliances

67 MashableAustralia 2015, Japan's NTT to put home care robot's in the home of the elderly, viewed October 2015, http://mashable.com/2015/07/29/japan-home-care-robot/\#wxqAizE55kqK.

68 Aware Home, viewed September 2015, http://awarehome.imtc.gatech.edu/.

69 MIT PlaceLab, viewed September 2015, http://web.mit.edu/cron/group/house_n/placelab.html. 
connected to a home network system using sensors. In addition, it aims to create a design environment in which residents' opinions are reflected in design outcomes.

One prototype project in this research is 'PlaceLab', which is a living lab that offers a smart home experience and is a testbed for the House_n project (see Figure 2.12). The main target of this research is to develop smart services for the delivery of health care and focuses on preventative medicine or proactive health care, net zero house and developing devices and applications for workplaces and cities.
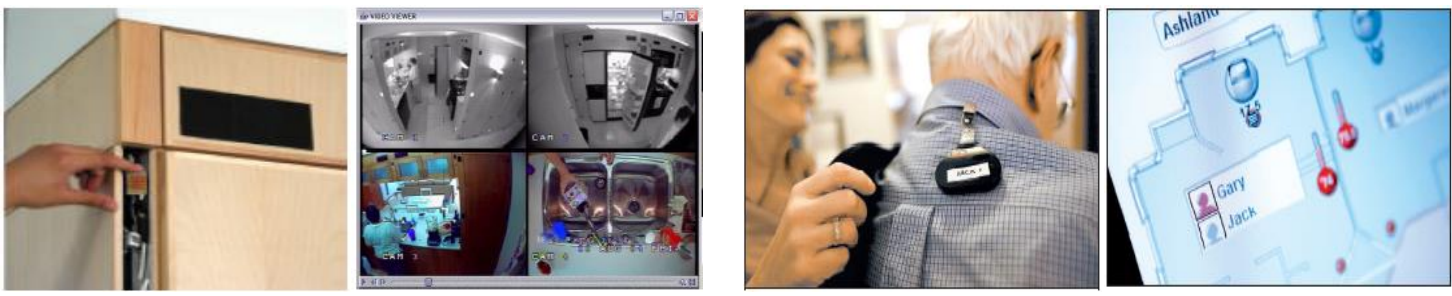

Figure 2.12. MIT PlaceLab example and Oatfield Estates' tracking system.

Oatfield Estates ${ }^{70}$ is an elderly care community built in Portland, Milwaukee. It was developed in 2000 by Elite Care Corporation and offers an independent and private lifestyle for the aged, as well as basic care. Using sensors and smart technology, it supports the elderly living environment through the control of appliances and facilities. This community is part of the Center for Aging Services \& Technology project, and MIT, Intel, Honeywell and GE (General Motors) are research collaborators.

As part of the European INTEGER Project, ${ }^{71}$ the Millennium House follows the concept of INTEGER (Intelligent + Green) and was built by the Building Research Establishment in the UK. The house is an experiment in the integration of intelligence and biotechnology. More than 150 companies and institutes took part in the project. The main objectives of INTEGER were to reduce building construction expenditure, reduce

70 Oatfield Estates_Elite Care Corporation, viewed September 2015, http://www.elitecare.com/.

71 INTEGER Project, viewed February 2015, http://www.integerasia.org. 
residents' ongoing living expenditures, decrease waste in construction and increase customers' living satisfaction. IT in the INTEGER project was integrated to increase the efficiency of lights, heating and ventilation systems, as well as the quality of life of residents.

\subsection{Transition from Traditional House to Apartments}

\subsubsection{HanOk to apartments}

Traditional housing, called 'HanOk', which consists of a main building and an outbuilding, were modernised in the 1930s, when housing demand increased and many housing developments were undertaken by private investors (see Figure 2.13 ). ${ }^{72,73}$ The modernisation of HanOk changed to traditional urban housing, called 'urban HanOk', which combined two buildings into one and developed new spatial structures. For instance, it converted 'Madang' (a courtyard), which connects inside and outside spaces, into an internal space. ${ }^{74}$ However, housing modernisation was interrupted by the Korean War and the social confusion that followed limited developments between the 1940s and 1950s. ${ }^{75}$

$72 \mathrm{Kim}, \mathrm{J}, \mathrm{Kim}, \mathrm{JK}$ 1995, 'A study on typological analysis of traditional urban housing', Proceedings of the Architectural Institute of Korea, vol. 11 (12), pp. 23-29.

73 Song, I 2002, 'Traditional urban housing vs multi-family housing', Architecture and Culture, November, pp. $120-122$.

74 Kim, Y \& Cho, S 2008, 'A study on the change process of unit plan multi complex housing', Proceedings of the Architectural Institute of Korea, vol. 24, no. 2, pp. 253-260.

75 Yoo, J 2004, 'A study on the transforming characteristics of the housing plan types in modernizing period of Korea', Proceedings of the Architectural Institute of Korea, vol. 20, no. 10, pp. 59-66. 
The history of apartments in Korea started with the construction of Hang-cheon apartments in $1956^{76}$ and Chong-am apartments in $1958 .{ }^{77}$ The apartment typology was not firmly established until 1962, when the 'Mapo apartment' was built in Mapo, Seoul, by the Korea National Housing Corporation as a residential complex. Between the 1960s and 1970s, significant growth in the economy and changes in building regulations resulted in the rapid development of apartment complexes.

However, in December 1997, there was a considerable decrease in construction because the economic crisis in Korea caused a sharp decline in housing demand and bankruptcy of construction companies. To restore the construction market, the government enforced a housing policy that liberalised the sale of apartments in 1998 (see Figure 2.13). ${ }^{78,79}$

76 Kim, S \& Kim, S 1993, 'A study on the changes of apartment housing plan in Korea', Proceedings of the Architectural Institute of Korea, vol. 13, no. 2, p. 113.

77 Park, I 2008, 'The development of house through apartment', Herald Media, 14 August, viewed October 2008, http://www.heraldbiz.com/SITE/data/html_dir/2008/08/14/200808140082.asp.

$78 \mathrm{Kim}, \mathrm{J}$ \& Choi, C 2007, 'A study on the change of area division in accordance with each room of the unit plan of apartment—-focused on the public housing size below in Seoul', Proceedings of the Architectural Institute of Korea, vol. 23, no. 5, p. 159.

79 Shin, J, Suh, K, Heo, J, Kim, H \& Kim, C 2002, 'A study on the unit plan characteristics of the recent super-high-rise-apartment', Proceedings of the Architectural Institute of Korea, vol. 18, no. 8, pp. 11-22. 


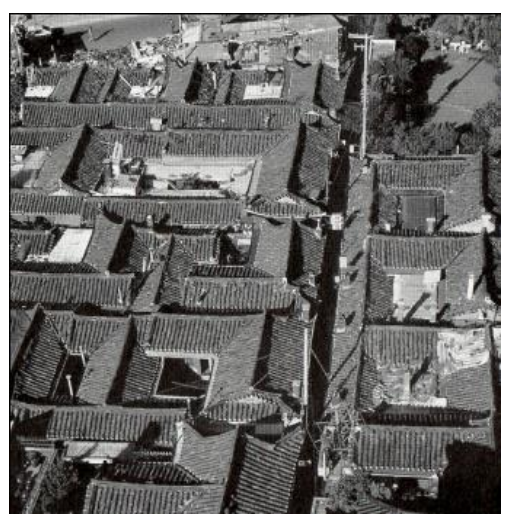

HanOk

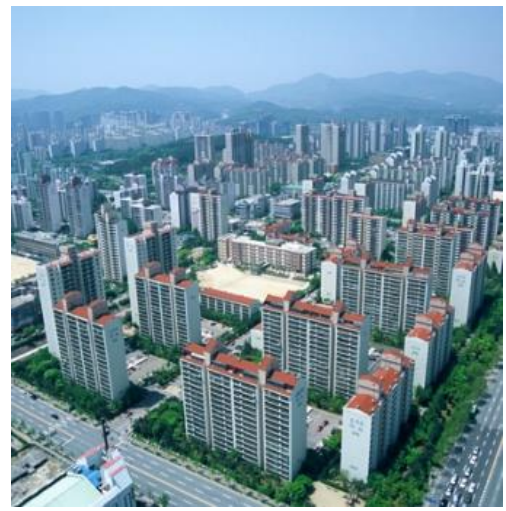

Apartment in the 1990s

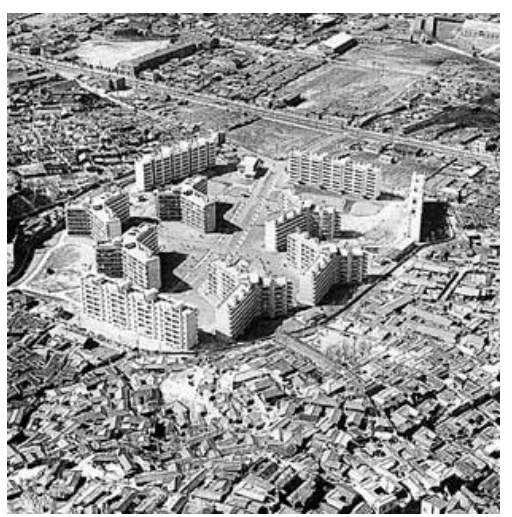

Mapo Apartment in 1965

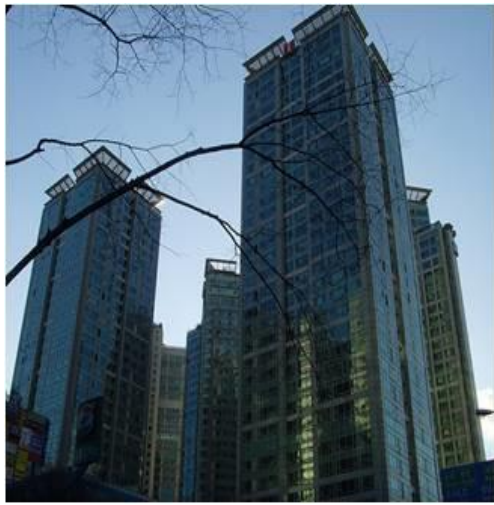

Apartment in 2000s

Figure 2.13. Transition from traditional Korean-style house to apartments. ${ }^{80,81,82}$

According to data released by the KNSO in $2007^{83}$ and Chosun Ilbo, ${ }^{84}$ more than $50 \%$ of the Korean population have moved into apartment complexes in the past 50 years. This illustrates the changing preferences and/or economic realities of consumers.

80 Kim, J \& Choe, S 1997, Seoul: the making of a metropolis, John Wiley \& Sons, England.

81 Kang, J 2005, 'Mystery of "the republic of apartments", The Hankyoreh, 2 Decmeber, viewed October 2008, http://www.hani.co.kr/section-021128000/2005/12/021128000200512210590007.html. 82 Kim, S 2006, 'Time of life, face of time', Heungkuk, viewed October 2008, <http://www.hungkuk.co.kr/>.

83 Korea National Statistical Office 2007, Statistics on the aged, viewed July 2007, http://www.nso.go.kr/.

84 'Why are Koreans so addicted to apartment?' 2007, Chosun Ilbo, 24 April, viewed November 2008, http://english.chosun.com/w21data/html/news/200704/200704240024.html. 
Statistical data released by Statistics Korea in $2016^{85}$ show that the percentage of apartment complexes increased from $52.7 \%$ in 2005 to $59.9 \%$ in 2015 , whereas the percentage of detached houses decreased from $32.2 \%$ in 2005 to $27.4 \%$ in 2015 . Thus, more people are transitioning from living in detached housing to living in high-rise environments.

\subsubsection{Changes to house unit plans between the 1950s and 1970s}

Between the 1950s and 1960s, house spaces were generally in a rectangular style. In a house plan, there was a master room (Anbang), living room (Maru) and a second room (Gununbang) at the front, and the kitchen, third room, bathroom and entrance were at the back. This structure reflects past lifestyle patterns and awareness.

The size of houses was restricted to $40 \mathrm{~m}^{2}$ and $3 \mathrm{LK}$ was the most popular structure in the 1950s. The style in which residents entered at the back and moved through a hall to reach the living room was influenced by the 1910s-1940s. In the late 1960s, 3LK structures became 4LK when two rooms were placed at the back.

In the late 1970s, consumers had better financial circumstances and increasingly demanded more and better-conditioned spaces. As a result, although the traditional structure of a master room, living room and a second room at the front still existed, the living room and kitchen became the centre of the plan. There was a dismantlement of the kitchen and the master room and more rooms were added to the back row and joined to the living room, which changed the unit plan style from LK to LDK. ${ }^{86}$

85 Statistics Korea 2016, Result of the 2015 population and housing census, viewed January 2017, http://www.kostat.go.kr/portal/korea/kor_nw/2/1/index.board?bmode=read\&aSeq=356061.

86 Yoo, J \& Cho, S 2001, 'The characteristics and the influences of standard urban housing in Korea between the 1950's and the early 1980's', Proceedings of the Architectural Institute of Korea, vol. 17, no. 12. 


\subsubsection{Changes to apartment plans from the 1980s to the present}

Until activating the liberalisation of a sale in apartments, LDK was used in most units in the 1980s. ${ }^{87}$ First, around $84 \mathrm{~m}^{2}$ (area of exclusive use) was adapted as a twobay style that included a living room and a master room at the front and two bathrooms in the middle of the $3 \mathrm{LDK}$ structure. Second, approximately $115 \mathrm{~m}^{2}$ was adapted as a 4LDK structure, which is a three-bay style that included a living room and two rooms at the front, two bathrooms on both sides and DK at the back. Lastly, a dressing room was added to the larger $132 \mathrm{~m}^{2}$ plan. ${ }^{88}$

Since liberalisation began, during 1998-2001, units around $84 \mathrm{~m}^{2}$ still used the 3LDK structure, but they were designed in the three-bay style and included a living room and two rooms instead of the two-bay style. Moreover, around half of unit plans had a dressing room and an antechamber. Further, units around $115 \mathrm{~m}^{2}$ used the 4LDK and 4L+DK structures. Three- and four-bay styles were generally used for the front row, most unit plans contained a dressing room and $50 \%$ of plans included an antechamber room. ${ }^{89}$

During the 2000s, the structure of separating the living room from the kitchen and dining room (L-DK and LDK) was the first choice when designing a house plan.

87 Choi, J, Cho, H, Park, I \& Park, Y 2004, 'A spatial analysis of the apartment unit plans from 1966 to 2002 in Seoul', Proceedings of the Architectural Institute of Korea 2004, vol. 20, no. 6, p. 159.

88 Ko, Y, Lee, S, Lee, K \& Kim, Y 2003, 'A study of transformation tendency of an apartment unit plan after the enforcement of price deregulation', Proceedings of the Architectural Institute of Korea, vol. 23, no. 2, pp. 79-82.

89 Ko, Y, Lee, S, Lee, K \& Kim, Y 2003, 'A study of transformation tendency of an apartment unit plan after the enforcement of price deregulation', Proceedings of the Architectural Institute of Korea, vol. 23, no. 2, pp. $79-82$. 
The L-DK structure was chosen by more houses planning than LDK. ${ }^{90}$ According to the comparison study of Korean, Japanese and Chinese structures, the percentage of total room size in the house were Japan (38\%), Korea (43\%) and China (44\%). ${ }^{91}$

The gross size of the living room declined when the unit area increased because the number of rooms also increased. Further, the number of rooms and bathrooms increased, as residents were more likely to focus on their privacy.

The total size of the kitchen and dining room steadied between 14\% and 17\%, whereas the bathroom stabilised between $6 \%$ and $7 \%$. It showed that planning bathrooms for parents was set up since the late 1990s.

Given that few activities take place in the entrance area, this space was only allocated $2 \%-3 \%$ of the gross size of the house unit. However, it is used as a buffer zone between inside and outside areas, and to take off one's shoes, which is traditional in Korea. The space with the smallest ratio to the gross size of the house was the storage space (average of $2 \%$ ). There were high demands on allocating more space. ${ }^{92}$

\subsubsection{High-rise apartments}

Modernisation began in traditional housing in the form of 'urban HanOk', but it was interrupted by the Korean War and social confusion. Since apartment building began in the 1950s and the 'Mapo apartment' was constructed in 1962, a residential apartment complex initiated its typology as well as its high-rise living environment. The

$90 \mathrm{Oh}, \mathrm{H} \& \mathrm{Kim}, \mathrm{D} 2001$, 'A study on space composition and the trend for interior design of the luxurious apartment', Proceedings of the Architectural Institute of Korea, vol. 27, p. 114.

91 Shim, W, Kang, S \& Cho, J 2000, 'A comparative analysis on housing unit plans of Korea, China and Japan', Proceedings of the Architectural Institute of Korea, vol. 16, no. 11.

92 Lee, K, Park, S \& Lee, H 2005, 'An analysis of the space size in the apartment unit plan', Proceedings of the Korean Institute of Interior Design, vol. 7, no. 2, pp. 52-55. 
policy of the 'liberalised sale of apartments' in 1998 boosted the supply of apartments and led to the phenomenon of high-rise living. More than half of the population resided in apartments in 2005 (Gelezeau, 2007), which is consistent with data reported by the KNSO (2007) and the Korean Statistical Information Service (KOSIS, 2016). ${ }^{93}$ According to a Chosun Ilbo article, ${ }^{94}$ the construction status that apartments are supplied 13 times more than single detached houses in 2007 demonstrates a transition to high-rise living.

Table 2.11 Status of Number of Floors of Apartments

\begin{tabular}{lcc}
\hline & \multicolumn{2}{c}{ Number of floors of apartments } \\
& 5 and less & 25 and more \\
\hline 2013 & $1,003,497$ & 798,525 \\
2010 & $1,000,171$ & 666,897 \\
2007 & 996,612 & 470,173 \\
\hline
\end{tabular}

The Ministry of Land, Infrastructure and Transport published statistical data regarding living environments in apartments and found that high-rise apartment buildings are constructed quickly. There were significant changes between 2007 and 2013 in the number of apartments with fewer than five floors and those with more than 25 floors. In 2007, 996,612 apartments had fewer than five floors; this increased to $1,003,497$ in 2013. In contrast, the number of apartments with more than 25 floors was 470,173 in 2007 and 798,525 in 2013. The total number of apartments with 25 floors or more is smaller than the number with five floors or fewer, but the increase during the

93 Korean Statistical Information Service (KOSIS) 2016, Number of houses and distribution rate of house, updated, viewed 2016, http://kosis.kr/.

94 'Why are Koreans so addicted to apartment?' 2007, Chosun Ilbo, 24 April, viewed November 2008, http://english.chosun.com/w21data/html/news/200704/200704240024.html. 
same period indicates steep growth in high-rise apartments. ${ }^{95}$ The data indicate that there is a trend towards more construction of high-rise apartment buildings and greater demands on high-rise apartments from prospective customers, which leads to changes in the residing environment to become more familiar with the high-rise living environment.

\subsection{Elderly Living Environment}

\subsubsection{Rise of silver towns}

Elderly people are generally characterised as being in poor physical health, forgetful, conservative, unemployed, dependent, stubborn and estranged. These negative images come from researchers who have not been focused on healthy elderly residents, but on those who live in welfare facilities, and these studies have mainly been conducted in Western Europe during the 1940s and 1950s. ${ }^{96}$ The studies treat elderly people different from other generations. However, life expectancy has considerably increased because of improvements in medical treatment, lifestyles and living environments. The increase in the elderly population has also transformed perceptions of seniors. Thus, older people in healthy condition have many needs, and there are various opportunities for service providers to provide support. As a result, new terms have been introduced in Korea, namely 'silver industry', 'silver town' and 'silver towers'.

95 Ministry of Land, Infrastructure and Transport, Korean Statistical Information Service 2015, Current status of number of floors of apartment, viewed December 2015, http://kosis.kr/.

96 Kim, C \& Park, Y 2007, 'Demand of the old life preparation for following in the thread silver town of the specialist group analysis', Korean Institute of Culture Architecture Journal, vol. 18, p. 45. 
These developments are intended to respond to cultural norms in which the family is the focal point for supporting older people in Korea. ${ }^{97}$ Korean elders have strong expectations to reside with their eldest son. ${ }^{98}$ Moreover, cohesiveness and harmony in the family are more important than individual achievement and privacy. These traditional norms are influenced by Confucian ideas in which respect for elders and filial piety are the most important virtues. As noted by Sung (1995), there are two factors in modern filial piety in Korea: ${ }^{99}$ behaviours such as sacrifice, responsibility and repayment and emotions such as harmony, love and respect. The Korean ethic of parental care is grounded in sacrifice, which transcends self-interest. Filial piety is, in part, a desire of children to repay what they owe their parents. However, the coresidence trend between parents and their children changed in the 1990s. Previous research has found dramatic changes regarding family status. While $93 \%$ of Korean seniors were living with their children in the early 1970s, that percentage dropped to $54 \%$ by 1994 . That is, in around two decades, approximately $40 \%$ of seniors chose to lead an independent life. ${ }^{100}$ The increased income of seniors became a catalyst for them to live alone. Therefore, the traditional co-residence with a son, especially the eldest

97 Choe, E 1970, 'Current and future prospects on problems of aging in the Republic of Korea', in Population aging: review of emerging issues, United Nations Economic and Social Commission for Asia and the Pacific, Bangkok.

98 Choi, J 1970, 'Comparative study on the traditional families in Korea, Japan and China', in R Hill \& R Koeing (eds), Families in East and West, Mouton, Paris pp. 202-210.

99 Sung, K 1995, 'Measures and dimensions of filial piety in Korea', Gerontologist, vol. 35, no. 2, pp. $240-247$.

100 Kim, I 1999, 'Population aging in Korea', Journal of Sociology \& Social Welfare, vol. 26, no. 1, pp. $101-123$. 
son, is no longer the preferred or most feasible living arrangement for most aging Koreans.

The Ministry of Health and Welfare found that elderly people choose to become less dependent on their children. The agency surveyed elderly people's opinions regarding the ideal method of living expenses and found that $65.2 \%$ of respondents aged 65-69 were independent, $26 \%$ used social welfare and only $8.1 \%$ received assistance from their children (see Figure 2.14). In contrast, of those aged over 85, 38.5\% were independent, $33 \%$ used social welfare and $28.5 \%$ received support from their children. This shows that younger people are less likely to be dependent, and that active seniors will be more independent and have their own source of income. ${ }^{101}$

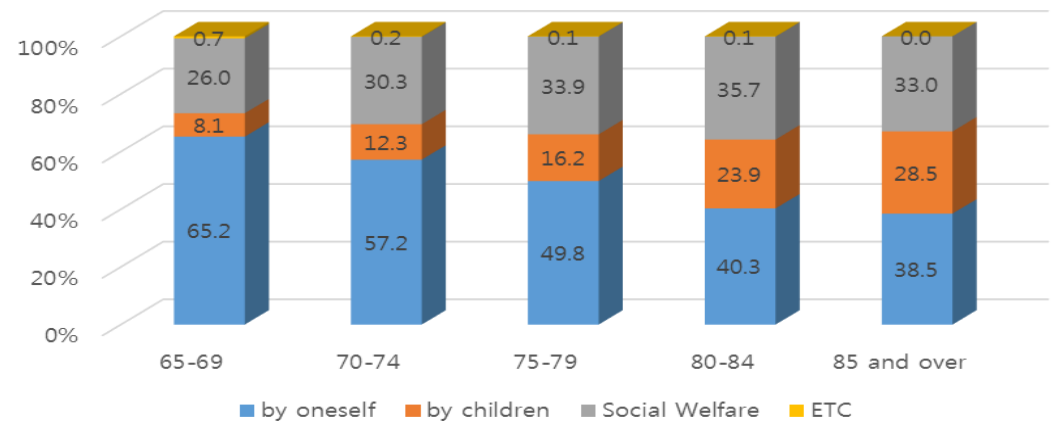

Figure 2.14. Ideal method of living expenses.

More income sources for elderly people leads to a larger aged-care industry. The silver town industry in Korea comprises $5 \%$ of gross domestic product, which is smaller than that of Germany and Japan. However, the size of the silver industry was around 27 trillion won (about \$23 billion) in 2012 and is expected to be around 73 trillion won

101 Ministry of Health and Welfare \& Korean Statistical Information Service, The research on current condition of the elderly, viewed October 2016, http://stat.mohw.go.kr/, http://kosis.kr/. 
(about $\$ 60$ billion) in 2020. The industry is expected to grow at an average rate of $13 \%$ every year. ${ }^{102}$

Further, the silver industry in Korea was valued at around 13 trillion won (about $\$ 11$ billion) in 2002, whereas it is expected to increase more than tenfold, to 148 trillion won (about $\$ 123$ billion), by 2020 (see Figure 2.15). ${ }^{103}$ To support these figures, retail markets target active seniors, who are aged in their 50s and 60s and have solid purchasing power. They release customised products for active seniors because, compared with past periods, active seniors make investments and consume products for themselves. ${ }^{104}$ However, the aged-care industry in Korea is still in the development stage. Thus, the demands, preferences and needs of the aging population are not yet fully understood.

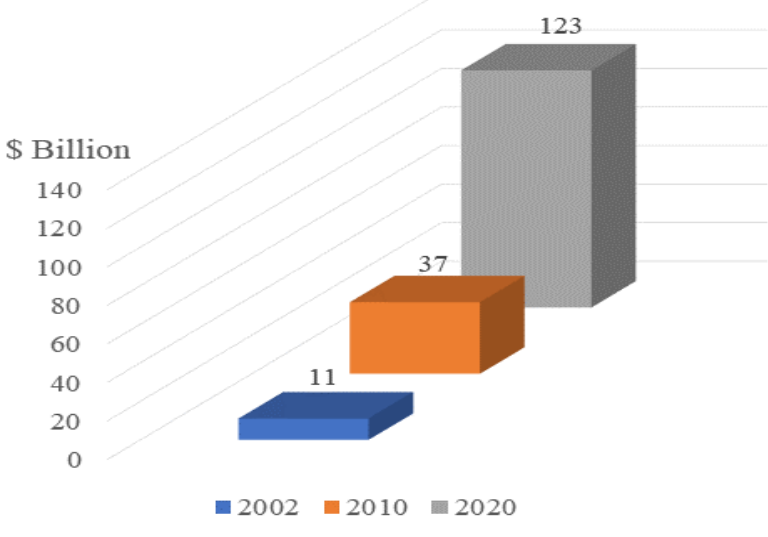

Figure 2.15. Estimate of silver town industry.

102 'Change of method of approach in terms of policy is important to promote silver industry', Newstomato, viewed September 2016, http://www.newstomato.com/ReadNews.aspx?no=691973. 103 Ministry of Health and Welfare, Estimate of silver industry, viewed July 2016, http://stat.mohw.go.kr/.

104 'It is now spending money for myself...5060, becoming major consumers' 2013, Senior Chosun, 19 June, viewed July 2014, http://senior.chosun.com/site/data/html_dir/2013/06/19/2013061900913.html. 
In 1993, the Ministry of Health, Welfare and Family Affairs implemented a policy to encourage the private sector to invest money in silver towns and build them ${ }^{105}$ in accordance with elderly people's demands and preferences. To attract developers to the upscale market to build silver towns (commonly referred to as retirement communities and nursing homes overseas), the policy allowed private investors to build full fee-charging housing for seniors. These facilities typically include living, leisure sports and medical treatment facilities. For instance, Seoul Seniors tower ${ }^{106}$ was the first full fee-charging silver town in Seoul. It was built in Jung-gu, Seoul, in 1998 and now has five branches in Seoul and Gyeonggi-do. It is located next to a hospital and consists of 144 units, a parking building and a nursing home with 30 rooms for people who need a higher level of physical care. The accommodation building contains sport facilities, leisure facilities, a convenience store and medical facilities. Each apartment has a monitor in the entrance, emergency pagers and fire alarm systems in the rooms. The fitness and medical facilities provide opportunities to keep in contact with others, and they reduce the financial burden by sharing high-quality services. Examples of silver towns and silver town facilities are illustrated in Figures 2.16 and 2.17.

As noted above, silver towns are designed for the aging population and feature smart technology to assist the elderly to live independently. The towns keep up-to-date with technology trends such as broadband Internet. In addition, they implement technologies aimed at aged residents for medical and security reasons. For example, emergency call systems are embedded in many locations throughout individual units and communal spaces to provide a quick response when needed.

105 Ministry of Health, Welfare and Family Affairs, Social welfare services, viewed June 2008, http://english.mw.go.kr/.

106 Seoul Seniors Tower, viewed August 2008, http://www.sst.co.kr/eng. 

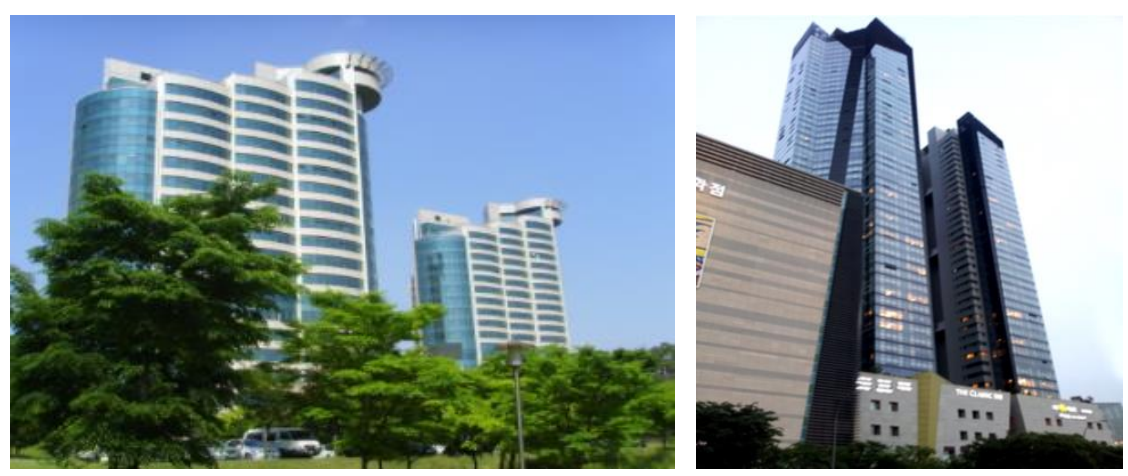

Figure 2.16. Silver towns.

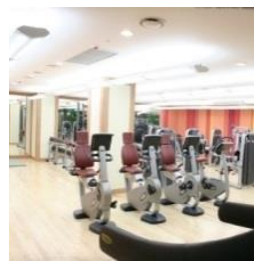

(a) Fitness

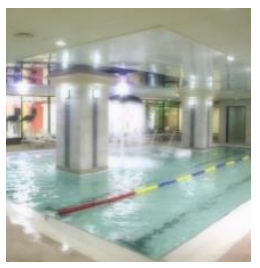

(b) Leisure

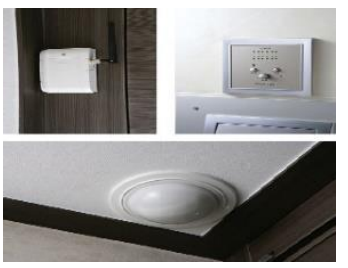

(c) Sensors/emergency

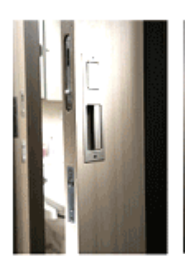

(d) Silver-centred design

Figure 2.17. Silver town facilities.

\subsubsection{Silver town status in Korea}

Since the first silver town became operational in 1998, around 20 silver towns were built within 10 years by various developers. In 2013, there were 20-25 silver towns in operation (see Table 2.12), with a small but steady increase. However, the number increased more quickly, from 25 to 31 buildings, between 2013 and $2015 .{ }^{107}$ Thus, it appears that more people are considering silver towns as their next dwelling environment, and that developers have deemed the silver town market to be a tangible industry.

107 Ministry of Health and Welfare \& Korean Statistical Information Service, The research on current condition of the elderly, viewed October 2016, http://stat.mohw.go.kr/, http://kosis.kr/. 
Table 2.12 Number of Silver Towns

\begin{tabular}{llllllll}
\hline & 2015 & 2014 & 2013 & 2012 & 2011 & 2010 & 2009 \\
\hline $\begin{array}{l}\text { Number of silver towns } \\
\text { Maximum capacity }\end{array}$ & 31 & 29 & 25 & 23 & 24 & 22 & 19 \\
(people) & 5,376 & 5,034 & 4,761 & 4,128 & 4,231 & 4,746 & 2,354 \\
\hline
\end{tabular}

Most silver towns are located in Seoul and Gyeonggi-do area (11 and 10 buildings respectively; see Figure 2.18). Thus, around two-thirds of silver towns are concentrated in the capital area. Further, most silver towns are urban or semi-urban in style, and developers respond to the preference of elderly people to settle in Seoul. Many existing silver towns have good accessibility to public transport, shopping, entertainment facilities and government buildings. Further, most silver towns have public parks or gardens within half a kilometre, even though the buildings are generally of an urban type. The data indicate that two-thirds of currently operating silver towns including both urban types and high-rise buildings. ${ }^{108}$ Recently, major companies such as GS E\&C Corporation ${ }^{109}$ and Lotte Hotel ${ }^{110}$ launched silver town constructions or the elderly-related medical services in collaboration with an existing senior specialised hospital. This demonstrates the competitiveness of the aged-care industry.

108 Kwon, JT 2015, 'An analysis of the current situation and development trends of housing for the elderly (silver town)', Master's thesis, Semyung University, Jecheon.

109 'GS E\&C Corporation announce launching a silver town building, the one would be a role model for senior housing' 2016, Bridgenews, viewed November 2016, http://www.viva100.com/main/view.php?key=20161031010008576.

110 'Lotte hotel conclude memorandum of understanding (MOU) with Bobath Memorial Hospital' 2016, Herald Corporation, viewed November 2016, <http://news.heraldcorp.com/view.php?ud=20161104000017>. 


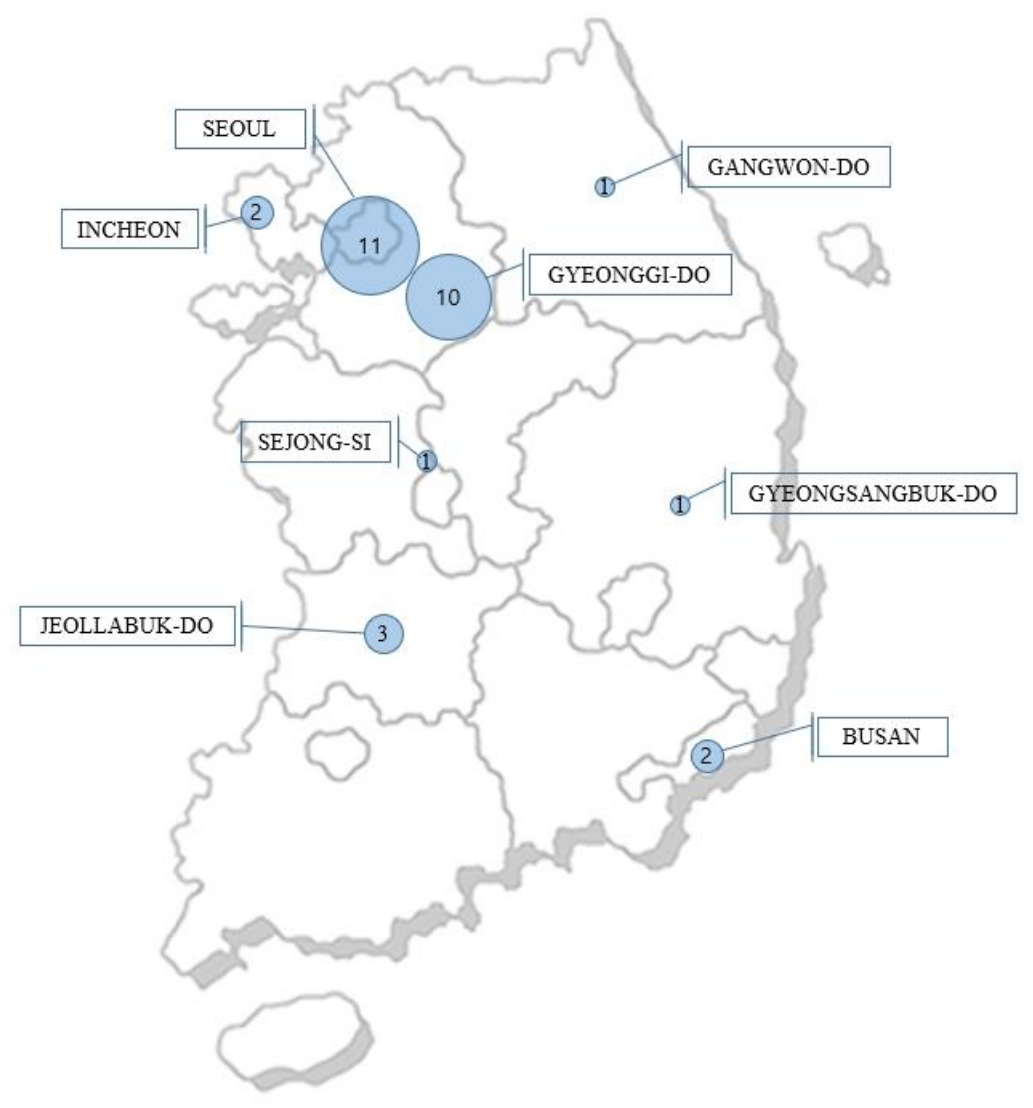

Figure 2.18. Silver town distribution.

\subsection{Selected Silver Towns}

\subsubsection{Silver towns and residents in numbers}

Figure 2.19 shows the styles of selected silver towns. They are tall, urban-style buildings, except for the semi-urban style of B tower. S tower is the oldest and GY tower is the youngest of the chosen silver towns. GS tower and B tower were built in the same year, but GS tower was built in an urban style in Seoul, whereas B tower is in the semi-urban style and is in a satellite city. The selected silver towns — excluding B tower-are in Seoul and have excellent accessibility through public transport such as subway lines and bus lines. It is easy to communicate with friends and family, and there is convenient access to the city centre to enjoy the urban lifestyle. More importantly from the elderly perspective, all five towers have excellent medical services, such as clinic facilities inside the building or an affiliated general hospital within walking 
distance. For example, all towers have an on-site clinic and a nursing unit on the ground floor or underground floor, and $\mathrm{S}$ tower is next to a general hospital building.

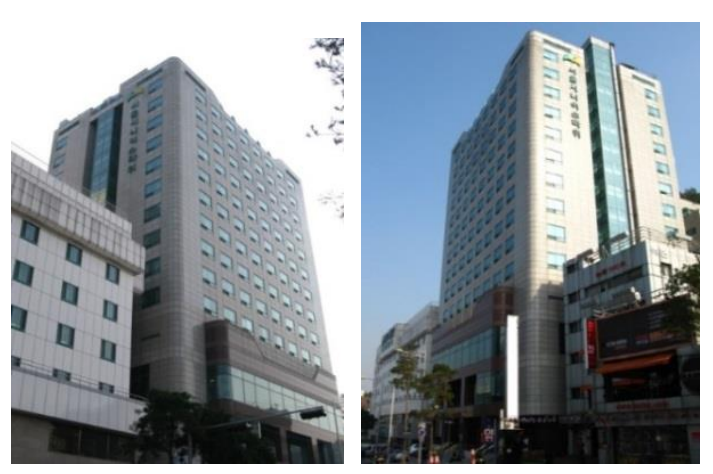

S tower (1998)

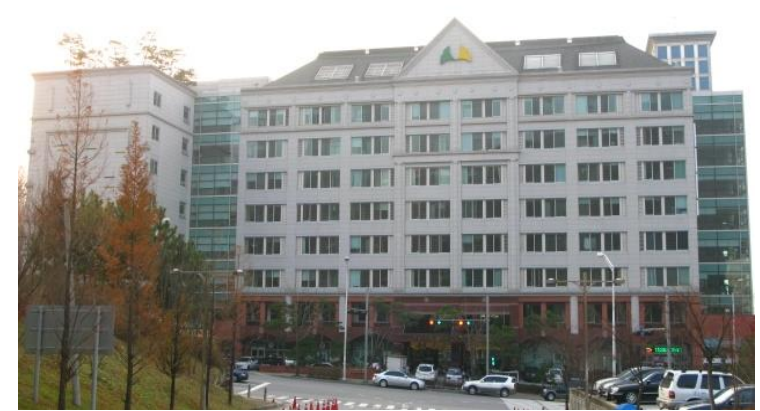

B tower (late 2003)
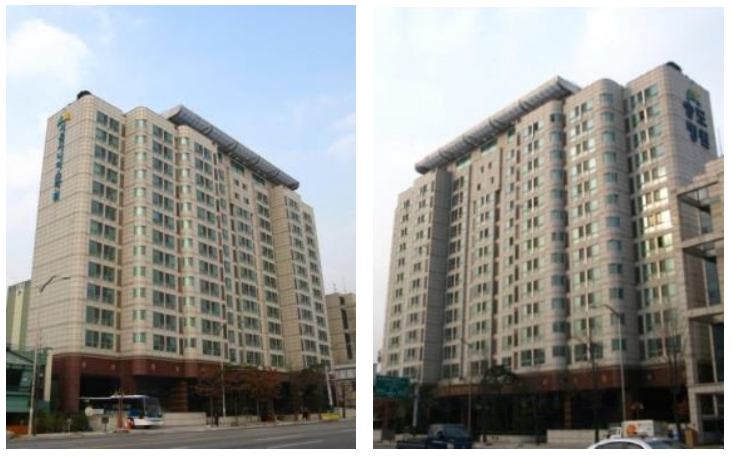

GS tower (early 2003)

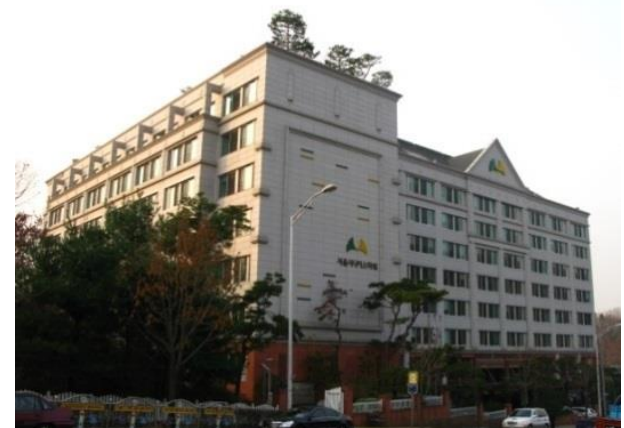

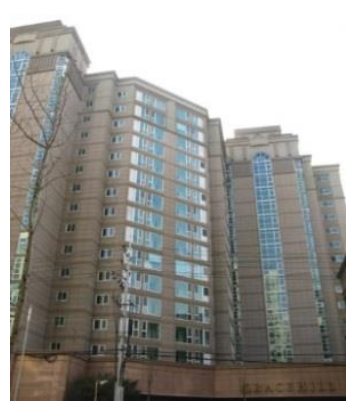

GH tower (2006)

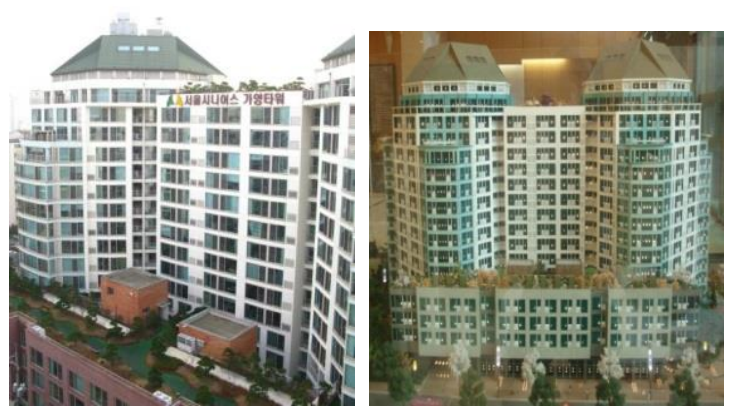

GY tower (2007)

Figure 2.19. Selected silver towns.

In terms of geographical position, four silver towns are located in the capital city, Seoul, and a semi-urban style of silver town is located in Seongnam-Si, GyeonggiDo. B tower is located slightly outside the city of Sungnam — a satellite city —and is aimed at elderly people who want a quiet and rural life, but who do not want to lose frequent contact with family and friends. Figure 2.20 shows the geographical features of 
selected silver towns. The total number of silver towns and their distribution features were mentioned earlier in this chapter; therefore, briefly, four out of 11 silver towns in Seoul and one out of ten silver towns in Gyeonggi-Do allows the researcher to carry out interviews, observations and surveys.

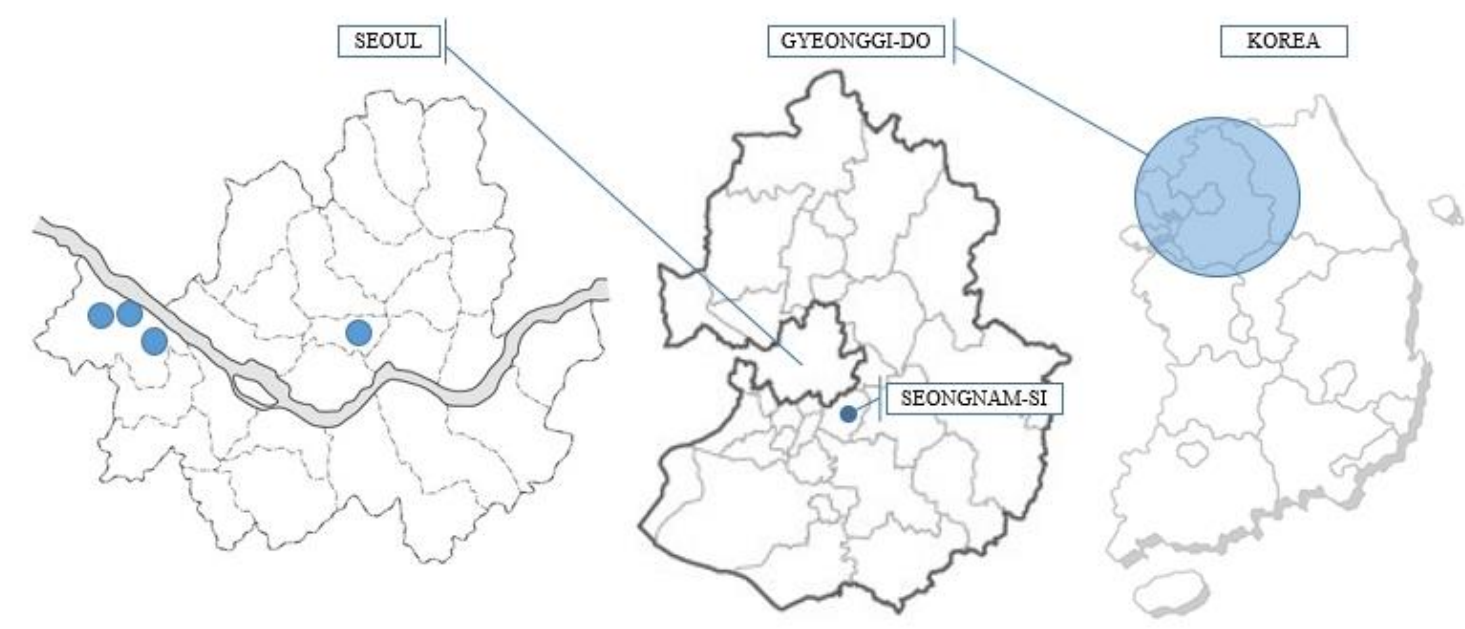

Figure 2.20. Selected silver towns' location.

Living in the capital city or a satellite city provides good accessibility for both the elderly and their family members. A number of residents still work, and seniors require easy access to public transport to enable them to be more active. Most of the residents' children had an issue with their parents moving into silver towns because they mistakenly believed the towers were similar to an asylum, sanatorium or nursing home, which would make others think that the children had abandoned their parents. Thus, the children wanted their parents to live in a nearby town so they could make frequent visits.

The selected silver towns were built in different years, with five silver towns built from the late 1990s to the late 2000s (see Figure 2.21). Five silver towns were selected according to their chronological sequence from 1998 to 2007. As part of the first generation of silver towns, S tower began service in 1998, followed by GS tower in 
early 2003 and B tower in late 2003. GH tower and GY tower were built in 2006 and 2007 respectively.

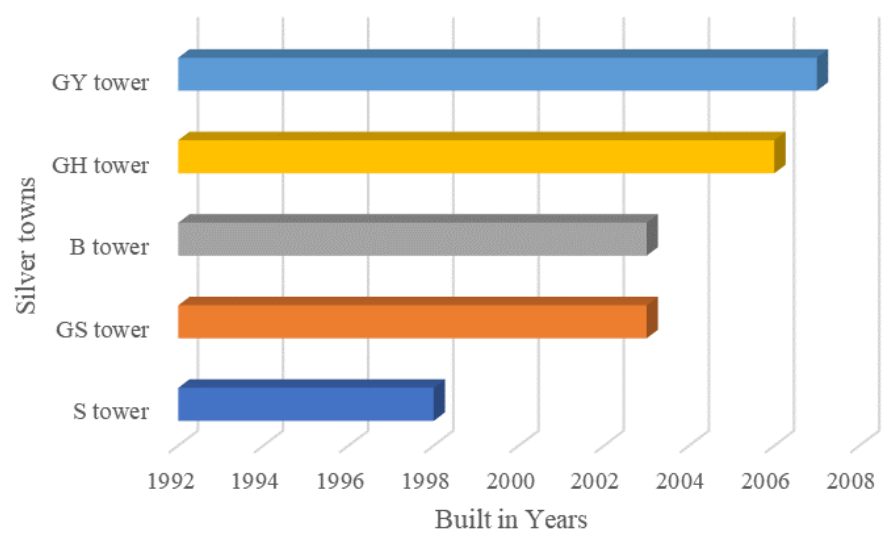

Figure 2.21. Years of construction of silver towns.

GY tower contains the largest number of units, with 419 in total, including 69 intensive care or nursing units (see Figure 2.22). This is followed by semi-urban style B tower with 254 units and GH tower with 182 units. Further, S tower has 144 units and GS tower has 142. Most residents can live independently, but some require simple support. Some of the elderly residents were worried about what would happen when their health issues increased. Thus, GY tower has introduced nursing care units in its other silver towns.

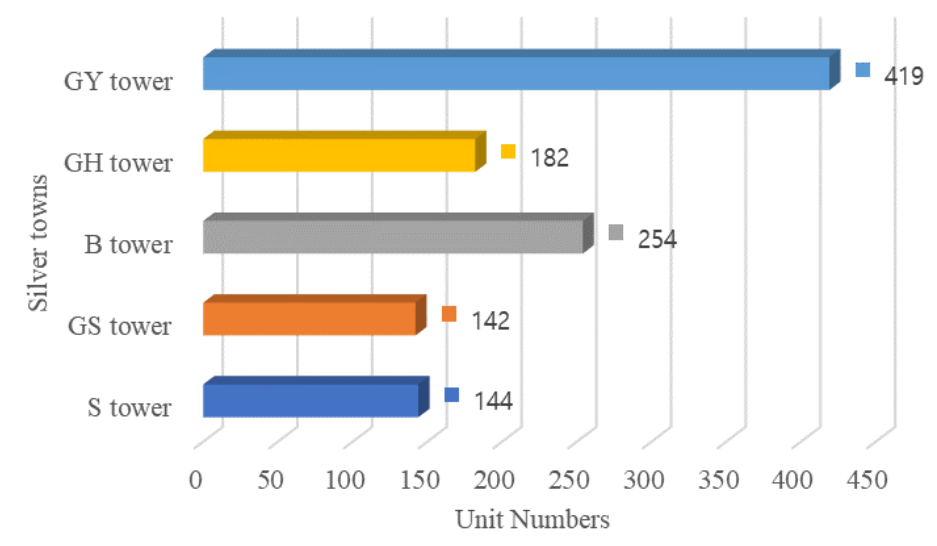

Figure 2.22. Number of units in silver towns. 
Four selected silver towns have more than 15 floors, including basements (see Figure 2.23). Semi-urban style B tower has 11 floors, which makes it a high-rise building. $\mathrm{S}$ tower has one basement level for machines, and support rooms for the senior residents are located on the ground floor to the second level. Individual units are located between the third and twelfth levels. Other silver towns have a similar layout, with lower levels containing machine rooms and communal facilities, and personal units located from the third level to the top level of the building.

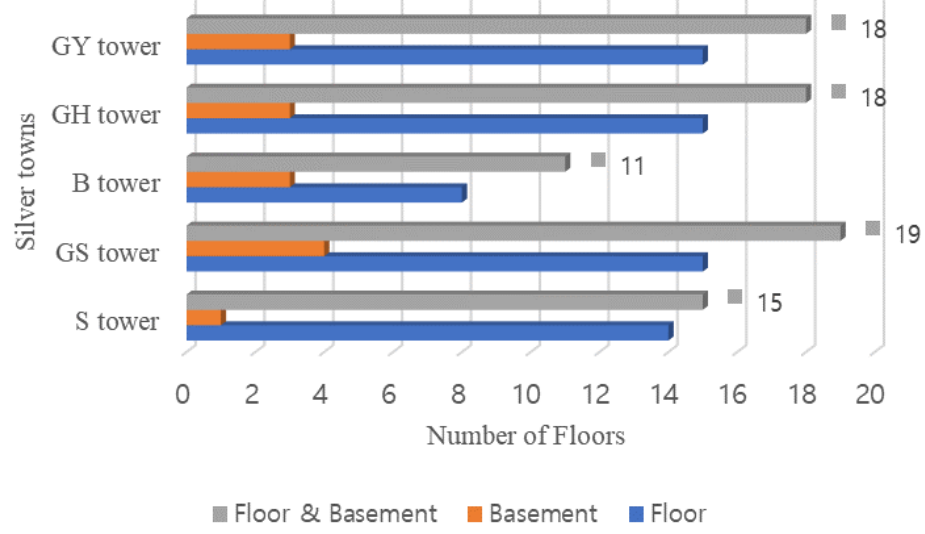

Figure 2.23. Number of floors in silver towns.

Figure 2.24 illustrates some of the facilities that support elderly activities and exercise in silver towns, such as a swimming pool, a golf practice range, a snooker room and a fitness centre. Further, other rooms are provided to encourage the residents to engage in sports.
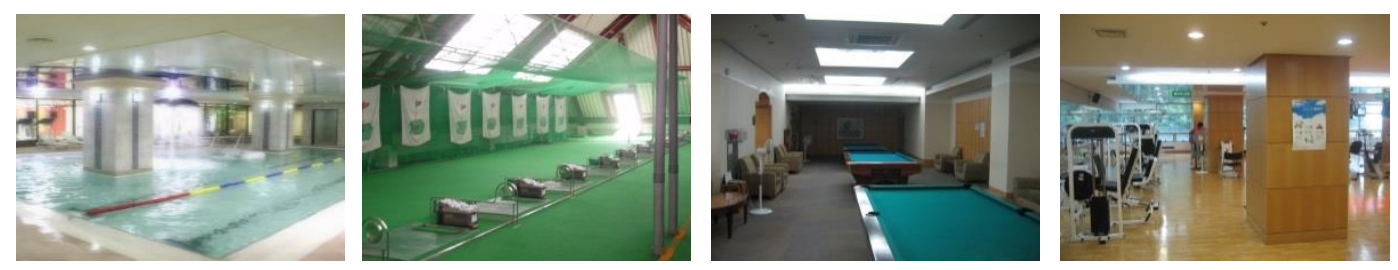

Figure 2.24. Silver town facilities (swimming pool, golf range, pool tables, fitness).

There are not only support facilities for exercise, but also leisure spaces (see Figure 2.25). For example, silver towns design education programmes and activities, 
and they provide rooms for computers and the Internet, library, cinema, karaoke,

Korean chess and calligraphy.
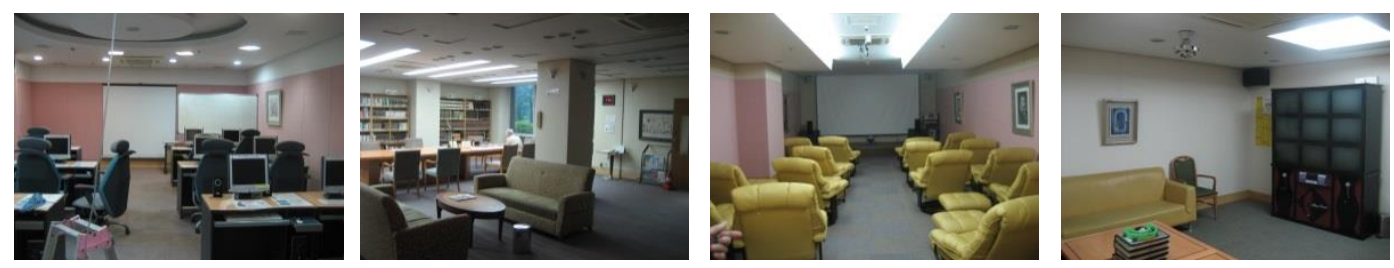

Figure 2.25. Silver town facilities (computer, library, cinema, karaoke).

Figure 2.26 shows that the building has ample space to support outdoor walks, a lobby for chatting and meeting with visitors, a restaurant serviced by professional chefs and nutritionists, and a nursing unit and physio room to support seniors' health concerns.
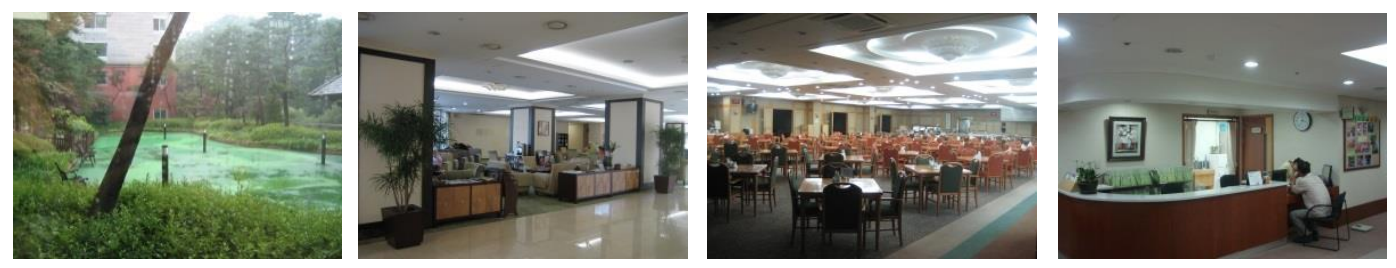

Figure 2.26. Silver town facilities (walk, lobby, communal restaurant, nursing unit).

As shown above, silver towns consist of both individual units and facilities for education, indoor and outdoor exercise, leisure, communal services and on-site medical services to provide an optimal living environment for the elderly. Further, efforts have been made to enable residents to communicate with non-residents by opening some facilities (e.g., swimming pool, sauna and restaurant) to the public. This increases visitors' familiarity with the building and its environment, and it helps to turn negative perceptions of silver towns into positive ones. 


\subsubsection{Advertised technologies in silver towns}

Table 2.13 Smart Technologies in Selected Silver Towns

\begin{tabular}{lll}
\hline Location & Categories & Advertised technology \\
\hline & & $*$ Nursing and emergency call system \\
& $*$ Movement detection sensor \\
& $*$ Portable emergency pager \\
& $*$ Real-time health check system \\
& $*$ Tracking system \\
& $*$ CCTV (S tower only) \\
& & $*$ Remote inspection system \\
Individual living & & $*$ Indoor air quality control system \\
units & & $*$ Light control/energy-saving system \\
& $*$ Environment control clevalor call system \\
& & $*$ Cardkey \\
& & $*$ Monitoring system \\
& & $*$ CCTV \\
& & $*$ Movement detection sensor \\
Public space & & $*$ Parking control \\
\hline
\end{tabular}

Note: Bold $=$ activated technologies

Advertised technologies or the presence of previous research technologies are categorised by location (i.e., individual units and public spaces, and then subdivided to care-related, environment-control-related, security-related and technology in communal areas). Among these technologies, the active systems are nursing and emergency calls, portable emergency pagers and movement detection sensors from the care-related category, with no active technology from the environment control section. Moreover, one security-related technology (i.e., card key) is active, along with CCTV in public areas.

Figure 2.27 shows which technologies have been installed and are currently active in each silver town. All technologies in the care, security and public categories are almost evenly integrated. S tower has an additional 'real-time health check system', 
but it is not in use, and other towers had not considered installing the system. According to the developers, there is a remote inspection system in four towers (excluding $\mathrm{S}$ tower), but it is not active because the residents prefer to check their meter manually. The only environment-related technology is the parking control system, which monitors residents' parking status and provides information regarding their parking location. This system is installed in GH and GY towers, but it is not in complete use. Therefore, installed smart technologies vary among the selected silver towns, but there are always five active technologies.

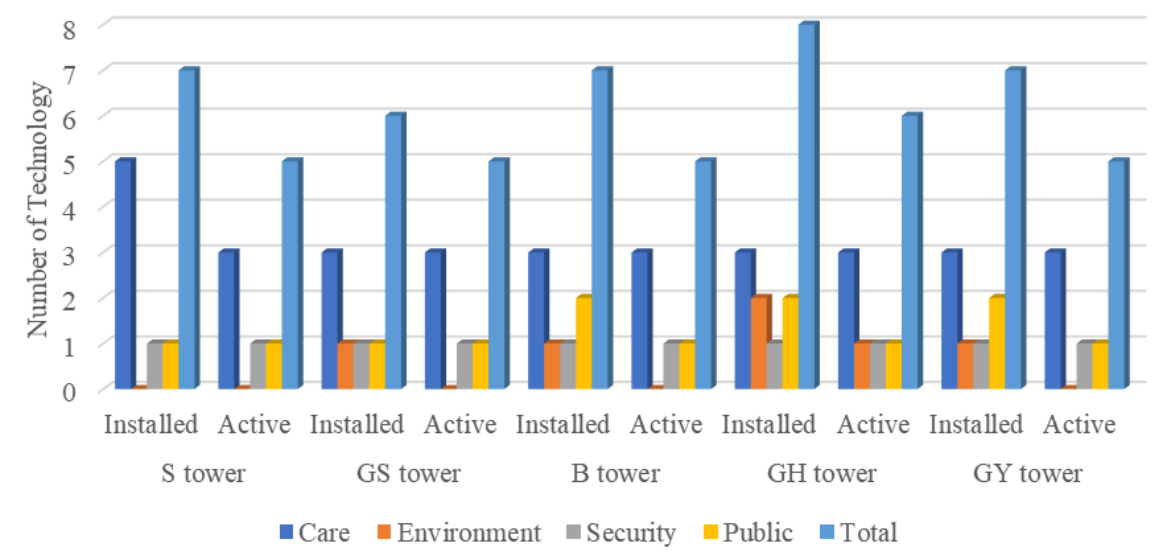

Figure 2.27. Installed and active technologies in each silver town.

\subsection{Conclusion}

As a result of the dramatic increase in the aging population, Korea will become the second-oldest country in the world within three decades. The aging population combined with the negative population growth rate has resulted in a lack of elderly housing. An optimistic environment for ICT-based technology development has combined with government support to make IT the country's strongest industry. This development provides benefits to citizens in terms of convenience and a technologyfriendly environment, and support is extended to other countries. Within a brief period, buildings have made a significant transition from detached houses to high-rise 
buildings, enabling more than $60 \%$ of the population to experience high-rise living. The expected increase in housing demand for the increasingly aging population has resulted in the development of silver towers, which are high-rise apartment towers integrated with smart technologies to support the elderly.

Since the silver town industry began, a number of studies have been conducted regarding the new phenomenon; however, most of them have not examined all aspects of the building environment and have remained in restricted research fields because of competitive industry circumstances and privacy concerns of developers and elderly residents. Thus, Chapter 3 will explore the limited research undertaken by previous studies to find a gap. It will address the theoretical framework and research methods used, such as intensive interviews, surveys and site observations, and it will discuss the methodological issues and analysis technique. 


\section{Chapter 3: Previous Research and Research Design}

\subsection{Introduction}

The previous chapter examined key aspects of the research background. The elderly population in Korea has seen significant growth compared with other countries, and this has caused issues related to elderly housing. As a result, elderly-only living environments, called silver towns, have emerged as an alternative to overcome the lack of seniors' housing. Silver towns are underpinned by ICT development supported by the government and the high-rise apartment experience, with more than two-thirds of the population currently living in high-rise buildings. This new senior housing trend is likely to continue among future generations.

Since silver town development began in the late 1990s, many researchers have examined the emergence of elderly-only buildings and related issues. One part of this chapter explores previous studies regarding silver towns and applied smart technology to find a gap in the research field and emphasise the importance of the research. The other part of the next chapter explains the research design, theoretical framework, data collection and data analysis procedures, method and techniques (e.g., interviews, observations and surveys). Additionally, it outlines the verification process and ethical issues protecting research participants' rights.

\subsection{Previous Research}

There is a range of existing literature on elderly housing in general and on technology-assisted living in particular. Many of these studies have a particular emphasis or disciplinary focus that informs a particular direction of investigation. The 
diversity of such interests includes studies on home automation and building services, ${ }^{111}$ sociological perspectives on the introduction of technologies in domestic environments, ${ }^{112}$ technology-centred studies on smart homes ${ }^{113}$ and gerontological and e-health services. Aldrich (2003) provided a comprehensive review of these developments in a survey. ${ }^{114}$ While some of these studies are directly related to this research, some are only peripherally related, and others may become relevant in light of the data collection and analysis that follows. This section presents a brief summary of selected studies that are directly relevant to this research at this stage.

To understand and establish the overall context of silver town developments in Korea, a number of government and policy reports were identified. They provided hard data about key phenomena underpinning the development of silver towns in Korea, including aging population trends, increasing population densities around the country and crucial factors underpinning IT developments. These data were summarised in previous chapters.

The transition to apartment development and high-density urbanisation in Korea has led to Korea being dubbed 'The Republic of Apartments' ${ }^{115}$ The key changes that reflect the transition from traditional HanOk courtyard houses to apartments such as the

111 Banham, R 1984, The architecture of the well-tempered environments, University of Chicago Press, Chicago.

112 Silverstone, R \& Hirsch, E (eds) 2003, Consuming technologies-media and information in domestic spaces, Routledge, London.

113 Harper, R (ed.) 2003, Inside the smart home, Springer, London.

114 Aldrich, F 2003, 'Smart homes: past, present and future', in R Harper (ed.), Inside the smart home, Springer, London, pp. 17-39.

115 Kim, J \& Choe, S 1997, Seoul: the making of a metropolis, John Wiley \& Sons, London. Valérie, G \& Kil, H (ed.) 2007, The republic of apartments, Humanitas, Seoul. 
Mapo complex in Seoul were briefly reviewed in Chapter 2. The recent interest in and developments of smart technology integrated into silver towns represent another unfolding of apartment typologies, and were also briefly described.

The above summaries indicate that the recent development of silver towns integrated with smart technologies is not an insignificant phenomenon; in fact, it is likely to persist and grow even larger in Korea. These studies, especially the background understanding of apartment typologies, will be useful in comparing changes to be documented in this research.

A number of studies have explored issues that are relevant to this research, such as elderly people's attitudes towards new technologies. For example, based on group sessions with older adults, Demiris et al. (2004) studied seniors' perceptions of the technology improving their daily life and monitoring their health status. The elderly participants showed an overall positive attitude towards the technologies. The aged are also willing to try new technologies if they are readily available. The research approaches the perceptions of smart technology from the aged point of view. ${ }^{116}$

Other research has attempted to understand how elderly preferences change when they have more information about various housing options with applied smart systems. Moreover, when seniors have continued use of technologies such as the Internet and mobile phones, their perception of supporting technology systems increases. Kim et al. (2007) examined elderly preferences for living arrangements using small group workshops and found that when digital technologies support convenient living and health services in aged living environments, the elderly are likely to want to

116 Demiris, G, Rantz, M, Aud, M, Marek, K, Tyrer, H, Skubic, M \& Hussam, A 2004, 'Older adults' attitudes towards and perceptions of "smart home" technologies: a pilot study", Journal of Medical Informatics and the Internet in Medicine, vol. 29, no. 2, pp. 87-94. 
maintain their independent living. ${ }^{117}$ Lee (2014) surveyed senior residents in three silver towns to explore the importance of the ubiquitous environment and found that if the respondents had Internet access, they had more perception of the ubiquitous system. If seniors do not use the Internet, there is less perception of the technology system. However, in general, there is a low expectation of the ubiquitous home network system. Further application of the ubiquitous system requires a safety and energy-saving system, which results in increasing development and maintenance fees. Therefore, systems that will be used frequently by the elderly should be applied. ${ }^{118}$ Hwang (2015) analysed policy and regulation in Korea regarding the u-healthcare smart home based on ICT and current research projects and government projects in Korea and other countries. The author found that legislation is not sufficient in the architectural field, and there is conflict between the law in the medical and architectural fields regarding remote medical treatment. In addition, developments are in limited fields such as communication and home appliances. Thus, it is required to develop u-healthcare home met with Korean. ${ }^{119}$

Similarly, other studies have focused on Korean housing developments to understand middle-aged preferences. For example, Kim and Lee (2007) identified the needs of digital network services for future housing developments through an empirical survey of respondents aged 45-65. They found that respondents generally have positive

117 Kim, M, Lee, J \& Lee, Y 2007, ‘A study of elderly preference on living arrangement using small group workshop method', Proceedings of the Architectural Institute of Korea, vol. 7, no. 1, pp. 311-317. 118 Lee, C 2014, 'A survey on residential environment's improvement plan of silver town by means of applying ubiquitous systems', Proceedings of Korea Society of Geothermal Energy Engineers, vol. 10, no. 4 , pp. $8-14$.

119 Hwang, J 2015, 'An analysis of the research and policy on the smart home design for the elderly based on the u-healthcare', Proceedings of the Architectural Institute of Korea, vol. 31, no. 4, pp. 53-60. 
perceptions of digital services in the housing environment and that the most wanted services are security and health care. ${ }^{120} \mathrm{Ha}$ and Kwak (2007) conducted a survey with middle-aged people to study the general trends of desirable services in silver towns. The respondents rated medical facilities and the importance of health highly. ${ }^{121}$

However, other studies have found that some people place more importance on the facilities of silver towns. Chai (2013) surveyed prospective silver town users to investigate the influence of preferences. Variances were divided by physical factors such as facilities and services, and psychological aspects such as lifestyle, preparation for old age and family values. ${ }^{122}$ Kang (2012) analysed the survey results of people aged 45-65 to understand the various aspects influencing their selection of a silver town and required services, as well as facilities for seniors. Based on the results, the study suggested a few factors to be considered in silver town development in the future. ${ }^{123}$ A survey of middle-aged people explored other preferences in silver town developments. Kim et al. (2014) examined previous research and surveyed potential customers aged 45-65 to analyse core aspects affecting their selection of elderly housing. The respondents outlined various preferences according to gender, financial

120 Kim, M \& Lee, Y 2007, 'Preference of consumers after late 40's for development future home network services', Proceedings of Korea Institute of Ecological Architecture and Environment, vol. 7, no. 2, pp. 47-55.

$121 \mathrm{Ha}, \mathrm{J} \& \mathrm{Kwak}, \mathrm{J} 2007$, 'A research on the service environment evaluation elements for development of the silver town', Journal of the Korean Housing Association, vol. 18, no. 5, pp. 143-150.

122 Chai, S 2013, A study on the preference determinants of consumers for silver town, Doctoral thesis, Hoseo University, Cheonan.

123 Kang, N 2012, 'Determinants of choosing to live in silver town for supply of dwelling environments of elder', Proceedings of Korea Institute of Ecological Architecture and Environment, vol. 12, no. 2, pp. $103-110$. 
status, health status and family status. Urban- and rural-style silver town developments need to meet with customers' preferences. ${ }^{124}$ Kim et al. (2016) surveyed people aged 30-70 regarding their perception of silver towns and their preferences to determine whether various aspects influence whether respondents will move into a silver town in the future. As a result, the younger generation can obtain more information about silver towns and people in median income show positive intentions to move in. Thus, the research suggests that silver towns are better suited to middle-class people. ${ }^{125}$

There are new proposals from regional governments participating in silver town development by attracting prospective customers with regional strength. From existing silver towns built in the Seoul metropolitan area, regional governments aim to understand the key characteristics to apply to silver town development. Kwon et al. (2015) selected four silver towns around the Seoul metropolitan area to explore major factors influencing seniors' decision-making to estimate the possibility of silver town development in Daegu metropolitan city. The study found that key aspects include accessibility, connectivity to the general hospital and cultural centres, and the environment around the silver town. Therefore, the research concluded that understanding the preferences of the elderly and giving them different weight depending

124 Kim, M, Won, Y \& Lee, J 2014, ‘A study of the elderly housing type development plan considering the preconsumer housing characteristic - focused on Seoul metropolitan area', Journal of the Korea Academia-Industrial Cooperation Society, vol. 15, no. 5, pp. 2844-2858.

125 Kim, J, Kim, S, Kim, J \& Jang, J 2016, ‘A study on preference characteristic of silver town and inclination to move in (실버타운 선호특성과 입소의향에 대한 연구)', Journal of the Korean Urban 
on the most important factors should occur prior to the development. ${ }^{126}$ Other local governments (e.g., Gangwon) have released strategic reports to attract prospective customers with their strength. Park (2015) analysed previous research regarding existing silver towns and the preferences of the middle-aged and suggested possible aspects that regional government can promote. As a result, the local government can publicise silver towns by combining preferences from prospective customers and Gangwon's strong points such as the abundant natural environment and the short distance from the capital city. ${ }^{127}$ The development of living environments for the elderly only is a new field, and the successful building of $\mathrm{S}$ tower in 1999 shows that it has potential as a new market. Seo et al. (2006) surveyed the residential spaces of silver towns from the perspective of marketing and highlighted features that are more marketable in silver towns in terms of spatial structure and technology options. ${ }^{128}$

Another aspect of previous research involves suggesting guidelines for silver towns by surveying prospective customers. Won (2013) investigated aspects of deciding to move into a silver town by surveying prospective consumers aged 30-50 to understand sustainable demand for silver towns and standardise the index of family relationships and consciousness of family support. The study contributed to the

126 Kwon, JH, Park, SH \& Kim, EJ 2016, 'A study on the characteristics of location factors of urban silver town - focused on the urban silver town in the Seoul metropolitan area', Proceeding of the Korean Housing Association, vol. 28, no. 1, pp. 101-105.

127 Park, SY 2015, A strategy to invigorate attraction of silver town, Policy Note No. 449, pp. 1-12, Research Institute for Gangwon.

128 Seo, Y \& Kim, M 2006, ‘A study on the paid residential space for the elder from a marketing perspective', Proceedings of Korean Institute of Interior Design, vol. 8, no. 2, pp. 74-80. 
government's policymaking decisions. ${ }^{129}$ Existing silver town studies can convey information to developers and provide better comparison opportunities to prospective residents. Kwon (2015) used a literature review and other data analysis to analyse current silver towns and suggested guidelines for developers and future customers. Guidelines for developers provide information regarding silver town facilities, services, changing the moving-in system and customers' preferences. The data provide opportunities to compare silver towns in compliance with silver town candidates and family circumstances. ${ }^{130}$

Many researchers have been concerned with the elderly living space and designing and planning personal areas, but the importance of public or communal spaces extends the study field. Specifically, smart technology in both individual and public spaces in silver towns is equally important to support elderly living, and it indicates the consideration of communal spaces as a part of silver town living environments. Song and Nam (2011) used existing case studies to examine service types in silver towns based on seniors' needs. They then analysed plans for public spaces in silver towns to present tangible designs that integrated smart technology. ${ }^{131}$ Song (2011) classified applied smart technology in existing silver towns and presented further possibilities of urban-style silver towns to be smarter for active seniors, recommending

129 Won, NK 2013, A study of decision factors of intension to move in silver town-focus on the preliminary silvers and preliminary seniors residing in Seoul and Kyoungki area, Master's thesis, Graduate School of Public Policy, Hanyang University, Seoul.

130 Kwon, JT 2015, An analysis of the current situation and development trends of housing for elderly (SilverTown), Master's thesis, Semyung University, Jecheon.

131 Song, N \& Nam, K 2011, 'A study on the smart design in public space of urban type silver townfocusing on the lifestyle of active seniors', Proceedings of Korea Digital Design Council, vol. 11, no. 3, pp. $164-172$. 
smart systems not only in living areas, but also in public spaces. ${ }^{132}$ Lim (2011) focused on seniors' social activity, which decreases considerably because of the loss of physical ability. Therefore, communal spaces in silver towns require support. The study examined the characteristics of public spaces in urban silver towns to produce guidelines. $^{133}$

IT to sustain elderly living in silver towns is an upcoming research issue. As it is assisted by the Korean government, IT developments in high-rise building environments have boosted developments in a number of different fields, including the ubiquitous city. Lee (2007) explained that the Korean government is extending the ubiquitous city plan to various cities based on IT development. To keep up with the extension of the ubiquitous city, seniors' residential places apply technology to bring about changes in elderly facility plans. These transitions to smart technology meet with the elderly characteristics lead ubiquitous silver town plan. ${ }^{134}$ Choi and Park (2010) found the developed devices which are based on location-aware technology in silver towns. In addition, the research carried out how designed technology works in security and living environments. It also anticipates future development and the limit of applications to high-rise buildings and apartments. ${ }^{135}$ High concern with health issues has led research on medical support by smart technology to cope with physical degeneration of the

132 Song, N 2011, A study on the design of the smart silver town in urban type for active senior, Master's thesis, Hanyang University, Seoul.

133 Lim, E \& Hwang, Y 2011, 'A study on the planning and design characteristics of public space in urban silver town', Proceedings of Korean Space Design Association, vol. 5, no. 5, pp. 65-73. 134 Lee, H, Yoon, H \& Kim, Y 2007, ‘A study on senior residences in a u-city’, Bulletin of Japanese Society for the Science of Design, pp. 150-151.

135 Choi, Y, Park, B \& Choi, Y 2010, 'Design and implementation of location based silver town uservice system', Proceedings of Korean Society for Internet Information, vol. 11, no. 3, pp. 53-63. 
elderly. Choi, Lee and Joe (2012) applied wireless communication sensors using the Cyber Physical System to show that elderly residents have easy access to receive and send medical information, and doctors can supply improved medical support from received patient information. In addition, there are effects to forge the elderly centred remote medical treatment systems in silver towns. ${ }^{136}$

Limited R\&D on medical treatment of the elderly and technology application in general apartments, which is the most popular dwelling type in Korea, is one of the most active research areas. Many major building companies are attaching to research institutions regarding smart technology and have actively applied their developments to general apartments. Jeoung et al. (2006) found that different types of living environments require different ubiquitous technologies, and that technology integration influences changes in the spatial structure of apartment living. ${ }^{137}$ The research examined residents' preferences for ubiquitous technology based on multi-generation living environments and apartment-type housing and did not focus on silver towns exclusively intended for elderly residents. Along similar lines, Oh et al. (2006) surveyed and analysed the characteristics of the digital lifestyle of residents living in apartments. The study was conducted with rooms designed for flexible space utilisation that served multi-purpose functions as a home office, for home schooling and for home entertainment. The study led to guidelines for new ways to design spaces in digital

136 Choi, M, Lee, J \& Joe, I 2012, 'Design and implementation of the aging-friendly telemedicine system based on cps for silver town', Proceedings of the Korean Institute of Communications and Information Sciences, vol. 37C, no. 8, pp. 690-696.

137 Jeoung, Y, Na, S, Park, J \& Rhee, E 2006, 'A study on the resident's needs for planning sustainable ubiquitous apartment houses', Proceedings of the Architectural Institute of Korea, vol. 6, no. 2, pp. 7380. 
homes according to the preferences of residents aged in their $20 \mathrm{~s}, 30 \mathrm{~s}$ and $40 \mathrm{~s} .{ }^{138}$ There is ongoing research regarding general apartments that embed smart home technology based on IoT development. Lee and Nam (2016) examined display houses from major building companies to analyse the range of current applications and anticipate future developments. They found that limited technology referred to mobile phone is applied and most technology is fixed on the walls. Future developments should implement improvements to increase the mobility of technology. ${ }^{139}$

Other countries' research on technology in elderly living environments has endeavoured to understand seniors and apply advanced technology in their living environments. Ahn (2004) explored cultural acceptance and perceptions of residential technologies by the elderly through an online survey conducted in the US. ${ }^{140}$ Participating SeniorSmart ${ }^{\circledR}$ Center's meeting regarding smart home and collecting other material from US and Korea, the research sought references to apply to the elderly living environment in Korea. Moon (2011) found that smart homes for seniors in Korea are in the early years of development. In addition, the SeniorSmart ${ }^{\mathbb{R}}$ Center is conducting ongoing research into monitoring systems to check bio-signals from the elderly. An alarm is activated if abnormal signs are detected. These endeavours are in progress to apply to smart homes for the elderly through the centre's research and it

138 Oh, C \& Lee, H 2006, 'Space design of digital home from the perspective of digital life style', Journal of Asia Interior Design Institute Association, vol. 6, pp. 48-56.

139 Lee, J \& Nam, K 2015, 'An analysis of smart home technology applied cases based on IoT (Internet of Things) — focused on major domestic apartment brand model houses', Proceedings of Korean Institute of Interior Design, vol. 18, no. 39, pp. 234-237.

140 Ahn, M 2004, Older people's attitude toward residential technology: the role of technology in aging in place, Doctoral thesis, Faculty of Virginia Polytechnic Institute and State University, VA. 
needs to be verified that this smart home technology will apply in smart home development in Korea.

While the above studies have largely focused on determining the preferences of residents for desirable technologies in living environments, other projects have focused directly on the development of specific technologies. Large research groups around the world are engaged in prototyping and evaluating smart technology applications ranging from discrete appliances to fully wired environments. For example, based on a prototype smart house, the Georgia Institute of Technology introduced a residential environment for monitoring residents' movements in their living environment as part of the Aware Home research initiative. Another research aim is the development of various devices that could help elderly and disabled people, such as digital family portraits ${ }^{141}$ and medical monitoring. ${ }^{142}$ Using a programmable space called Gator-Tech smart house, the University of Florida's Mobile and Pervasive Computer Laboratory prototyped an assistive environment to help elderly and disabled people. ${ }^{143}$ As an extended example of the connected retirement community study, Elite Care Corporation built an aged-care community called Oatfield Estates in Portland, Milwaukee, in 2000. The facility uses sensors and smart technology to support the elderly living environment

141 Mynatt, E, Rowan, J, Jacobs, A \& Craighill, S 2001, 'Digital family portraits: supporting peace of mind for extended family members', Proceedings of SIGCHI 2001 Conference on Human Factors in Computing Systems, vol. 3, no. 1, pp. 333-340.

142 Blanson Henkemans, O, Caine, K, Rogers, W, Fisk, A, Neerincx, M \& de Ruyter, B 2007, 'Medical monitoring for independent living: user-centered design of smart home technologies for older adults', Proceedings of the Med-e-Tel Conference for eHealth, Telemedicine and Health Information and Communication Technologies, pp. 368-373.

143 Helal, S, Mann, W, El-Zabadani, H, King, J, Kaddoura, Y \& Jansen, E 2005, 'The Gator Tech smart house: a programmable pervasive space', IEEE Computer Society, vol. 38, no. 3, pp. 64-74. 
in terms of the control of appliances and facilities. ${ }^{144}$ While these studies are relevant to this research in terms of how the adoption of these technologies may be studied (as documented in, for example, case studies by Harper, 2003), the process of technology design and development (e.g., the July-August 2007 special issue of the ACM Interactions journal on 'ICT Design for Elders') is less relevant to this research.

Conversely, a few useful studies have directly engaged with issues of spatial design and elderly needs. For example, the documents shared at a recent conference on 'Supportive Technology and Design for Healthy Aging' organised by the American Institute of Architects ${ }^{145}$ are much more relevant and useful to this study. While such studies provide useful information about designing elderly environments in Korea and elsewhere, they mostly focus on the developmental phases of such environments - that is, they mainly attempt to identify the needs and preferences of the elderly. There are no in-depth studies on silver towns in Korea that investigate the ways and extent to which smart technologies influence the elderly living environment from the perspective of elderly residents.

\subsection{Importance of This Study}

Dramatic economic growth combined with a lack of land has resulted in a trend towards high-rise living environments over the past half a century or more. The government has heavily invested in $\mathrm{R} \& \mathrm{D}$ related to ubiquitous or smart cities, and both technology developers and developers of elderly residential buildings understand the ability of smart technologies to support elderly independent living. Thus, silver towns

\footnotetext{
144 Oatfield Estates_Elite Care Corporation, viewed September 2008, http://www.elitecare.com/. 145 Supportive Technology and Design for Healthy Aging Conference, University of Washington, 1112 May 2007, http://www.aia.org/SiteObjects/files/Supportive\%20Tech\%20Handouts.pdf.
} 
embedded with smart technologies will become the next target dwelling space of the elderly.

It is important to research the experiences of the first generation of elderly people residing in silver towns integrated with smart technology because this new living trend has not yet been exposed to the public, and their perspective will be valuable when following generations choose silver towns as their next dwelling space. In the meantime, prospective middle-aged customers' interest in silver towns and supporting technology has increased, and those who are more familiar with smart technology have paid attention to the new phase of silver town development. Further, developers have advertised that silver town developments are moving towards user-centred facilities that use smart technology to support seniors' independent living. However, the perspective of elderly residents has not been examined. Thus, prospective consumers and current silver town residents might receive limited or one-sided information regarding silver towns embedded with smart systems. To ascertain the direction of silver town development, it is important to understand current users' perceptions of the buildings and technologies.

The development of silver towns began in the early 2000s. A number of existing studies have conducted survey-based analysis or reviewed previous studies related to silver towns; however, meeting with silver town residents in person has been beyond the scope of research for many reasons, despite the importance of obtaining the perceptions of elderly residents. This is because silver town development is still in its infancy; thus, developers do not intend to open its settlement status to the competitive market. Moreover, the elderly desire a quiet and peaceful life to enjoy their privileges; therefore, they are reluctant to open their space to others. Hence, this study, as the first of its kind to conduct interviews and surveys with current silver town residents, as well 
as individual unit observations, represents a significant breakthrough in the study of silver towns. Further, it observes the immediate concerns and awareness of the elderly regarding silver town building environments and smart technology as a new paradigm for senior living.

\subsection{Theoretical Framework}

The main research aim is to examine emergent patterns in new elderly living environments (silver towns) integrated with smart supporting technology from the elderly perspective. Key aspects that must be explored include how the elderly perceive and comprehend applied technology in silver towns, how they decide whether to use smart supporting technology and whether there have been changes in their living environment as a result of using smart systems. Thus, the elderly perception, understanding and use of technology are key phrases.

Davis's $(1986,1989)^{146147}$ technology acceptance model (TAM) is a theory relating to users' technology acceptance. It is based on Fishbein's (1967) theoretical model of human behaviour and Fishbein and Ajzen's (1975) theory of reasoned action. ${ }^{148}$ TAM targets the processes that cause a user to use a system for theoretical understanding in information design and implementation and a practical methodology that designers and implementers can use to assess a new system before the application.

\footnotetext{
146 Davis, FD 1986, A technology acceptance model for empirically testing new end-user information systems: theory and results, unpublished doctoral thesis, Sloan School of Management, Massachusetts Institute of Technology.

147 Davis, FD 1989, Perceived usefulness, perceived ease of use, and user acceptance of information technology, MIS Quarterly, vol. 13, no. 3, pp. 319-340.

148 Fishbein, M \& Ajzen, I 1975, Belief, attitude, intention and behavior: an introduction to theory and research reading, Addison-Wesley, MA.
} 


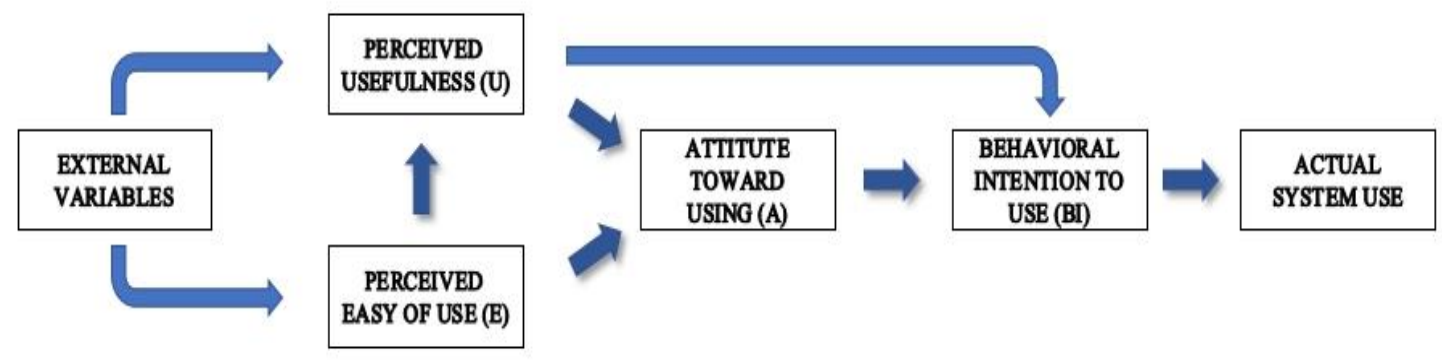

Figure 3.1. Technology acceptance model (Davis, 1989).

Figure 3.1 illustrates the flow of the acceptance process. It demonstrates two important factors: perceived usefulness and perceived ease of use. These two phrases from TAM theory are understood in the research as 'the degree of user's belief that there is an advance in the work performance by using a particular system' and 'the degree of user's belief that usage of a particular system would support the user to be effortless or no trouble'. Users' attitude towards using affects their intention to use, and intention to use affects users' actual use of a system.

TAM was introduced in the late 1980s, and it was updated and expanded to TAM2 by Venkatesh and Davis (2000), ${ }^{149}$ who extended the influential factors and external variables to include social influences such as subjective norm, image and voluntariness, and cognitive instrument (e.g., job relevance, output quality, demonstrability and perceived ease of use). Further, they improved the lack of coverage of variance in usage intention and behaviour to more than 50\%. However, Bagozzi $(2007)^{150}$ argued that around $40 \%$ of the variance of use of technology systems still cannot be explained.

149 Venkatesh, V \& Davis, FD 2000, 'A theoretical extension of the technology acceptance model: four longitudinal field studies', Management Science, vol. 46, no. 2, pp. 186-204.

150 Bagozzi, RP 2007, 'The legacy of the technology acceptance model and a proposal for a paradigm shift', Journal of the Association for Information Systems, vol. 8, no. 4, pp. 244-254. 
Further development of the theory resulted in Venkatesh et al.'s (2003) unified theory of acceptance and use of technology (UTAUT). ${ }^{151}$ UTAUT is a unified model based on eight previous models in terms of information system usage intention and behaviour, and it increases the explanation of the information system usage rate to around $70 \%$.

Figure 3.2 shows that four important features directly affect users' intention to use, and their actual use of, a system. Three factors - expectancy of performance, expectancy of effort and social influence — affect intention to use, and one factorfacilitating conditions - directly influences use of a system. In addition, the model introduces demographic moderators, such as gender, age, experience and voluntariness of use, that do not directly affect users' behaviour and intention, but that directly influence the four key features.

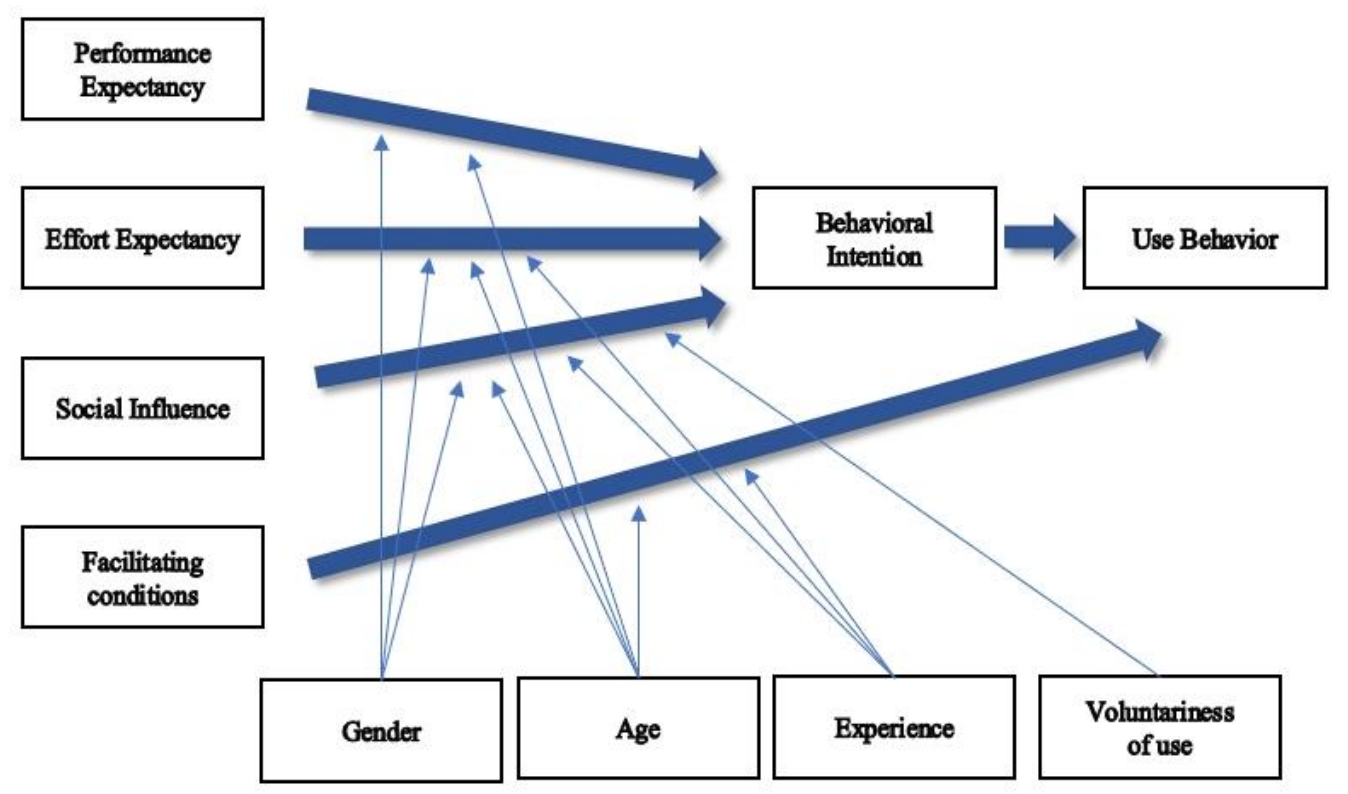

Figure 3.2. Unified theory of acceptance and use of technology (Venkatesh et al., 2003).

151 Venkatesh, V, Morris, MG, Davis, GB \& Davis, FD 2003, 'User acceptance of information technology: toward a unified view', MIS Quarterly, vol. 27, no. 3, pp. 425-478. 
Based on these theories of technology acceptance, a number of researchers have explored the variance in elderly behaviour and intention to use smart or ambient assisted living technology. Chen et al. (2014) targeted elderly users in Hong Kong using TAM and UTAUT as ground theory ${ }^{152}$ to understand different influences on gerontechnology usage. As shown in Figure 3.3, the study adapted demographic data such as age, gender, education level and economic status as moderators, and it modified external variables to consider elderly-related issues such as health condition, ability of perception, life and satisfaction. In conclusion, usefulness and ease of use do not significantly influence gerontechnology, and the external variables were better able to predict technology use. Moreover, financial ability and opportunity of instruction are barriers to elderly people using technology. To encourage technology use among the aged population in Hong Kong, Chen et al. (2014) recommend positive reinforcement and small group instruction for the elderly.

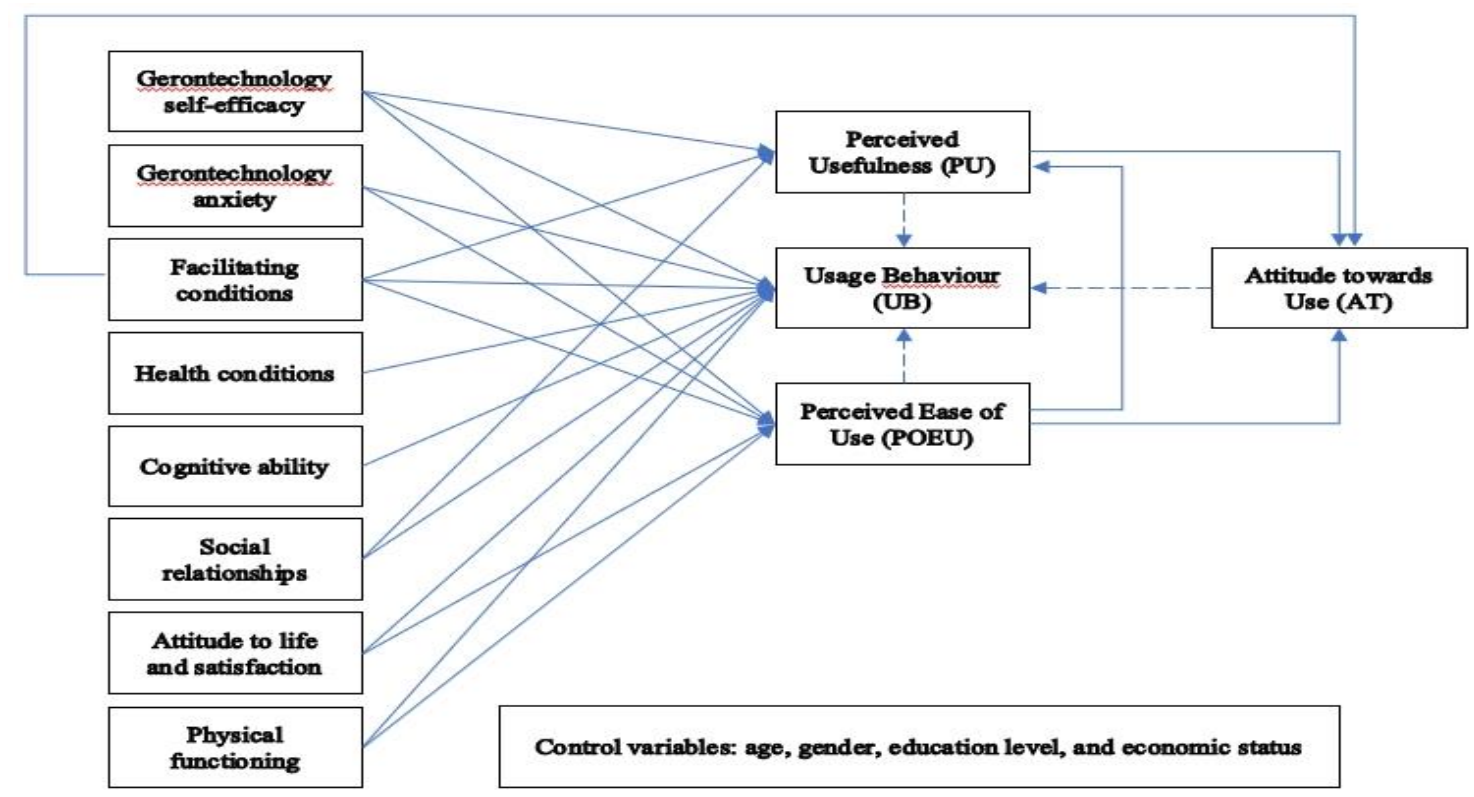

Figure 3.3. Senior technology acceptance model (Chen et al., 2014).

152 Chen, K \& Chan, A 2014, 'Gerontechnology acceptance by elderly Hong Kong Chinese: a senior technology acceptance model (STAM)', Ergonomics, vol. 57, no. 5, pp. 635-652. 
Other theory-based research has examined technology acceptance by the elderly. For instance, Mishra (2015) $)^{153}$ conducted a literature review of TAM as a theoretical framework and analysed the acceptance of smart home technology by the elderly. Mishra searched 379 articles and narrowed them down to ten articles that focused on the perception of smart home technology by the elderly and caretakers. The major concerns relating to technology acceptance by the elderly and caretakers were privacy, trust, stigma, usability and training, and affordability.

Weegh et al. (2015) $)^{154}$ conducted a literature review to understand the variance of ambient assisted living technology acceptance by senior citizens. They found 16 perceptions of supportive smart technology and 11 aspects that affected the adaptation of supporting technology by the elderly. The factors affecting adaptation were perceived usefulness, perceived ease of use, control and security, financial ability and willingness, privacy versus independence and safety, user involvement, human replacement, awareness, reputation and alignment to current lifestyle, government and politics and legal aspects, and experience.

153 Mishra, BH 2015, Attitude of senior citizens towards smart home technologies: literature review, degree thesis, Human Ageing and Elderly Service, ARCADA.

154 Weegh, H \& Kampel, M 2015, ‘Acceptance criteria of ambient assistant living technologies', Studies in Health Technology and Informatics, vol. 217, pp. 857-864. 


\subsection{Research Design and Methodology}

\subsubsection{Overall approach}

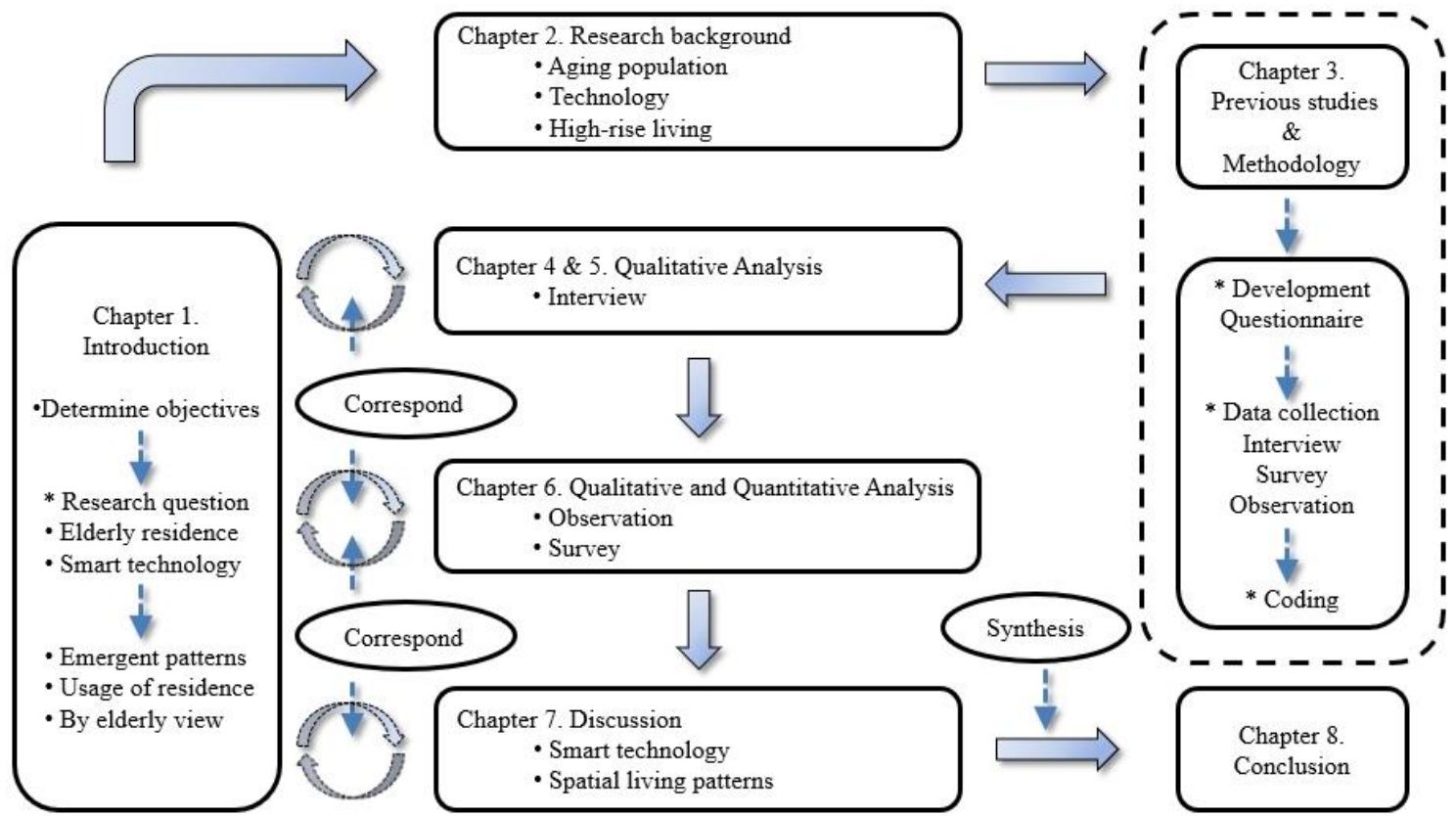

Figure 3.4. Research structure.

The research design comprises the overall scheme of the research, beginning with problems arising from the elderly population in relation to smart technology and the elderly living environment, followed by research questions derived from the study background. Next, data collection and data analysis using qualitative and quantitative methods are followed by an interpretation of the analysed data corresponding with the main and sub-research questions, followed by the conclusion. Yin (1994) explained that the research design deals with a number of aspects, including research questions to be asked, selection of relevant data, the collection of appropriate data and methods to analyse the collected data to lead to the conclusion.

It is hard to say that there is only one type of research design chosen or it is hard to distinguish only one type of research design that fits for the research (Bryman, 2012). Given that circumstance, the research is designed with selected silver town cases to apply mixed methods research, which originated in 1959 when Campbell and Fisk 
applied diverse methods to collect data but mainly emerged and developed in the $1980 \mathrm{~s}$ (Creswell, 2015, p. 43). Yin (2009) compared single- and multi-case studies and explained that multi-case studies have the strength of theoretical replication to acquire different results from theoretical reasons. The mixed methods design, which consists of both qualitative and quantitative methods, is used in this study. The research method extends method from qualitative methods (i.e., open-ended interview) with silver town residents and observation of individual units as well as the communal space of silver towns to quantitative methods (i.e., survey). The selected towns were listed according to when they were built, and they represent the current trends in elderly residential spaces. Collected data were quantitatively analysed using the Statistical Package for the Social Sciences (SPSS). The qualitative method accords with the research question, which examines the emergent patterns and use of smart silver towns integrated with smart technology from the elderly perspective.

\subsubsection{Data collection}

Figure 3.5 displays the data collection procedure. Several developers in Korea were contacted via e-mail, telephone or through their website to determine their availability to participate in the research. As confirmed in the literature review, no silver towns have previously been opened to researchers. The process began with contacting a larger number of silver towns to obtain information regarding advertised technology from their website. The silver towns frequently updated their website to attract potential consumers; thus, it was difficult to find the same information at different stages of the process. Finally, five silver towns were selected as research cases. Developers were wary of exposing the details and status of their buildings and residents, which is understandable considering the competitive circumstances. 


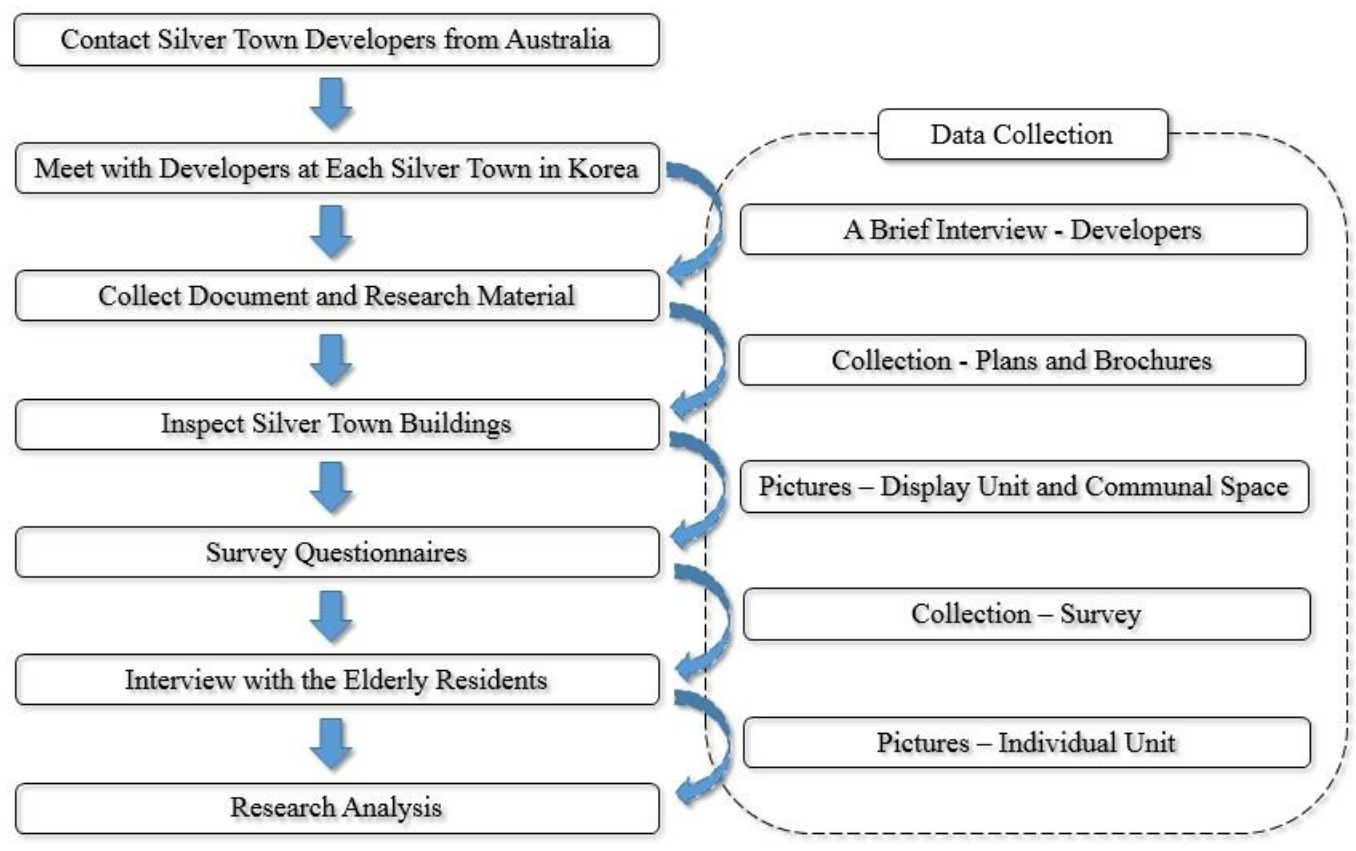

Figure 3.5. Data collection.

To obtain a deeper understanding of the research purpose and hear about the limits of assistance for the elderly residents' interviews, observations and surveys, the researcher conducted face-to-face interviews with the developers. The interviews were recorded and kept on a secure portable external hard drive. These interviews were conducted to comprehend the developers' intentions for the silver towns in relation to applied smart technologies and facilities, and to confirm the issues that the researcher targeted. Throughout the meetings, additional data related to silver town buildings and unit plans were collected to enhance the researcher's understanding. Additionally, the interviews strengthened the bond between the researcher and the developers with an understanding that these are contributions to the research field and provide advantages for silver town development - not only their own, but also upcoming developments.

After the interviews with the developers, the researcher received a guided tour of each silver town, including display units and communal facilities. The display units are used for visitors who stay overnight or who want to experience silver town living before making a final decision; thus, the researcher was not able to observe an actual dwelling 
and how the residents associate with the living environment integrated with smart supporting technology. However, the researcher was able to access and confirm applied smart systems with the developers' intentional purpose of application prior to conducting interviews with the senior residents. Further, from the interviews and site observations, the number of advertised technologies were narrowed down to active and inactive applied technologies in selected silver towns.

For the five silver towns, a preliminary survey was done with elderly, nonresidents, to clarify the questionnaires. After an adjustment through the preliminary survey, a total of 500 questionnaires (100 for each silver town) were distributed in a random selection in August 2009. A response rate of 22.6\% was achieved, with 113 respondents returning the questionnaires. Most surveys had been fully completed, and a few were partially incomplete. In terms of survey distribution, there is no definitive minimum number to be distributed at least, but Evans (1991) noted that obtaining a larger sample reduces uncertainty; ${ }^{155}$ thus, a larger sample is on demand and it is believed that the survey distribution numbers of the research is rational. Many studies have examined whether a higher response rate is linked to the representativeness and validity of the survey (e.g., Fincham, 2008). ${ }^{156}$ It has been found that a higher response rate increases the quality of the survey results. Holbrook et al. (2007) found that a survey response rate that did not require participants' personal information would increase the rate, albeit not significantly. ${ }^{157}$ However, in this study, it was essential to

155 Evans, SJ 1991, 'Good survey guide', BMJ, vol. 302, pp. 302-303.

156 Fincham, JE 2008, 'Response rates and responsiveness for surveys, standards, and the journal', American Journal of Pharmaceutical Education, vol. 72, no. 2, pp. 1-3.

157 Holbrook, A, Krosnick, J \& Pfent, A 2007, 'The causes and consequences of response rates in surveys by the news media and government contractor survey research firms', in JM Lepkowski, NC 
ask about respondents' demographic information to enhance the interview results and to determine who would be willing to express their perspective for the research. Residents' personal information such as phone number and e-mail address, were kept highly secure by the developers, and contacting the elderly participants separately was not allowed.

The survey questionnaire consisted of a cover page and close-ended questions in both English and Korean; however, when it was distributed, for the participants' convenience, only the Korean version of the questionnaire was offered. A cover page explained the purpose of the survey and provided ethical approval to increase reliability and understanding of the study and to prevent possible ethical issues. Close-ended questions enabled the participants to choose one answer out of three choices. The questionnaire comprised three main parts. The first section contained multiple-choice questions regarding awareness, frequency of use and satisfaction with each smart technology. The second section concerned demographic information such as age, gender, education level and duration of living in the silver town. These questions were also presented in the multiple-choice style. The third section requested a personal interview with the participant to examine a range of supporting technology and further understand the level of awareness, frequency of use and satisfaction with each advertised smart technology, regardless of its operational status.

Next, the researcher contacted each resident who had expressed a desire to be interviewed to set a time and location for their interview. Thus, 30 interviewees from five selected silver towns were interviewed in September 2009; additional interviews were conducted in August 2010 and August 2011. Although a minimum sample is not required in qualitative research, many studies have suggested an appropriate number of

Tucker, JM Brick, ED De Leeuw, L Japec, PJ Lavrakas, MW Link \& RL Sangster (eds), Advances in telephone survey methodology, Wiley, New York, pp. 499-678, 
interviewees. For example, Mason (2010) suggested a sample number of $28-31,{ }^{158}$ and Bryman (2012) cited Warren's (2002) suggestion that at least 20-30 interviewees are required as a minimum sample. ${ }^{159}$

The interviews were conducted one-on-one to increase interactions between the interviewer and the interviewees. Semi-structured and open-ended interview questions were used, and all interviews were recorded using an electronic voice recorder. At the same time, key aspects were noted in handwritten form in case the recording failed, as mentioned in Creswell's (2014, p. 244) interview protocol. The recordings were saved in individual files on a secure external hard drive. The interviews began with the researcher giving each interviewee a cover letter that introduced the research purpose and provided information about its confidentiality and ethical approval received from the University of Melbourne. This was followed by a verbal explanation.

There was no fixed duration for the semi-structured interviews; however, the researcher targeted one hour as a maximum period. The shortest interview was around one hour because of the interviewee's personal appointment, and the longest interview lasted around five hours. The average duration was one-and-a-half hours to three hours. These relatively long interviews meant that a large amount of time was spent translating the interviews from Korean to English.

The interviewees spoke about many things related to smart technology and silver towns. Some demonstrated how to use and respond to the technology. The questions consisted of four major sections. The first part related to interviewees' personal

158 Mason, M 2010, 'Sample size and saturation in PhD studies using qualitative interviews', Forum: qualitative social research, vol. 11, no. 3, http://www.qualitativeresearch.net/index.php/fqs/article/view/1428/3027.

159 Bryman, A 2012, Social research methods - 4th edition, Oxford University Press, United Kingdom. 
information to verify their living conditions and environments. The second part dealt with their thoughts regarding modern technology in daily use, such as mobile phones and computers, as well as its development. In the third part, participants demonstrated the technology systems embedded in their individual unit and in public areas, as well as how they perceived and interacted with the technology. The last part related to their preferences regarding applied technology, whether they have a choice and what they would like to add or remove. It was difficult to keep the participants on track without interrupting their talking.

Ten out of the 30 interviewees allowed the researcher to take photos of their individual units to obtain a better understanding of how the seniors associate with their living environment and how they interact with smart technologies. Having an authority from ten interviewees to make site observations considering the elderly privacy concerns was a remarkable mark that the research has in-depth findings. Most interviewees nominated the interview location as their individual unit, which implied that they were open-minded towards the interview. In qualitative interviews, the researcher is an active participant who collects in-depth data while the participant discusses issues relating to silver towns and reliability, and a sense of fellowship regarding applied technology and silver towns has increased. The elderly residents expected that their contribution to the research would be returned to them in the form of developments in silver towns.

After the interview, site observations were conducted with the elderly residents' authorisation. The authorisation was made on the day of the interview, but a list of what to examine and how to observe was prepared prior to the individual interviews. The researcher used a digital camera to take photos of individual units integrated with applied smart technology, as well as the living environment that the elderly residents 
interacted with. The residents' verbal explanations were also recorded on an electronic voice recorder.

\subsubsection{Data analysis}

Creswell (2014) explained the qualitative data analysis procedure in six steps: organising, reading through, coding, generating themes, representing themes and interpreting findings. To follow these steps, the researcher translated the interviews from Korean to English. A significant amount of time was spent on the translation from Korean to English and there was particular difficulty interpreting the meaning of certain expressions that do not have an English or cultural equivalent. The interview data was prepared for data analysis, and then qualitative data analysis imports thematic analysis, which adapts computer software to extract key aspects or themes (Bryman, 2014, pp. 13, 565). At the beginning of analysis, NVivo software was adapted to narrow down core themes (or code) from the large transcripts, making it relatively easy to search for patterns and compare coded data. Further, it helps to reduce data and interpret material.

Qualitative data analysis focuses on comprehending the thoughts and feelings of participants by seeking specific data rather than general information. The findings are presented regarding emerging patterns of the design and use of new elderly-only living environments integrated with smart technologies from the senior residents' perspective. The range of active and inactive smart systems, the intended purpose of using or not using smart technology, the different usage patterns of supporting systems and their influence on living environments by having and using applied smart systems from the perspective of elderly users are also explained.

Photos from site observations are analysed to underpin the findings from the interview analysis in visual form. Each photo is combined with secondary material such as individual unit plans to demonstrate locations, features and numbers of smart 
systems, as well as other additional supporting technology, and it shows changes in terms of technology development, unit design and technology application in the different years in which the silver towns were built. Moreover, it examines how the senior residents use the unit space integrated with smart systems (e.g., how smart technology is associated with elderly residents' households and how the elderly use their individual unit). Further, it examines the usage and modification of smart systems from the elderly perspective, and it visualises comparisons among the selected five silver towns. Additionally, secondary information such as building plans, unit plans and brochures increase the understanding of the building structures and purposes of silver towns and technology application from the developers' perspective.

Quantitative data are commonly recognised as 'numbers' rather than 'text'. Survey analysis results also form part of the supportive role of qualitative data analysis in numeric form. A three-point Likert scale was selected to conduct the survey. The scale aimed to discover the intensity of feelings and evaluate the degree of agreement with the themes in question by Alan B (2012). Multiple indicators are the most suitable technique for demonstrating awareness, frequency and satisfaction regarding technology in silver towns. Creswell (2014) outlined six quantitative data analysis steps, but this research uses four steps because it plans to limit the survey analysis until the descriptive analysis rather than conduct further statistical tests. Here are procedures for the research from arranged respondents to non-respondents, considering possible response bias, which may change the direction of the result, and providing descriptive analysis results, followed by the final step, an interpretation in quantitative research, that presents the analysed data results in tables, figures, and graphs. As a data analysis technique, the survey data are sorted, coded and imported into SPSS for Windows to be analysed to represent the descriptive data in diverse forms. 


\subsubsection{Verification and prominent criteria}

The research conducted tasks to ensure validity, replication and reliability from data collection to interpretation. Creswell (2014) stated that validity and reliability are key aspects in obtaining a meaningful interpretation of the data in qualitative research. He introduced six strategies to ensure internal validity: data collection from multiple sources, ensuring interviewees' intentions, repeated and long periods of observation, examining the research between peers, the informant's involvement in the study and clarifying the analyst's bias. In addition, to secure external validity, an ample and comprehensive description must be provided. For reliability, three aspects must be examined: details of emphasis of study, the part of the researcher and the participants and the basis of their selection; adapting diverse data collection and analysis methods; and ensuring clear and detailed information of data collection and analysis.

Bryman (2012) noted three important criteria: reliability, which is whether the question keeps getting consistency to have reliability; replication, which is whether the research procedure needs to be replicable to increase its reliability; and validity, which is whether the findings demonstrate accuracy and honesty. The research must continually maintain these important factors to bring validity, replicability and reliability to the collection of data and the conclusion of the findings.

\subsubsection{Ethical issues}

Ethical issues in qualitative research was concerned, its importance was emphasized and it was clarifed aspects by many previous researchers. Bryman (2012) mentioned that many students neglect spending time on ethical issues to acquire ethical approval through ethics committees. Diener and Crandall (1978) described four main considerations: harm to participants, lack of informed consent, invasion of privacy and deception. Creswell (2014) said that the research should adapt a code of ethics, which 
are the ethical rules and principles regulated by the professional association that leads the academic research to protect participants' right.

Thus, a consent form was given to participants along with other information that informed them of the purpose of the research, as well as the method, usage and storage of the collected data and their confidentiality. Further, additional information advised participants of their anonymity, their priority in decision-making and rights, the availability of the report summary, and research permission and ethical approval by the University of Melbourne in written and verbal form.

\subsection{Conclusion}

The aim of this research is to understand the new phenomenon of living environments integrated with smart technology systems for the elderly. This new trend needs to be understood from the perspective of current senior residents. Further, previous research has been conducted regarding silver towns and smart technologies, but these studies have been limited to analysing unit plans, building facilities from the designer or developer perspectives, smart systems from the technician's point of view and prospective customers' preferences via survey. That is, no researchers have previously met face-to-face with elderly residents to discuss their living environments embedded with smart technology.

Hence, this research conducts interviews with the elderly residents and selected silver town developers as a key qualitative research method targeting current senior residents to understand the recent trend in design and the use of elderly-only environments integrated with smart technology systems from the elderly point of view. It also explores introduced technologies and patterns of use. Moreover, quantitative research methods such as surveys (in the numeric form) and the qualitative method of on-site observations underpin the interview analysis results to assist in understanding 
applied smart systems in selected silver towns and changes in spatial layouts resulting from the use of supporting technologies.

Chapter 4, which is the first chapter of the qualitative analysis, examines the character of selected silver town interviewees to understand their background and conditions. It aims to provide a better understanding of the status of elderly people and their attitude towards applied new technologies in silver towns. 


\section{Chapter 4: Elderly in Selected Silver Towns}

\subsection{Introduction}

These days, it is natural to find technology being used in the elderly living environment, but it is still difficult and complicated for the older generation, who are not familiar with smart environments. The elderly have been exposed to technology for many years, albeit in a limited form. In fact, they may not have perceived whether they have used or been assisted by technology, given its rapid development. Nevertheless, building designs focus more on designing and planning personal areas with agedfriendly details. Senior-centred design previously referred to architectural design features, but the design trend now includes technology as a design aspect to embrace IT development. Modern apartment buildings and elderly living buildings apply different types of technology to support comfortable living conditions. A significant increase in the elderly population has resulted in a transition in the elderly living environment, as well as increased interest in the building environment integrated with modern technology.

As discussed in Chapter 3, previous researchers have examined silver town buildings and public spaces, as well as the future development of applied technology. However, for the first time since silver towns were created, elderly residents have allowed this researcher to interview them regarding their perception of silver towns integrated with smart technology. Given that silver towns are only built for the elderly, it is important to understand their perspective for technology design and development purposes. As part of the qualitative research analysis, this chapter explores the character and perspective of elderly residents regarding technology development and silver town environments using interviews from five selected silver towns. 


\subsection{Demographic Data of Interviewees}

Thirty people from five selected silver towns agreed to be interviewed (see

Figure 4.1). These respondents returned the survey questionnaire and expressed interest in the interview. They submitted written consent before the interview. Ten elderly residents from GH tower participated, followed by GY tower with eight participants and B tower with only two residents. The interviewees preferred to take part in the interview at their individual unit or at a public facility within the silver town, and the meetings were scheduled at their convenience. The length of the interviews varied, with the shortest interview taking one hour and the longest five-and-a-half hours. Some residents focused on their experiences with their silver town and its integrated smart technology systems, and some included their personal or family history and social issues relating to seniors and silver towns. In addition, some residents opened their unit for additional observations, which enabled the researcher to take photos of their dwelling and the smart systems, and they provided a tour of the silver town to visit some of the public spaces.

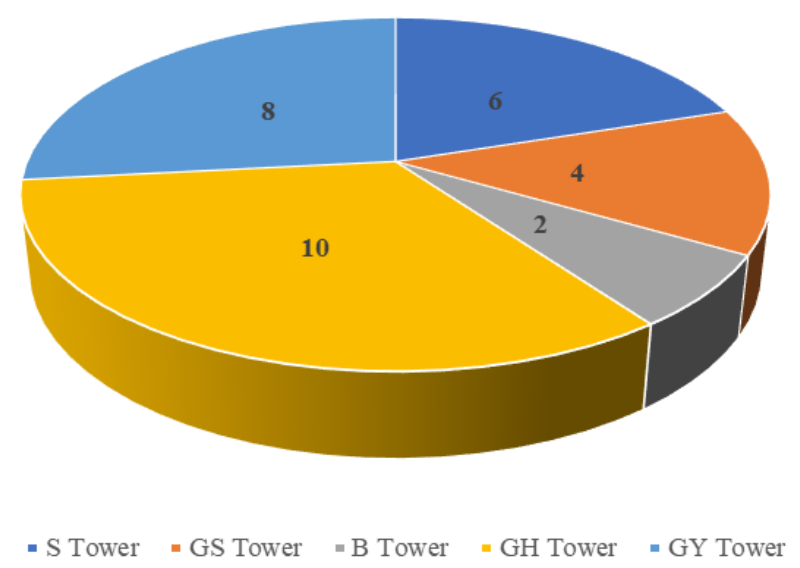

Figure 4.1. Number of interviewees. 
Figure 4.2 shows the average age of participants in each silver town. Residents aged 71-75 were the dominant group in S tower, B tower and GH tower, whereas the 76-80 age group dominated in GS tower and GY tower. Considering the year in which the $\mathrm{S}$ tower was built, it was predicted that the average age of its elderly residents would be higher than that of residents in other silver towns; however, this link was not found. Figure 4.2 shows that the average age of the GY tower interviewees was higher than that of the $\mathrm{S}$ tower interviewees. Thus, the ten-year gap between the building of the towers is not directly connected to the interviewees' average age. Further, respondents aged 86 or more were only found in the GH tower and the GY tower, which were the most recent developments among those selected. The research did not aim to have a variety of different age groups among the elderly residents. Figure 4.2 verifies that the research includes interviewees from different age groups.

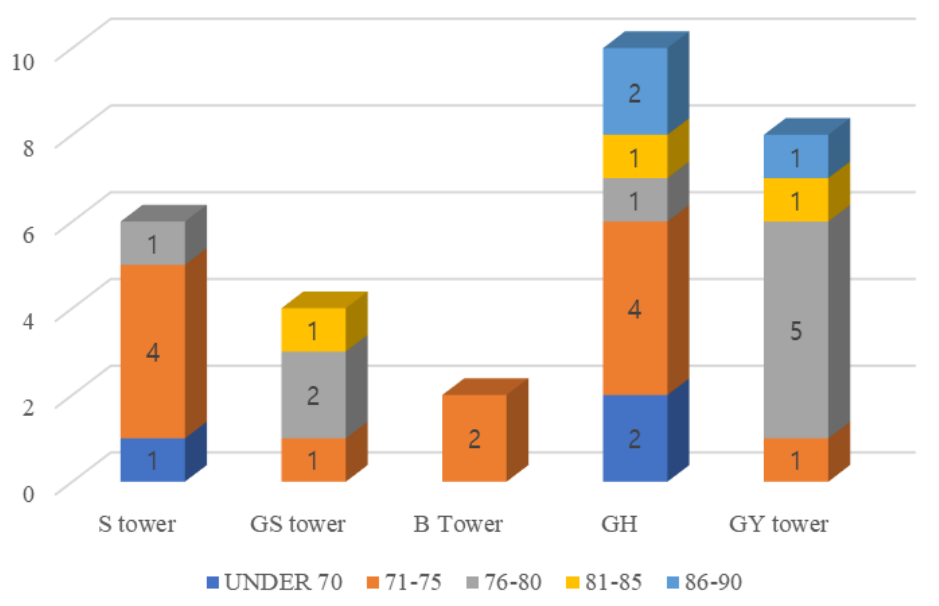

Figure 4.2. Age group of interviewees.

Figure 4.3 illustrates how long the 30 interviewees had lived in their chosen silver town. In contrast with Figure 4.2, most residents in the $\mathrm{S}$ tower had lived in the tower for more than eight years, which is almost similar to the initiation of service date, whereas seniors from the GY tower had resided there for less than 24 months when the interviews were conducted. In the other three silver towns, the residents' dwelling 
period aligned with the age of the building. For example, the residents of the B tower, which was the third tower built among the selected silver towns, had a medium term-ofresidence period. Thus, there is a link between residence period and the construction year of the silver towns. The residents' average dwelling period differs because the first and last silver towns chosen for the study were built up to one decade apart. Further, the residents rarely move once they have settled in a silver town.

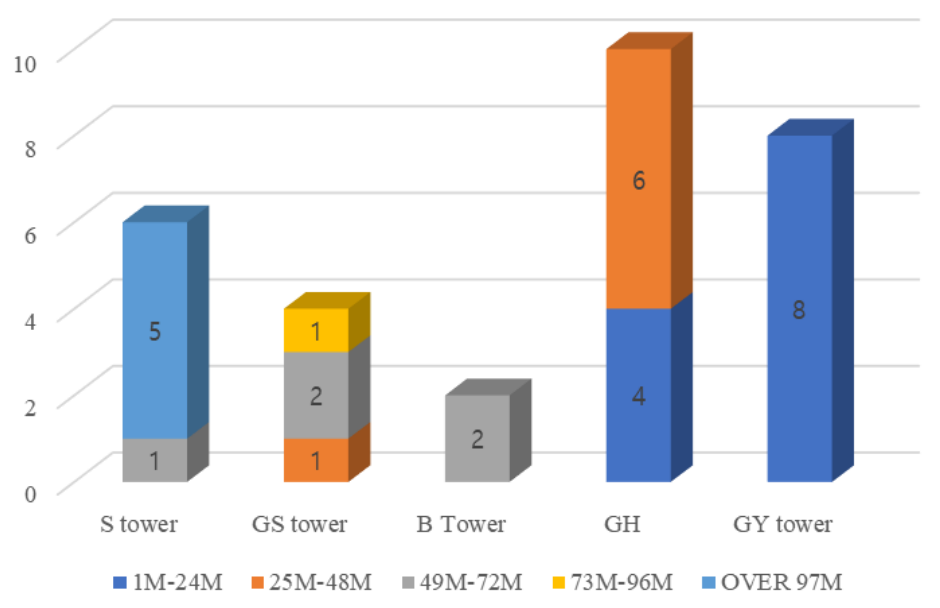

Figure 4.3. Residence period of interviewees.

Figure 4.4 shows the education level of the silver town residents interviewed for this study. It shows that the average highest level of education attained was below the completion of middle school. Less than $10 \%$ had graduated from university or received an equivalent level of education. Five out of the six interviewees from $S$ tower had completed university, and seven GY tower interviewees had completed university, which is higher than the average level of education among the younger generation. ${ }^{160}$ All interviewees had completed high school. Figure 4.4 suggests that people who finish a higher level of education are early adapters, and these residents had more

160 Statistics Korea 2017, An analysis of character and changes in different lifetime stages, viewed May 2017, http://kostat.go.kr/portal/korea/index.action. 
opportunities to obtain information when selecting the first or second generation of silver towns in Korea.

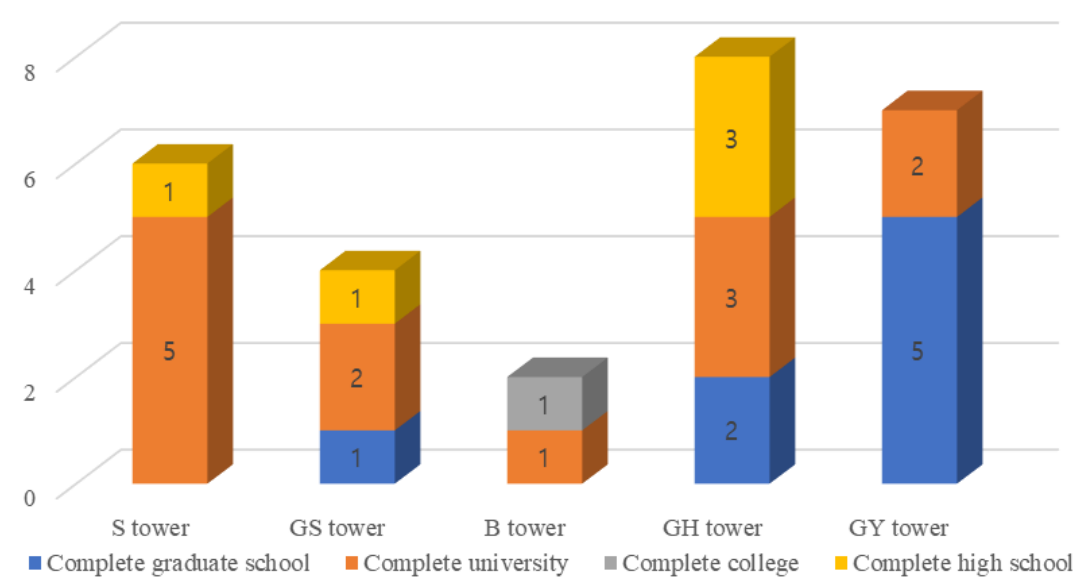

Figure 4.4. Education level of interviewees.

\subsection{S Tower Interviewees}

\subsubsection{Aging}

As people age, the deterioration of their physical and mental condition does not depend on how much money they have or whether they obtained a higher degree in education. Old age affects everyone and causes frustration, struggles and depression. When people perceive that their health is physically and mentally deteriorating, it can be difficult to adapt to and cope with new things. According to S4:

Young people don't understand how much the old people lose their minds when they do. All these people went to professional colleges and universities. They have much knowledge and they know everything and these people come here. However, in the end, they turn that way.

\subsubsection{Becoming technology friendly}

Although there are many concerns and much negativity surrounding technology development, many seniors are willing to deal with technology to connect with the 
younger generation (e.g., their children). This is a significant motivator that challenges them to keep up with technology developments. S4 mentioned that:

Many react negatively towards computers and they think this is a very hard thing. When you try it, it is really nothing and it is so great.

The elderly cope with difficulties in communicating with their children and grandchildren - especially when they live far away. Most interviewees did not want to spend time learning how to operate a mobile phone or computer, but if it helped them to connect with their children and grandchildren, they were more willing to learn. S4 said:

I often get to e-mail my son living in Canada. If I want to call them, I must be home and things but with e-mail, it is very convenient.

In addition, S5, who was in a similar situation, stated that:

When my grandchildren went to college in the U.S., I used to send emails in

English and things like that. I wanted to help his English studies and at that time, I used a lot.

Mobile phones are similar to computers in terms of their communication ability; however, in terms of size, mobility and receiving an instantaneous response (e.g., short message service or video calls), smart phones are better than computers for the elderly. S5 explained:

I think the cell phone is great because I always send a text message to my grandchildren in the morning. I send it daily.

\subsubsection{Reasons for choosing a silver town}

Different generations have a different understanding of silver towns because they are a relatively new concept. The elderly want to continue living independently; therefore, many residents choose to move into silver towns despite their children or relatives' contrasting opinions. S5 expressed their experience: 
There were many who came in here because they had decided to. To me, I think the image of this silver town was probably not that great for your children. I am sure from the children's point of view, they were thinking why they are wanting to go in there... difficult choice.

S2 shared a similar experience:

At first, my children were saying why we are going to places like this and others looked at us weird. They don't know anything about this place and then after visiting my place several times, they now say it would have been nice for them to have entered here.

The elderly want to be independent but not isolated. Silver towns are more likely to be considered for single living because the elderly can associate with a similar age group in a comfortable environment. They need to communicate with others, and they will be more comfortable with people in the same age group. S1 stated that:

I was interested a little because I thought I shouldn't depend on my family. When there was a presentation, I felt that people work at the town and other elderly would play a certain role of the family instead of the family members. I thought it would be better than to live alone so I continued to have interest in the topic.

The elderly tend to want to maintain independent living, but there is a greater possibility that they will have health problems. Thus, elderly couples depend on each other emotionally and psychologically based on strong bonds as life companions. As a result, they will look for a place where they can maintain a stable life. For example, S3 shared the following: 
I had some high blood pressure and my mom passed away so I was shocked and depressed. My husband was worried that all these things will cause me to lose his wife. Therefore, he decided to come in without letting me know.

The degeneration of physical movement makes it difficult for the elderly to spend time on meal preparation and housework. Therefore, silver towns provide customised health and meal services for residents, as well as smaller houses that require less housework. S4 demonstrated that:

My health degenerated because I didn't eat properly. But here, they prepare all the meals for me. That was the first thing I looked at when I was coming in here.

\subsubsection{Non-residents' perceptions of silver towns}

As part of the first generation of silver towns, $\mathrm{S}$ tower was often believed to be an inappropriate facility for the older generation until people visited the building and experienced silver town living. Silver towns (known as assisted living or retirement communities in other countries) were a new concept in elderly housing. Therefore, people did not understand this type of environment unless they had visited a similar facility overseas. Recently, the rapid increase in the elderly population became a serious social issue, and the government invested in development and support as a result. It is important to understand the needs of potential customers (e.g., those aged in their 40s and 50s) when considering the future development of silver towns to ensure that there is a stable supply of elderly-only living environments. However, this did not occur when the first silver towns were being developed, resulting in negative public perceptions. For example, many people believed that the aged-care facility would be gloomy and dismal. S6 stated that:

My relatives thought maybe I was angry with my children and they were all worried about everything. Then one day, I invited all of them here and showed 
him how I was living, and how I was eating my meals and treated them with dinner as well. Then they were all happy and told me that I did a good job and had foresight. They were praising me in the end.

Further, in terms of the filial duty of Korean children, it is difficult for them to support their parents' decision to move into a silver town. First, the children do not understand the nature of silver towns and believe them to be care facilities. Second, they worry that other people will think they have not fulfilled their duties towards their parents. According to S5:

I think the image of this silver town was probably not that great for their children. I am sure from the children's point of view, they were thinking why they want to go in there. It is difficult choice not only themselves but their children.

Some children were initially unhappy with their parents' decision to move into a silver town; however, they later admitted that silver towns were an optimal place for their parents because their parents could live comfortably. Other visitors, after several visits, also confirmed that silver towns were appropriate institutions for retirement. Visitors often see residents comfortably socialising with other residents of a similar age, and they observe that many customised services are provided by well-trained staff to meet older residents' demands. Moreover, the smart technologies that supply additional medical support changed visitors' opinions. S2 stated that:

At first, my children were saying why we are going to places like this and others looked at us weird. They don't know anything about this place and then after visiting my places several times, they now say it would have been nice for them to have entered here. 


\subsubsection{Silver town living experiences}

Security and safety issues that are related to smart technology since they have perceived advantages from the systems. S3 quoted that:

There is no concern for being robbed and it is peace of mind. When you live in a general house you worry if there will be a robbery or if I have left the gas on or something.

However, the older generation is not familiar with smart technologies, and even those who experienced elderly-centred technologies in the first generation of silver towns require continuous adjustments. Thus, there are negative issues relating to systems in terms of privacy invasion. S6 stated that:

Some buildings might invade a person's privacy, no? For example, in my own residence, if you take off your clothes or if you have your shirt off or something then that is sensed. Not in the room. As mentioned before, there is personal privacy so that can't be in there and it is also not necessary.

\subsection{GS Tower Interviewees}

\subsubsection{Aging}

In general, silver town residents do not face difficulties managing their daily life without assistance. This is because a condition of entering silver towns is that residents must be healthy. However, residents understand that circumstances change, and emergencies resulting from chronic illnesses or degeneration are a significant concern. GS3 stated that:

Suddenly, my wife's nose began to bleed. I couldn't touch it at all then we just moved with my car and went to a hospital and it was just too much. Then my back hurt so I had to go here and there and it turned into an emergency case. 
The process of degeneration is not the only barrier to exploring new technologies. Current residents call themselves the 'analogue generation', which means that they are not friendly or familiar with smart technology. They prefer landlines to smartphones and newspapers to computers. According to GS2:

I don't really use the cell phone. I don't really get to answer the mobile phone because it not only bothers my exercise and activities, but also other people, so I don't like to carry it around. In addition, I have a landline to make local and long-distance calls at home.

\subsubsection{Becoming technology friendly}

Compared with the past, technology now develops much faster in terms of variety and quality. It can even be difficult for the younger generation to keep up with advances in technology if they do not consistently pay attention to it. Thus, technology development can be scary for the elderly, even though many of them have been exposed to technology in the past. It is natural that they will find it difficult to keep up with developments. GS1 said that:

I don't know how much development the world will experience but it is scary. The computer... It is a scary machine since it takes only a couple of minutes to calculate what it takes years to calculate. I am not sure how much further technology would be developed.

GS6 explained that:

I cannot handle the computer and technology is rapidly changing in the modern environment. As a result, I cannot follow the flow. It seems that old people cannot follow the flow at all in the present situation. 
Moreover, elderly residents give up acquiring knowledge of technology because of space concerns. For example, most residents are downsizing their space; therefore, they have less space in their unit for a desktop computer. GS4 said:

I am sorry, but I have stopped using the computers. There is no place to put it here because it is so narrow here. Rather than using that, there are phones and everything. And I am not that used to them.

GS4 mentioned that mobile phones, which are smaller and lighter, could replace computers for basic functions; however, some seniors found them annoying. GS2 expressed:

I carried it around when I went out and when I needed it so I can use it but I don't really get to answer the phone because it is not convenient when I am exercising or anything. Even when there is a meeting, it can bother other people so I have to think about it so I don't carry it around.

However, the elderly interviewees generally had a positive attitude towards technology. Based on this positive approach, there are many other ways that the elderly can become technology friendly. For example, technology that assists with medical emergencies can lead to happy endings, which is a strong reason for residents to use smart technologies. Experiencing technology support helps residents to understand or remember the technology, even if there is a medical emergency. GS3 explained that their positive experience with technology improved their awareness and positivity:

We have benefited greatly because of the developments in medicine, I am able to live. I think the world has become such a great place. The medicine has developed so much and I try to respond actively in this changing world.

Before the elderly entered the silver towns, they did not understand the type of support they could receive from smart technology. An introductory session that listed 
the smart technology systems integrated in the silver towns did not provide a clear idea; however, direct or indirect examples of support from smart systems gave the residents a better understanding of how the smart technologies could assist them. For example, the residents believe that technology will make their life easier and more convenient, and that it will fill a gap in their life. GS2 said that:

If there is a system like that you could leave the house even when you have forgotten to turn the iron off or didn't close the garage door properly.

When the elderly residents chose to move to a silver town, they were concerned about maintaining their relationships with their family and friends. This motivated them to learn how to use a computer and different applications. GS shared their experience:

I cannot live without the Internet. I am an integrant. I communicate with my kids through that, and even the short videos, and the e-mail as well. I always use it.

Further, GS3 discussed that:

I have often visited Hokkaido in Japan with my friend and took hundreds of pictures. I sent it to my daughters and grandchildren living in Seoul and the US.

I think I am good at this among my friends.

\subsubsection{Reasons for choosing a silver town}

The elderly find that sharing an environment with people of a similar age is more comfortable. According to GS3:

I have told my children, when I get old, I will not live with them. When I am here, I feel more comfortable. It is more fun and better to live here rather than living in a house or an apartment alone.

If the elderly have had previous experience with an emergency, their concerns regarding immediate treatment and the medical system would be the main selection criterion. Developers advertise that one of the strengths of silver towns is that they have 
a 24-hour clinic system that is attached to each silver town and applied in individual units using smart technology and a well-constructed connection with the general hospital. Therefore, in terms of immediate medical response, it is the best place to be for elderly residents who are concerned about their health. GS3 discussed that:

My wife had nasal bleeding so we went to the clinic and the local hospital but we couldn’t do anything. Then my back hurt so it turned into an emergency case. More than anything, this silver town had a hospital next to it so I thought it would be more stable since there is a nursing system, we can contact them right away when there is an emergency, in the same building.

Another aspect is while most elderly residents are retired from work, some of them still have a job or run their own business. As shown by the various ages of the interviewees, those in their late 60s and early 70s are still capable of working, and if they have a professional job, they can work longer. Thus, many seniors maintain social contact with their former colleagues, friends and family, so they need to travel regularly. Therefore, having easy access to public transport is an important factor when choosing a silver town. GS2 stated:

This place is close to an airport. We have to often go back to the States so we decided on here. I like it because the transportation is convenient. In addition, there is a subway line five connected to the centre of Seoul. In addition, many interviewees noted the importance of transportation and location, which provide better accessibility for themselves and for visitors. GS1 agreed: Yeah, I went to see the N tower. I couldn't go there because of the transportation situation. I still have to go somewhere in the afternoon. It is very hard to get to the silver town without cars. On the other hand, if you have a car, you can't bring it into the city and can't take subway, the line 3 . 
Another reason for the importance of easy access to transport is that the elderly tend to lose focus and direction, which affects their driving skills. When people age, driving becomes more difficult, and this becomes a social issue because of increased traffic accidents involving the elderly. Some countries stipulate that people in their 70s must renew their licence to prove their capability to drive. Thus, the elderly consider this when selecting a silver town. Many silver town residents use public transport, such as the subway or a shuttle bus offered by the silver town. These transport options provide easy access between the centre of Seoul and the silver town, and there are no parking concerns involved. GS2 stated:

The location was too far and since we planned to live without a car, the access by public transport was not good and the airport was also too far.

Easy access to transport is one reason why urban and semi-urban style silver towns receive more attention from the older generation when they conduct a preinspection of silver towns.

However, the elderly must also make compromises when choosing a silver town. Living in an urban-style silver town means that residents live close to a main road or public transport, which causes issues regarding sound and air pollution. Severe air pollution is caused by the Asian dust phenomenon, in which yellow sand or dust travels to Korea from China and Mongolia. Hence, it is difficult to remove oneself from these concerns, even though silver towns supply ventilation systems and provide systems to prevent noise. GS3 explained:

The problem here is that right next to us, there is a big street so it is very noisy every day and the air is bad. 


\subsubsection{Non-residents' perceptions of silver towns}

Non-residents have compared silver towns to asylums and nursing home, which are usually understood to be institutions in which people require extra care because of physical or mental impairments. Generally, the image of an asylum is that of an isolated and abandoned place for the aged population. Moreover, most people think that an asylum is the final stage of the older population. Thus, without a clear image of silver towns, non-residents are concerned when visiting or moving into them. GS1 mentioned:

Even now, when my friends ask me where I live, I just say that the apartment is here. They just think that I live in an asylum for the aged.

The elderly are vulnerable, especially in terms of emotions. Therefore, they are often embarrassed to introduce the silver town when people evaluate the tower, because they do not want to be involved in a conflict with others.

On the other hand, there is a perception among non-residents that silver towns are luxurious places that only allow rich people. GS2 said:

Generally, I think, when I talk to the taxi drivers or when I talk to my friends, they believe that you have to have a lot of money to be living in here.

Silver town developments were initially advertised as luxurious retirement places for residents. Customised medical services, meal services and other care programmes combined with support facilities have cemented their image as expensive places. Residents pay service fees for senior-centred systems and services, and this has contributed to the negative image of silver towns.

\subsubsection{Silver town living experiences}

Since the elderly have experienced the benefits of supporting technology, they have become more attached to smart systems. For instance, residents were surprised by 
the immediate reaction by staff members and nurses when they pulled a string. GS4 expressed the experience:

You can just simply pull on it. Then the person from the downstairs would run up here all surprised.

GS tower interviewees discussed the size of their unit in the silver town and compared it with their previous apartment or detached house. In addition, they raised the issue of co-residing. It is generally understood that silver town living involves partial cohabitation, which means that people must consider the number of other residents. GS2 found that:

Even in the same silver towns, this one is a pretty small size. Only about 200 residents here. Other places have about 350 or 400 residents which is about twice the size, so there can be lots of different types of people. That would be very difficult. This place has a relatively small size and it feels like a family as well.

\subsection{B Tower Interviewees}

\subsubsection{Aging}

An increased average lifespan resulting from medical developments means that the elderly population has grown. However, this does not mean that they are free from the degeneration process. Depression, losing sense and pessimism caused by mental and physical degeneration have become one of the biggest social issues despite improvements made in medical care. B3 discussed that:

The world is changing and it is difficult to follow the trends. I can't even follow the changes mentally and physically. That is why the elderly become pessimistic even if they don't have anything wrong with them. In the past, these people were able to walk $100 \mathrm{~m}$ in one minute, but now even if they try hard, they can't. 
Although they don't know, they continue to think about things. I wonder if I can.

If you continue to think like that, it becomes a mental problem.

\subsubsection{Becoming technology friendly}

If seniors find that something is wrong, their latent fear regarding smart technology emerges and causes them considerable distress. Using smart devices for the elderly is a challenge because they become more concerned about making mistakes as they age. According to B3:

I could follow and adapt well to changes or any conversation so I didn't have a particular fear about change. However, now, I am old and live with many old people in the silver town, for the old people, the changes, that is a problem.

However, B tower interviewees had a mostly positive attitude towards smart technology, and they often used a computer and a mobile phone. In addition, they easily accepted technology development. B2 stated:

Technology is rapidly developing, it is true that adapting and keeping up with the development is a hard thing to do for me, but then what do you do? You don't get any younger. You can't make time go backwards.

\subsubsection{Reasons for choosing a silver town}

Before selecting a silver town, the elderly spend a significant amount of time visiting and gathering information. Silver towns in Korea are a unique style of building that contain facilities to support the elderly. Some residents had knowledge regarding silver towns in the US and Japan. B3 had lived in the US in the past:

While living in the US, I visited the places, I thought the facilities were so nice. I thought the living patterns were great and when I met and socialised with the elderly residing in there, I thought it was a very pleasant place. 
After analysing the information, residents carefully choose a silver town. Their considerations include whether they want to maintain their independent lifestyle, whether there is easy access to transport and whether they can blend with other residents. B3 discussed that:

My wife also thought deeply about a silver town. We thought when we get older, we wouldn't live with our children, but must choose something that we could live with our own ways of thinking. I thought about maybe living in the city and living in a small quiet place would be better to visit the children as well as our friends easily. Similarly, B2 stated that:

All my children live in the US, and my wife has already gone, I just decided to come in here. Since I am alone, if I live with other people, I thought I would have many questions. We would have many different opinions and create an atmosphere where we could talk to each other.

Sharing ideas, opinions and information regarding social, medical and financial issues with the same age group, who have a similar mindset, is an advantage of living in a silver town. Further, all facilities, activities and programmes aim to satisfy residents' psychological and physical needs. This results in a unique elderly-centred living environment, with residents participating in many different activities and programmes. Another advantage of living in a silver town relates to crime- and health-related concerns. The elderly residents consistently nominated these as important factors. As a socially weak group, seniors face a higher rate of random crime. Thus, they seek a crime-free living environment. These concerns are also shared by their family members, who cannot look after their elderly parents. Therefore, it is important to have medical and security facilities. B3 noted that: 
After hearing about places like that, there is no medical facility and there are no security facilities that would protect me.

When the elderly research silver towns, they also evaluate management status.

Given the limited income source, the financial status of a silver town directly affects elderly residents. Financial issues are closely related to their living environment; in fact, there were some cases of business failure during silver town developments. It explains the status of silver town businesses at an early stage so the elderly needed to find a silver town with a solid financial background, as outlined by B3:

I have visited several places in the beginning stages of silver town developments, the business men think that they probably earn a lot of money because it is a silver town. They operated only with the purpose of profit. Now they have all failed.

It is important for the older generation to receive psychological comfort from medical support and their living environment. According to the developers, silver towns are designed based on research on the older generation and examples of similar cases overseas, but it could not bring satisfaction mark from all possible consumers. Given the size of the apartment or detached house that the resident previously lived in, unit size and building shape are another concern relating to mental stability. B3 explained that: I wasn't satisfied with how it was being built and they just built the buildings in any way they liked. One of the silver towns that I have visited had an oval shaped plan. If it is a rectangular plan, it will give you a sense of stability.

However, the one I visited was very unstable.

The decision to move into a silver town is not easy. Most residents believe that this move is the last or second-last move they will make during their life. Therefore, they put effort into searching for and visiting the site before making a final decision. 


\subsubsection{Non-residents' perceptions of silver towns}

Elderly residents become unhappy when they hear non-residents speak badly of silver towns. They dislike that people believe that silver towns are luxurious places for rich people. B3 explained that:

If someone says he or she lives in the silver town, people are surprised and surmise that person must have been a great person. This is not a good situation socially. When we first came here, we didn't know the directions very well and so we would often take a taxi. Whenever I asked the driver that you know this place? Then they said, ah the place where the rich and old people live? People only think about those things.

\subsubsection{Silver town living experiences}

When the elderly decide to move into a silver town, they inspect at least one silver town model to obtain information and compare the living environment of their current dwelling with that of the silver town. Most of the older generation face the issue of downsizing because units in silver towns are smaller than general apartments and detached houses. However, since settling in the tower, they have accepted the smaller unit size as part of living in an elderly-only living environment. B3 stated:

The space I am currently living in is only a quarter of the space I was living in before I came in here. Although it is only a fourth, now that I have lived here for six years, this space is even big for me.

Others said that living in a high-rise apartment building that was higher than 2030 floors was no longer comfortable. Silver towns tend to be smaller, even if they are still considered a high-rise type of building. Further, the environment around the silver town can emotionally affect residents. As discussed earlier, most silver towns are close to an affiliated general hospital, and some even have a clinic facility within the tower to 
provide optimal medical treatment at any time. On-site medical care is better for residents' mental health, because the sights and sounds of hospitals can make residents depressed. For example, B2 said:

One thing that makes me think about something and I love the environment here but the mortuary of the general hospital nearby. It looks so bad when people are going in and out of that place. I don't hate the facility but the fact that I know that I will be going to the place soon does not make me feel so great.

\subsection{GH Tower Interviewees}

\subsubsection{Aging}

Although medical advances are extending people's life expectancy, elderly people still face many challenges to maintaining independent living. GH7 noted that smart technology can help to increase mental stability:

Regardless if you have learned or not, those people can utilise them more but we usually forget about things easily and there is something like that and the hoteltype opening door is also good.

\subsubsection{Becoming technology friendly}

The elderly generally think that smart technology involves complicated machines that are difficult to control and maintain. As a resident mentioned earlier, seniors are afraid of making mistakes. Thus, if they have trouble with technology, they may become frustrated, anxious and depressed because they do not know what to do. GH9 stated that:

I think that the change is good in general, but when something is wrong I was in trouble and it was very annoying.

GH tower residents do not consider technology a priority. Some residents prefer to engage in activities offered by the silver town rather than spending time learning how 
to use a computer. They move into silver towns to live a comfortable and convenient life. GH2 explained:

When I came into this house, I came with the plan to buy a new computer but once I got here, it has not gone like that. There are many things to do other than the computer so I don't do it diligently.

However, many interviewees used a computer and mobile phone for their own purpose; that is, each resident had a personal reason for becoming familiar with the technology. For example, GH9 discussed using a computer to communicate with a child:

I use a cell phone. I used to teach, to some extent, how to send the text messages to our friends. Even though I taught them several times, it seems to be difficult for them. My child was in the Philippines, but I did not send e-mail to her even though I can use it so easy. However, my daughter mentioned about e-mail frequently so, I certainly learned how to use e-mail.

\subsubsection{Reasons for choosing a silver town}

Many GH tower interviewees noted that a reason for moving into a silver town related to their relationships with their family members, including children, parents and partners. Filial piety is a natural part of life in Korea, with most children wanting to look after their parents; however, parents do not want to be a burden to their children. If parents have enough finances or a regular income, their demands not to become a responsibility are even higher. They do not seek distance from their children, but they want to live independently. GH1 illustrated their experience:

I try not to become a parent who is bothersome for the children. My daughter worries less about me since I have moved in.

GH2 moved into a silver town when taking care of their mother: 
The crucial incident for me to decide to come in a facility like this was when I was taking care of my own mother. I hurt my back, while I was holding my mother. Since she is heavy, I had to take her to another system because my mother had a hard time moving. I had her in a care facility where they can provide her with full care. It might be weird to think what if my life was a little more abundant, how would it be? Thus, I did everything like that and this place is great financially and also in facilities.

When a senior's partner is deceased, the senior moves in with their children because they are financially and emotionally devastated. Living with their children comforts them; however, at the same time, they think about the independent life they had before. GH7 mentioned that:

My husband and I have lived in our own way for some period of time. Now I am alone. I always thought, I wish I could live on my own in an independent way as long as I can, rather than depending on my children.

Further, once one person in a couple has a physical disadvantage, the bond between them becomes deeper and stronger because, for the weak one, their partner is the only person they can rely on. GH5 shared an example:

Now, my husband depends on me, I am just the pager, myself, a human pager. If he doesn't see me, he just looks for me. My husband, needs much of my care. Additionally, an interviewee was affected by the decision of her close friends to move into a silver town. She moved in after conducting research with her friends. GH2 explained her experience:

I had a friend here. We all three came to see it together, when they were starting to build it. We all went to see the $S$ tower locating other place and we all did it together but only the first friend came in here. Then the decisive friend came in 
and then I came in as the third person because I had already done all the research. Thus, I knew all the advantages of this house and that's why I came in here.

The elderly consistently expressed concerns regarding emergency and medical support, which was also a concern in their previous dwelling. Personal experiences and their unhealthy condition increased their anxiety, leading them to find a place with satisfactory medical facilities. GH8 said:

I should go out or call 119 (emergency contact in Korea) when I am suddenly sick when I was living in an apartment. But I have confidence to be helped here when I push the bell. It is much more relaxing having that confidence.

\subsubsection{Silver town living experiences}

There are many pros and cons regarding smart systems for elderly people who are not technology-savvy. Further, having smart systems in their living environment requires continual adaptation.

When most residents moved into the silver town, they attended an introductory session run by the tower that provided brief information regarding the smart technology that provides immediate medical treatment. However, they had not realised how much comfort the systems would bring to their life. After their experiences, the residents' reliability on the silver town increased.

From the senior's perspective, understanding smart technology was not always positive, there were also negative aspects. The elderly require consistent—albeit calm and relaxed - exercise to maintain their mobility over a short period. Some residents believe that smart technology induces less motion. GH1 advised that: 
While living, things like the light in the bedroom or other are being controlled by remote controller. Those remotes have been around here for a long time and things have become more remote controlled.

All generations want to make their life easier, more comfortable and more convenient. When people age, it is more difficult to complete tasks; thus, the elderly seek to optimise their environment. Some residents focus more on the services and facilities provided by silver towns than the space provided for their exclusive use. Others worry about downsizing their personal space because they believe that living in a large apartment represents wealth. People who choose to live in a silver town must downsize their living space; however, they find that other services and systems, which are elderly-centred, improve their quality of life. GH1 focused on these things:

When I was outside, I lived in a bigger house. When I decided to come in here, I decreased the size of the house. So, I just brought the minimum number of things, thinking about the utilities and services. In apartments, for example, there are problems of water or electricity. Then the service provider says, yes, we will be there but it takes one or two hours for them to get here but here, there is a problem and they just come and tell you. They tell you we will be there in 10 minutes and they do come right then. Moreover, if you want to go to the gym, you must pay separately but here, everything is included. So, we are just convinced and receive that much more benefits.

GH4 added that:

The silver town provides meals for me and treats me so kindly here. I am old and living alone so now I wanted to come here and live in comfort.

Senior residents also discussed co-residing with people of a similar generation in the same building. This is rarely experienced in modern society-especially among 
those living in high-rise apartment complexes. When residents move into silver towns, they are concerned about living cooperatively because they may have had little contact with their neighbours during general apartment living. According to GH7:

I have to deal with many things so when I first came here, it was small so I was frustrated and I thought do I need to really be here? I was really worried and depressed. However, now that the time has passed, there are many treatments here and now there are not that many places where the elderly can talk so when they come here, they can have conversations. When we eat, we can meet and we are glad to see each other, and the friendships are great. So, it is great to gather together and live there. Once again, now, I feel comfortable and think that it was a great decision for me.

\subsection{GY Tower Interviewees}

\subsubsection{Aging}

As seniors age, their reactions become slower. These physical changes can be serious; however, a more critical issue for the elderly is declining mental abilityespecially deterioration of memory. Memory naturally begins to decline in the older generation, and this creates frustration and an obstacle to learning technology. GY6 explained that:

Well, I cannot follow that because my memory is gradually decreased even in repeated thinking. I started learning computers, but since the beginning, I could not remember well. Therefore, I did the first two months for beginner's course only.

It is impossible to restore their psychological and physical status to their former condition, even if there is excellent medical support. All interviewees acknowledged that degeneration is an inevitable part of the aging process. 


\subsubsection{Becoming technology friendly}

The elderly are often afraid of change and unfamiliar things. When they become used to something, they prefer to repeat it rather than accept a new challenge. If the repetitive behaviour becomes an old habit and is combined with weakened physical ability, the elderly cling to old customs. GY4 said that:

It would be nice for people to still read paper books and write letters, but it seems that technological advances actually degrade the quality of human life in a way.

In addition, the complexity of technology combined with declining memory makes it almost impossible to learn how to use smart technology. GY6 shared their own experience:

I cannot handle the computer and the technology is rapidly changing in this environment, so we cannot follow the flow. It seems that we cannot follow the flow at all in the present situation.

However, GY tower residents responded positively to technology developments, although they observed many different types of barriers. Some interviewees believed they should learn and adapt to new things gradually rather than trying to catch up to changes in technology. GY3 stated that:

No matter what, these cultural and technical changes will continue, regardless of any particular person's will and the past or present, because the flow of change never stops. You need to change yourself as you get older, to adapt to these changes and the new culture.

Thus, the elderly understand and accept that it is impossible to keep up with advances in technology, and that they should try to challenge themselves as much as possible rather than aim for something that is beyond their ability. GY5 noted that: 
I think that the elderly must not give up, but try to adapt ourselves to the changing age. I'm just trying to learn as much as I can to keep up with the times. In line with previous interviewees' comments, family is the key to engaging elderly residents in smart technology because they always want to be connected to their children and grandchildren. They can begin by learning basic things such as Internet navigation and how to send emails. Various modern technologies enable them to keep in touch with their family without barriers of time and location. According to GY7:

Since there are lots of changes, lots of people in our generation do not know how to use computer due to difficulties. However, I am trying not to fall behind. Now I am exercising and practising the Internet and sending e-mail sometimes. It is difficult for us but we are trying to adapt. We worry about being disconnected from the younger generation.

There are many opportunities for elderly residents to become familiar with smart technologies. Once they increase their knowledge, they can use these technologies for their own purposes. GY5 explained that:

Later, I realised it was necessary to learn if I wanted to be able to communicate through e-mail with friends who lived far away. Finally, I bought a computer and got my children to teach me how to use e-mail and search the web, and became generally familiar with how it worked. The same thing happened with the cell phone.

Early education — whether for personal or job-related reasons — gives the elderly more experience with smart technology. Some residents gained experience with computers for work-related reasons, while others were exposed to computers in the early stage of their development. Thus, it is easier and more natural for them to use and understand the technology. According to GY2: 
Fortunately, I was engaged in international trade while developments in computers occurred. Therefore, it was not difficult for me to keep up with. I had to establish a computer network to make my business work in the 1990s so I could catch up with the technology then.

Silver town residents have more opportunities to get close to technology - not only because of applied technology, but also because of the education programmes run by developers. The developers invite instructors to design customised learning programmes for the elderly, and many senior residents participate in these classes. For the older generation, who are more familiar with analogue devices than smart technologies, maintaining a positive attitude towards technology will increase their interest in embedded smart systems.

\subsubsection{Reasons for choosing a silver town}

People often say that they become easily confused or frustrated in an emergency, even if they know what to do or how to react. Silver towns have excellent facilities and immediate response systems, whereas people who live in general apartments and detached houses must deal with emergency situations on their own. GY5 related that:

My wife developed a problem in her spine. That's why we chose to live here.

We feel safer having a hospital nearby.

Additionally, the elderly — especially female residents who are socially considered the meal provider or preparer-have difficulty preparing meals. However, silver towns provide a customised meal service, with meals prepared for each resident's health conditions. GY4 pointed out that:

These are some of the advantages of silver town for elders. You don't have to worry about meals. My wife said she could not cook anymore. 'I am not doing it because I cannot hold a pan anymore', she said. At that time, I was at a loss for 
words. We decided to move again, this time to a silver town where it provided meals for us so that she would not have to cook anymore.

GY7 added:

Since a housewife has to prepare all the meals and the necessities of life in the Korean family, it was very hard and unmanageable. That is why we came here. As an urban-style silver town, GY tower has excellent accessibility to public transport. Many elderly residents no longer drive a car, preferring to use public transport. Similar to other urban-style silver town residents, GY tower residents said that easy access was one of the tower's strengths. GY5 explained that:

There is convenient transportation nearby, including the subway station.

\subsubsection{Silver town living experiences}

Elderly residents of GY tower had lived in the silver town for less than two years, which is a short period compared with $\mathrm{S}$ tower residents, who had generally lived there for more than ten years. The tower residents had also not considered the beneficial and non-beneficial aspects of smart systems because they were new to the residents. However, now that the elderly understand the advantages of smart technologies, they are more attached to them. As GY7 discussed:

When we lived in a detached house, we would call 119 (emergency call in Korea) when we had some trouble, but it was not reliable. Well, when something happens suddenly, it is relaxing here because of the emergency system.

The residents were initially concerned about the size of their individual unit; however, they changed their mind after living in the smaller space. GY4 stated that: First, I felt that the space here is much narrower, but I console myself with the fact that I don't need a big space to live in when I have all the other amenities of 
this building at my disposal. I wanted a larger one at first, but recognised after living here that 25 pyeong (approximately $84.12 \mathrm{~m} 2$ but its exclusive use of space is $60 \mathrm{~m} 2$ - two-bedroom type) would be optimal and economical for two people.

\subsection{Discussion}

\subsubsection{Interviewees' character}

The selected silver towns are the first and second generations of silver town developments, and the elderly residents who participated in the research were aged between their 60 s and 80 s, which indicates diversity of age. The interviewees had never expressed their thoughts regarding silver towns to anyone outside of the towns, apart from welfare or social-work-related studies conducted by the development party itself, which were aimed at improving their living conditions. Thus, the interviews gave the elderly residents an opportunity to express their opinions to someone outside of the silver towns.

As most statistical data demonstrate, the character of silver town residents is like that of the elderly. For example, once they have settled down in one place, they will stay there for the long term. Interestingly, the interviewees' average education level was much higher than that of Korea's aged population. Further, all interviewees made their own decision to move into a silver town rather than being advised by family or friends. This demonstrates a strong desire to live independently. Thirty interviews were conducted among hundreds of selected silver town residents, but this implies that the elderly who have been exposed to higher education opportunities would make better candidates to catch the idea of the new seniors-only living paradigm and to gather information regarding silver towns. 
A decline in memory and physical ability made it difficult for residents to keep up with technology developments, and they had increased concerns about health conditions. However, many interviewees challenged themselves to learn new technologies to keep in touch with family and friends. Further, they extended their use and knowledge of technology for their own purposes. This positive attitude towards technology leads to an attention that there are more things to be carried out in regard to the silver town with smart systems from the elderly perspective.

\subsubsection{Silver town living and smart systems}

There are concerns among the elderly regarding medical conditions and time spent on housework and meal preparation, which become more difficult for the elderly to undertake. A major reason for moving into a silver town is to be free from those worries and time-consuming jobs, and to live a more enjoyable lifestyle by participating in customised activities. Although compromises must be made, residents can still live independently. Initially, residents were concerned about living in a smaller personal space and sharing a large public space with other residents in the same building. However, most residents eventually understood the advantages of silver town living after settling in.

Initially, smart technology systems were not a priority for the elderly. They were simply systems applied by the developers to support their independent living. However, their daily life is attached to many types of smart technology, and it is difficult to avoid using the technology because it is widely used for communication, transport and medical purposes. Fortunately, the interviews showed that the elderly residents were in favour of technology developments. They had a positive attitude towards learning smart technologies because they were not only essential for everyday life, but they were also closely connected to their living environment. 
In addition, since the senior residents have lived in silver towns, they have gained direct or indirect experiences with smart systems because the systems meet their concerns. For instance, the emergency call system, which the seniors did not have in their previous dwelling, made them feel safe. Moreover, the key cards, which work for many things within the silver towns, comfort the elderly by providing easy access to facilities and protecting the residents from negligent accidents.

However, there are also concerns about privacy issues and the purpose of the systems. Residents' perspectives of silver towns integrated with smart technologies need to be explored for further development.

\subsection{Conclusion}

Words such as 'complicated' and 'scary' represent smart technology from the elderly perspective. These feelings are amplified by the degeneration of seniors' physical and psychological health. Thus, many older generations avoid coping with technology developments and face difficulties in keeping up with changes. However, the interviewees have challenged themselves to learn these new technologies.

From the first development of silver towns to more recent developments, there has been a significant amount of negative attention from non-residents. Regardless, many elderly people have chosen to live in silver towns, and improved evaluations from residents will lead to more positive perceptions, thereby boosting their development.

Most elderly interviewees were not aware of the benefits of the smart technology systems when they moved in. However, they are now more familiar with smart systems and they understand how the technology can help them. Therefore, senior interviewees expressed their opinion of their living environment integrated with smart systems for the first time. Chapter 5 explores the diverse smart systems applied in silver towns, their 
positive and negative aspects, and how they are being used and understood from the perspective of elderly residents. 


\section{Chapter 5: Applied Smart Technology from the}

\section{Perspective of Senior Residents}

\subsection{Introduction}

People who live in apartments these days have more technologies to make their life easier and more convenient; however, these technologies are not elderly centred. Compared with general apartments, the technologies applied in silver towns target senior residents, even though there are limited technologies. In addition, given their positive attitude towards technology, elderly residents use smart systems in silver towns although smart systems did not get attention preferentially.

To verify whether the applied technology is being understood and adapted as a supportive system, and to make changes to the elderly living environment from the seniors' perspective, this research needs to examine the in-depth interviews. Despite privacy concerns, the residents willingly participated in the interviews. The interviewees in this study showed that they have a knowledge of embedded technology by recounting their experiences with smart systems to demonstrate their understanding and perception. Further, all current technology used in silver towns requires further development, which is in progress. To ensure that the development progresses in the right direction, it is important to understand current residents' perspectives.

Similar to the previous chapter, this chapter analyses the in-depth interviews conducted with the respondents. First, technologies introduced by the developers are classified according to whether they are active, inactive or not integrated. Next, individual technologies are categorised into several subsections to provide an understanding of technology from the seniors' point of view, both physically and psychologically. The research also investigates how technology usage will affect the design of the living space from the elderly perspective. Further, this chapter examines 
the preferences of the elderly, as well as further developments required of current and upcoming technologies.

\subsection{Active Technologies}

A number of technologies have been introduced into the elderly living environment, including 'nursing and emergency call system', 'portable emergency pager', 'movement detection sensor', 'card key system' and 'CCTV'. The following sections are subdivided into installed devices, shapes and instruction, issues caused by them, demands and feelings, and discussion and findings of each active technology.

\subsubsection{Nursing and emergency call system}

\subsubsection{Location, shapes and instruction}

The nursing and emergency call system was originally designed to determine residents' health status. The system can be activated in an emergency, and it enables residents to communicate with on-site staff and nurses in the attached clinic.

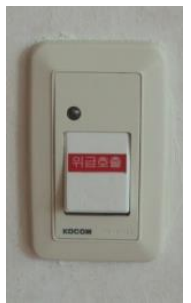

S tower

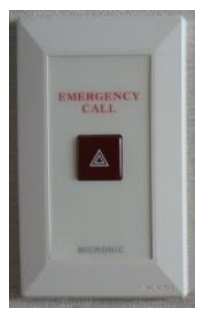

GH tower (rooms / bathrooms)
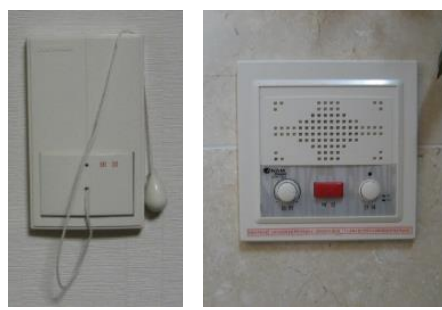

GS tower

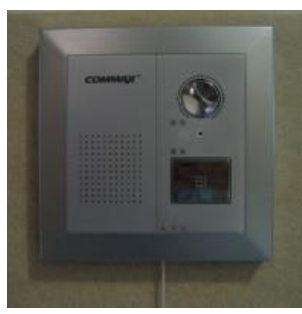

Figure 5.1. Nursing and emergency call.

There are many different unit plans in silver towns, but the call system is in every bedroom, bathroom and living room: 'There is one in the master bedroom. There is one in the living room and there is one in the bathroom. There is one in the second 
bedroom as well. So in total, there are four in the house' (S2). Further, 'Yes, these are in the living room, in the bedroom and every other room. I have two bathrooms here. And they both have it' (GS2). It is placed not only in every room, but so that seniors can easily reach it whenever they feel uncomfortable: According to GY6:

There is in bathroom, living room, office, master bedroom, also in the small bedroom. There are two places in the master bedroom. They are everywhere, and there are two in the bathroom. One is near the toilet, and the other is beside the bath tub.

Due to the different periods of development of silver towns, they are dissimilar in their method of activation and shape. S tower (developed in the late 1990s) only has a button. S4 said:

There is the button. In emergencies, if you press that, the light comes on in the nurses' room right away.

S5 added:

It is just in a square shape. You just press it and it turns on and directly connects to the nurse.

Other silver towns additionally applied the pull-and-push call system to provide better accessibility in various situations. B2 mentioned:

There are ones you push the button and there are the ones you pull on the string. According to GH3:

It is on the wall, although all the locations are different. There is this red thing on the wall. It allows you to press it. If you press it then it calls, and there is this string in the bathroom. It is located where you can see it well. If you sit on the toilet, the string is where you can reach it. If you fell in the bathroom, you can pull on that string and the nurses and staff come here and help. 
Many residents (e.g., GH3) understood the purpose of the system, which creates an immediate emergency signal. When one activates the system, the alarm goes to the nursing unit in the building downstairs. In the meantime, an alarm lamp placed on top of the entrance door outside starts blinking to guide paramedics to easily find the spot.

\subsubsection{Patterns of use - causing false alarms}

Interviewees became aware of the nursing and emergency call systems by using them accidentally. When pressed or pulled by residents or visitors, the seniors would receive a call from the nursing unit or staff to confirm whether there was an emergency. For example, S4 related the following story:

One day, the nurse called me at my room. She asked me if I was ill. I said no but she said that the emergency call was called in. Therefore, I looked and saw when the cleaners came, I guess something got stuck in there and the nursing and emergency call system was paged. I told the nurse that it wasn't me, I think it was the cleaning lady pressing it accidentally so the light came on in the nurses' room.

The nursing and emergency call system has never been integrated into apartments or detached houses, so it has caused much interest not only for residents, but also for visitors. Sometimes visitors have triggered false alarms. GH8 stated that:

When visitors come to my home, they used to push the bell with much curiosity. The elderly are relieved to have the call system, even though they have not used it in an emergency. The immediate response from the nursing unit and staff allows them to rely on the silver town's emergency system. GY8 stated:

Just pulling it. If it is working mistakenly, the staff contacts me to see if something happened. I did not use it but when somebody touched the handle, it was responded to by the staff naturally. I think that it is good. 
The delicacy of the system has also caused false signals to be sent to the nursing and staff unit. Residents often generate an alarm when there is no emergency. GS3 presented an example:

Pulling one is very delicate so if you come here and raise these, this gets stuck and the signal is transferred. That's why it is bent like this.
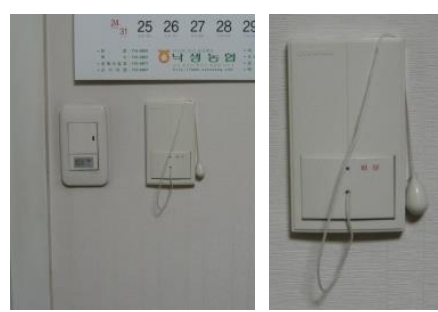

Self-alteration
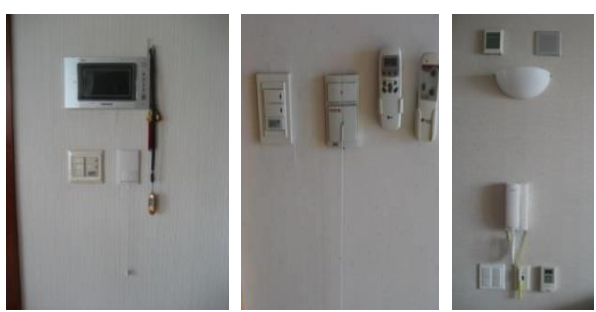

Too many switches

Figure 5.2. Patterns of use of nursing and emergency call.

Accordingly, some residents who have pushed or pulled it accidentally have devised their own way to prevent false alarms, even though it is not advised or recommended. GS4 stated:

The reason I have it hanging here is because you know you can just simply pull on it. Then the nurses or staff would run up here all surprised. Thus, I try to be careful with it. When I need it, I release it and then pull it and when I don't need it, I leave it like this since I don't ever need to pull on this.

The location of the call was another reason that people triggered an emergency warning but in other words, this implies that the call button is installed in accessible and evident places. GH8 complained that:

This is too close to the light switch. Thus, since I have moved in here, I pushed it mistakenly for a while. It happened many times.

\subsubsection{What the elderly want}

The nursing and emergency call system is one of the most highly recommended smart systems required in silver towns because of safety and medical concerns from the 
elderly and developers. The system's importance has been shown in previous research regarding the technology preferences of prospective customers. To meet demands, all silver towns have shown its significance by embedding it in not only every unit, but also in the communal spaces of silver town buildings.

It is normally perceived as a necessary system, even though senior residents have not used it and have had no reason to make an emergency call with health issues. This is because as people get older, their health condition is one of their biggest concerns. For this reason, having a reliable emergency system is recognised as a mandatory system in silver towns. S2 stated that:

Of course, yes. We must have it. Especially as there was a person who slipped in the bathroom. In that case, you just press the button and they come and help you. It is greatly useful here.

In addition, it provides mental stability and shows a distinction between previous dwellings and silver towns. GS3 explained that:

The elderly must have something related to their lives so the nursing and emergency call is something that is different from general apartments so I think that is good.

\subsubsection{Discussion}

In terms of location, the system is almost everywhere and has a close range, but there is a concern regarding how the elderly can activate it in an emergency. The person who had experienced an urgent situation believed that there is not enough time and mobility, unless the person is with their partner or others.

The nursing and emergency call system has been embedded inside and outside units. It covers the entire silver town building to provide immediate action in an emergency. Many residents have activated the system because of its sensitivity. The 
actual frequency of emergencies is very low because of the seniors' healthy status, which is a compulsory condition of moving into silver towns.

However, it has the biggest effect on the psychological stability of the elderly based on the interviewees' awareness of it, as it reminds them that they have a care system that will be able to make emergency contact in any sudden cases. It extends the boundaries of elderly residents from individual units to entire building facilities.

\subsubsection{Portable emergency pager}

\subsubsection{Shapes and instruction}

Portable emergency pagers are supplied to produce an immediate response to prevent sudden accidents among elderly residents. The wireless technology operates not only inside the unit, but also within silver town facilities and around the silver town.

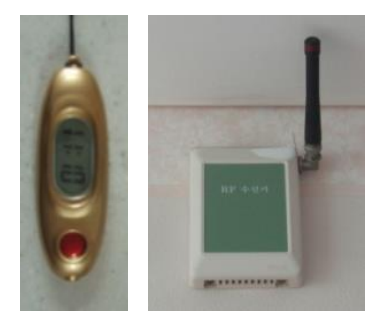

GS and B tower

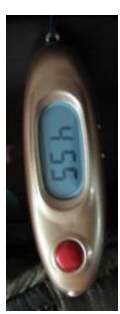

GH tower
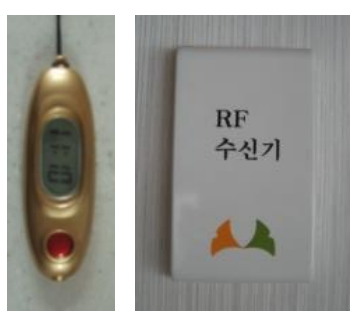

GY tower

Figure 5.3. Portable emergency pager.

The size, purpose and how to operate the pager were demonstrated by B3:

I did not even think about this when I first came in here but there is a portable warning system. It is very small, so people can carry it in emergencies. While you are carrying this around here, there are chances when you can collapse. If you press the button, it shows your location. Even the hallway, you can page it to which hallway on which floor.

\subsubsection{Patterns of use - the elderly condition and regular battery changes}

It is strongly recommended that the elderly carry their pager both inside and outside the unit; however, many residents do not take it because they do not feel as 
though they have serious health issues. Moreover, they are concerned that, similar to the nursing and emergency call system, it will not be useful if they are not conscious to operate it. S4 stated that:

The thing is people who are fully aware of their actions can carry that around and press it in emergencies but others will not be able to press it even if they have it.

Unhealthy condition of seniors emphasises the necessity to carry the pager, but people in good health avoid carrying it, even though they know why it is important. According to GS3:

If I feel a little off or I have a disease, I would wear it but I think I am okay so I don't carry it around with me. If you see, I haven't seen many people who are wearing this in here because they are in relatively healthy states. Apart from silver town staff, many people who have full awareness enlighten others who have a disability or who do not carry the pager. GS2 explained:

One is that people don't put it around their necks because they don't know when they will experience something. They leave it in their drawer or they leave it on the door or something. Thus, it is as if we don't have them. When I see some people who are not so comfortable, I tell them 'put it on'. You can't get to the phone, you can't go there if something happens in the middle of the night. In that case, you just have to press the button, that's the only way.

Healthy condition is not the only obstacle for portable emergency pagers to be carried by the elderly; the regular battery change is another concern. GS2 discussed that: Another problem is when you don't use it, the battery goes out. When you need it, the battery is gone so it doesn't work. If you take it to the nurses' room, they 
do it for you. However, you have to always think about doing that with a schedule. You have to always be prepared.
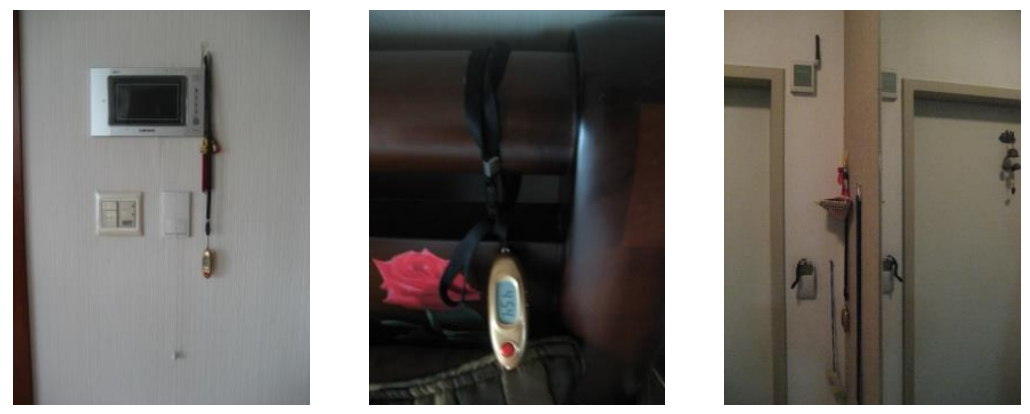

Misplacement in living room, bed frame and entrance

Figure 5.4. Patterns of use of portable emergency pager.

A personal experience of using the pager for a medical issue increased a resident's interest in keeping the pager working and close by. The resident understood how important it was to get a response in an emergency. GS2 related the following:

The other day, I was a little dizzy so I rested a little bit and then went down stairs to get some medicine and get a shot. I felt a little better after that. I was a little scared then. As a result, I checked the batteries, the battery was out. I changed the batteries there and then, I put it next to the bed. Even if I am sleeping in the middle of the night, I could use it.

Although the seniors knew that the nurses and staff would advise them when to replace the battery, it would not be precise, and it is a large task to perform for the staff and nurses. GS3 discussed that:

If the batteries go out, the staff and nurses replace them for you and provide services like that. Since I have lived here for about six years, I think I have changed the battery once or twice.

Further, GS4 said that:

When it is about time, the nurse calls me and they change it. The first time they gave this to us, they did it but these last couple of years there is no response. 


\subsubsection{What the elderly want}

In the first silver town development (S tower), portable emergency pagers were not included as a care system. It was understood that the building had enough resources to take care of all residents, and the tower is located next to a general hospital to assist in providing an instant response to an emergency. According to S1:

I have never received it. It would be nice to have something like that. You never know what can happen. Even now, I am a little dizzy so how do I know if I am going to faint or anything. When I feel like I am in danger, I can press it right then.

Residents who did not have a pager believed it would be useful in an emergency and would make them comfortable given their uncertainty regarding their health status. These elderly residents have been updated by friends and family regarding newly built silver towns. S4 explained that:

There is an emergency or something. It's not like I am going to be healthy forever. If it is given to me I can put it in my pocket and walk around and use it in case of emergency.

Other silver town senior residents who had pagers agreed that they were grateful to have them, even though they had never used them. They anticipated that it would be helpful in the future. GH5 said that:

We just call the front or nursing unit and they come. However, this is for people who are a little uncomfortable. People who have disabilities and who are older definitely need it.

Further, GY4 explained that:

It must be a good system, just not for people like me. Someday I'm sure I'll need it. 
A resident presented an example of another resident's experience as the reason why elderly residents should carry their pager. This indirect experience aroused the attention of B3, who related the following story:

The one resident wasn't able to walk very well so he would walk in short and quick paces. He collapsed in the hallway one day because he tripped on something. He couldn't stand back up on his own. However, he didn't carry that thing. If he had it with him, he would have pressed it.

\subsubsection{Discussion}

As described by the residents, most residents who do not have a mental or physical disability have not used their pager, even though they have lived in silver towns for many years. In addition, they kept the pager in their unit, despite their awareness of its purpose and the probability of having a sudden illness. GS4 stated:

I am hanging it a certain location so I don't forget where I always put it.

However, it is no use because I never use it. I've been here for more than 6 years. I am not sure if someone else has used it before.

Further, GY4 said that:

We hang it around our necks, and it's operated by pushing a button. Recently I haven't been wearing it. I just hung it on the porch because I don't need it very much.

Conversely, some interviewees still believed there would not be an opportunity to push the button inside their unit because of the nursing and emergency call system installed in every room. They pointed out that there is a mutual conflict in the role between the nursing and emergency call system and the pager. GH10 explained:

It is the portable carrier hanging around the neck. It is hanging in the bed corner since I do not use it. No one knows the future but currently, I hang it at my side. 
GY3 expressed that:

I have an emergency pager that was given to me. I haven't had to use it yet. Well, I didn't feel that I needed it right away, so I put it in a drawer. I know where it is.

The interviewees admitted that it was an essential part of the care system in silver towns, but they did not immediately need it. As GY8 stated:

I just put it in the drawer. I think that it is necessary for the aged people. They need it when they cannot walk or act as they want, or think of being at some risk. However, I do not need it yet.

Even if the pager is not used, the battery needs to be replaced regularly, and the residents complained that the silver town administrators take the pagers and keep them in the office. GH6 pinpointed that:

We had the one, the one that we put around the neck, but they collected them from us this time.

GH7 added:

When we came in here, we had the pager and wherever we went, we carried it around then it tells your location. There was no reason for us to go here and there to use it. Since we didn't really carry it, the staff just re-collected them all. Some elderly residents confused the purpose of the portable emergency pager with the signal to the nursing unit or reception used in the emergency tracking system, which can track the location of residents at all times. This is because it pinpoints the location when it is activated, but the tracking system does not need to be activated. GS3 said: 
If there is a problem, you press it. It tells you from which position it is able to be contacted. If you press here, since there is a sensor here, they will be able to know who it is.

GY6 misunderstood this:

Tracking. Ah, well, is it the thing hanging in the neck and push to operate? Even though I have it, I did not use it.

It requires them knowing how to utilise and reserve those collected pagers for a sudden emergency or figuring out what would be a replacement.

Although the elderly have not needed to use their pager, the wireless pager widens the range of mobile space for the elderly. In addition, it provides mental stability, as in other care systems. The duplicate role of the portable emergency pager and the nursing and emergency call system, combined with seniors' healthy status, has resulted in infrequent use of the pager. Nevertheless, the interviewees have been constantly told that the pager is an important item within silver towns.

\subsubsection{Movement detection sensor}

\subsubsection{Location, shapes and instruction}

Movement detection sensors detect movements of people for safety reasons. If there is no movement detected for a certain amount of time, which is set by the user, it sends a signal to the facility to activate an emergency alarm.

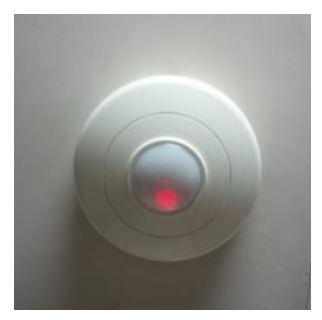

S tower

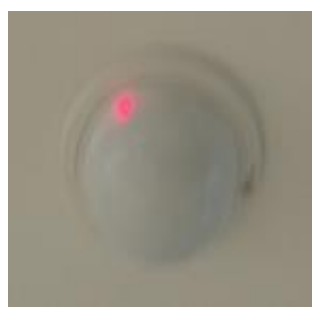

GS, B and GY tower

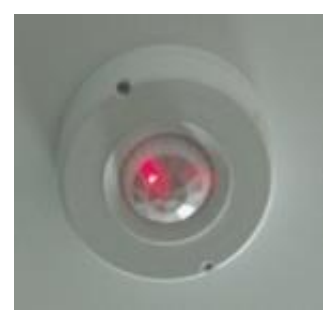

(1)

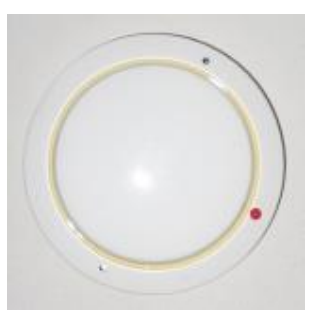

GH tower

Figure 5.5. Movement detection sensor. 
Movement detection sensors are only installed on the ceiling. Thus, it is above eye level and works without interference from residents. Further, the sensors cover most key spots in individual units. Many interviewees were aware of its placement. According to S2:

They have one in the master bedroom and there is on in the bathroom, and there is one in the living room. We have the one with two large rooms, the large unit but people with small rooms have their own and I think everyone has it. I think they all have it in the bathrooms and in the living rooms.

The sensors operate automatically and the light goes on if any movement is detected. If no movement is detected, the light goes off. Then, if there is no movement for a set amount of time, the sensor sends out a signal to the main alarm system installed in the staffroom or nursing unit. Some interviewees precisely understood the activation sequence. GY4 explained:

The movement detection sensor. It detects your movement and alerts someone in the case of an emergency. A red light comes on, flashes and turns off. GS3 continued:

If nothing moves here people assume that there is a problem, so the signal is transferred.

One interviewee immediately and actively demonstrated how the sensor would be activated. GS4 explained that:

These are off right now. Lift your hand. See. This turns on like this. This checks if there is a person in here or not. 


\subsubsection{Patterns of use-too many similar sensors on the ceiling}

Some residents could not tell the difference between movement detection sensors and CCTV or smoke detection sensors because CCTV is also embedded inside units in S tower, which may further confuse residents. S2 explained:

There is this thing on the ceiling that goes tick-tock tick-tock. When we first move in, it makes that noise when there is movement in the room. I think it is for the front to notice that the elderly is working and moving around. If there is no movement, they call and see. If we don't answer the phone, they come and check on us.
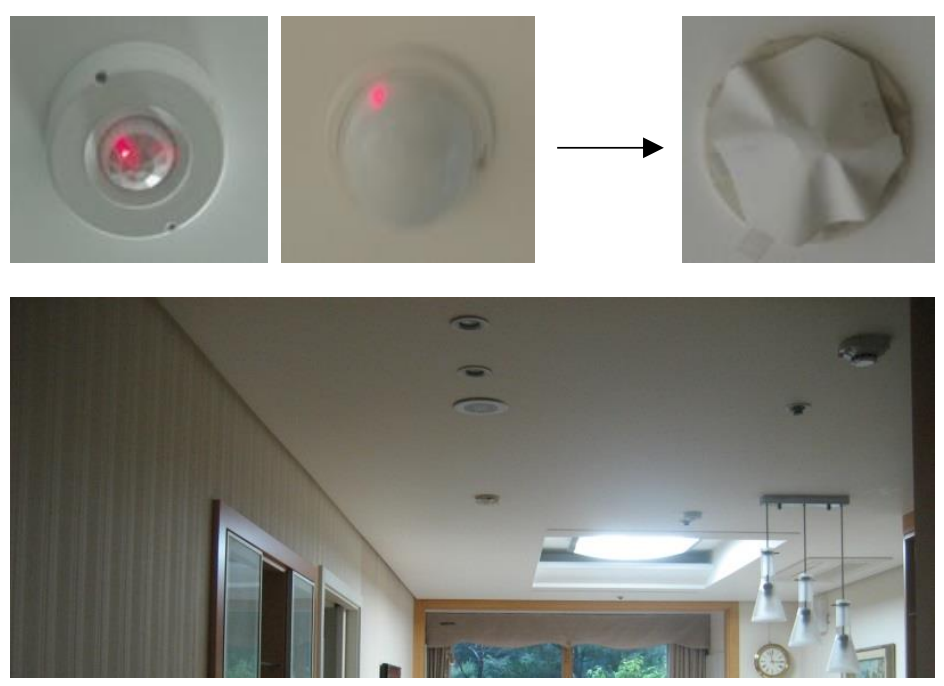

Self-alteration in living room

Figure 5.6. Patterns of use-movement detection sensor.

All silver towns have other sensors such as smoke detection sensors, ventilation inlet and outlets on the ceiling. Thus, the elderly is easily confused between movement detection sensor and others. S tower resident GY8 noted that:

There is a sensor in the ceiling. There is a smoke detection system in the ceiling. One thing is blinking in the ceiling that I do not know. 


\subsubsection{What the elderly want}

It is difficult to check whether sensors operate correctly unless an emergency occurs. Thus, one interviewee suggested that if the sensor had a voice recognition function, it would provide reassurance. GS3 suggested that:

If this works with words, then it would be great. But we can't do anything about it, with our current technology.

Elderly residents would not have an opportunity to observe the sensor, as in other systems. If it sends an emergency alert, the seniors would not notice it. Therefore, if there are no consistent education programmes or publicity regarding the sensors, it would be difficult for the seniors to perceive them. Movement detection sensors have not reported emergency cases, although other care-related systems have alerted staff to real emergency cases and false alarms.

\subsubsection{Discussion}

Many interviewees demonstrated their understanding of how the sensors work and what their purpose is. Interviewees' awareness was derived from their orientation conducted by developers, as well as brochures and their own curiosity; however, they were often not aware of their existence or locations. GH10 explained:

The staff said that there is something to sense the movement. If there is no movement, they come up because something may have happened.

Further, GY3 said:

I heard that in the orientation, so I know that they are installed. I don't know the specific location, know how they work, or if there are any risks. However, I do not need it yet. 
Additional efforts are required to increase residents' awareness that sensor systems are operating to support their safety. For example, GH10 was suspicious of whether it operated properly, even though GH10 understood its operation well:

It does not have any. I do not know while I am looking around the detection system like that.

Most respondents were not sure how long it would take to send an emergency alarm when there was no movement. Developers used different timeslots: one silver town set it for ten minutes and another fixed it at 15 minutes. The developers need to arrange the time before they provide precise information to the elderly residents.

Some residents believe that the sensor is another type of surveillance camera because it detects their movement. B3 was confused:

That is why there are sensors on the ceiling everywhere so it tracks the movements of the people.

This may lead to another controversy regarding invasion of privacy if there is not a clear understanding of the features of sensors through repeated education.

Further, when sensors go on and off, they make a tick-tock sound. Some interviewees complained that there is no problem with the light and sound during the day, but they are annoyed by the sound and the flashing light at night. Thus, some people covered the sensor with paper. However, in this case, the detection sensor becomes useless and malfunctions, and this needs to be communicated between the residents and developers.

\subsubsection{Remote inspection}

\subsubsection{Instruction}

The remote inspection system remotely checks the water and electricity meters from a facility in a machine room or a staff room. Thus, the residents do not need to do 
anything. Reducing service providers' labour time and costs directly affects the residents' independent and convenient lifestyle.
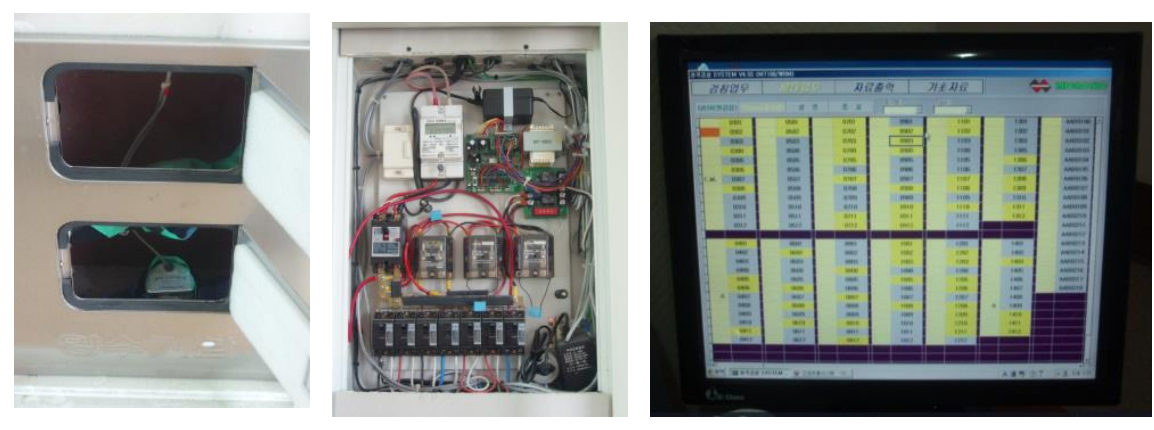

GS, B, GH, GY tower

Figure 5.7. Remote inspection.

There is no remote inspection system in S tower; thus, meters are inspected manually by the staff. Most interviewees understood how the inspections were conducted. S3 said:

When you enter the main door, there is this thing, so they inspect it every month on the same day and the facilities department does it for us.

$\mathrm{S} 4$ confirmed that there is no remote inspection system:

The inspection is done by the employees here once a month.

However, other silver towns have embedded a remote inspection system as one of the environmental control systems. Similar to other technologies, an introductory session or a brochure was provided by the developers. B3 was the only interviewee who remembered the session and the system's operation and location:

I heard about it briefly and they told me that there is an automatic meter reading system. They don't go from house to house in order to inspect the meters. I think there is an automatic meter reading system. The meter is in the hallway outside the front door. There is a control panel. In the control panel, there is a dashboard, so it is filled with all the calorimeter of electricity, hot water, cold water and heating. For the remote inspection, there is a machine room in the 
basement and I know that there is a system that inspects all the meters in the machine room.

Most answers by the other interviewees regarding the remote inspection system were in line with the comment made by GY8:

I do not know how it is done here. I do not know if they do it in person but I have never seen the staff that comes into the house for inspection or detection. Maybe they do that outside.

\subsubsection{Patterns of use-prefers to be done in a manual way}

Most interviewees did not know or understand how the inspections were conducted, and although they had knowledge of the remote system, they wanted the inspection to be conducted manually by the staff, and they wanted to observe when the staff checked the meters. B3, who understood how the system worked, indicated that:

When they are inspecting the meter, I confirm the date they are doing it and I do the inspection for my own house and compare it.

Regardless of whether the inspection was conducted manually or by the staff, GH6 understood that:

I think they come up and do something.

Further, GY4 confirmed that:

No. It's done by the staff, so we don't know much about it. We only know how much we used by reading the bill.

\subsubsection{Discussion}

At the beginning of the interviews, the seniors did not show any interest in the remote inspection system because they had no knowledge of it or they were only concerned with paying the bill. GY5 expressed: 
This is something managed by the facility team, so it's not really our business. I pay a monthly utility bill and it's all taken care of for me.

However, the residents' interest increased during the interviews. For example, B3, who already had a perception of the technology, stated that:

These days, I haven't seen anyone who came to inspect the meter and I asked once how it is done and how is the electricity consumption coming out like this. When I asked, they told me that there is a way to know even without checking by coming to the house every month. I think it is there down there.

This is in line with the analysis of the character of the elderly; that is, if they receive more information regarding a smart supporting technology that is used in their living environment, their interest increases dramatically, even if they think it is a complicated system.

\subsubsection{Card key system}

\subsubsection{Location, shapes and types}
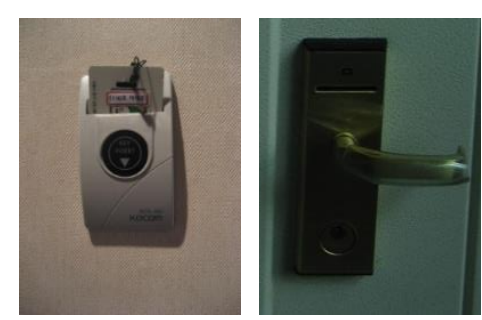

S tower
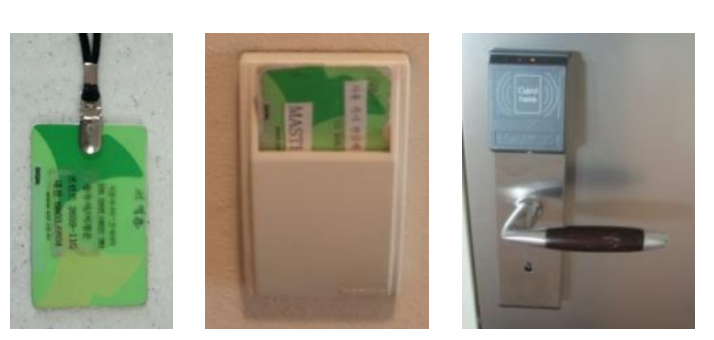

GS, B and GY tower

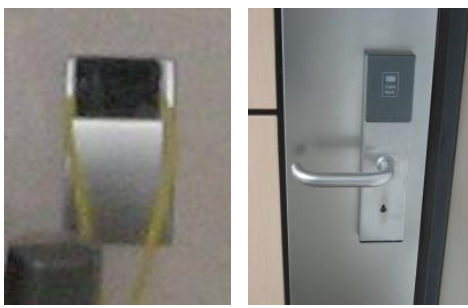

GH tower

$$
\text { r }
$$


general apartments, but their convenience and simplicity make them ideal for silver towns. According to GY3:

Other than the card key, we were instructed not to keep the key in the holder when we go out. Other than that, I can't think of anything else. They said that power management is carefully controlled, including the lighting.

This is because the card key in the card key holder supplies electricity, and residents can easily forget where they placed it because of their memory deterioration. S6 stated:

Since we are seniors, we could put it in our pockets and then if we change, it could be in other pockets, so it is comfortable to put it always in the slot. When you leave, you take it out and then you have to leave it at the front, I always leave it in the front. I never take it outside. They tell us not to take it.

The residents have high awareness of how to use the card key. Although it is not a typical entrance key compared with their previous dwelling, the residents slowly became used to it. GS2 explained:

When you are leaving, you must take it with you. If you don't have that, you can't come back in. If you forget it, then you have to go to the front and open your door with a temporary key and then take the key back and take my key out. Now, it has become a daily habit, so I rarely forget about it. When I am leaving, I usually automatically take it out.

The residents tap the card key to open the entrance door and put the card key in the card holder at the entrance to activate electricity, and then they remove it from the holder to cut the electricity supply and close the door when they leave. B2 explained:

Well, it is made of a card and if you put the card on the lock, it opens and there is nothing hard about it. 
The residents have significant interest in other functions related to the card key daily usage. S6 explains:

The system that is automatic is the one at the main door. When you leave the house, the key, you know the indoor key is taken out and then everything else except for the refrigerator automatically goes out. When there is no person, there is no reason for all the electricity to come on.

According to GY2:

If I take the key out from the key holder when I leave, the lights automatically turn off. Even though I forget to turn off the induction heating, it's automatically turned off.

\subsubsection{Patterns of use-card replacement and renewal issue}

Many seniors use the card key in inappropriate ways. They replace the key with other cards such as business cards and credit cards. GY7 discovered that the card key could be substituted with others by accident:

It is working with other cards. Maybe it was before I received that one on moving day. My stuff had already arrived, but I did not have a card key. I needed to turn on the light, since the light was out. My son inserted some card, maybe his business card. Then the light was on.
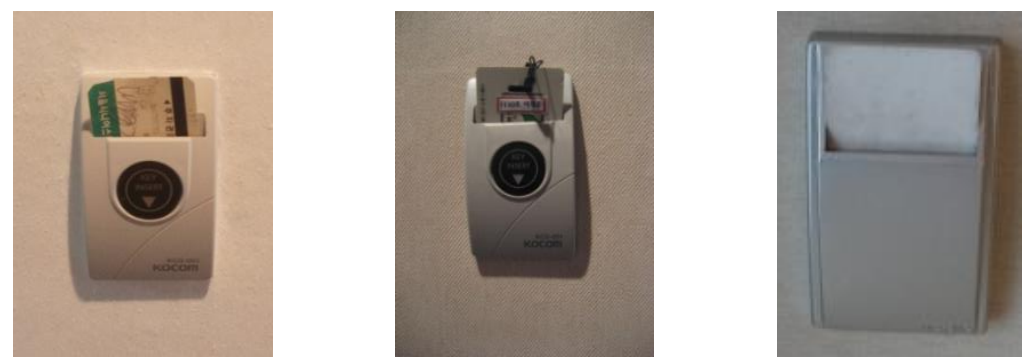

Wrong replacement by parking ticket and other cards

Figure 5.9. Patterns of use-card key 
There were cases in which the elderly residents learned that it was replaceable by chance, and then many residents intentionally used other cards to have a constant electricity supply for housework, despite not being in the unit. S2 exampled:

Other thing, when you are washing your clothes, you have to go out then you have to leave a business card in there, right?

The elderly sometimes made replacement card keys because of an inaccurate perception regarding electricity cut-off. They wrongly believed that when a card key is removed from the key holder, it severs the electricity supply. GH2 described his experience:

Honestly, I don't take them out. I just leave one in there and live like that. When I go on a trip, I don't want to empty out the refrigerator.

It is unknown how S3 had three card keys, one of which was always in the card holder and two others used for access purposes:

We have about three of them I think. Thus, we just leave one card in there permanently and have one card for each person with our names on them.

The expiration date for a card key is only 12 months - that is, the key should be renewed in the silver town once a year. This irritates people sometimes, even if they are reminded of the renewal time by the staff. It is convenient because the renewal date is notified by a silver town staff member every year, but the elderly are annoyed because they will get frustrated one day when the key does not work. S4 understood:

You have to charge that. When it is time for you to charge it, it tells you then you go and charge it.

Conversely, it prevents security risks due to the loss of a card key. One advantage of using a card key is that there is a simple procedure to get a new card 
without concerning security. When a resident loses a key and tells the staff, the staff will invalidate the old card and print a new one. According to GS3:

I have lost the key outside before so that means anyone can come and open the room with it. However, the front tells me that they have expired so we need to renew them. I think that's why they are entering new expiration dates.

\subsubsection{What the elderly want}

Deterioration of memory is one of the biggest concerns of the elderly, and it causes them to lose important things or to forget their daily routine. Therefore, having a card key system provides an advantage, especially in terms of mental relief, and it indicates why seniors need to have smart technology. GS2 stated:

I lock the door when I leave the house and I don't have to turn the light off because when you take that out, the light goes off. Moreover, there is the safety system like that. I think they did a great job with that since old people forget easily. They could leave with the lights on but if you take this out, then the air conditioner and water go off as well. It gives me peace of mind.

A card key is thin and light, making it easy to carry. In addition, it reduces the burden on security. These benefits bring psychological and physical comfort to increase residents' levels of satisfaction.

\subsubsection{Discussion}

The misuse of unsuitable alternative cards can cause a serious fire hazard and jeopardise the safety of the entire silver town facility. For this reason, all residents must follow instructions, and the staff must continuously educate and inform the residents not to use cards other than the authorised card key. GS2 explained:

There are many people who just take their card key around them and put a business card or a credit card in the slot and operate the electricity. As a result, 
there could be some dangerous elements such as leaving the electric pot on or something and you can just leave without knowing.

Residents have been told many times to keep the silver town safe. This malfunction should be fixed to ensure there are no disasters.

Additional functions relating to energy savings were mentioned, because card keys control electricity supply and reduce safety issues from unwanted things left behind. GS3 stated:

Energy conservation. The systems related to lighting control. If you take a card key out, the lights automatically go out.

GH5 further stated:

If you put the card key in there, they all come on. If you take it out, when you leave, then most of the power energy is off. Only the basic things are on. It is also saving energy.

In addition, GS3 said:

Here is an electric heater. For example, if you turn and leave it on, you could do that if you have dementia or something but if you take the card out, then all the lights go out.

As GH5 pointed out, when the residents take the card key out of the holder, the electricity supply remains on for basic appliances, and precise information should be delivered to seniors to not slot an unauthorised key in. Next, silver town staff can check residents' absent status. This could be a temporary or long-term absence, but the software system connected to the card key enables staff or nurses to identify residents' absent status, regardless of whether they let the staff know. This procedure is closely related to security and safety issues. GS4 explained how to use it properly: 
When you are leaving, you take it with you. When you come in, you put in the holder so then the electricity works. After that, the nurse room and front know that I am home.

GS3 also added:

If you put the card key in, then the nurse room recognises that you are in. If you take that out, then it means no one is at home since this system automatically turns off on its own.

The key provides access to public facilities in silver towns such as the swimming pool and fitness centre. It is used for meal services provided by silver towns, in which elderly residents take a meal at a communal restaurant. Thus, a card key contains access to all silver town facilities and provides information about senior residents.

\subsubsection{CCTV}

\subsubsection{Location}

CCTV is video surveillance that is already used in a wide range of fields for anti-crime, education, medical and traffic-control purposes. It has been installed in selected silver towns for the safety and security of the residents.
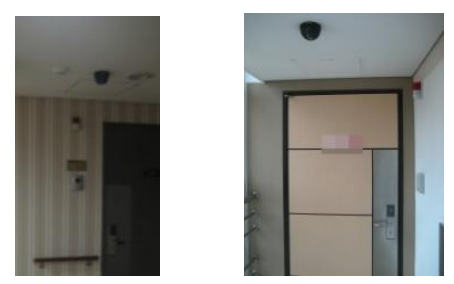

CCTV at unit entrance
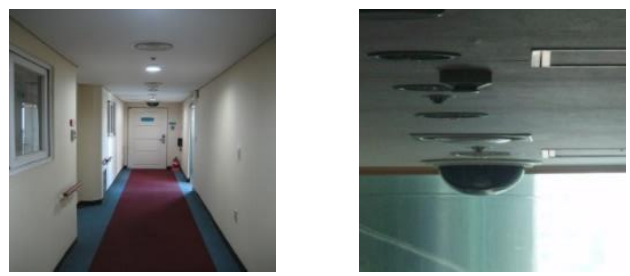

CCTV at corridor
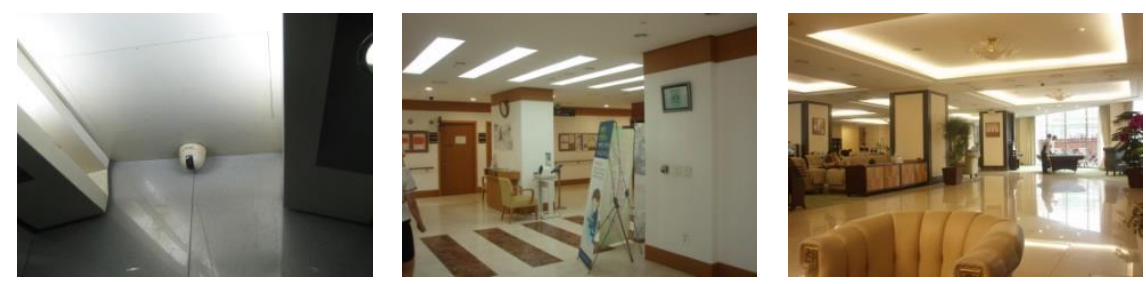

CCTV at elevator, nursing unit and lobby

Figure 5.10. CCTV in communal space. 
The seniors in S tower mentioned its location in hallways and elevators. S1 explained that:

There are two in the hallway in the eighth floor because there are two hallways.

One for each hallway.

S2 added:

There is one in front of the elevator and they are in several important places. The front knows who goes up and down the elevators.

However, interviews with other silver town residents showed that there are more in various areas. This implies that a newly built silver town has better coverage. GS1 confidently stated:

It is installed everywhere. CCTV is at that end of the hall, and also at the other end of the hall, and in the middle and in the elevators. They all have it. In every public space.

An interviewee from GY tower pointed out more details of locations of CCTVs in the building. This was not only because of a different understanding between $\mathrm{S}$ tower and GY tower residents, but because of an increased number of CCTVs in GY tower. GY3 demonstrated that:

I think they're at every corner in the corridor, and in the hall, the public bathroom and outside.

Others found more areas; for example, GY4 supplemented the parking lot, building porch and elevator, GY5 added the sports centre and GY6 added a downstairs pool, a fitness centre and a garbage dumping area.

There is another example that shows the actual experience of receiving CCTV's assistance and it also indicates that the elderly have direct experience with CCTV at the parking area as well. GS3 described this: 
Once I was in the underground third floor but someone hit my car. I carefully thought about CCTV and I went to the front and told them to look at it since there is a CCTV. They told me they will look at it and then I was able to find out who hit my car. Therefore, I was able to deal with the problem. That's what CCTV does.

\subsubsection{Patterns of use-no contact, less perception and suspicion}

Some senior residents were confident that they had CCTV in the building, but they did not know where it was. This is understandable because the surveillance cameras do not interfere with their daily life. This condition has been seen from movement detection sensors as well. Thus, even though the residents received an introductory session or gathered information from many different sources, it faded away without constant observation because of a memory decline. GH10 was confused:

I know that there is no CCTV indoors and outside as well.

GY8 added:

I do not think that CCTV or some system is installed here. It is necessary to have it in the living place for the aged people.

In addition, B3 showed awareness of the location of the CCTV and was suspicious of its purpose because it was a surveillance camera. This doubt derives from a lack of knowledge of its original purpose:

It all shows where I am or what I am doing in the building. Which hallway, which floor and there are CCTVs everywhere. There is a CCTV even outside and outdoors. Even to the area where I think is outside the areas of the seniors' town but I am not sure why they have to record everything. 


\subsubsection{What the elderly want}

The analysis showed that regular education or publicity regarding smart systems would increase awareness and satisfaction. There is already high demand for repeated sessions to inform residents about applied technology and other smart technology related to the elderly, and the need would increase for smart systems that do not require some action from the residents. GH5 explained why instruction is needed:

The CCTV in the hallway or in the elevator, I didn't know that they were there until I did this survey.

\subsubsection{Discussion}

The interviews showed that the residents did not understand the locations of the CCTV, so it only gives an idea that $\mathrm{S}$ tower has a smaller number of CCTVs and GY tower has a larger number. That is, the range of protection varies from $\mathrm{S}$ tower to GY tower. Recent developments have covered more spaces and therefore decreased the number of blind areas. An administrator confirmed that the latest silver town development increased the number of CCTVs for security and safety reasons, and the interviewee was confident that the coverage was more than $95 \%$. Increasing the number of cameras and the range of coverage means that the elderly will feel safe wherever they are in the silver town.

Each technology in silver towns has positive and negative aspects. GS3, who had used CCTV records, indicated both advantages and concerns:

When I go to the front, there are tens of monitors there. Then they are all lined up. Some people say that it is an invasion of privacy but we were able to catch the robber. It is bad to invade other people's privacy but I think it is here because of the safety. 
Once again, the privacy issue has emerged, showing that it is still a sensitive issue. Considering the older generation's stubborn character, they need to be clearly educated regarding the function of the camera for safety purposes.

\subsection{Inactive or Not Installed Technologies}

\subsubsection{CCTV in individual units}

\subsubsection{Experimental application}
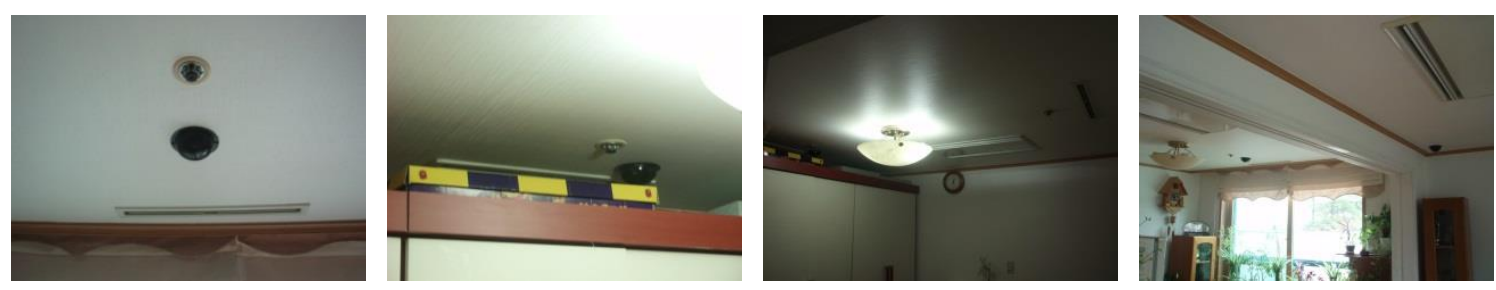

CCTV in bedrooms and living rooms

Figure 5.11. CCTV in individual unit.

CCTV inside units is a significant concern because it is placed not only in living rooms, but also in bedrooms and bathrooms, which are highly sensitive and personal spaces. S4 described that:

There are CCTVs in the houses and outside the houses but I was surprised at first. There are CCTVs on top of the bed and in the bathroom as well.

Some residents described its method of operation method in detail and added that they had observed CCTV inside units until recently. According to S5:

The one you were talking about the black thing that is CCTV. When I went to the nursing room, if there are people in each room, they were in bright colour and if there were no people in the room, then it was in a dark colour. As a result, I guess if people move the room changes into a brighter shade and if there are no people, it changes back to darker shade. I know that much. 


\subsubsection{Privacy threat from CCTV}

If it is installed in the intensive care unit system or at an extra care facility within a hospital to look after patients 24 hours a day, CCTV is generally understood. However, without any physical and psychological disability, the elderly are concerned about their privacy. They described it in different levels of violation, but they generally considered it an invasion of privacy. GH3 confirmed that:

Not in here. We don't have one in the room. There is none in the room because it is a family, a personal space.

There was extensive consideration because of the camera in the bathroom, which is the most private place in the unit and causes issues for the elderly residents' visitors to $\mathrm{S}$ tower as well. S2 stated that:

Since they are in the bathroom, the grandchildren, the young ladies come and hate it and get out of there.

\subsubsection{Positive stand}

Some people were more focused on emergency, protection and hazard situations rather than privacy. If a senior falls and no one is around, the unit CCTV could be the quickest method of response. Therefore, some residents think that it is being used for emergency purposes and that it does not transfer a clear image of the resident. S1 understood that:

I believe it is operating but I heard that when a person faints, then that is filmed there. It doesn't show the whole face or anything, even though they can see a blurred image of it and everything.

Other residents have paid attention to the practical support. The elderly who have greater concerns for their health condition would consider the camera from an extra care point of view. According to S4: 
It is not really affecting me anyway. People could think that it is restricting the personal freedom in life. In some sense, I think it is better to watch us like that and take care of us now that we are old people. I really like that idea that there is a particular protection.

S2 added:

The ones inside also protect you. What are they going to do with watching the old people? Who cares about watching residents? I don't care about that. The older generation normally suffers from anxiety about sudden collapse, and if they live alone, the level of concern increases. If an incident occurs, it is highly possible that there would be no opportunity to activate the nursing and emergency call. Therefore, in an emergency, some people think that it is necessary. For example, S1 stated:

I am not sure if they work properly in emergency situations. Even though I have the emergency bell, if you fainted because of a stroke or something then you can't press it. Therefore, they can only know if the CCTV thing is being operated.

GH5 agreed:

There are people who live alone, in the single rooms. There are many single men and also women. They need that.

\subsubsection{Negative attitude}

Only one negative issue is caused by CCTV — that is, invasion of privacy. All interviewees from $\mathrm{S}$ tower expressed a serious concern with the camera. S4 emphasised that: 
When people are alone, they sometimes take off their clothes if they are hot or some other reasons. People thought that there is a serious invasion of privacy but the company said that it doesn't show anything. They shouldn't see it, right?

Other silver town residents who did not have CCTV in their individual unit also said that it should not be allowed because of privacy issues. GS3 worried that:

There is a possibility that our privacy will be invaded.

GS2 strongly agreed:

There is no CCTV at the unit and they shouldn't use that.

\subsubsection{Discussion}

The applied purpose of CCTV in public areas is security and safety. In comparison with CCTV in outside of the unit, CCTV in domestic areas is embedded for special care purposes. Nevertheless, it creates a more serious dispute in terms of privacy than CCTV in communal areas. CCTV in an individual unit was one of the biggest themes because of the invasion of residents' privacy. CCTV is only installed in S tower, which was the first development, and there have been many privacy concerns among both silver town residents and developers. S4 explained:

I think at first, they installed it because they were worried the old people would get hurt but because of the privacy issues, they don't operate them.

The privacy issue would be the concern from the beginning of the development because one of the conditions of silver towns is that residents should not have a physical or psychological disability. However, $\mathrm{S}$ tower was the first generation of silver town development, so it was difficult to decide the limit of the service period, and the average lifespan at that time was different from today.

It is unclear whether silver towns plan to use CCTV later because of the deterioration in the health of the elderly. It may be possible to use it to support the 
elderly. Although silver towns have stopped operating CCTVs, they have not been removed from individual units. Thus, this makes residents think that it is still active. As a result, although it does not send any clear images, some people block the CCTV in their own way. S2 provided some examples of alternation:

Some people even put a piece of paper on there and they sometimes complain that they can't live because of that. It would be nice if they could put a plastic bag on top of it.

None of the interviewees who discussed the privacy issue had a positive perspective. All S tower interviewees noted the pros and cons, but they all still covered the camera with a plastic bag or paper. It is likely to be a controversial problem because residents in other silver towns do not have any experience of having CCTV inside their units. Some people think it is worthwhile for the older generation-especially in single living — and for an extra medical care facility: 'Generally, the young people do not accept privacy invasion but the old people don't care. We are just done so what kind of bad things would we do? Rather than having negative things, we are more with positive things because of these' (GS3). GS2 added:

I think in case of patients in serious care in the hospitals then CCTV would be good to have. It can be also good for places like intensive care since even if the nurses come and go, something can happen in the middle of that.

\subsubsection{Real-time health}

\subsubsection{Real-time health check or regular medical check-up}

Real-time health check systems in silver towns aim to remotely check the health status of the elderly using the Internet. Wherever elderly patients can access the Internet, they can directly connect to the nursing unit or medical doctor. 
Current real-time health is understood by senior residents to involve regular medical check-ups at affiliated clinics or general hospitals rather than Internet-based health checks. S5 misunderstood this:

The health check system is about twice a year in a general check-up.

GS2 added that:

We have a general examination that we do twice a year for our health screening.

A clinic is attached to silver town buildings, and an affiliated general hospital is within walking distance. Therefore, the residents can conveniently visit the clinic regardless of time and waiting. S1 said that:

There is this health check-up every six months at the hospital here.

Further, B2 stated that:

When you come into this place, there are nurses and doctors and they are operating regular medical exams.

GY5 also agreed:

This provides us with a comprehensive medical check-up once a year.

\subsubsection{Planned for ideal service but reality is different}

Surprisingly, many seniors understood what a real-time health check was, even though they had never seen or used it before. This shows that they have paid attention to medical-related services, even though the services require knowledge of an advanced technology. GS4 mentioned:

Real-time health check system must be a system that checks your health status real time.

Some interviewees were able to provide more information of real-time health checks operated through the Internet. GS2 addressed this: 
I also use the Internet but I don't know how to contact the doctor remotely. I have only heard about it. I have never done it before.

Others believed that it provided instant access to medical information in an emergency for immediate medical treatment. According to B3:

The real-time health check system is a hospital that can always check our health status within the facility. Even if a catastrophic situation happens, the system allows the medical team to react in the most urgent way. However, there are no special systems that check these [in] real time or check the health status [in] real time.

As it is understood by elderly residents, the real-time health check system is based on the Internet enabling residents to receive medical check-ups on demand. In addition, the system supplies accumulated medical records to a medical attendant to prepare for an emergency, and the elderly patients therefore receive better medical treatment. However, since $\mathrm{S}$ tower was constructed, other silver towns have not implemented real-time health check systems.

\subsubsection{Discussion}

There has been a trial in S tower to conduct real-time health checks using the Internet. The tower allocates monitors at the nursing unit, and residents then have access to the computer system from their individual unit. Thus, it offers immediate and frequent contact between elderly patients and doctors, and it also reduces the effort required to meet the doctor at the clinic or the general hospital. However, the trial was unsuccessful for a number of different reasons, and it has not been applied in any other silver towns. It is understood that it is too early to implement the system. The challenge for the real-time health system fell through and has had an adverse effect on following 
silver town developments. Thus, most residents misunderstand the real-time health check system as a regular health check at the attached clinic or general hospital.

The first reason for the system's lack of success was that many elderly residents were not familiar with complicated computers and were prejudiced against the Internet. In addition, all selected silver towns included a clinic facility within the same building or connected to a general hospital within walking distance, so it was convenient to go downstairs to meet the medical team rather than use the Internet at home. GS2 stated:

I don't need to because if I take the elevator down, there are the doctors and nurses here. If there was no hospital here, then maybe but we have a hospital right next to us. Therefore, if it is urgent, I can just go down and tell them I am sick. They give me a shot and a medicine. It is so convenient.

\subsubsection{Indoor air quality}

\subsubsection{Shapes and instruction}

Indoor air quality systems have not been installed, but they are advertised by silver towns. Indoor air quality control systems are one-stop service systems that are controlled by mobile phones or other devices to automatically maintain optimum air quality in accordance with elderly preferences.

Air conditioning systems in summer and heating systems in winter are most perceived to control air quality and temperature. S4 stated:

What we have is the air conditioning system in the summer and the central heating in the winter. They are just provided for us. The people who are prone to the cold should be able to turn it on more and pay more money according to the meter.

B3 added that:

All the heating is conducted through the pipes under the Ondol (floor heating). 
GS2 further noted that:

The air conditioning and heating need to be controlled by yourself and the air cleaning system can be done when you turn on the air conditioning, it eliminates the humidity.

A few interviewees expressed interest in the ventilation system and were aware of how it operated. GS4 explained:

What it says here is air supply. If you go up here and put your hands there, the air comes in, right? It is not that air directly comes into the house but there is a filter. There is a round filter and the air goes through it. I usually turn this on at nights then the air can be ventilated. However, there are many residents who don't know about the 'air supply' thing.

\subsubsection{What the elderly want}

Generally, air quality is one of the greatest concerns of the elderly, and urbanstyle silver towns should not be free from air quality issues. Further, the building has corridor access, which is important for operating the ventilation system. Some residents purchased air purifiers at their own expense because they were not satisfied with the air quality and the ventilation system.

In addition, the elderly were concerned about their electricity bill. Given their limited income, it was sometimes a more important issue than environmental control. GS2 explained that:

Since it takes too much energy, there are not that many people turning that one on because of that. If they turn it on too much, the electricity would be too high. The old people are very sensitive about the cost. So would anyone turn that on? No one would. 


\subsubsection{Discussion}

The current system in silver towns is similar to that of general apartments in terms of floor heating and individual cooling control systems. Air supply systems are not common in general apartments, but they are common in hotels and office buildings. When the elderly decide to move into an urban-style silver town, they know that the building will have corridor access and that the air quality will be poorer. It is a misconception that silver towns have an 'indoor air quality system' that is passively managed. However, the elderly are aware of the importance of maintaining air quality, and they want better air quality. As it is a common consideration for all unsuccessfully applied smart systems, advanced technology is required to meet residents' demands.

\subsubsection{Light control and energy saving}

\subsubsection{Shapes and instruction}

Light in silver towns is often controlled using timers or remote controllers. Energy-saving systems that have remote access and a one-stop control function are connected to mobile phones to control all heating and cooling appliances.

Remote controls are provided to control lights in individual units at GH tower, but they are rarely used because the elderly turn the lights on and off manually. They have done it this way for several decades, so it is difficult for them to adjust from a passive method to the use of a digital device. GH8 demonstrated:

The light is turning on at $7 \mathrm{am}$ when the timer is set at 7 o'clock in the main bedroom.

GH5 added:

You can lie on the bed and you can turn the lights on and off with the remote controller. 
In addition, the elderly irregularly need to change the battery in the controller, similar to portable emergency pagers, which causes extra work. GS4 explained:

This is switch 1, switch 2 and this is sleep. If you press this, it says 30 minutes which is for sleeping. You never use this. I just turn the lights off when I sleep. The remote controller is operated by a battery, too.

For energy saving, an advertised plan by the silver town developer seems to be planned because the prototype system has been applied in general apartments, but it has not yet been realised in silver towns. However, elderly residents perceive that the card key system has an additional function that cuts off electricity when the key is removed from the key holder at the entrance. GS3 explained that:

The card key system's related to lighting control. In the front, there is the card key holder. If you take that out, the light automatically goes out.

GH5 elaborated that:

If you put the card key in key holder, they all come on and if you take it out, most of the power is off. Only the basic things are on, so it is saving energy.

\subsubsection{Passive control}

The older generation saved energy in their own way for a long time; thus, it is difficult for them to suddenly adjust their lifestyle from analogue to digital because of the appearance of smart systems. Moreover, they have a fixed belief that the technology is complicated. Therefore, the elderly prefer to use a passive style unless the smart technology offers remarkable benefits such as reduced energy bills. S4 explained that:

I used to unplug and plug the multi-consent now and then to save energy.

GY4 added that:

Energy saving is possible by choosing not to use the air conditioner even when it's hot, and turning off the heater even though you're cold. I do this to save 
energy by not using heat in the kitchen, turning lights off in the daytime, and only using a small lamp when I'm reading.

\subsubsection{Discussion}

Residents stated that it was difficult to undertake some tasks by themselves, such as medical treatment and emergency response, and that they required professional assistance. However, it appeared that they could look after things such as light control and energy savings. The provision of a remote control or an advertised image of energy saving based on a mobile phone would not be successful because the elderly believe that there are few differences regarding energy savings between the use of smart technology and the old-fashioned method. Similar to the card key system, smart systems that will induce the elderly to use them for energy savings and light control must provide easy access, efficient functions and a simple design.

\subsection{Seniors' Preference for Smart Technology}

Silver town residents' perceptions of smart technology show that there is high demand for care-related systems such as the nursing and emergency call system, movement detection sensors and portable emergency pagers. This aligns with the biggest concern for the elderly, which is that their health status could suddenly cause trouble. GS1 elaborated on this:

When you become old, you can have a sudden death. Therefore, if there is no emergency act, you can die. This actually happens day times as well as night times. Thus, the emergency system itself is very important.

B3 added that:

The most needed system is the nursing and emergency call system. The movement detection sensor is also good. Since it is a silver facility, health management and emergency planning are the most important things. 
The nursing and emergency call system, which is located throughout individual units and is directly connected to the nursing and staff unit, is considered the most necessary smart system within silver towns. In relation to the number of systems and accessibility, the system is installed in every room and in places where an emergency is likely to occur. GH6 observed that:

The thing that I especially think is the nursing and emergency call system. There are lots of emergency situations, they use it a lot.

When seniors could not reach the nursing and emergency call system, they demanded other ways to contact a medical team. An alternative system would be a portable emergency pager, which can be used inside and outside individual units if residents carry it with them or keep it close by. The pager is provided to help prevent sudden incidents, as explained by GS2:

Wireless this. I think if I am uncomfortable or I am sick or if I collapse or something, I must depend on that thing greatly.

S5 provided an example:

I fall in the house. The emergency bell is all the way over there but my leg is broken and I can't get there. Additionally, no one is coming home and I can't get to the bell but it is an emergency. Therefore, if I press it, the emergency personnel will come. I think we absolutely need that, it would be good.

An alternative is to use movement detection sensors, which detect seniors' movements and send a signal to the nursing unit if there are no movements for a certain amount of time. The sensor is not like the call system or the pager in terms of visibility because it is situated in the ceiling and works automatically. However, if the elderly remember that the sensor is placed on top of the unit and will provide assistance if something unexpected occurs, it will provide peace of mind. GH1 said: 
If I don't make a movement for a while because you don't know when I will make a movement, I hope that there is a system that senses the movements. S4 added:

There are times when people faint before they can get to the button to press for a nurse and emergency call. So, I wish there was the sensor thing.

Hence, there is no such thing as one having priority over other systems. Regardless of frequency of use, care-related systems complement one another.

The card key is important for safety and security reasons because memory degeneration is of great concern. GH7 stated that:

Regardless if you have learned or not, we usually forget about things easily and there is something like that and the card key opening door is also good.

In contrast with the residents' previous apartment or detached house, the card key is simpler, lighter and can be hands-free. Previously, when the elderly opened an entrance lock, a key or complicated number combination was required. The number combinations were long and difficult to remember, even though residents set their own combination of pin numbers and used them every day. GH8 stated that:

I think that door key is the best. I had to put the number as a code with key together in the previous residence so it was inconvenient. Here it is good to open by just touching the key without a code number.

In silver towns, card keys conveniently work as an all-in-one access card. They allow residents to access facilities such as the communal restaurant, swimming pool and fitness centre. GY4 detailed its usage:

The card key system in this place is absolutely necessary. The same card key is used not only for the entrance, but also for meals, gym access and other purposes. It's a necessity here. 
All systems provide tangible benefits, such as helping the elderly to worry less about their memory decline by using multi-safety devices.

\subsection{Experience After Usage of Smart Systems}

\subsubsection{Sense of acceptance of applied technology}

The elderly residents found that the smart technology was complicated and difficult to use. According to GS2:

I don't even use that simple thing very often and when the whole house is automatic, then I probably wouldn't know how to use it. Everything must be simple and easy. If it is difficult, people don't use the complicated things.

However, as the elderly have experienced or have knowledge of smart systems, they believe the technology is beneficial because the systems in silver towns are closely connected with emergency acts and safety and security issues. Generally, the elderly residents feel secure, protected and relieved because they have access to smart systems. It is understood that smart technologies are there to support their independent living. GY4 illustrated that:

I feel a sense of comfort because of these systems. This system is here to help us, not to harm us. I like it because I feel like it's protecting us.

GY8 added:

I do not think that those things affect me significantly. Those systems are necessary things here. So, I do not think that I am not comfortable because of those things.

Further, S6 augmented:

I feel very stable. You live in a healthy condition rather than wanting to live a long life. In that sense, this is a great advantage. 
Tangible benefits include being supported by the systems and receiving medical assistance and psychological relief. Intangible benefits are that the residents' radius of action is not limited to their individual unit; however, the entire silver town building has not yet been evaluated from the perspective of the residents or developers.

Smart technologies help the elderly to feel comforted in different ways, and direct and indirect experiences during silver town living alleviate the preconceived idea that smart technologies are complicated. Care-related systems have become a particular reason to select silver towns as the next dwelling place. B3 explained:

When you ask the old people why you came here, there are many people who would say because of emergency-related systems. If you come in here, you feel relatively safe about that.

Of the available care systems, the nursing and emergency call system and portable emergency pagers affect the elderly the most. First, the nursing and emergency call system encourages residents to be more interested in technology. According to GH8:

Definitely I have a safer feeling. Certainly, it is. I had to go by myself or call 119 when I suddenly became sick in my apartment. However, I have confidence that I would be helped here when I push the bell. It is much more relaxing having that confidence.

Second, portable emergency pagers provide instant contact to the care unit, thereby conveying mental stability, even if residents have not used the technology before. This extends their physical space in the silver town building facilities and provides mental relief. The wireless device secures a wider range of areas for seniors. GY3 stated that: 
I don't feel much safer under active surveillance, or safer with most of those systems, but I feel that it's good to have the portable emergency pager. For example, if a robber broke in, or if you had a stroke in the bath, it would be necessary to get help right away.

GH6 added that:

The pager is comfortable and that makes me feel relieved.

There is still an argument regarding invasion of privacy because of the installation of CCTVs inside units, even though they are no longer in operation. Most residents are cautious about being observed and believe that it should not be allowed. However, some residents feel safer and more protected as a result of CCTV. S4 expressed:

I really like that idea of having CCTV in the unit. I think it would be very uncomfortable if we lived in an apartment because there is no particular protection.

A greater understanding of the purpose of CCTV and an increased feeling of protection would decrease hostility towards CCTV and accentuate its advantages. S5 discussed that:

Well, when I first came here, I felt a little like I was being watched. When I look up at the ceiling, there are many things. I felt uncomfortable and rather felt reluctance. However, as time passes, it is safer and it is better. I feel it is good because I have that.

\subsubsection{Needs for consistent instructions}

Some residents undertook an introductory session when they moved into the silver town, although the details of the instructions have faded from memory. GY5 said: 
They did an orientation session explaining those systems. We also received a manual.

However, others said that they only received a manual, or that there was no session. GY7 stated that:

No, I did not have a special education but got some manual which includes general information about silver town and applied technology. It is a thick one which I have not read yet.

B3 added:

When I came in, I didn't even get to ask. That is why no one told me about how to get the information of what we have and how to use smart systems.

One thing that should be considered is that constant and repeated education is more important than whether the elderly have received an introductory session and a manual. As shown in the interviews, if residents receive more information about the smart technology, their perception level will dramatically increase. Thus, repeated explanations will significantly increase their understanding of, and interest in, smart technologies.

Considering seniors' mental and physical degeneration, consistent and repeated education is required and is in high demand in relation to integrated smart systems and the operation of technology. B3 observed that:

You continuously have to let them know but even if you continuously let them know, the effects don't show well. In addition, it was important for the people to tell us these smart systems would be doing this here and these are installed here and even if you are not doing anything, it is reflected, but there was no education like that for us. 
There was an introductory session for silver town facilities and smart systems when the elderly moved in. However, the session was sometimes replaced by a brief meeting and brochures. Thus, silver towns should increase awareness of smart systems to increase seniors' understanding of technology and their attachment to it.

\subsection{More or No More Technology}

\subsubsection{More advanced technology}

Understanding smart technology through direct experiences from living in silver towns would promote positive thinking and enhance interest. S1 suggested that:

If it is more developed, it will be more modernised and I want the silver industry to be more convenient for the elderly and everything.

Some residents want more technology because it improves safety and security. As an early adapter of silver town technology, GY4 wants to see more developed silver towns with advanced smart technology:

This system is here to help us, not to harm us. I like it because I feel like it's protecting us. Of course, this place must be improved, expanded and developed technologically.

This would increase residents' satisfaction with current integrated smart systems in silver towns. Moreover, as the elderly have difficulties coping with modern technology, they will immediately think it is too complicated. However, when they start learning it, they will adjust and it will become convenient for them. GY7 expressed a positive view of smart technology:

At first, in the beginning, the people can feel like it is complicated because of not knowing how to apply it, but when they are familiar with how to use it, it can be very convenient and good for our lives. 
Therefore, the elderly confidently stated that they wanted more advanced technology systems to support their independent life and increase their living space.

\subsubsection{No more technology}

The older generation could have trouble keeping up with the fast development of technology, as well as its complexity. GS2 was concerned:

It depends on the people whether they have the knowledge in using that or not.

If you don't know how to operate it, what use would it be? I hate complicated things. It gives me a headache.

S1 added that:

Since it is difficult for the elderly to adapt to the daily changes, and even though it might be harder to adapt to high technology, don't you think it will be possible for us to accept it?

Second, most seniors have limited financial income; therefore, a financial burden is a concern. GH3 expressed that this should be a prior consideration:

Well, it is good but it must be cheap. That is good for the seniors but for those who don't have money. At least the price must be affordable.

Further, GY8 agreed that:

The more advanced technology is not necessary anymore and it is not advisable. The financial problem can be serious.

Therefore, having more technology in silver towns would not be a problem in terms of safety, security and energy saving, but the increased expense could significantly affect the elderly perspective. GS1 expressed:

I guess if new technologies come in, it is a good thing. However, there is the cost burden depending on new technologies. Since there is a limit to the amount of income for the elderly, there can be problems there. 
Some people believe that the integration of smart technology is a time trend because of none or low frequency of use of the current systems, and it will disappear as time goes by, even though technology would be upgraded and updated. GS2 worried that:

I don't think it is necessary for people to charge so much money by installing all these systems in the house. I am thinking rather those are in the trend of disappearing or something.

Lastly, some of the interviewees understood that the more that seniors use technology, the more the degeneration of the seniors is accelerated. This is because the elderly are required to exercise to reduce rapid psychological and physical deterioration, but they feel that the use of technology makes them neglect this. According to GY8:

Seniors must move, even in indoor areas, to maintain their health. If they can control electricity, TV, by pushing the control switch while remaining seated or lying, it is not good for the aged people. Rather the elderly should consider making themselves move for their health, even though it may be difficult.

\subsection{Discussion}

The interviews provided an understanding of emerging trends in silver towns integrated with smart systems from the perspective of senior residents. Specifically, the analysis extracts applied technology, whether it is in action or not, as being targeted and subdivided to be carried out of the current residents' perspective. For example, active technologies include care-related technologies (e.g., nursing and emergency call systems, portable emergency pagers and movement detection sensors), security-related technologies (e.g., card keys and CCTV) and environment control-related systems (e.g., remote inspection system). In addition, other inactive technologies were debated, including real-time health checks and CCTV inside individual units. 
Advertised technologies by developers and residents' understanding of these technologies illustrates the gap in knowledge regarding the purpose of the smart technologies in silver towns. The in-depth information, opinions and suggestions provided by the elderly interviewees produced substantial evidence to support elderly usage patterns and attitudes towards their dwellings integrated with smart systems which the developers could not have anticipated during development. This became clear when the senior residents demonstrated their usage and perception of the technology. For instance, the developers expected that the elderly residents would always carry their portable emergency pager, both inside and outside their unit; however, the residents tend to leave it in their unit because of their good health and the size of the pager.

Additionally, the environment control-related systems did not receive as much attention as other systems because of the residents' habit of doing things manually rather than using a machine or device. Further, there are previously activated systems that are no longer in use because the elderly residents did not want to use them due to controversial issues such as privacy invasion and complexity of use.

Moreover, the elderly showed that technology embedded in silver towns corresponds with their concerns. They considered care-related or health-related technology a priority in silver towns, followed by security-related systems. Although most residents had not yet experienced an emergency, they need to be assured that they can immediately contact doctors and nurses in an emergency. These emergency contact systems enhance seniors' mental stability, and mental relief increases confidence of movement, thereby extending seniors' range of activity. Further, multi-function systems such as the card key were popular because of their convenience, smaller size and lighter weight. The interviewees understand the systems' benefits and supportive aspects, even if they do not have direct experience with them. 
However, the elderly require consistent instruction in smart technologies to reduce confusion and increase interest. Some interviewees mentioned that they have recalled applied smart systems since the research began. Most interviewees could not remember the smart systems being introduced when they moved in. For example, the portable emergency pager is an emergency contact system that can track a resident's location in real time. Wireless function causes this confusion which could be prevented by providing correct information in an instruction session.

The elderly stated that smart systems need to be more updated and advanced in terms of complexity and difficulty even though learning it is slow. There are changes and upgrade actions through silver town development. Upcoming technologies, even though they are not going to erase the complex image of technology immediately, at least it can take the negativity out and become friendlier. However, new technologies should not create a financial burden for the elderly, and they should be in line with seniors' preferences. Based on the residents' perceptions, there are limitations to the application of smart technology; thus, it is important to understand seniors' preferences in future developments.

\subsection{Conclusion}

The interview analysis demonstrated that there are differences between advertised smart technologies, technologies applied by developers and active technologies from the elderly perspective. Further, the senior residents' understanding of each active and inactive technology showed a range of issues based on the status and demands of residents and silver towns, as well as both positive and negative aspects relating to patterns of use and intended purpose.

Elderly interviewees' perceptions of individual smart technologies leads to carerelated systems and card key in the category of security-related systems, that are closely 
associated with medical support or security matters as important systems in silver towns. The systems provide psychological and physical comforts that expand residents' living boundaries.

Surprisingly, residents endorse that there is not only more technology but advanced technology is demanded based on their experience, although current residents do not want additional technology because of their stereotyped conception of technology and their limited income.

Chapter 6 conducts qualitative analysis of silver town observations and quantitative analysis of surveys to provide an understanding of aspects in numbers and figures. The interviewees allowed the researcher to conduct site observations to obtain images of individual unit plans and the locations of the applied technologies. This will enhance the understanding of changes in the spatial structure in accordance with adapted smart technologies, as well as changes in the actual usage of smart technologies in the units. Additionally, photos of the units show how residents deal with space in relation to their household belongings from their previous dwelling and in relation to the embedded technology systems. Further, the survey gathered information regarding smart systems from a larger number of respondents in selected silver towns. The results illustrate the character of the respondents and verify the results of the qualitative data analysis, as well as residents' awareness, frequency and satisfaction in relation to a range of active and inactive technologies. 


\section{Chapter 6: Quantitative Research}

\subsection{Introduction}

Smart technology embedded in silver towns is analysed using information obtained from the interviews with the current residents of the selected silver towns. Analysis was conducted on a range of technologies to determine whether it was being used. Each technology was then investigated in terms of its operation, debatable issues, demands and findings from the elderly perspective. This chapter examines how the elderly use and adapt these technologies in their living environment, what technologies they prefer and their additional requirements.

In this chapter, observations as an additional method of qualitative analysis involve collecting documents, such as silver town plans and brochures from developers to examine the features of silver towns. Individual units integrated with technology were inspected with the permission of some interviewees. These units had not previously been opened to the public. This increases the transition of the initial perspective from the developers to the senior residents in relation to the elderly living area and applied technology. The examination first identifies silver town unit plans and then draws upon embedded technology in individual units. Lastly, it investigates the residents' lifestyle associated with technology that they had not previously encountered.

Moreover, quantitative analysis was conducted of the survey, which was designed to capture demographic information regarding age, dwelling period in the silver town, spousal status, gender and education. The data were analysed to understand the range of active and inactive technologies in selected silver towns through awareness, frequency of use and satisfaction. These three categories will provide an understanding of the different perspectives of elderly residents and silver town developers. 


\subsection{Survey Respondents}

Table 6.1 Average Age and Average Dwelling Period of Selected Silver Town Residents

\begin{tabular}{lcccccc}
\hline & S tower & GS tower & B tower & GH tower & GY tower & 5 towns \\
\hline Facility built & 1998 & Early 2003 & Late 2003 & 2006 & 2007 & \\
$\begin{array}{l}\text { Average time } \\
\text { occupied (month) }\end{array}$ & 87.2 & 61.2 & 56.5 & 24.7 & 16.7 & 41.6 \\
\begin{tabular}{l} 
Average age \\
\hline
\end{tabular} & 3.52 & 4.29 & 4.0 & 3.83 & 3.55 & 3.75 \\
\hline
\end{tabular}

* Average age: 3 (71-75), 4 (76-80), 5 (81-85)

Elderly residents rarely change their home once they have settled down. Table 6.1 shows the average dwelling period, which supports the character of the elderly. The average dwelling period of respondents was around 87 months for $\mathrm{S}$ tower. This was expected because $\mathrm{S}$ tower is the oldest development, having been built in 1998. GS tower, which began service two years after $S$ tower, had a dwelling period of more than 61 months. GH tower's residents had lived in the town for 15 months on average, which is in line with its opening year. Generally, the data in Figure 6.6 align with the different opening years of silver towns; that is, older buildings indicate a longer dwelling period.

The average age of survey respondents is illustrated in Table 6.1. The figure for GS tower is 4.29 , which converts to around 77 years, representing the highest average age among the selected silver towns. In contrast, the figure for $\mathrm{S}$ tower respondents is 3.52, which is around 73 years. Thus, although $\mathrm{S}$ tower is the oldest town, it has the youngest average age of residents, which means that there is no relation between years of service and average age of senior residents. In addition, based on the average figure of the five silver towns' respondents, the elderly residents were aged between 73 and 77 years.

In general, in relation to the number of participants in the study, GH tower had the largest number of participants with 46 people, followed by S tower with 23 . GS tower and B tower had a lower response rate, with fewer than ten participants. 
Table 6.2 shows the gender and spousal status of the participants. There was a balanced response from males and females in general; however, GH tower had more female than male participants (28 compared with 17), whereas GY tower had the opposite balance (13 males compared with five females). Further, GH tower had the highest number of respondents, while GS tower had only six respondents.

In relation to spousal status, there were almost twice as many single residents in S tower than those living with their partner. Conversely, in GY tower, there were six times as many residents living with their spouse (18 compared with three). The other towers were almost evenly balanced.

Table 6.2 Gender and Spousal Status of Selected Silver Town Residents

\begin{tabular}{lccccc}
\hline & S tower & GS tower & B tower & GH tower & GY tower \\
\hline Gender (male/female) & $11 / 11$ & $3 / 3$ & $2 / 6$ & $28 / 17$ & $5 / 13$ \\
Spouse (single/with spouse) & $15 / 8$ & $3 / 4$ & $4 / 6$ & $24 / 22$ & $3 / 18$ \\
\hline
\end{tabular}

Table 6.3 illustrates the educational background of respondents. Forty-three out of 104 respondents graduated university, 23 residents had a post-graduate degree and six residents did not complete high school. Compared with the average education level of Koreans in a similar age group (i.e., completion of middle school), the residents' education level is significantly higher, with most finishing university.

Table 6.3 Education Level of Selected Silver Town Residents

\begin{tabular}{lccccc}
\hline & S tower & GS tower & B tower & GH tower & GY tower \\
\hline High school incomplete & 2 & & & 4 & \\
High school complete & 6 & 2 & 1 & 13 & 4 \\
College complete & 1 & & 2 & 3 & \\
University complete & 10 & 3 & 7 & 15 & 8 \\
Graduate school complete & 4 & 2 & 1 & 6 & 10 \\
\hline
\end{tabular}




\subsection{Technologies in Silver Towns}

Advertised technologies, or technologies in the presence of previous research, are categorised by location (i.e., individual units and public spaces, and then subdivided into care-related, environment-control-related, security-related and technology in communal areas). There were 15 advertised technologies, including nine applied technologies. Further, active technology systems are narrowed down to seven: nursing and emergency calls, portable emergency pagers and movement detection sensors from the care-related category, remote inspection and light control systems from the environment control category, card keys from the security-related category and CCTV in public areas.

Table 6.4 shows which technologies were installed and currently active in each silver town. All technologies in the care, security and public categories were almost evenly integrated. S tower has additional systems - namely, 'real-time health check system' and 'CCTV inside personal unit' - but they were not in use, and other towers did not even consider installing them. 
Table 6.4

Smart Technologies in Selected Silver Towns

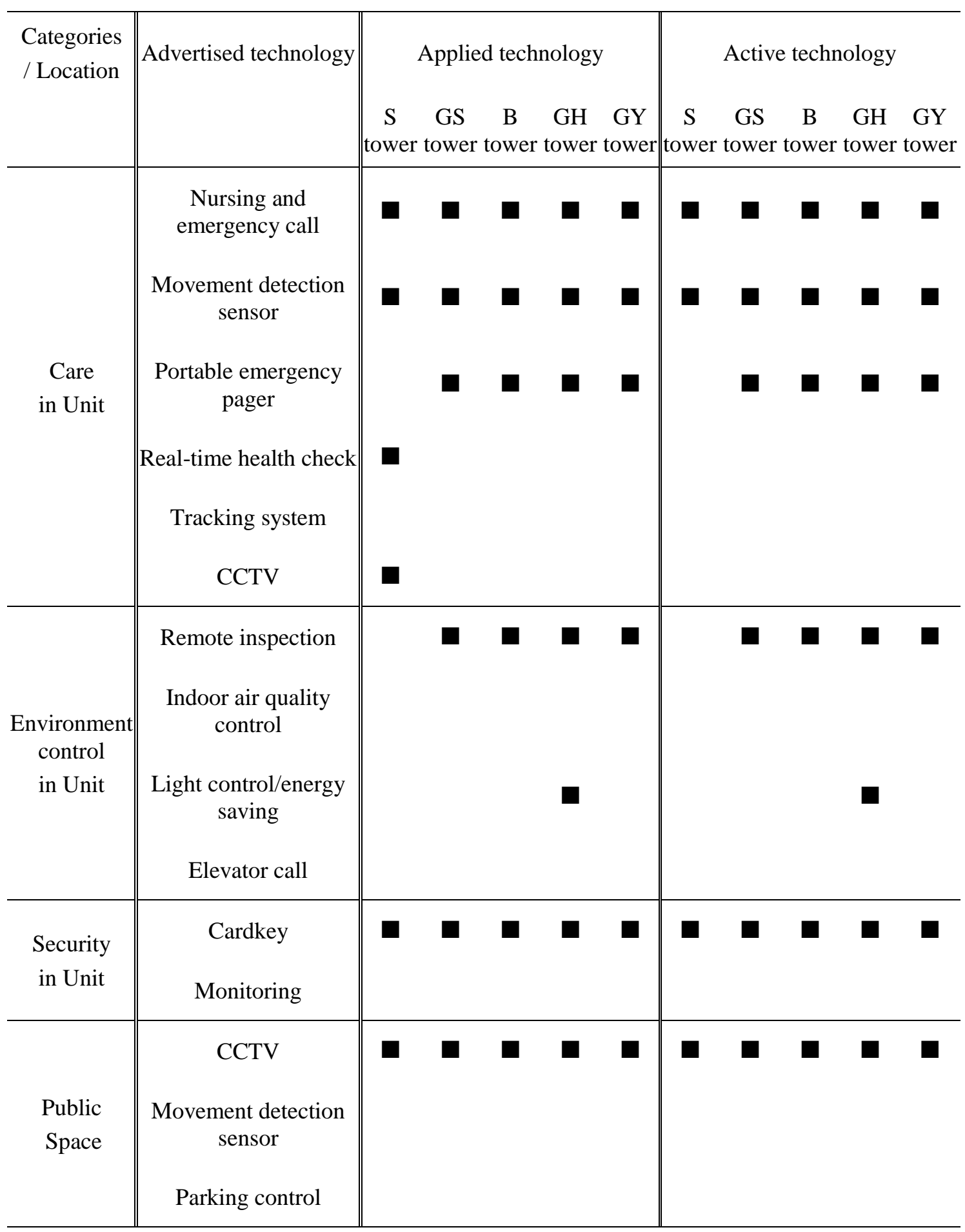


Based on the developers' perspective, a remote inspection system is applied in four towers, excluding $\mathrm{S}$ tower, but it is not actively used because the elderly prefer their meters to be checked manually. There are seven active technology systems in selected silver towns but the technology which is actively being used by the elderly is the 'card key system' due to various reasons such as the elderly's healthy condition, complicated operation and the elderly preference.

\subsection{S Tower}

\subsubsection{S tower unit plan and smart technology}

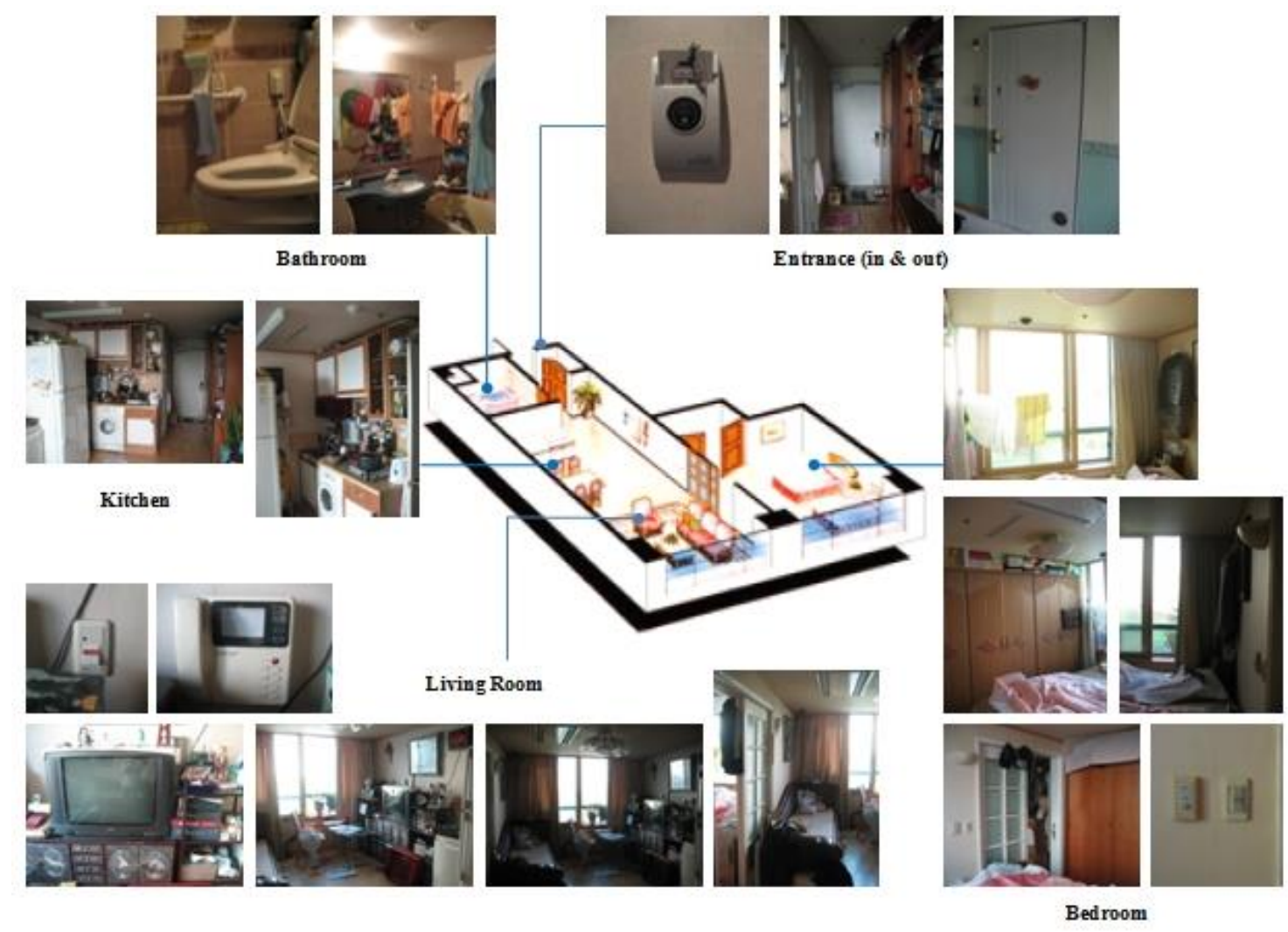

Figure 6.1. S tower unit.

There are three size types of individual units. The plan shown in Figure 6.1 is a medium-sized area with exclusive use space of around $39.7 \mathrm{~m}^{2}$. As the first silver town development in Korea, the building supplies from smaller (around $26.7 \mathrm{~m}^{2}$ )- to medium (around $52.9 \mathrm{~m}^{2}$ )-sized units. Each unit consists of one bedroom, one living room and a 
bathroom. Although the space is designed for a couple, there is a massive shortage of storage space, and it is difficult to transfer all belongings to a one-bedroom unit from a previous apartment. The resident, who has lived in this unit for more than 15 years, has gradually obtained more belongings during this time. He did not realise that there was CCTV inside the unit. He said:

Not in the room. As mentioned before, there is personal privacy so that cannot be in there and it is also not necessary.

A picture of the bedroom area shows the presence of CCTV, although it is no longer active. Current residents' perceptions regarding applied smart technologies’ locations and activation were limited to actual beneficial ones but reasonable. However, there is some interference between the technologies and belongings in the bathroom, the living room and the bedroom. Even movable objects hide the emergency call button in the bathroom. This is not an encumbrance in a normal situation, but it could be considered a burden in an emergency. For example, the TV and other objects in the living room severely obstruct access to the emergency call button, and it is difficult to recognise it from the front. It is understood that the button has not been used for a long time. In fact, the elderly resident has never pressed the emergency button; as a result, a stack of his belongings had formed an obstacle. As shown, there are differences in furniture allocation between the display unit plan and the actual bedroom pictures. This implies that there is different usage of the individual unit between the original interior design plan, which was made by the developer, and the residents' version of the design. The wardrobe replaced the mattress in the display plan; thus, the resident's mattress is intentionally placed in the corner of the room, where the emergency button is located for emergency reactions. However, it hides the button completely. This indicates that 
the resident did not seriously consider using the emergency button at the beginning, and even later it has been formed due to non-use.

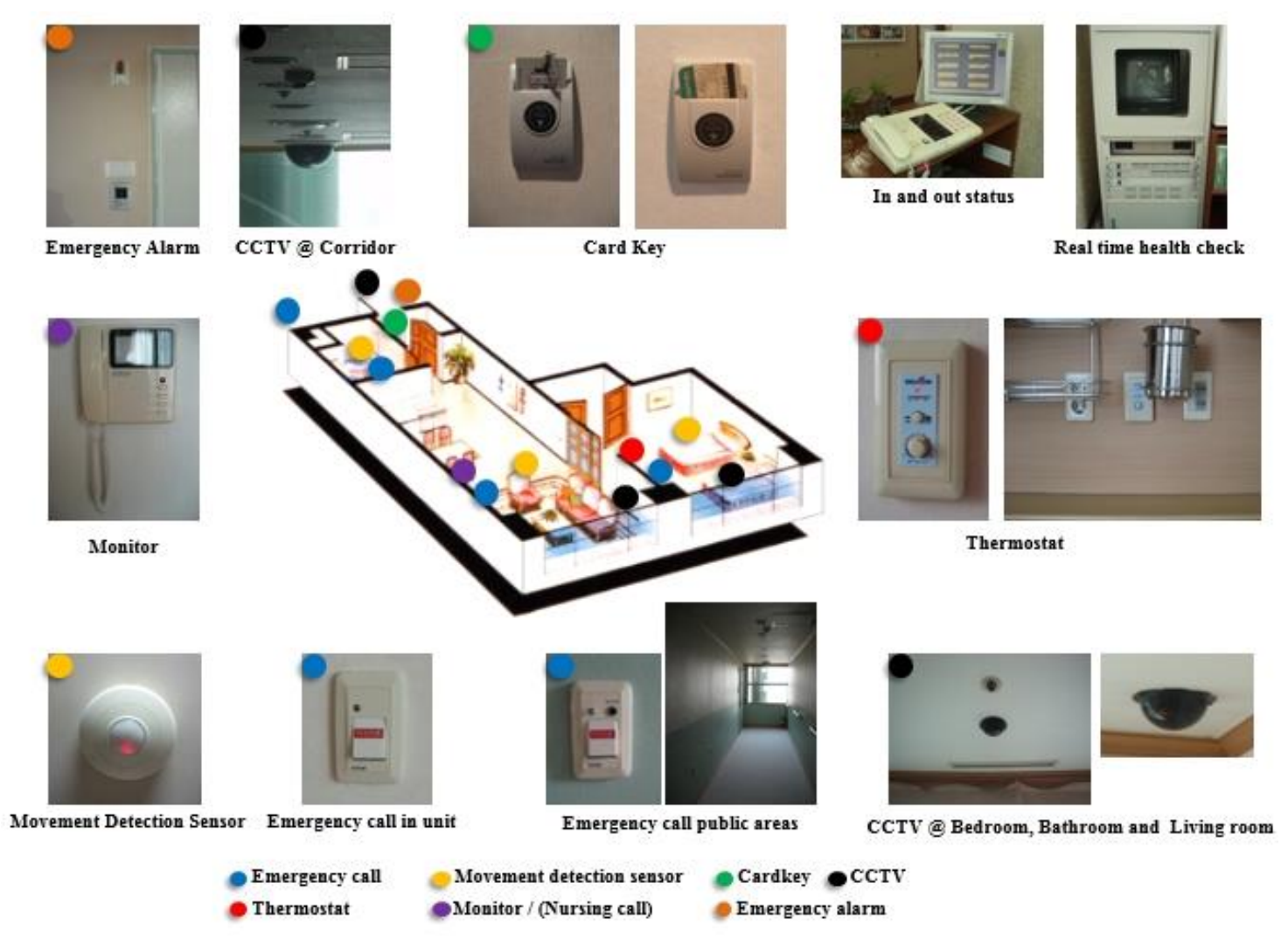

Figure 6.2. S tower unit with technology.

The number of technologies inside and outside the $\mathrm{S}$ tower unit are shown in Figure 6.2. The emergency call buttons and movement detection sensors are in the bedroom, bathroom and living room. The emergency alarm sign outside the entrance door makes it easy for staff and paramedics to find the unit. Only a single type of emergency call button is applied, and it is large enough to be recognised because it is a push button. A card key holder, a monitor and a thermostat are in the unit. The card key holder at the entrance is a device to supply and cut electricity when the card key is inserted into the holder. The monitor has a simple function for checking visitors or connecting to reception. The thermostat is an analogue-style dial.

The CCTV outside is generally considered a security-related device, but there are some CCTVs inside the units. More specifically, they are in the bedroom, living 
room and even bathroom, which is significantly personal space. They are no longer in operation because the elderly residents complained of an invasion of privacy, but some seniors still think it surveys them, so they cover the CCTV with plastic bags or paper. From the developers' perspective, they are concerned about fast emergency response times and treatment in the case of an emergency, but they did not consider the elderly residents' privacy.

As the first silver town development, $\mathrm{S}$ tower experimented with a real-time health check system that enabled senior residents to have instant face-to-face communication through the Internet or a special device. Figure 6.2 displays a screen in the nursing unit for the system. However, it did not undergo further development because the elderly preferred a passive way to see on-site medical staff, and the complexity of using a computer and the Internet made it fade away. In addition, a portable emergency pager had not been supplied to $S$ tower residents like in the other silver towns, but the button-style nursing and emergency call system with a deactivation function was implemented throughout the communal corridor at regular intervals to replace the portable emergency pager, which is applied in later versions of silver towns if there are urgent situations.

When the residents slot a card key into the key holder at the unit entrance, it not only supplies electricity, but also sends information regarding whether the seniors are at home to a computer system in the staffroom or nursing unit. That is, on-site staff and nurses can check the in-and-out status of the elderly for safety and security reasons. Figure 6.2 shows a malfunctioning card key holder because it is possible to replace it with alternative cards such as a business card, credit card and even a parking ticket rather than the authorised card key. 


\subsubsection{Descriptive analysis of $S$ tower's technology}

Table 6.5 Survey Respondents for Active Technology in S Tower (People/\%)

\begin{tabular}{|c|c|c|c|c|c|c|c|c|}
\hline \multirow{2}{*}{$S$ tower } & \multicolumn{2}{|c|}{ Awareness } & \multicolumn{3}{|c|}{ Frequency } & \multicolumn{3}{|c|}{ Satisfaction } \\
\hline & Aware & Unaware & Use & $*$ & Non-use & Satisfied & $*$ & Dissatisfied \\
\hline $\begin{array}{l}\text { Real-time } \\
\text { health check }\end{array}$ & $19 / 90.5$ & $2 / 9.5$ & $13 / 59.1$ & $8 / 36.4$ & $1 / 4.5$ & $15 / 62.5$ & $9 / 37.5$ & \\
\hline $\begin{array}{l}\text { Nursing and } \\
\text { emergency call }\end{array}$ & $22 / 96.7$ & $1 / 4.3$ & $1 / 4.3$ & $1 / 4.3$ & $21 / 91.3$ & $13 / 59.1$ & $5 / 22.7$ & $4 / 18.2$ \\
\hline $\begin{array}{l}\text { Movement } \\
\text { detection } \\
\text { sensor }\end{array}$ & $18 / 75$ & $6 / 25$ & & $1 / 6.6$ & $17 / 94.4$ & $4 / 26.7$ & $5 / 33.3$ & $6 / 40$ \\
\hline $\begin{array}{l}\text { Portable } \\
\text { emergency } \\
\text { pager }\end{array}$ & $17 / 70.8$ & $7 / 29.2$ & $3 / 21.4$ & & $11 / 78.6$ & $5 / 46.5$ & $4 / 36.4$ & $2 / 18.2$ \\
\hline Card key & $23 / 96.8$ & $1 / 4.2$ & $21 / 91.3$ & $2 / 8.7$ & - & $22 / 96.7$ & $1 / 4.3$ & - \\
\hline $\begin{array}{l}\text { Indoor air } \\
\text { quality }\end{array}$ & $20 / 83.3$ & $4 / 16.7$ & $17 / 77.3$ & $4 / 18.2$ & $1 / 4.5$ & $14 / 63.7$ & $6 / 27.3$ & $2 / 9$ \\
\hline CCTV & $19 / 90.5$ & $2 / 9.5$ & $4 / 23.5$ & $5 / 29.4$ & $8 / 47.1$ & $8 / 44.4$ & $7 / 38.9$ & $3 / 16.7$ \\
\hline
\end{tabular}

The real-time health check, nursing and emergency call system, movement detection sensor, portable emergency pager, card key, indoor air quality and CCTV showed a high percentage of awareness in silver towns. The real-time health check system was only tested in $\mathrm{S}$ tower, and the system was no longer active. Although there was high awareness, senior residents comprehended its concept but considered it a regular health check service or immediate medical service from the on-site clinic. More than $70 \%$ of respondents were aware of the portable emergency pager, even though they had not received one in $S$ tower. This implies that $S$ tower residents, as the first silver town dwellers, received information from other affiliated silver town residents regarding the pager. Nearly all participants said they had not used the pager because they had not received one. Further, there was almost no usage of the three active technologies, but a few seniors marked the frequency of the nursing and emergency call system and the portable emergency pager because they had received a confirmation call 
from a staff member or nurse when there was no emergency to activate the system.

Thus, there was no parallel in proportion to awareness and satisfaction. The card key illustrated exceptionally high awareness, frequency of use and satisfaction because the elderly used it daily for opening the door, supplying electricity and accessing other facilities. As an urban-style silver town, air quality is an important consideration, and all three sections had high marks.

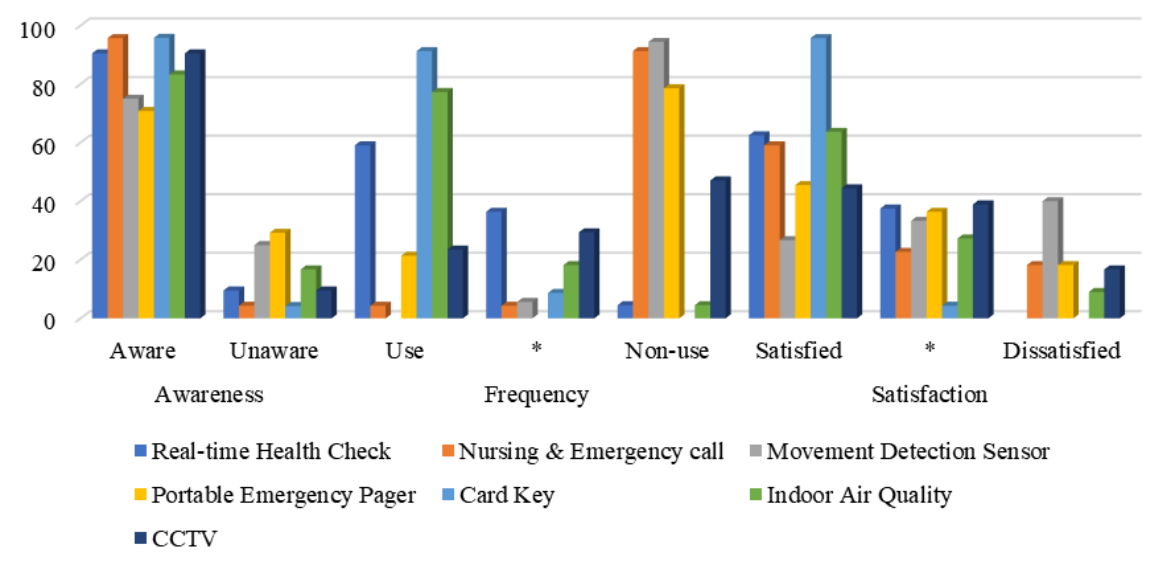

Figure 6.3. Survey respondents' active technology in $\mathrm{S}$ tower.

Figure 6.3 presents the proportions of respondents regarding each technology.

All technologies are highly perceived by the elderly respondents, and frequency of use is divided into smart systems in use and not in use. In addition, the figure generally shows that a larger number of people are satisfied but hold various opinions about technologies. 


\subsection{GS Tower}

\subsubsection{GS tower unit plan and smart technology}

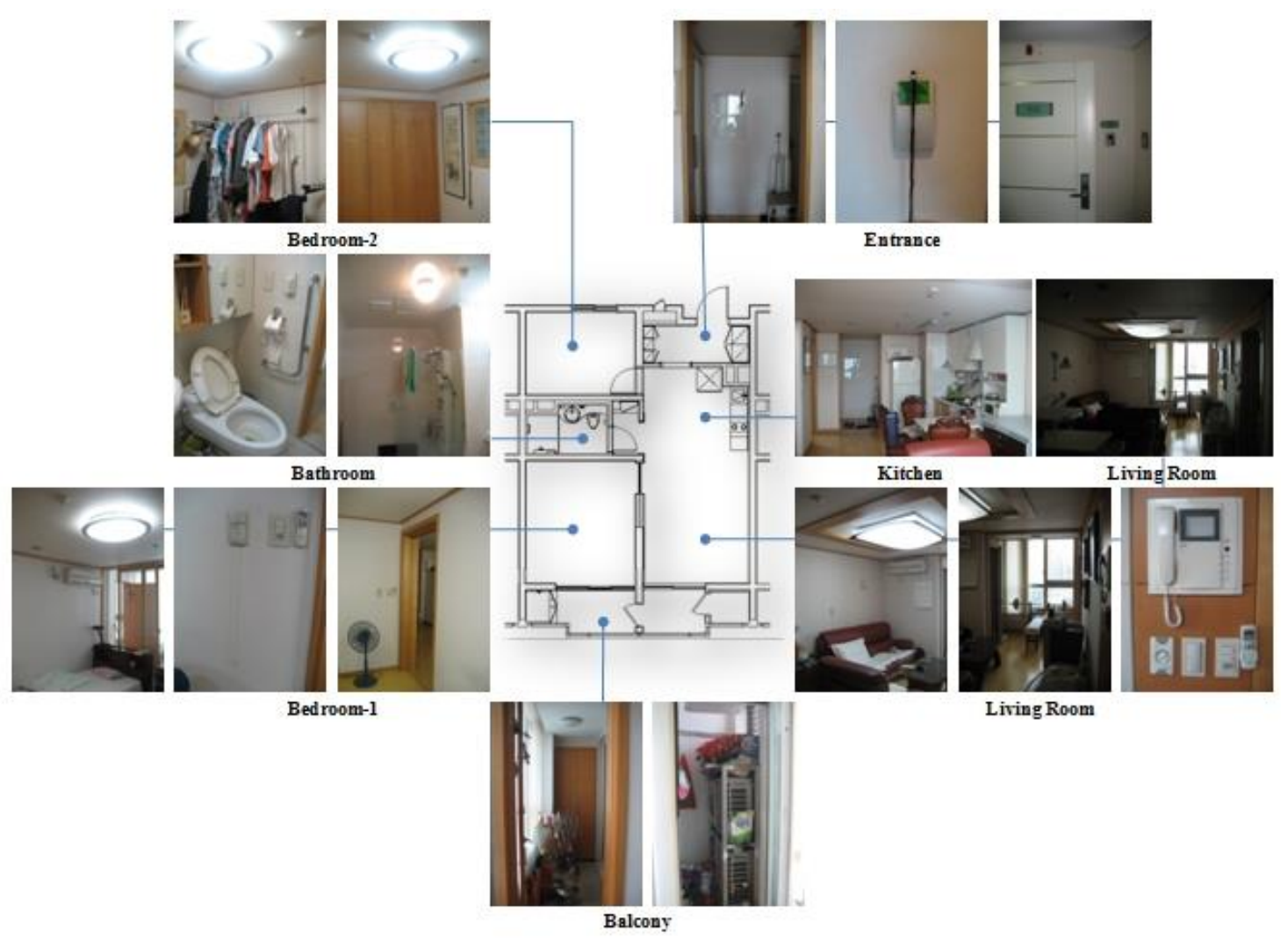

Figure 6.4. GS tower unit.

GS tower illustrates a representative medium-sized unit of $55.2 \mathrm{~m}^{2}$, which is much larger than the units in S tower. The smallest unit sizes in S tower and GS tower are $26.6 \mathrm{~m}^{2}$ and $38.6 \mathrm{~m}^{2}$ respectively. The above unit comprises two bedrooms, a bathroom and a living room and is designed for two people. The resident confirmed that their previous dwelling was larger than their current silver town unit, so they had to clear out many of their belongings before they moved in. For this reason, the residents' belongings were relatively well organised compared with those of the $\mathrm{S}$ tower resident. However, some places still require extra storage.

The resident had not made any changes to the technology as other residents had-especially to the nursing and emergency call system - to prevent them from 
accidentally setting off a false alarm because of its sensitivity. The resident just releases the string as it is applied, whereas some other elderly residents do not. However, there was little interference between the household and the technology. In the living room, the resident hung the portable emergency pager on the wall, where it was too obvious because they had never used it. Although they knew it would be needed in an emergency, hanging the pager on the wall in the living area rather than leaving it within close range is the same as adding another type of emergency call button.
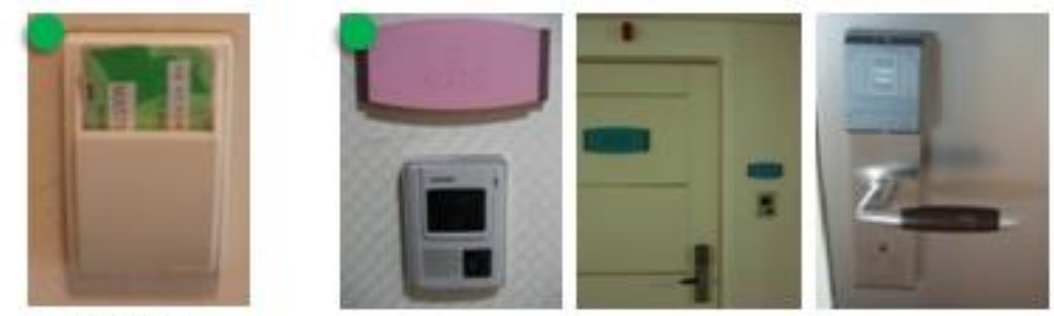

Card Key

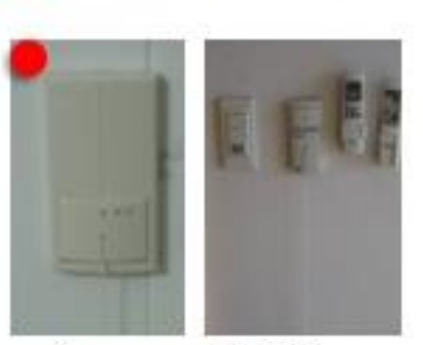

Emergency call_1\&2

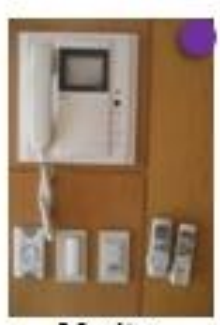

Monitor

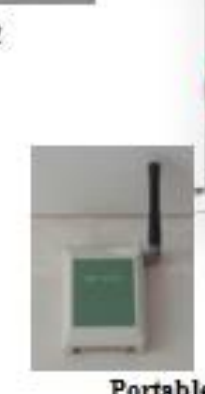

Portable emergency pager

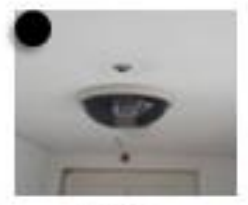

CCTV

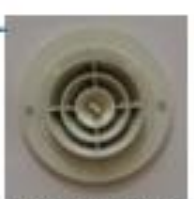

Air Supply

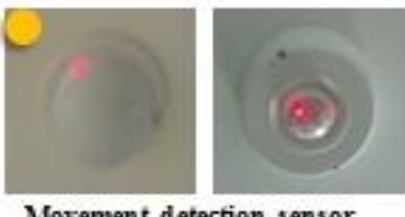

Morement detection sensor

Emergency call_1

Movement detection sensor

Cardkey

Monitor / (Nursing call)

Portable emergency pager

- cCTV

Figure 6.5. GS tower unit with technology.

Emergency call systems and movement detection sensors were present in every room. GS tower introduced the combination of pulling a string and pushing a button in emergency call systems to increase accessibility whereas $\mathrm{S}$ tower has only one button- 
type system. A long string hanging from the emergency system offers better visibility and a second opportunity to activate the system, even if the elderly patient misses the button at first. Two types of movement detection sensors were embedded in different rooms. There was no CCTV inside the unit, which shows a change in individual units. It confirms that the developer listened to privacy concerns from $\mathrm{S}$ tower residents. From the beginning of its development, the tower did not consider using CCTVs in individual units, but increased the number of cameras in communal areas to reduce blind spots for security and safety reasons. The monitor looks more advanced, but it functions the same way as S tower's monitor, which is for checking visitors and contacting staff at reception.

A portable emergency pager is supplied to the GS tower residents rather than installing a nursing and emergency call system in public areas. The wireless device is based on Radio Frequency Identification (RFID) technology and can provide an instant emergency response without hazard spot in silver towns. However, the residents placed the pager in a drawer or hung it in a visible place because they do not activate it frequently. All emergency systems, such as emergency call systems and a portable pager, are connected to an emergency call monitor at the nursing unit to receive a simultaneous response in an emergency.

The monitor at the nursing or staff unit has other functions; for example, it verifies whether the residents are inside or outside their individual unit. All visitors should pass through reception when they enter the silver town, and the staff contact residents to confirm visitors. Thus, the function to check in-and-out status is considered a necessary system for security purposes. Moreover, the monitor shows how much electricity and water has been used by each unit. However, contrary to the developers' 
plan, seniors prefer that the silver town staff read the meter manually; therefore, the remote inspection function is used for reference.

\subsubsection{Descriptive analysis of GS tower's technology}

Table 6.6 Survey Respondents for Active Technology in GS Tower (People/\%)

\begin{tabular}{lcccccccc}
\hline \multirow{2}{*}{ GS tower } & \multicolumn{2}{c}{ Awareness } & \multicolumn{3}{c}{ Frequency } & \multicolumn{3}{c}{ Satisfaction } \\
& Aware & Unaware & Use & $*$ & Non-use & Satisfied & $*$ & Dissatisfied \\
\hline $\begin{array}{l}\text { Real-time health } \\
\text { check }\end{array}$ & $4 / 66.7$ & $2 / 33.3$ & $1 / 20$ & & $4 / 80$ & $4 / 80$ & $1 / 20$ & \\
$\begin{array}{l}\text { Nursing and } \\
\text { emergency call }\end{array}$ & $7 / 100$ & & - & - & $7 / 100$ & $5 / 71.4$ & $2 / 28.6$ & - \\
$\begin{array}{l}\text { Movement } \\
\text { detection sensor }\end{array}$ & $6 / 86.7$ & $1 / 14.3$ & $3 / 50$ & - & $3 / 50$ & $4 / 80$ & $1 / 20$ & - \\
$\begin{array}{l}\text { Portable } \\
\text { emergency pager }\end{array}$ & $7 / 100$ & - & - & - & $7 / 100$ & $4 / 57.1$ & $3 / 42.9$ & - \\
$\begin{array}{l}\text { Tracking } \\
\text { Card key }\end{array}$ & $5 / 71.4$ & $2 / 28.6$ & & & $5 / 100$ & $3 / 60$ & $2 / 40$ & \\
$\begin{array}{l}\text { Indoor air } \\
\text { quality }\end{array}$ & $7 / 100$ & - & $7 / 100$ & - & - & $7 / 100$ & - & - \\
CCTV & $6 / 85.7$ & $1 / 14.3$ & $4 / 66.7$ & $2 / 33.3$ & & $5 / 83.3$ & $1 / 16.7$ & \\
\hline
\end{tabular}

A similar pattern emerged within other silver towns, as illustrated by the perception of residents in GS tower regarding active technology. There was $100 \%$ awareness, but no one had used the nursing and emergency call system or the portable emergency pager. In this tower, the elderly residents returned the portable emergency pager to the staff because of non-use; therefore, the frequency rate shows $0 \%$. The indoor air quality system is also in high demand among GS tower respondents. All seven respondents were aware, used and satisfied with the card key. There was no dissatisfaction for any of the five active technologies in GS tower, although not all respondents were satisfied. 


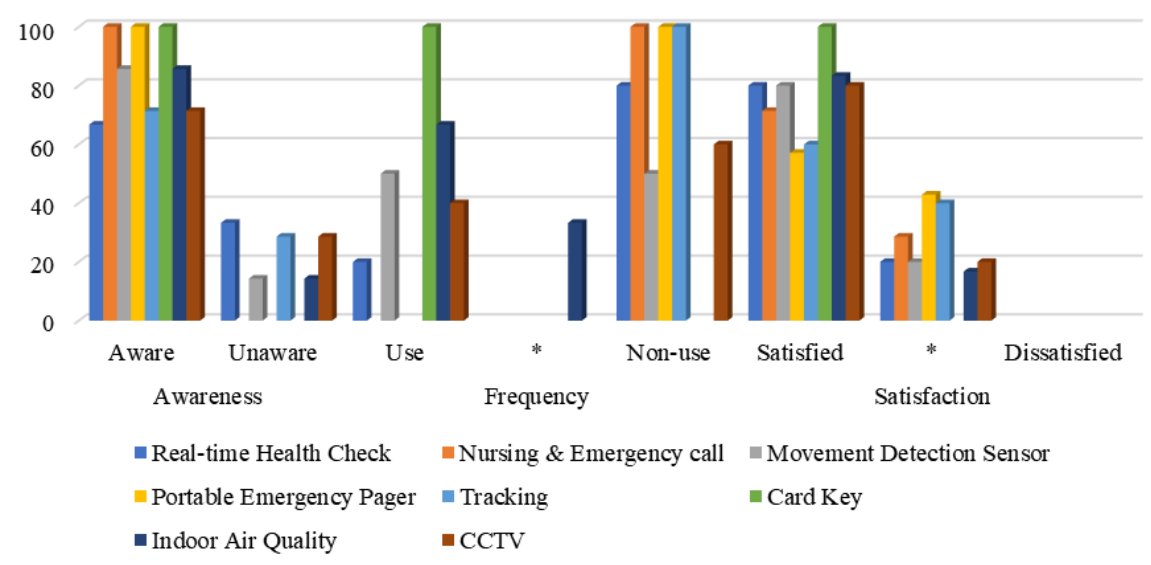

Figure 6.6. Survey respondents for active technology in GS tower.

GS tower respondents showed significant awareness in all active technologies and obvious selection of use or non-use by each technology has been illustrated, especially there are many $100 \%$ non-use technologies. Generally, there was high satisfaction and no dissatisfaction for any active or inactive technologies.

\subsection{B Tower}

\subsubsection{B tower unit plan and smart technology}

B tower was built in the same year as GS tower, but B tower is semi-urban and is located in one of Seoul's satellite cities, whereas GS tower is in the urban style and is located in Seoul. The unit size is, on average, larger than the previous two silver towns. The smallest unit size (approximately $41.5 \mathrm{~m}^{2}$ ) was similar to GS tower (around $38.6 \mathrm{~m}^{2}$ ), but the size gap was larger in relation to medium-sized units between $70.9 \mathrm{~m}^{2}$ for B tower and $55.2 \mathrm{~m}^{2}$ for GS tower. Unit sizes in B tower were also larger than $\mathrm{S}$ tower. The plan image below is medium and is around $80 \mathrm{~m}^{2}$. The $\mathrm{B}$ tower unit has two bedrooms, one living room and a two-bathroom unit for a couple. The residents had lived in the unit for around six years— since B tower had begun service — and had a well-organised space for their belongings. It was difficult to find any intentional interference between the household and technology, but some changes to technology were found in bedrooms, the entrance and the living room. First, the resident rolled up 
the string on the emergency call system in the bedroom, so it would not hang loosely. The residents did this because they had an experience with setting off the emergency alarm unintentionally and were immediately contacted by the nursing unit, which surprised them. The string and thermostat were located side by side in the main bedroom, and the string was close to the light switch in the second bedroom. It is effective to place switches in the same location, but it can sometimes create a false alarm through accidental touch. Considering the physical degeneration of the elderly and the emergency system's sensitivity, there is a greater chance that they will accidentally activate the system.

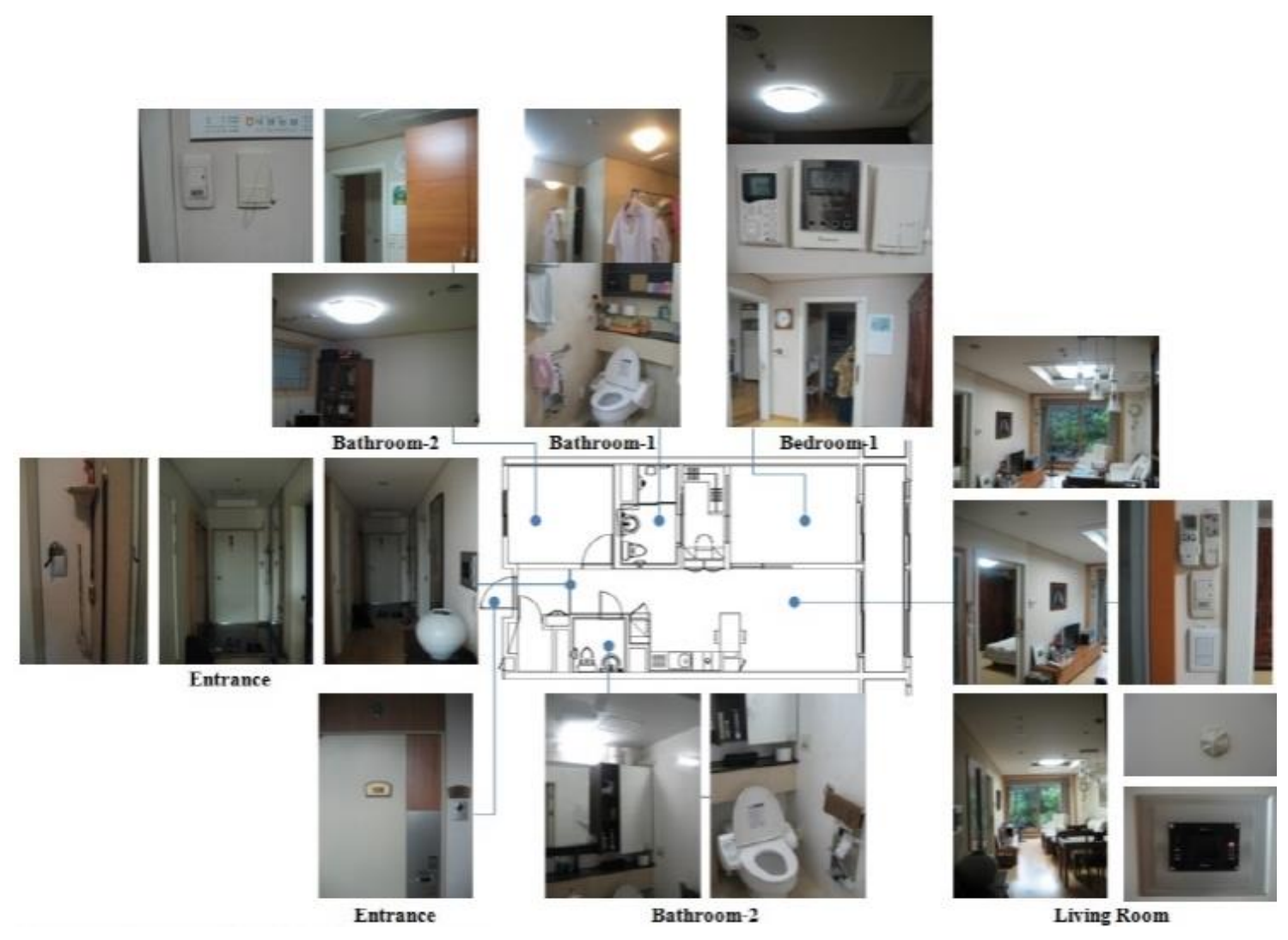

Figure 6.7. B tower unit.

Second, the elderly usually struggle with their memory; thus, the resident hung the pager next to the card key so they would not forget its location. As there are many technologies in close range inside the unit, elderly residents believe that the pager is 
only required outside the home. However, the reality is that they are usually hung on the entrance wall and overlook the pager because of non-use. From the developers' perspective, portable emergency pagers are given to seniors to carry around, but the usage frequency is extremely low. Lastly, one of the movement detection sensorsparticularly in the living room-is covered by paper. The sensor is located in the living room in front of the main bedroom. When the resident sits and watches TV or moves in and out of the room, there is visual interference because of the light flickering on the sensor. A red light blinks on and off with a slight ticking sound. When seniors enter or leave the main bedroom, the sensor responds to their movements by flashing, which irritates the elderly at night in terms of both light and sound.

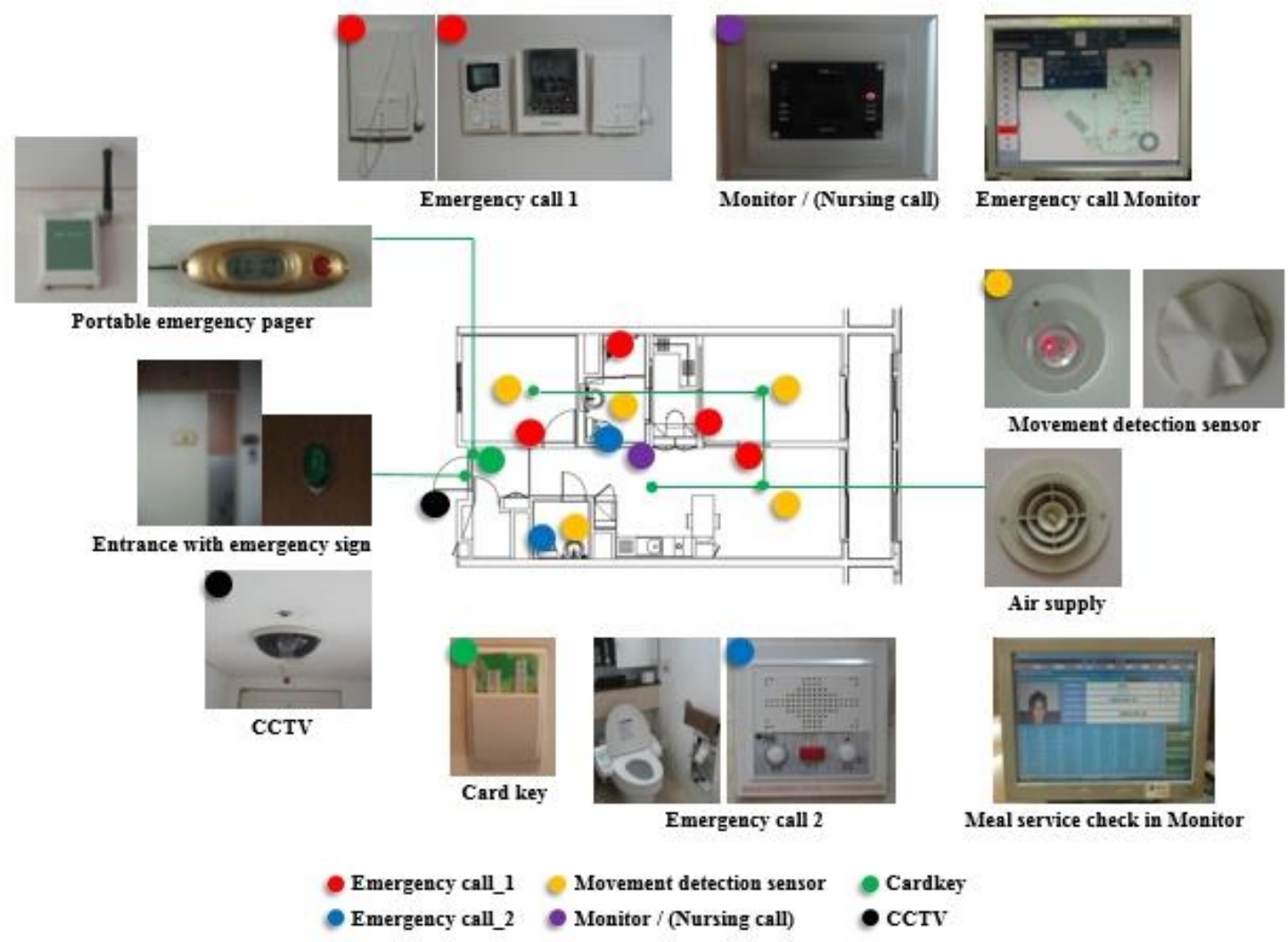

Figure 6.8. B tower with technology.

There are different types of nursing and emergency call systems in B tower. One is similar to GS tower (i.e., pull-and-push) and the other has an emergency button and a 
speak button next to the toilet to enable the elderly to communicate directly with a nurse. A monitor is located in the living room to combine the nursing and emergency call functions so the elderly can speak to clinic staff. Movement detection sensors are in every room. The thermostat is digital, which makes it easy for residents to control.

A portable emergency pager is also provided for seniors to carry so they can make an immediate report if there is an emergency. Once the resident activates the pager by pressing a button, the system receives a signal and places a mark on the emergency call monitor to inform the patient's name, their exact location and a brief medical record to assist in providing a better initial response. Simultaneously, the emergency alarm sign, which is located outside an individual unit, has a flickering light to lead paramedics or staff. The same monitor demonstrates a remote inspection function, but as at GS tower, it is used only for the same.

Further, a monitor installed in the dining area indicates whether elderly residents have eaten. If it appears that a senior resident has not eaten a meal, a staff member contacts them. When residents check in for a meal service, they need to tap their card key to the system, and then the staff can see their personal information and determine whether the seniors have additional needs or require a customised nutrition service.

\subsubsection{Descriptive analysis of B tower's technology}

Table 6.7 Survey Respondents for Active Technology in B Tower (People/\%)

\begin{tabular}{|c|c|c|c|c|c|c|c|c|}
\hline \multirow{2}{*}{ B tower } & \multicolumn{2}{|c|}{ Awareness } & \multicolumn{3}{|c|}{ Frequency } & \multicolumn{3}{|c|}{ Satisfaction } \\
\hline & Aware & Unaware & Use & $*$ & Non-use & Satisfied & $*$ & Dissatisfied \\
\hline $\begin{array}{l}\text { Real-time health } \\
\text { check }\end{array}$ & $8 / 80$ & $2 / 20$ & $1 / 10$ & $4 / 40$ & $5 / 50$ & $7 / 70$ & $3 / 30$ & \\
\hline $\begin{array}{l}\text { Nursing and } \\
\text { emergency call }\end{array}$ & $11 / 100$ & - & - & & $11 / 100$ & $11 / 100$ & - & - \\
\hline $\begin{array}{l}\text { Movement } \\
\text { detection sensor }\end{array}$ & $9 / 90$ & $1 / 10$ & $3 / 33.3$ & & $6 / 66.7$ & $7 / 70$ & $1 / 10$ & $2 / 20$ \\
\hline $\begin{array}{l}\text { Portable } \\
\text { emergency pager }\end{array}$ & $9 / 90$ & $1 / 10$ & - & & $9 / 100$ & $5 / 62.5$ & $2 / 25$ & $1 / 12.5$ \\
\hline
\end{tabular}




\begin{tabular}{lcccccccc}
\hline Tracking & $8 / 72.7$ & $3 / 27.3$ & & & $9 / 100$ & $7 / 77.8$ & $2 / 22.2$ & \\
Card key & $10 / 100$ & - & $11 / 100$ & - & - & $11 / 100$ & - & - \\
$\begin{array}{l}\text { Indoor air } \\
\text { quality }\end{array}$ & $9 / 81.8$ & $2 / 18.2$ & $2 / 25$ & $4 / 50$ & $2 / 25$ & $6 / 75$ & $1 / 12.5$ & $1 / 12.5$ \\
CCTV & $8 / 72.7$ & $3 / 27.3$ & $3 / 42.9$ & $1 / 14.2$ & $3 / 42.9$ & $3 / 37.5$ & $4 / 50$ & $1 / 12.5$ \\
\hline
\end{tabular}

B tower residents demonstrated $100 \%$ awareness and satisfaction in terms of the nursing and emergency call system and card key, but the card key showed $100 \%$ usage, whereas no respondents had used the nursing and emergency call system (see Table 6.7). Additionally, respondents had high awareness and satisfaction with the movement detection sensor and portable emergency pager, but none had previously used the pager. In contrast with $\mathrm{S}$ tower, the first three technologies showed higher satisfaction.

Portable emergency pagers were first supplied by B tower and have received relatively good reviews, even though they have not been used. The tracking system, which does not exist and apply, but is indicated as one of the portable emergency pager's functions by the elderly resident due to its wireless device, demonstrates the same pattern as the emergency pager. Indoor air quality also shows a similar trend of high awareness and satisfaction rate, indicating that it is considered a highly concerning aspect. Overall, B tower residents had significantly higher awareness and satisfaction compared with other silver towns. 


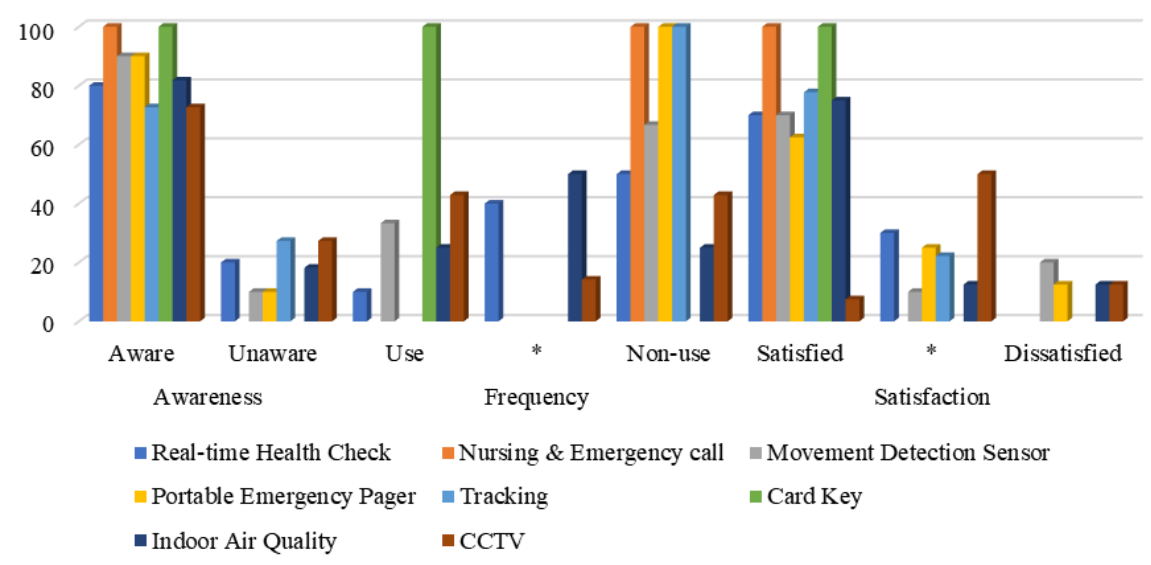

Figure 6.9. Survey respondents for active technology in B tower.

Except for the card key, other technologies have lower usage rates, but awareness and satisfaction figures lean to one side. Compared with S tower, awareness and satisfaction are similar, but frequency trends towards non-use. B tower is a semiurban-style silver town, which means that the tower has the advantage of natural ventilation, but the system is still a concern among active technologies, which proves how much the elderly residents value good air quality.

\subsection{GH Tower}

\subsubsection{GH tower unit plan and smart technology}

GH tower's plan shows a medium-sized unit and a one-bedroom unit. The unit includes one bedroom, a living room and a bathroom. Although there is only one bedroom, the dwelling size $\left(53.7 \mathrm{M}^{2}\right)$ is similar to that of GS tower's two-bedroom unit. The unit is currently occupied by a single female. The bathroom has a separate bathtub and shower to provide wheelchair accessibility, while other towers' units provide a shower on top of the bathtub or only a shower booth. There are some elderly-centred designs - for example, an adjustable basin in the bathroom and a foot valve to use the kitchen sink tap. Interestingly, the unit design includes a dressing room rather than a second bedroom. Moreover, to compensate for the smaller size, the entrance and living room are in a straight line to provide a wider view. 


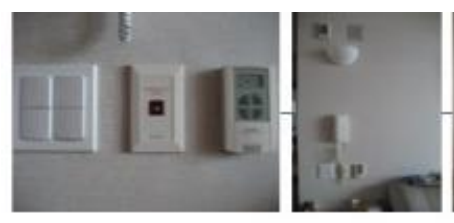

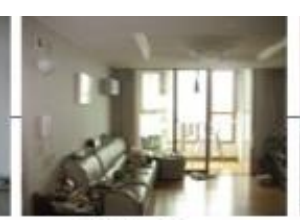

Living Room

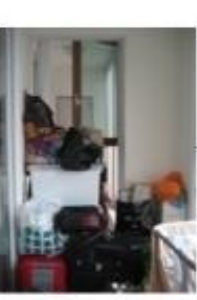

Terrace
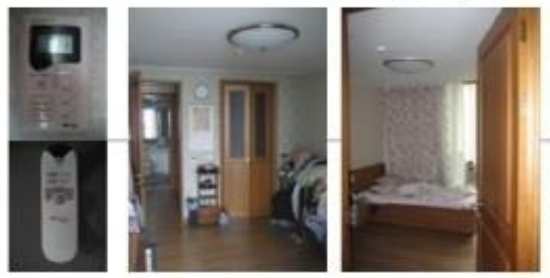

Bedroom

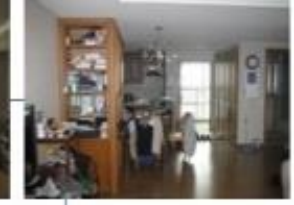

E) 1

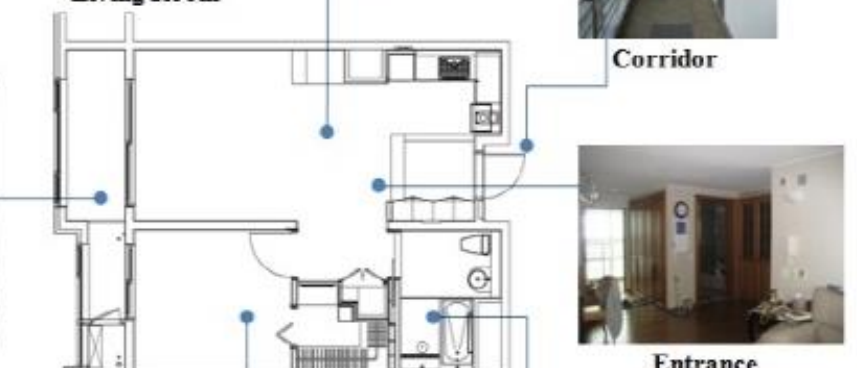

Entrance
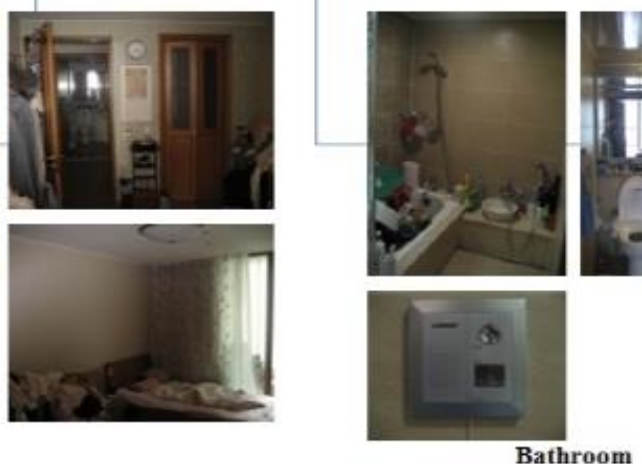

Figure 6.10. GH tower unit—case one.

The residents brought many belongings from their previous house. Thus, even though the unit has a separate storage space next to the main bathroom and a dressing room in a bedroom, there are many visible possessions. This did not present an obstacle for the smart systems in the living room and bathroom, which means that the senior cares for the smart systems, as instructed by the developer. However, there is an obstacle in the bedroom because of the position of the mattress, which slightly shadows the emergency call button. This shows that the button has not been pressed by the resident. Switches, a temperature controller and an analogue-style interphone are located on the wall of the living room, but the smaller size of the button-style emergency call seems to offer no false alarm situation by accidental press. In contrast with other silver towns, GH tower does not include a movement detection sensor in the bathroom, so lights and a ventilation fan are installed on the ceiling. Except for the 
string in the bathroom's emergency call system, there are no other strings but only simple button-style call systems and movement detection sensors; therefore, there are no personal technology modifications in this unit.

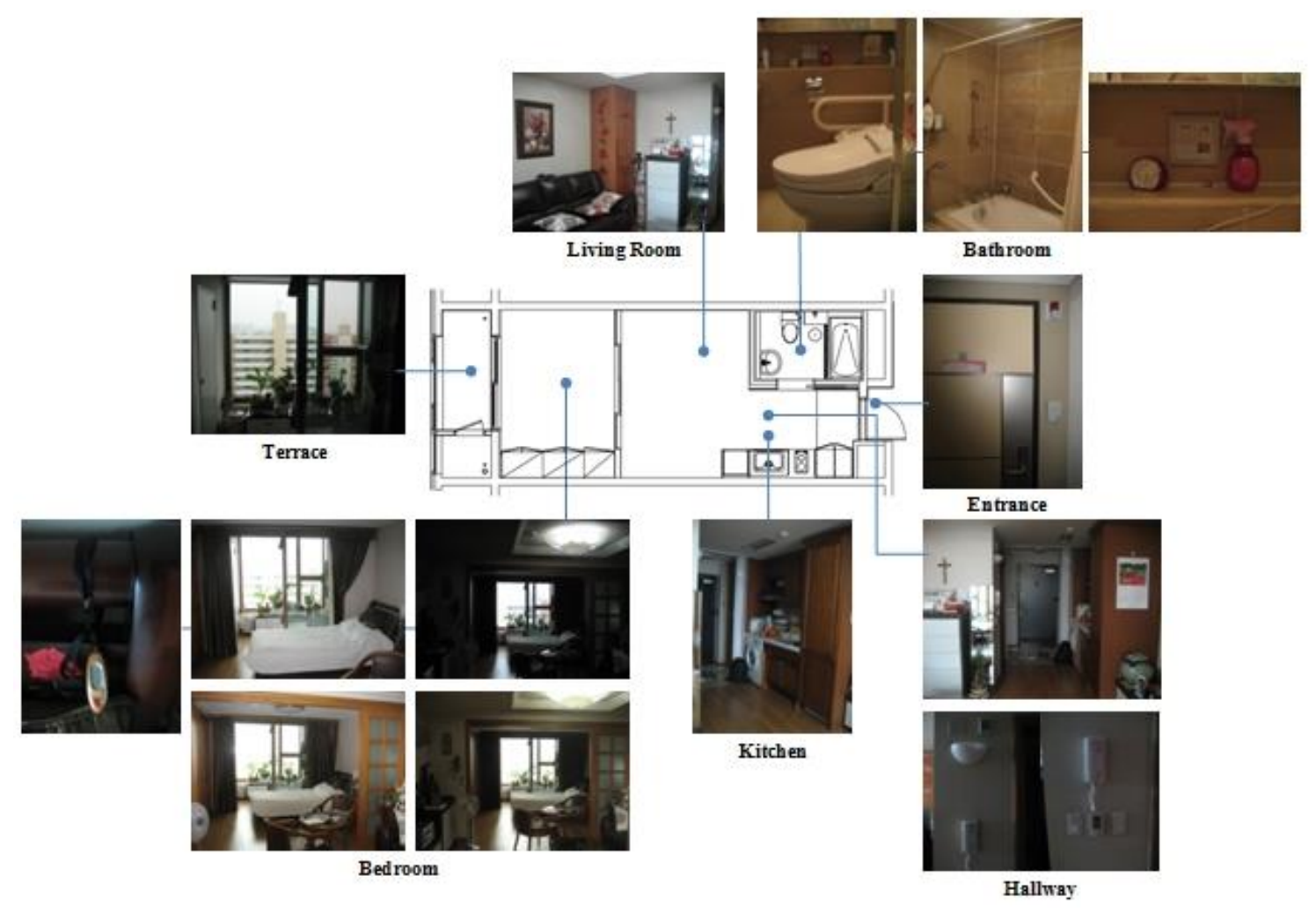

Figure 6.11. GH tower unit—case two.

The other GH tower plan represents the smallest type and only targets a single senior. The size is around $33 \mathrm{~m}^{2}$, which is a little smaller than the previous $\mathrm{S}$ tower plan. There is a nine-year gap between the building of GH tower and S tower. Since S tower's development, there has not been a single senior unit supply among selected silver towns but GH tower responds to the elderly demands in regard to space and price. It is a onebedroom unit consisting of one bedroom, a living room and a bathroom, but the terrace, bedroom and living room are in a straight line, so there are no windows in the living room. A single female resident occupies the unit and is relatively well organised with her belongings and spaces, as she mentioned that she had downsized her belongings. 
The unit contains simple smart technology systems, including two movement detection sensors, three emergency call systems and a portable emergency pager (see Figure 6.12). The senior resident is highly aware of the locations of the technologies, and the household is arranged so that there is no interference.

However, the nursing and emergency call button in the bedroom is hidden by the curtain, which the developer could easily catch the point that if the developer had considered the general culture of the older generation as having curtains for sliding door rather than blinds. The portable emergency pager is tied to the bedframe. The pager is offset by the hidden emergency call button, but the pager cannot be carried outside. Thus, even if the senior does not have a reason to use it, it should not be an alternative solution for both systems.

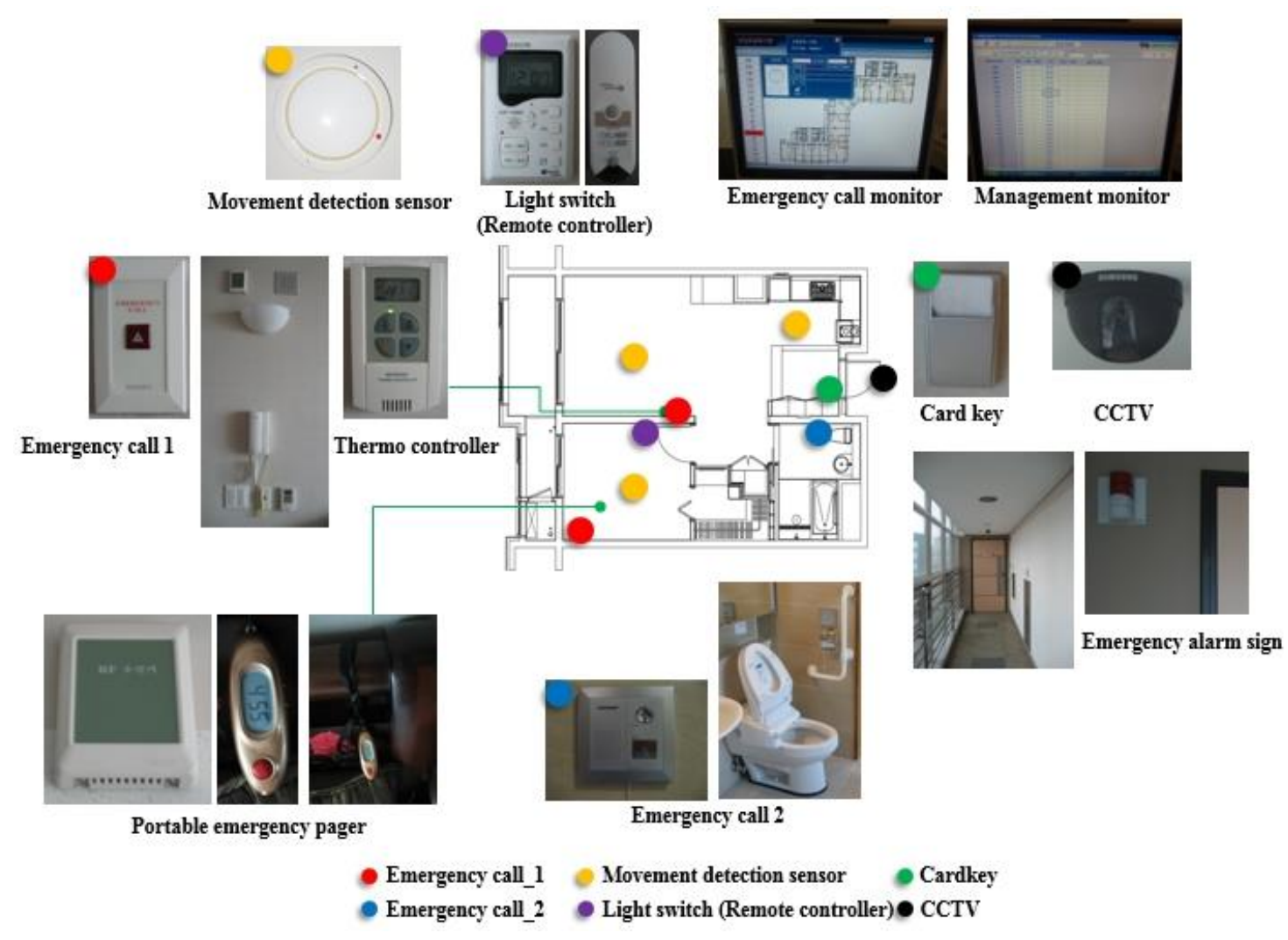

Figure 6.12. GH tower unit with technology.

GH tower services two types of nursing and emergency call systems. The first one is a button-type system in which the button is much smaller than that of other towns 
and is located in each room except for the bathroom. There is a concern that the seniors will miss the smaller size of the emergency contact button. The other type in the bathroom has three switches, including a button to speak with the nursing unit in the silver town and to signal an emergency, and a string to signal an emergency. Other selected silver towns, except $\mathrm{S}$ tower, apply two different types of movement detection sensors around the unit, but one type of movement detection sensor is installed in the living room, kitchen and bedroom. The same portable emergency pager as other silver towns operated by RFID is provided, but the resident always leaves the pager at home; thus, the wireless device has no purpose. A well-designed digital thermostat controller and a digital light controller are provided in the unit, but there is only an analogue monitor.

In contrast with other silver towns, there is no emergency call system both a button and a pulling style in the shower or bathtub area. There is only one emergency call system installed next to the toilet in the bathroom. In addition, there is no movement detection sensor in the bathroom area. Therefore, in total, only one nursing and emergency call system exists among the care-related technology systems. As a result, the only existing emergency call system provides an advanced and varied emergency contact, but the bathroom's safety level is a bit weaker than other selected silver towns in terms of the emergency call system.

A light switch in the living room area adds an alarm function. When the resident sets the timer, the light comes on as an alarm to wake the senior, and a remote controller provides a light control function in any place in the unit and stops alarm sounds from the light switch. It is a convenient device, but the elderly prefer to passively control lights. 
Additionally, the nursing and emergency call monitor, which is the same as B tower's emergency call monitor, is applied to respond immediately in an emergency. The management monitor illustrates elderly residents' in-and-out status for security and safety reasons, and the monitor has an additional function that shows the current room temperature to determine whether there is an abnormal temperature. In addition, the remote inspection system and monitor is ready, but it is only used as a secondary system because the elderly residents prefer a manual method of checking.

\subsubsection{Descriptive analysis of GH tower's technology}

Table 6.8 Survey Respondents for Active Technology in GH Tower (People/\%)

\begin{tabular}{|c|c|c|c|c|c|c|c|c|}
\hline \multirow{2}{*}{$\mathrm{GH}$ tower } & \multicolumn{2}{|c|}{ Awareness } & \multicolumn{3}{|c|}{ Frequency } & \multicolumn{3}{|c|}{ Satisfaction } \\
\hline & Aware & Unaware & Use & $*$ & Non-use & Satisfied & $*$ & Dissatisfied \\
\hline $\begin{array}{l}\text { Real-time health } \\
\text { check }\end{array}$ & $40 / 88.9$ & $5 / 11.1$ & $14 / 34.1$ & $9 / 22$ & $18 / 43.9$ & $32 / 80$ & $6 / 15$ & $2 / 5$ \\
\hline $\begin{array}{l}\text { Nursing and } \\
\text { emergency call }\end{array}$ & $42 / 91.3$ & $4 / 8.7$ & - & $2 / 4.8$ & $40 / 96.2$ & $23 / 57.9$ & $13 / 34.2$ & $3 / 7.9$ \\
\hline $\begin{array}{l}\text { Movement } \\
\text { detection sensor }\end{array}$ & $22 / 68.8$ & $10 / 31.2$ & - & & $6 / 100$ & $1 / 20$ & $2 / 40$ & $2 / 40$ \\
\hline $\begin{array}{l}\text { Portable } \\
\text { emergency pager }\end{array}$ & $36 / 86.7$ & $6 / 14.3$ & - & - & $35 / 100$ & $12 / 38.7$ & $9 / 29$ & $10 / 32.2$ \\
\hline Tracking & $6 / 17.1$ & $29 / 82.9$ & & & $9 / 100$ & $5 / 62.5$ & $1 / 12.5$ & $2 / 25$ \\
\hline $\begin{array}{l}\text { Remote } \\
\text { inspection }\end{array}$ & $20 / 71.4$ & $8 / 28.6$ & $1 / 12.5$ & $2 / 25$ & $5 / 62.5$ & $3 / 50$ & $3 / 50$ & - \\
\hline Card key & $46 / 100$ & - & 43/93.4 & $3 / 6.5$ & - & $40 / 87$ & $4 / 8.7$ & $2 / 4.3$ \\
\hline $\begin{array}{l}\text { Indoor air } \\
\text { quality }\end{array}$ & $5 / 19.2$ & $21 / 80.8$ & $3 / 42.8$ & $2 / 28.6$ & $2 / 28.6$ & $4 / 66.7$ & $2 / 33.3$ & \\
\hline $\begin{array}{l}\text { Light } \\
\text { control/Energy } \\
\text { saving }\end{array}$ & $24 / 63.2$ & $14 / 36.1$ & $20 / 74.1$ & $2 / 14.8$ & $3 / 11.1$ & $20 / 74.1$ & $6 / 22.2$ & $1 / 3.7$ \\
\hline CCTV & $31 / 70.5$ & $13 / 29.5$ & $1 / 3.3$ & $1 / 3.3$ & $28 / 93.3$ & $18 / 64.3$ & $10 / 36.7$ & - \\
\hline
\end{tabular}

The number of survey respondents was significantly larger than for the other silver towns, but a similar trend was demonstrated in all categories for all ten technologies. For instance, there was a relatively high perception of all active systems, but extremely low frequency in usage. More than $90 \%$ of respondents said that they did 
not use CCTV, which means that only a few people had experienced the benefits of CCTV. The result of the tracking system illustrates a significantly different trend; most of the elderly were not aware of the tracking system and it is a quite accurate description because the system does not exist but is misunderstood by the elderly residents. Satisfaction with the card key was high, but slightly lower than for other silver town respondents, suggesting that some respondents had an issue with card key replacement or malfunction. The indoor air quality system also showed opposite awareness rates compared with other silver towns. Survey participants understood that the indoor air quality system was a more advanced, all-in-one control system. When the elderly could not understand the systems or were unsure about the smart technology, the number of respondents dropped sharply. For example, there were 46 respondents for card keys, which are used every day, and fewer than 30 for remote inspection and indoor air quality systems.

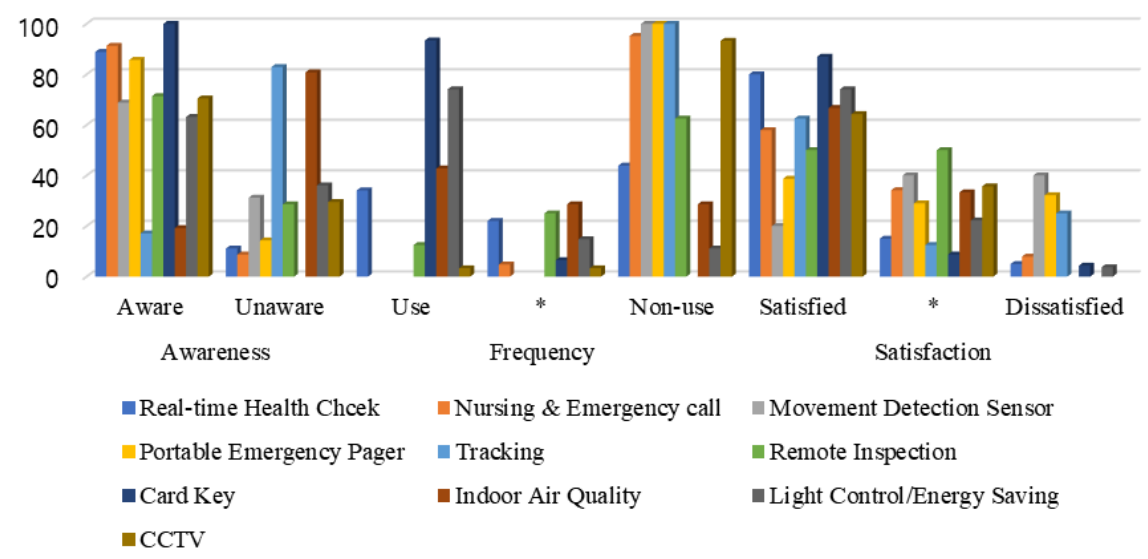

Figure 6.13. Survey respondents for active technology in GH tower.

GH tower also shows similar patterns of awareness, frequency of use and satisfaction, but light control/energy saving, which is only applied in GH tower, has a high usage rate. Sleep mode, timer mode and a remote controller that can control lights in the main bedroom was applied in the tower, and it is questionable whether the high 
frequency comes from these functions because the interviewee preferred to control the lights manually. Further, many residents understand that the card key can be considered an energy-saving system because of its ability to control electricity.

\subsection{GY Tower}

\subsubsection{GY tower unit plan and smart technology}

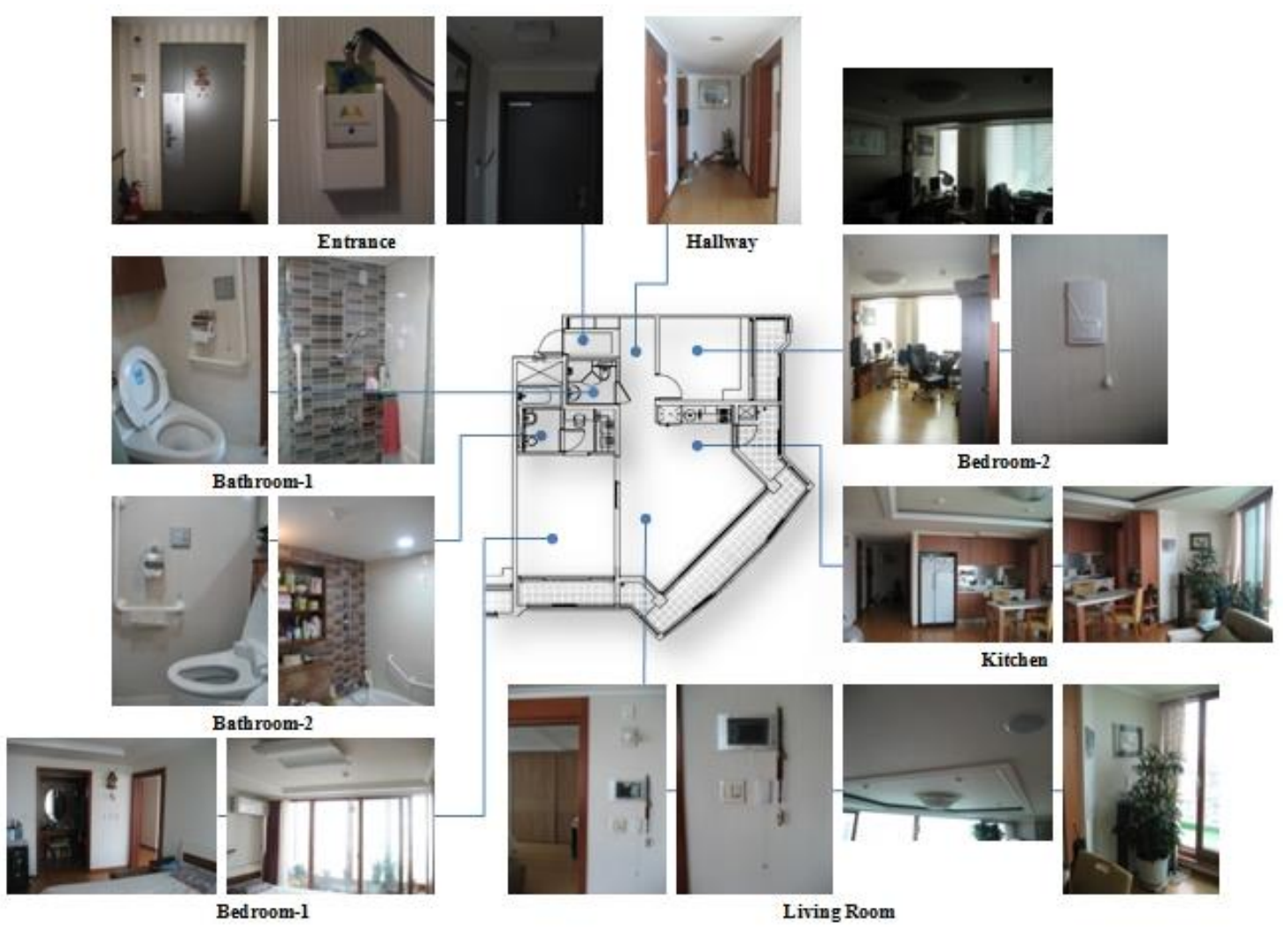

Figure 6.14. GY tower unit—case one.

Overall, the GY tower unit plans illustrate some changes to the layout and size, and GY tower supplies the largest number of units (total 419 units), including intensive care units (ICUs). S tower supplies studio and one-bedroom units, but there is no longer a studio layout, except for the ICU at GY tower. In addition, there are more onebedroom units to target single residents, two-bedroom units for couples and up to three bedrooms for couples. The unit layout and plan is usually similar to general apartments, but there are some elderly-centred details in the design. A significant number of 
belongings brought from previous dwellings influences changes in the unit size. The largest-sized unit at $\mathrm{S}$ tower has become similar to the smallest-sized units in other silver towns as developers provide diverse unit types.

The presented plan is a pentagonal design and is a medium-sized unit of around $84.7 \mathrm{~m}^{2}$ among GY tower units. It is larger than units in GS tower and GH tower, and it has a similar space configuration of two bedrooms, two bathrooms and a living room, similar to B tower. The side units use a three-bay plan design, and the two bedrooms and the living room have access to a wide range of terraces. The unit introduces a dressing room — the same as in the GH tower unit—which is also popular in general apartments.

A relatively larger space enables senior residents to make well-arranged spaces. However, there are some disturbances and changes in accessibility of the systems and to prevent false alarms respectively. In the living room, the pull-and-push nursing and emergency call system is blocked by a plant and a speaker. Having another emergency call button for better accessibility in urgent situations delivers peace of mind, but the location of the call button needs to be optimum from the unit design stage. The portable emergency pager hangs on a monitor's antenna because its hanging location gives the best accessibility and visibility in case of emergency, but the residents hang it there because it is not used at the moment. The monitor has a slightly updated function from B tower because it enables direct vocal communication with the nursing unit. There is a pull-and-push emergency call system at the bottom of the monitor. Therefore, three devices that have the same emergency contact function are in the same place. The residents understand the function of each system, but they have not had to make urgent contact. 
The residents attached adhesive tape to the string of the nursing and emergency call system in the second bedroom, which is currently being used as a study, because the string attached to the system conflicted with the household. A built-in wall closet covers a whole side of bedroom one; as a result, a pull and button-type emergency call is concealed by the furniture. This demonstrates that the system was not on the radar of the elderly when they moved in, and the residents' healthy condition and downsizing resulted in non-use. In addition, the developer applied the long string in emergency call unit in bathroom two, hung down to the bathtub to enable it to be reached if the elderly fall while taking a shower. However, the residents knotted the string because it kept moving and it is easy to activate because of its sensitivity.

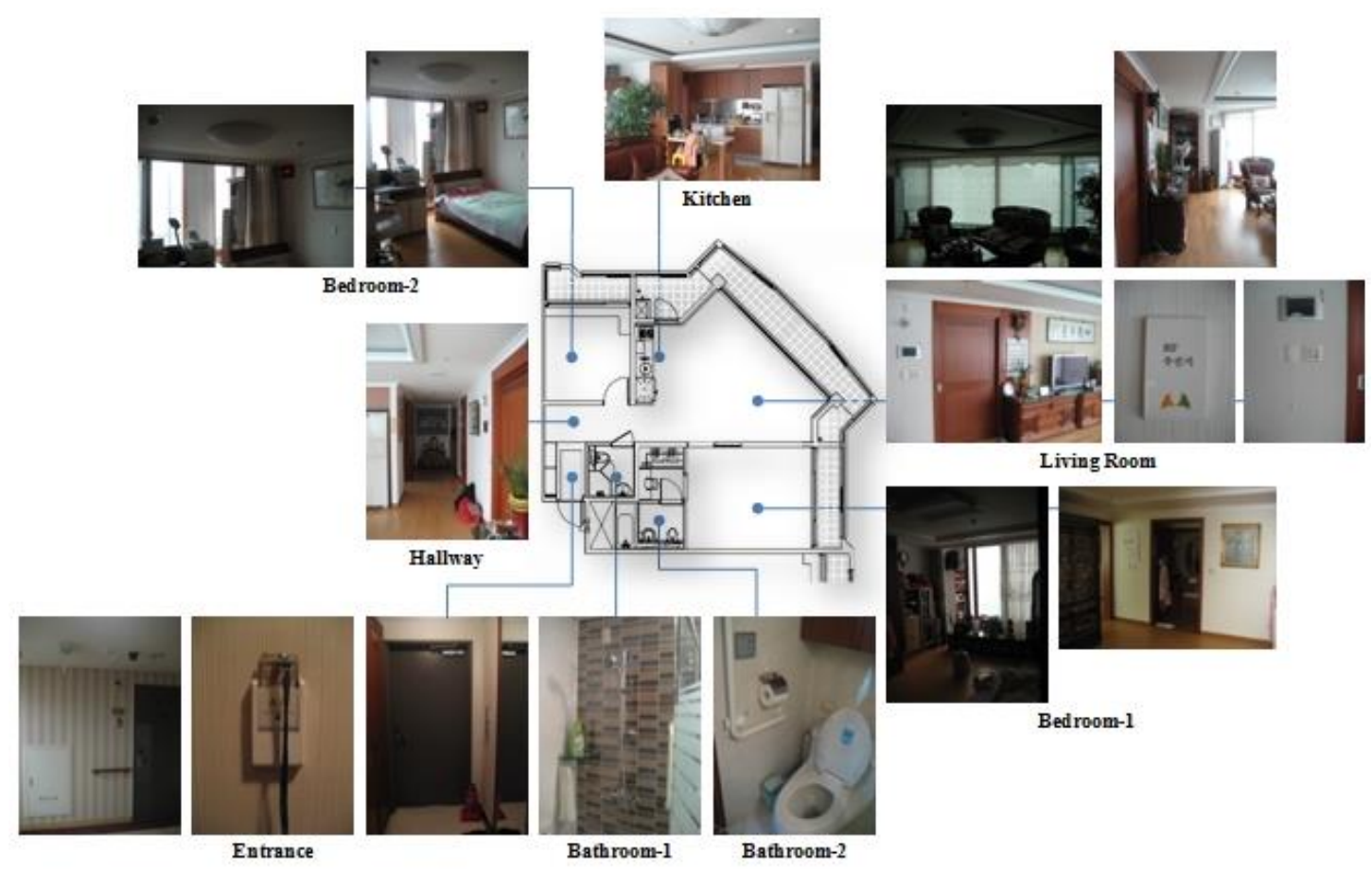

Figure 6.15. GY tower unit—case two.

The unit is the same size as that of the other GY tower unit in Figure 6.15.

However, the residents possess more household than the other resident, despite the large unit size. The unit also consists of two bedrooms, two bathrooms and a living room. The 
elderly-friendly design includes an adjustable basin and a wall-attached chair in the bathroom one shower.

Bathroom one does not have any interference caused by belongings; the elderly residents allow the string to hang to its full length, whereas many other residents tie a knot to make the string shorter. However, the string in bathroom two has been knotted. If both emergency call systems in the two bathrooms were located in a lower position than the current one, the button and the string could be used selectively by the seniors in an emergency, and a shorter length of string could be supplied to prevent modification of the smart technology.

There are other impediments to the systems in the living room and main bedroom. The nursing and emergency call system in the corner of the living room is obstructed by a plant, and a sofa and a dining table block the path; therefore, it would be difficult to reach the call system in an emergency. The two-bedroom images above illustrate that many households do not consider limited room space. In the main bedroom, many belongings are stacked up, and a couple of furniture pieces obstruct the walls where the nursing and emergency call system is installed; thus, one of the emergency systems cannot be accessed.

The portable emergency pager is not included in any pictures of this unit because the senior residents keep it in a drawer in the living room because they have not activated it. They feel as though they might need it someday, but currently they do not use it. 


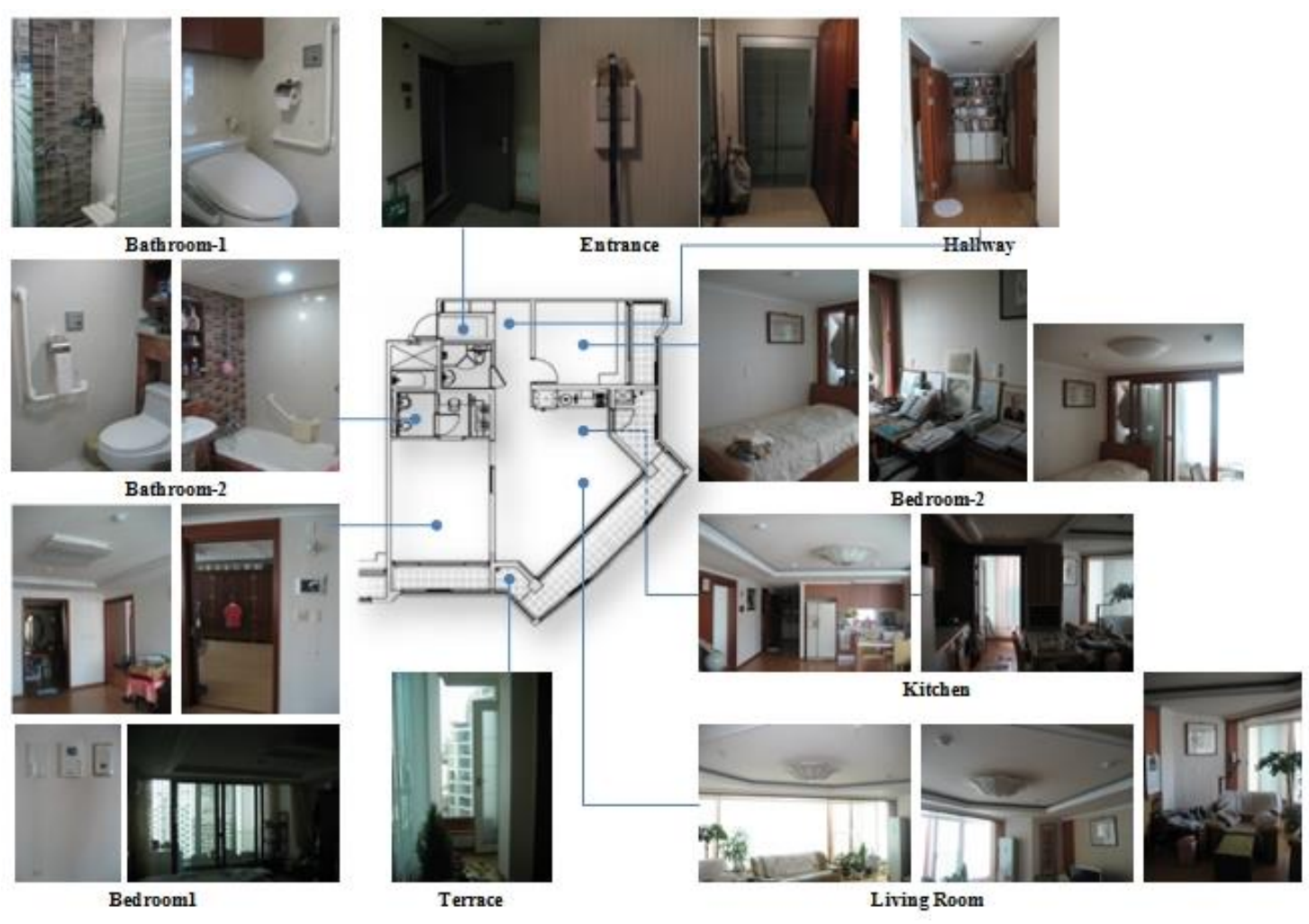

Figure 6.16. Image of GY tower unit—case three.

The unit is the same size as the two GY tower units in Figures 6.14 and 6.15.

The residents have organised this household better than the other residents in the same unit size, which is the result of giving away many of their possessions before moving in. The unit comprises two bedrooms, two bathrooms and a living room. The same seniorfriendly design found in the other GY tower units is also applied.

Bedroom two shows the bed next to the emergency call system. The resident is in relatively good health condition and has not yet experienced an emergency. The senior thinks a possible emergency could occur while he sleeps at night. It is a good example of clearing visibility and accessibility by what the user expects regarding potential hazardous cases. However, it could be a controversial example that according to the statistical data from Korea Consumer Agency's Consumer Injury Surveillance 
System, ${ }^{161}$ slip and fall were the major negligent accidents happening to the elderly inside the home; therefore, it could be said that securing a clear path to access the emergency call system provides a better chance to activate the system. In the same room, the other emergency contact system placed on the other side of the wall appears to have a clear view, but it is obstructed by a desk and picture frames; thus, if the resident falls, it would be difficult to pull or press the emergency system.

Both emergency call systems next to the shower are situated in a high position. In an emergency, the residents would not be able to reach the button. It seems that other technologies are being advanced in silver town developments, but the emergency system in both bathrooms has fallen behind. Strings have been knotted to prevent disturbances during showers. The string in bathroom one has been shortened as much as possible; thus, this system is out of service.

An emergency call system in the living room appears to be clear of obstructions; however, the path is blocked by a sofa, a side table and a dining table. Therefore, it can hardly be counted as an emergency call system. Similar to GY tower case one, the seniors incorporated built-in furniture when they moved in, which completely covers an emergency call system. This shows that no attention is paid to smart technologies at the beginning of the dwelling — even if they are health-care-related — because of a lack of space for the household.

161 Consumer Injury Surveillance System of Korea Consumer Agency 2013, An analysis of safety accident of the elderly, viewed April 2017, http://www.ciss.go.kr/www/index.do. 


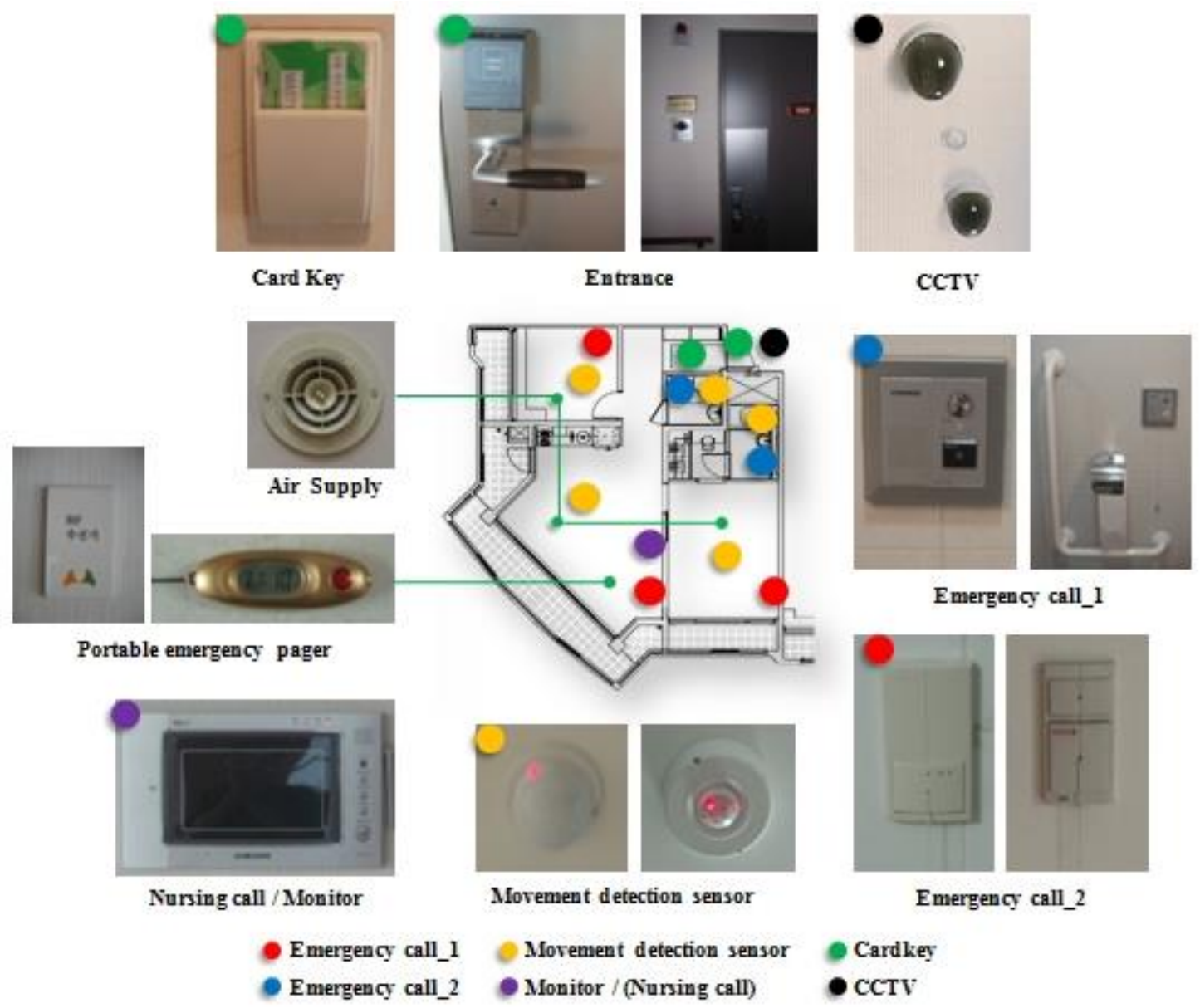

Figure 6.17. GY tower unit with technology.

GY tower also presents two types of nursing and emergency call systems. The one in the bathroom is the same as in GH tower, with multi-functions, and the other one is the same as in B tower, with a combined pull-and-push device. These systems are placed in two bedrooms, and there are two call systems in both bathrooms and the living room.

\subsubsection{Descriptive analysis of GY tower's technology}

Table 6.9 Survey Respondents for Active Technology in GY Tower (People/\%)

\begin{tabular}{|c|c|c|c|c|c|c|c|c|}
\hline \multirow{2}{*}{ GY tower } & \multicolumn{2}{|c|}{ Awareness } & \multicolumn{3}{|c|}{ Frequency } & \multicolumn{3}{|c|}{ Satisfaction } \\
\hline & Aware & Unaware & Use & $*$ & Non-use & Satisfied & $*$ & Dissatisfied \\
\hline $\begin{array}{l}\text { Real-time health } \\
\text { check }\end{array}$ & $19 / 90.5$ & $2 / 9.5$ & $10 / 50$ & $5 / 25$ & $5 / 25$ & $16 / 80$ & $4 / 20$ & \\
\hline $\begin{array}{l}\text { Nursing and } \\
\text { emergency call }\end{array}$ & $23 / 100$ & - & - & $1 / 4.3$ & $22 / 96.7$ & $19 / 90.5$ & $2 / 9.5$ & - \\
\hline
\end{tabular}




\begin{tabular}{|c|c|c|c|c|c|c|c|c|}
\hline $\begin{array}{l}\text { Movement } \\
\text { detection sensor }\end{array}$ & 20/90.9 & 2/9.1 & $4 / 22.2$ & $3 / 16.7$ & $11 / 61.1$ & $4 / 22.2$ & $3 / 16.7$ & $11 / 61.1$ \\
\hline $\begin{array}{l}\text { Portable } \\
\text { emergency pager }\end{array}$ & 20/90.9 & 2/9.1 & - & - & $20 / 100$ & $12 / 63.2$ & $7 / 36.8$ & - \\
\hline Tracking & $17 / 77.3$ & $5 / 22.7$ & & & $18 / 100$ & $9 / 56.3$ & $7 / 43.7$ & \\
\hline $\begin{array}{l}\text { Remote } \\
\text { inspection }\end{array}$ & $14 / 66.7$ & $7 / 33.3$ & $2 / 14.3$ & $4 / 28.6$ & $8 / 57.2$ & $12 / 80$ & $3 / 20$ & - \\
\hline Card key & $21 / 100$ & - & $22 / 100$ & - & - & 20/90.9 & $1 / 4.5$ & $1 / 4.5$ \\
\hline $\begin{array}{l}\text { Indoor air } \\
\text { quality }\end{array}$ & $14 / 66.7$ & $7 / 33.3$ & $6 / 35.3$ & $3 / 17.6$ & $8 / 47.1$ & $8 / 53.4$ & $5 / 33.3$ & $2 / 13.3$ \\
\hline CCTV & $12 / 57.1$ & $9 / 42.9$ & $3 / 25$ & $3 / 25$ & $6 / 50$ & $9 / 69.2$ & $2 / 16.4$ & $2 / 16.4$ \\
\hline
\end{tabular}

In GY tower, the movement detection sensor indicated a high awareness rate, but it unexpectedly showed the highest dissatisfaction rate (slightly more than $60 \%$ ). No seniors had used the portable emergency pager. Similar to GH tower, a couple of residents were not happy with the card key system. In terms of the indoor air quality system, there is higher awareness from GY tower respondents than GH respondents, but after comparing them with other silver town participants, it is a relatively low perception. The tracking system, which is misunderstood by the senior residents as part of a portable emergency function, shows similar figures to the pager.

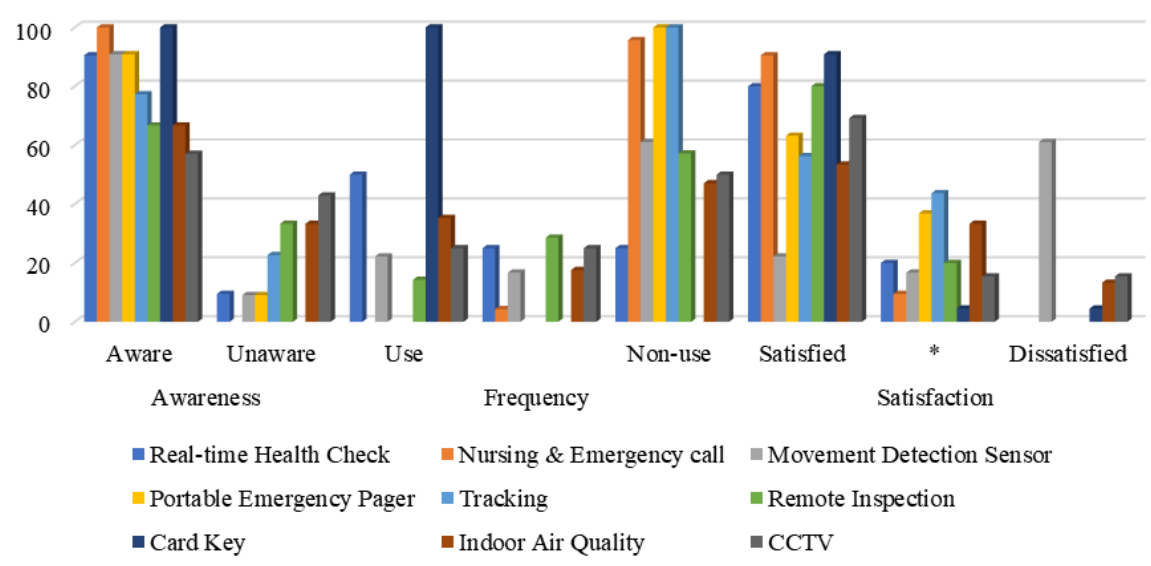

Figure 6.18. Survey respondents for active technology in GY tower.

Slightly more than $60 \%$ of dissatisfaction derives from movement detection sensors, which is one of the greatest concerns of elderly residents. 


\subsection{Summary}

From unit observation, the nursing and emergency call systems are in bedrooms, bathrooms and living rooms, and bathrooms usually have two types of call systems. One is on the side of the toilet and the other is in the shower or bathtub; however, GH tower's bathroom has only one call system next to the toilet. S tower only installed button-style systems in its units. The next silver town introduced the pull-and-push system, which was followed by the nursing and emergency call system that includes pull, push and speaking functions and is embedded next to the toilet. A string on the pull-and-push emergency call system is usually tied up or knotted to prevent accidental activation, which has caused false alarms. Some residents have brought many belongings from their previous dwellings, which interferes with the call system in the living room and bedrooms. S tower places emergency call buttons outside of the unitmostly in public corridors at regular intervals - to allow elderly residents to push it in an emergency.

Two types of movement detection sensors, similar to GS tower, are embedded in the living area, two bedrooms and two bathrooms. The portable emergency pager uses a simplified design for the radio frequency receiver. The digital monitor, which includes the nursing and emergency call function, is in the living room.

The location of movement detection sensors is generally the same as the nursing and emergency call system. There is usually one sensor located in the bathroom, but GH tower did not install sensors. Newly built silver towns show similar-shaped sensors, but they use a simplified and different design. Some residents cover the sensor to hide the light that flashes when it detects elderly movement.

As the most recent silver town development among those selected, the CCTV coverage rate is greater than in other silver towns. The installation of more CCTVs, 
which will decrease hazard spots and increase the safety of the elderly, is still in progress.

CCTVs were installed inside units in S tower, but they disappeared from the next development. However, silver towns use more CCTV outside of units as a type of security technology. The images of monitors show an improvement in their design and function. Various monitor types have been used in the selected silver towns, from analogue to digital, and including additional nursing and emergency call systems. Dial thermostats to fully digitised thermostats are installed in various silver towns.

Portable emergency pagers are wireless devices based on RFID technology. Pagers are not supplied at $\mathrm{S}$ tower, which uses nursing and emergency call systems in communal areas. From GS tower to GY tower, pagers enable elderly residents to move confidently around the silver town. However, the images show that the seniors leave their pager at home. They hang it on the wall in the living room or in the entrance area, or they tie it to the bedframe. This indicates that residents do not carry the pager all the time, but they keep it close or place it in a conspicuous place as a substitute for the nursing and emergency call system.

The card key must always be placed in a card key holder at the entrance to supply electricity to the unit. However, the elderly have worked out that the card key can be replaced with a similar-sized card, such as a business card or parking ticket. In addition, they keep the authorised card key in a cloth pocket or purse, as it is a multifunctional card that can be used at other facilities or for meal services. This increases the risk of fire, a security breach or difficulties in management work from the perspective of developers.

On-site staff and the nursing unit have computer monitors to support the elderly. First, when seniors activate the emergency system, a screen displays the exact location 
and the patient's medical record with alarm sounds. Second, a monitor shows whether the resident is in their unit or outside, and the current room temperature is displayed to show whether there is a higher temperature.

From the descriptive analysis, high awareness of all active technologies in all selected silver towns indicated that many residents were concerned about smart systems in relation to care, security and safety issues, even though there was no direct use or constant observation of systems such as movement detection sensors and CCTV. Few residents were unaware of the active technology because they did not use these systems and therefore did not consider possessing them at home.

Frequency of use illustrated that the systems were rarely activated, excluding the card key. Senior residents did not need to use the systems because their health condition was not as bad as that of people in the ICU. Further, false alarms caused by accidental activation ensured that users were careful with the systems. However, this does not mean that the technology is useless or does not work properly, but that it is available in case of an emergency.

Compared with other categories, which represent a clear understanding (e.g., aware or unaware and use or non-use), satisfaction does not correspond with the awareness rate for some technologies. For example, two-thirds of awareness proportions has been displayed on many technologies, but less than half of satisfaction come up at some technology systems. More specifically, only one respondent from S tower was not aware of the card key system, although it was used as a door key and for many other functions every day. However, in total, nine residents were dissatisfied with the card key. This implies that more work is required so the residents are not dissatisfied.

The real-time health check system was tested at $\mathrm{S}$ tower only at the beginning of its development. The computer and devices still exist in the nursing unit, but they are no 
longer applied in silver town developments, including S tower. However, the elderly respondents had a high response rate because they misunderstood the service to provide complementary medical support from the on-site clinic or an affiliated general hospital within walking distance. Moreover, the tracking system, which was never intended or applied by developers, is also misunderstood as one of the portable emergency pager's functions by elderly residents. The interviewees confirmed the importance they placed on the quality of indoor air.

\subsection{Discussion}

Survey respondents' demographic data show that dwelling period and average age are not linked. The elderly are likely to stay in one place when they feel that they have settled down; therefore, it was predicted that residents with a longer dwelling period would have an older average age. For example, $S$ tower residents have lived in the tower for more than seven years on average, and GY tower residents have dwelt in the building for less than two years. However, the average age of the two towers' residents is very similar.

Generally, selected silver towns have a similar but slightly different number of smart technology systems. Around 15 types of technology were advertised by silver town developers, including eight applied technologies in GH tower and seven in $\mathrm{S}$ tower, as well as five active technologies in $\mathrm{S}$ tower and six in GH tower. A smaller number of smart technologies are in operation in each silver town compared with intentionally applied technologies by developers. Further, senior residents used fewer technologies during their stay.

Respondents' understanding of each technology demonstrates a gap of intended purpose and patterns of use between the developers and users. For instance, the realtime health check system was an experimental system for smart and remote medical 
services at $\mathrm{S}$ tower, but the data showed high awareness and satisfaction rates in all selected silver towns. The portable emergency pager case also illustrates high awareness, but with a lower satisfaction rate. It is explained by $0 \%$ frequency, excluding three S tower respondents who had not used the pager yet or who were not content with it. Another example is CCTV, which is installed throughout silver towns for security and safety reasons. It has a high perception rate but low frequency and various satisfaction rates. Low frequency indicates that direct or indirect support or assistance is required to find something. In addition, higher dissatisfaction at $\mathrm{S}$ tower is affected by CCTV applied inside individual units, which is a privacy concern. In general, from the descriptive data regarding each smart technology, high frequency of use leads to high satisfaction, whereas high awareness is not associated with high satisfaction and frequency rates.

Site observation — especially of individual units — illustrates actual interactions between smart technology and senior residents, changes in spatial layouts or space and the intended purpose of technology installation, and patterns of use of the elderly through unit plans and photos. There are many obstacles between the seniors' household and smart systems because residents brought too many possessions from their previous dwellings and they have not used the technology since they moved in.

Further, the older generation did not know how much their living in the silver town would be attached to smart technology. For example, one resident had furniture that covered the full side of one wall, where the developer had placed a nursing and emergency call system. Further, residents hung their portable emergency pager on a wall or a bed frame and did not take it out when they left their unit. Additionally, the seniors modified the smart technology to prevent false alarms. Some button-pull-type nursing and emergency call systems embedded high in the bathroom cannot be reached 
by the elderly; thus, the button becomes useless. A string attached to the system can be used; however, the string is too long and sensitive and can cause a false alarm.

Therefore, the residents tie a knot in it, which makes the system meaningless because they cannot activate it if there is an emergency.

Current silver town unit plans are similar to general apartments, but they are smaller. The latest silver town developments supply larger units, but most are still smaller than the residents' previous dwelling. Therefore, this creates difficulties in terms of residents' possessions and technology systems, and it forces seniors to make an obligate allocation of their furniture in positions that conceal the system.

Spatial layout must also change to meet with the older generation's character and patterns of use of smart technology. The change needs to consider preferences for spatial usage by using smart technology to extend seniors' boundaries.

\subsection{Conclusion}

The images and representative unit plans at each silver town showed changes that have taken place in relation to unit plans, layouts and sizes. In the ten-year gap between S tower and GY tower, improvements were made to the elderly-centred architectural design based on users' demands, but there are not many differences due to smart technology systems yet. Images of current individual units illustrate how the elderly use their living environment and how technology and seniors' living patterns and households cause interference. More significantly, active technology and other attached systems or programmes on the selected unit plans were pinpointed to increase the understanding of their features and placement, and they demonstrate how smart systems are being integrated by developers and used by elderly residents.

The survey explored the selected silver towns' features and details to determine their status, elderly respondents' characters and the perceptions of the elderly regarding 
awareness, their usage rate and satisfaction with active technologies. Higher awareness for all active technology supports seniors' interest in smart systems to assist their living. In contrast, lower-frequency use means that there are no opportunities to activate the smart systems because the residents are relatively fit or they are dissatisfied with them. Various levels of satisfaction with smart technology show that there are many different concerns and demands regarding applied technology. These results present emerging issues of the elderly-only living environment in relation to the range of applied technology, gaps of intended purpose and patterns of use of smart devices.

The research has uncovered considerable issues from the analysed survey data, site observations and interviews, and these issues need to be examined before discussing the further development of silver towns. Chapter 7 compares the analysed data to extract probable discussion aspects, and it explores possible challenges resulting from selected silver towns integrated with current technology from the elderly perspective. 


\section{Chapter 7: Discussion}

\subsection{Introduction}

Chapters 5 and 6 analysed the elderly living environment (i.e., silver towns) integrated with smart technology support from the elderly perspective. Chapter 5 outlined the current elderly residents' character and their interest in modern technology and its development to obtain a better understanding of the patterns of use of applied smart technology. In addition, it analysed senior residents' perspectives regarding silver towns to uncover changes in their living environment since they moved in.

Chapter 6 provided an extensive understanding of the elderly perspective in relation to silver town environments embedded with smart technology systems. Diverse patterns and the design of smart system usage, as well as differences in intended usage, were underpinned by the analysis of active and inactive technologies based on the elderly perspective. Introduced technologies in silver towns were examined to explore the effect of changes in spatial layout and active boundaries. The surveys and site observations analysis chapter investigated a range of respondents and their units to analyse the technology differences between developers and senior residents. Further, analysis of awareness, frequency of use and satisfaction with active and selected inactive technologies shows patterns of use and different usage purposes. Lastly, photos of unit plans show changes between units in chronological silver town developments and how seniors interact with smart systems and their living environment.

Nevertheless, many issues remain in terms of introduced smart technology systems and silver towns. This chapter cross-references the three analysis chapters to investigate possible areas for further development. That is, it provides an understanding of the issues related to each active or inactive smart system and the silver towns' 
building environments derived from the perspectives of the elderly residents and developers in interviews, surveys and on-site observations.

\subsection{Elderly Interviewees and Respondents}

A comparison of the demographic data of the interviewees and survey respondents provided interesting results in terms of average age, average period of silver town dwelling and average educational background. S tower had many more residents who had lived in the tower for a longer period than those in GY tower, but there was little difference in average age of resident members. The average dwelling period for the interview and survey respondents was more than seven years at $\mathrm{S}$ tower and one year and one-and-a-half years respectively at GY tower; thus, there was a significant gap in the two towers according to the year in which they were built. The interviewees' average age at S tower and GY tower was around 72.5 years and 77 years respectively, and the average age of S tower and GY tower survey respondents was around 72.5 years and 73 years, thus indicating that the average age of both towers was similar.

In terms of the average period of silver town dwelling, the interview and survey analysis indicated that the dwelling periods were almost similar to the year of creation for each silver town. The survey results showed that there was around a two-year gap between the year of silver town service and the dwelling period of the respondents; for instance, GS tower and B tower began service seven years earlier, and respondents from both towers had an average dwelling period of five or so years. Further, the amount of time between the interviewees moving into the silver town is closer in the survey analysis; for example, four out of six interviewees from $S$ tower stated that they had moved in which the tower initiated its service. This provides evidence of the character of the older generation, who do not usually move after settling down. 
Interestingly, silver town residents had a higher education level than that of the aged population in the rest of Korea. The interviewees' average education level was almost at the university level, and the survey indicated a similarly high education level (i.e., completed college curriculum or higher). This result comes to end whether there was an influential effect on the senior residents' educational background to select silver towns.

\subsection{Range and Intended Purpose of Smart Technologies}

There are differences in the number of smart technologies among advertised systems by several developers, applied technologies by selected silver town developers, active technology supporting silver town residents and smart systems perceived by the elderly residents as active technologies. For example, around 15 advertised technologies are being publicised by silver town developers to lure current or prospective customers, whereas up to nine smart systems are applied in selected silver towns. In detail, four to five are affiliated with care-related technology, one or two belong to environmentcontrol-related systems, and there is one system each for security- and public-related systems.

Further, the number of smart technologies in active operation has decreased from nine to six. Most are care-related systems such as the nursing and emergency call system, movement detection sensors and portable emergency pagers. The five smart active systems include the technology that the elderly residents feel that they currently use. That is because some technologies require no action on the part of the seniors, such as movement detection sensors and CCTV, whereas card keys and the nursing and emergency call system require the elderly to physically use them to be recognised as used or using technology. 


\subsection{Intended Purpose of Smart Technologies}

Developers intended for smart systems - especially those that are more focused on medical and health-related services - to support elderly independent living.

However, the elderly perspective and their understanding of smart technologies are different from the original considerations of the developers.

\subsubsection{Nursing and emergency call—active technology}

\subsubsection{Seniors' healthy condition}

The nursing and emergency call system provides immediate medical treatment or a response for the next level of service, and elderly residents are aware of the system. However, the low frequency rate for usage from the survey results shows that the elderly residents rarely activate the call system because there are other care-related systems that demonstrate similar patterns. Most senior residents are healthy enough to take care of themselves; therefore, they do not intend to use the emergency call button.

\subsubsection{Interference}

When a room has two emergency calls, one is located close to a light switch or other devices such as a thermostat or monitor so users have easy access when they stand, and the other one is located lower on the wall so it is at eye level when they are laying on a bed. These placements often create issues in the unit. For instance, as shown in the photos of the individual units, the call button is hidden by a curtain or blocked by a bed frame or furniture, rendering it useless in the bedroom or living room. This shows that the planned layout of the unit and furniture differed between the developers and the elderly, and that the residents brought more belongings than the developers expected.

Further, if the elderly feel that there are too many nursing and emergency call systems or other supporting systems in the same unit, then the elderly tend to disregard one emergency call system. For example, a digital monitor including a nursing contact 
function and a portable emergency pager are replaceable systems. In this case, losing one nursing and emergency call system is not significant for the use of space for their convenience. This is surprising given that they prefer the nursing and emergency call system as the priority technology in silver towns.

\subsubsection{False alarms}

Another consideration of the emergency call system is that it causes false alarms because of its sensitivity. When it incorporates a string, residents sometimes activate false emergency alarms because it is next to other switches. The elderly become used to the locations of the switches and, especially at night time, they may inadvertently use the emergency call button rather than another switch.

Based on the elderly health condition, they rarely use the call system, but the string hangs down a long way to make it easy to pull, and it is easily activated. Therefore, as shown on the site observation photos, the seniors knot the string, which is located in bathrooms or bedrooms. The string is too long and right next to the shower, so it is highly possible that the residents make contact with it. Usually, the string in the second bedroom is also knotted to prevent interference with the household; thus, the elderly make their own modifications to avoid setting off a false alarm.

Generously, most residents try to carefully manage the system to produce fewer false alarms; however, false alarms are also caused by visitors. Some visitors accidently activate it or touch it because of carelessness and curiosity, which is understandable because people do not often see these systems in general apartments or detached houses. Therefore, many seniors tie the string up or wrap it around the call system.

Despite the irritating false alarms and non-use of the system because of residents' good health, the nursing and emergency call system was chosen as one of the most necessary systems in silver towns by current silver town interviewees and survey 
respondents. The survey analysis results reported high awareness and satisfaction rates, even if the satisfaction rate was not as high as awareness, which may be caused by false alarms and malfunction cases.

\subsubsection{Required an improvement and preparation}

The nursing and emergency call system overcame the older generation's biggest concern (i.e., medical or health issues), which provides mental relief for the elderly. The system will also be available to the following generation (i.e., prospective customers); thus, the emergency call system is required to make an improvement. If there is a preconsultation process between developers and prospective customers before finalising the building plan, the above conflicts could be reduced. Silver towns are elderly-centred living environments that provide customised smart technology systems. In some units, the location of the call system limited residents' own layout plans. If the emergency call system were relocatable, unit designs could be flexible, thereby increasing usage of the personal area.

\subsubsection{Movement detection sensor-active technology}

\subsubsection{No use but high perception}

The interview and survey respondents demonstrated high awareness because it is an emergency support system, even though they do not engage with it. Interviewees had not experienced or heard of emergency cases occurring in silver towns as a result of the activation of movement detection sensors, but they strongly perceived that the sensors worked properly. Some interviewees actively demonstrated how the sensor worked and how it was activated. Despite their strong perception and understanding of its operation, the interviewees did not have precise information regarding the designated time at which the sensor would send an alarm. The silver town staff disagreed with one another in relation to the self-activating time. Among care-related systems, the sensor is the only 
device that can be activated without contact by the elderly - that is, it is activated if there is no movement for a certain period appointed by an engineer. There are different opinions regarding the sensors' operation time, varying from 15 to 20 minutes. This confusion creates curiosity and confusion among the elderly residents.

\subsubsection{Confusion or misunderstanding}

Some interviewees confused the sensor with other devices because many devices are placed on the ceiling; thus, the elderly often thought that the air inlet or smoke detector was the movement detection sensor. As a result, when they were asked questions regarding the movement detection sensor, they showed high perception, but when they were asked to pinpoint its location, many interviewees were confused.

There was another misunderstanding regarding the movement detection sensor because other sensors were installed for different purposes. Some residents in $\mathrm{S}$ tower believed that the movement detection sensors were another type of surveillance camera. Since the privacy issue emerged from $S$ tower, some interviewees said that they were concerned about being watched. There is no other surveillance camera inside the unit, but because the CCTV triggered suspicion, the elderly overreacted to the movement detection sensors.

\subsubsection{Annoying sensor}

When the sensor detects elderly movement, it is activated with a flashing light. When the light is off, it means that there is no movement or that the elderly resident is out of the radius of the sensor. Some interviewees said that the sensor caused a disturbance because of the flashing light. As shown on the unit plans of B tower, the sensor is located between the main bedroom and the living room; thus, whenever the resident enters or leaves the main bedroom, a small red light in the sensor repeatedly turns on and off. Moreover, it emits a tick-tock noise that becomes louder at night. 
During the daytime, the light and sound would not be a concern, but they annoy residents during the night. Thus, as shown in the B tower photo, residents cover the sensor with paper to hide the flashing light, rendering the sensor useless. Developers must be aware of this situation because it is against safety regulations, even though current silver towns request residents not to tamper with the sensor.

\subsubsection{Needs for instruction and development}

There are several reasons why silver towns need to provide constant instruction sessions. First, this is a common issue for touchless systems such as movement detection sensors and CCTV. Residents do not need to do anything to operate them, but they support residents as care- and security-related technologies. These two active technologies in silver towns play a role in emergency support, safety and security, so there was a high perception rate; however, the elderly residents' understanding was not as high as for other care-related systems. In addition, silver town staff members' varying answers regarding the sensors' appointed time to emit an emergency alarm increased residents' confusion.

Further, the sensor needs to be exposed because there is no chance that the elderly residents will touch it or check its operational status. If it is hidden in the ceiling area, it will provide flexibility in terms of architectural spatial and structural design. It could be a challenge that technicians and architects need to overcome, and the next developments will consider applying enhanced sensors.

\subsubsection{Portable emergency pager-active technology}

\subsubsection{Too big, heavy and battery change}

Some interviewees said that the pager was not convenient to carry because of its size. The portable emergency pager is relatively small—about the length of an index finger and the width of two fingers. It appears that the pager is considered an optimum 
device to have, and it is expected that it would be the most useful supporting carerelated technology. However, the residents viewed the pager differently, even if it was considered one of the necessary technologies in silver towns.

In addition, some interviewees found that the battery made the pager too heavy. The pager is battery-operated, which means that whenever the battery is removed, it must be replaced; however, because the residents do not use or carry the pager, they do not know when to change the battery. This type of technology, which is rarely used and requires extra care, irritates the residents. One interviewee said that there is no method for checking the residual battery, so they are not sure whether it would work if needed. A silver town staff member said that they informed elderly residents when it was time to replace a battery, but given that there were hundreds of residents with different time frames for replacing the battery, it would be a difficult task to do.

\subsubsection{Wrong placement}

The residents understood that there was a high possibility they would have a sudden emergency one day, but their current medical condition was good enough that they did not need to rely on the pager. Therefore, they placed the pager in a noticeable location, such as the entrance or on a wall in the living room. A GY tower unit photo showed that one interviewee had placed it with switches for the nursing and emergency call system and a monitor, which also had a function to contact a nurse directly. In this case, the pager was the third emergency call system. Without carrying it out of the unit or using it inside the silver town, it merely works as another type of emergency contact inside the unit. Another photo from a GH tower resident showed the pager hanging on a bed frame so it could be used in an emergency. 


\subsubsection{Tracking device}

The only wireless device supplied to the elderly residents is the portable emergency pager, so people could easily be confused by it. Except for GH tower residents, other silver town respondents demonstrated high awareness regarding both portable emergency pagers and tracking. During the orientation that all residents receive when they move in, it is explained that the pager can trace the patient's location in an emergency. If they press a button on the pager, staff members will receive an emergency signal and information about the resident's exact location, as well as their personal medical record. Thus, the elderly misunderstood the pager to be a tracking device.

\subsubsection{Next role of pager}

The portable emergency pager is a wireless device based on RFID technology. It enables elderly residents to carry the pager whenever they are outside their individual unit. S tower did not apply the pager at the beginning of its service, but it replaced it with the button-type nursing and emergency call system embedded in the building corridors as an alternative device. This shows that there has been an improvement in the application of smart technology.

The pagers are often considered a secondary technology system that assist the nursing and emergency call systems, even though it would be the first option for the elderly residents outside of their individual unit. If the residents started carrying the pager inside the unit as well, the nursing and emergency call system could be replaced by the pager - that is, the pager could become the priority care system. If the pager is smaller and lighter than the current one, it will affect the design of architectural plans by providing more flexible choices. 
There is no doubt that this wireless technology makes the elderly hands-free and widens their active areas. It could also prevent a risky situation when seniors fall or slip. Once the older generation keep in mind that they have a supporting technology that they can use in an emergency, it will significantly increase their confidence that their range of actions will not be limited to individual units, but to the whole silver town building. If the pager is not being carried, the RF-related facilities become useless.

The pager would not send constant signals to enable staff or family members to track down elderly residents for safety reasons. However, as expressed by a few interviewees, it would be beneficial to have a tracking system that does not provide visual information, but that sends tracking signals because of safety and privacy concerns.

\subsubsection{Card key—active technology}

\subsubsection{Secure but privacy issue}

Considering the older generation's physical degeneration, many people have hand tremors and a declining memory, which causes difficulties in using key- or pintype locks. However, a card key complements these weaknesses. In general, a card key is often used in offices and commercial buildings to obtain easy access and to record incoming and outgoing visitors for security reasons. The card key in silver towns has the same basic function, but it is applied in a residential environment.

A monitor is connected to a card key holder in each unit, and it is connected to the staff or nursing unit, which checks residents' in-and-out status for security purposes. That is, the card key logs in-and-out status, so it is used as a security system as well as another type of care-related system. If the staff note that no activity has been logged for a long time, they visit or make a call to check on the resident's status. For this reason, some residents place a replaceable card in the card key holder so they are recognised as 
staying in the unit at all times. This increases the difficulty of the staff's management task, and it is also a security breach.

Another way to check the residents' status is when the card key is used for the meal service. When seniors receive a meal service, they should tap the card at the system receiver to confirm; meanwhile, the system records their presence and presents their personal information on the screen. If residents skip the meal service a certain number of times, staff will contact them to check their status. The silver town misunderstands that the resident is in trouble or is finding it difficult to move. Thus, this is another instance in which the card key works as a type of care-related system, as well as for security purposes.

However, these examples are related to a privacy issue. Some interviewees did not have knowledge of being monitored; therefore, silver towns must regularly inform residents that the card key includes this function. Other interviewees were aware of its monitoring function, so they altered their use of the card key, which caused wrong information to be sent regarding their absence.

\subsubsection{Energy-saving function and card key replacement}

Once the elderly residents became used to using the card key, they found that it worked not only for opening entrance doors, but also for using electricity to operate appliances such as lights, heating and cooling when the card key is placed in the card key holder at the unit's entrance. As the card key controls electricity inside a unit, the elderly often think that it is another type of energy-saving system. Through the survey questionnaire, the residents learned the concept of an energy-saving system, and during the interview, they explained that there is an energy-saving function in silver towns. However, they preferred to save energy in a passive way rather than relying on smart 
technology. They became confused when describing the card key as another type of energy-saving system because they misunderstood its purpose.

Another misunderstanding that causes the wrong usage of the card key is that elderly residents often believe that removing the card key will cut the entire electricity supply to the unit, including to basic appliances such as refrigerators. Therefore, some elderly residents slot another type of card into the key holder to supply electricity so they can use their card key elsewhere. They have learned to do this from their children or the repair staff, who sometimes put another type of card into the holder when they are working. Elderly residents have observed that credit cards, business cards and even parking tickets can replace the authorised card key, even though they understand that this creates a fire hazard.

For example, they may operate the laundry machine and put a kettle on the stove at the same time, and then leave the unit by replacing the card key with an alternative card, thereby resulting in a fire. A few interviewees confessed that they had experienced a similar situation, but fortunately it did not progress to a large fire. Since then, they have stopped using other types of cards.

In addition, one interviewee possessed three authorised card keys and an extra key that always stays in the card key holder. From the developers' perspective, this is a security breach and can create difficulties in maintaining silver town facilities and supplying secure services.

\subsubsection{Renewal issue}

Elderly residents were annoyed that they had to renew their card key every 12 months, even though silver town staff members notified them at the appropriate time. This is because the card key provides access to other facilities in silver towns and it works as an all-in-one service card; therefore, if it does not work, they feel embarrassed 
because they cannot do anything. Members of the older generation are afraid of making mistakes, and they become easily confused. Thus, if their card key malfunctions, they would panic, and this becomes a barrier to using the technology.

The survey analysis showed that there is almost $100 \%$ awareness and frequency of use, which means that elderly residents fully understand the card key system. However, these types of malfunctions and extra burdens make residents a little dissatisfied.

Technology applied in silver towns needs to be precise and should not have alternative or replaceable methods. Thus, it is recommended that developers remind residents of the potential fire hazard and fix the malfunctions of the card key system.

\subsubsection{CCTV—active technology}

\subsubsection{Increased coverage}

CCTV in silver towns is most likely perceived as a security camera. From $\mathrm{S}$ tower to GY tower, as shown in the unit plan photos, silver towns have applied updated CCTVs in terms of design, image resolution, size and, most importantly, number of cameras. There has not been a direct comparison among elderly residents, but developers have confirmed that there has been an improvement in the coverage of blind spots. As proven in the interviews, some interviewees received support when they damaged their possessions or lost personal items. They immediately contacted silver town staff members to review the camera footage and resolve the incident. Since these incidents, there have been increased demands for CCTV, and later silver town developments have installed more CCTVs to reduce blind spots and crime.

It is important not only to have more CCTV, but also to increase coverage to create a reliable and safe environment. That is, it aims to provide complete coverage in public areas, including outside silver towns, such as the gardens and walks, for both 
developers and residents. It is also a way of increasing the mental stability of silver town residents. Thus, the effective design of architectural plans needs to be followed to remove unnecessary blind spots. Further, these improvements could contribute to seniors' psychological wellbeing when they understand that they are being protected.

\subsubsection{No use but high satisfaction}

Security and safety is a significant concern for senior residents, and CCTV meets these criteria. CCTV follows the same pattern as other technologies, which do not require the elderly to activate the system. In the survey analysis, residents demonstrated high awareness and low frequency. CCTVs cover seniors' concerns and increase their perception. Interestingly, satisfaction rates are considerably higher than 'non-action' types of technologies such as movement detection sensors. This is because the other system has many alternative care-related system options, while CCTVs in public spaces are not replaceable. If senior residents carry a portable emergency pager, it would work as a substitute for CCTV; however, residents unfortunately do not want to carry them.

\subsubsection{Remote inspection-active technology}

\subsubsection{Prefer an old style}

Remote inspection systems operate automatically and increase maintenance efficiency. Among the selected silver towns, newly built silver towns additionally monitor water and electricity usage so staff can measure correct usage and send bills. However, as mentioned, the older generation prefer this to be done manually so they can double-check their usage and compare it with the usage on the bill. Therefore, the staff must undertake extra work, and the remote inspection system is not operational, even if the facility is ready.

Seniors prefer to check their meter manually for financial reasons. Most silver town residents retired from work a long time ago, which means that they have a limited 
income source. Thus, they want to see detailed information regarding service fees and energy bills.

\subsubsection{Reliability}

Many interviewees noted that they rely on staff members and nurses and have high satisfaction. Thus, to improve the efficiency of the remote inspection system, silver towns need to increase their credibility by allowing residents to read their monitor, which is located in a staff room. Another way would be to regularly remind residents that the silver town has a remote inspection system that automatically reads meters and improves maintenance efficiency.

\subsubsection{System-related monitors—active technology}

\subsubsection{Emergency monitor}

A screen always displays emergency calls because the system is linked to all emergency-related systems, such as the nursing and emergency call system, portable emergency pagers and movement detection sensors. As shown in the silver town unit photos, if a system is activated by a resident, the screen displays an emergency signal and a staff member or nurse on duty will immediately respond by implementing emergency procedures. When the system receives an alarm call, the resident's exact location, identification and medical history are displayed on the monitor. The screen is continually monitored by a duty manager; however, real emergencies rarely occur because the elderly are in good health, unless there is an unexpected incident.

\subsubsection{Monitor for in-and-out status}

The on-site nursing unit or staff facility contains a few computer monitors connected to smart technology systems. The in-and-out status of residents is listed for security reasons. This system is connected to card keys, so when a card key contacts a card key holder, the senior's status changes from 'out' to 'in'. If the status remains 
unchanged for an unusually long time, a staff member or nurse makes a call or visits the unit to inquire into the health of the resident. However, residents can insert alternative cards in the key holder to receive a consistent supply of electricity, so the accuracy of this system is doubtful.

All residents are required to abide by regulations to maintain cohabitation living. To correspond with the developers' original purpose, residents should regularly be instructed that they should not use cards other than the authorised card key, and that the key holder should be fixed to only work with the authorised card.

\subsubsection{Room temperature watch}

Room temperature is also monitored to capture unusually high temperatures to alert staff to the possibility of a fire hazard. To save money, some residents buy a personal heater, which is typically part of the older generation's character, or to have extra care of air quality due to the worsening air pollution issue, air-purification devices are being purchased. However, once again, to control the heating and cooling systems in the unit, the card key should first be properly used, and staff members must be informed of devices purchased by residents. The room temperature controls can then be operated as usual.

\subsubsection{Meal service}

For the meal service, an additional monitor is placed in the communal restaurant. When the elderly resident taps the card key to check in, their unit number and medical information regarding food appear on the screen so they can receive a customised meal. This is one of the key functions of the card key, and this type of system monitors seniors' health issues and status. However, senior residents sometimes want to skip the meal service and have a meal outside. If the residents do not inform a staff member a certain number of times, the meal service staff notify the duty manager 
and the manager makes direct contact with the resident. A few residents complained that they had received unwanted contact and doubted that it related to care because there is an extra charge for the meal service.

\subsubsection{Real-time health checks —installed then currently inactive technology}

\subsubsection{Developers' perspective}

Silver town developers installed a real-time health-check system so that the elderly could receive a medical check whenever they felt uncomfortable in their unit; however, there is a requirement that seniors have a computer with an Internet connection. The limit of the real-time health checks was not confirmed-nor was the extent to which the experimental system had been tested - but it is presumed from the interviews with the developers and the collected material that medical consultations or treatments were expected. Further, there was an expectation that the system would be specialised for the silver town only because it was a pioneering system in silver town development.

\subsubsection{Complicated computer use}

Some elderly residents did not want to have an Internet connection or a computer at home because they were not familiar with the technology. They wanted to spend more time doing what they were interested in; thus, this was not supported by the residents. Although the seniors were open-minded towards technology and took classes run by the developers to learn how to use the computer, computers and the Internet are still difficult for the elderly to use. Therefore, they would not voluntarily use the realtime system unless there were particular benefits.

Applied CCTVs in living rooms and bedrooms implies that there is an additional purpose, even though it was not given by the developer. CCTV inside individual units could provide the role of a monitor, and the telephone could be a device for 
communication; thus, the elderly could receive a medical consultation without leaving their personal unit. However, the CCTV service had been stopped because of privacy concerns, and it is possible that the system will not become active again.

\subsubsection{Preferred face-to-face}

The character of the older generation was also an obstacle to proceeding with the experiment of the real-time health-check system. The system provides an instant medical consultation and a faster service than any other method, but the seniors generally preferred to conduct their medical check-ups face-to-face, believing that this method would be more reliable. Further, all silver towns have an on-site clinic and nursing unit, or they are affiliated with a general hospital for medical support within walking distance. These conditions encourage the elderly to be more active. Therefore, they prefer to walk down to an on-site clinic or visit a general hospital within close range rather than use the system at their unit.

Additionally, a prerequisite condition for seniors wanting to move into a silver town was that there should be no difficulty maintaining their daily life by themselves; thus, the residents should rarely need to activate the system. Moreover, there is a mandatory service every six months in which the residents receive a comprehensive medical examination at an affiliated general hospital. This decreases the probability that the elderly will need the real-time health-check system. The survey analysis found a high awareness rate and significantly high satisfaction regarding the system. These high figures come from regular medical check-ups among four selected silver towns, excluding S tower, even though the real-time health-check system no longer exists, and the concept of the system has been informed. Moreover, most interviewees were aware of the system, but they pointed to their six-month medical check-up as their real-time health-check system. 


\subsubsection{Next challenge}

The real-time health-check system has not been implemented in other silver towns because the experiment at $\mathrm{S}$ tower failed. Considering the facilities required for the real-time health-check system, there were comparatively fewer monitors and nurses at $\mathrm{S}$ tower compared with the population of elderly residents; therefore, the residents might not have received the service at their convenience. This uncertainty increases the low frequency of the system because medical issues are a high priority for the elderly. Further, the elderly residents turned away from the system.

However, future generations may be more inclined to use this service given their increased knowledge of computers and the Internet. Therefore, the key aspects would include the type of independent role that the real-time health-check system would play, how elderly residents would assimilate the system and how the system would naturally melt into the living environment. This would not be another technology device, but a part of the dwelling. Further, if it is connected to mobile phones because the system is based on the Internet connection, it could extend the service areas from silver towns and be used by the elderly at any time. This in turn would increase the mental comfort of the elderly and become a ubiquitous system.

\subsubsection{CCTV inside—-installed then currently inactive technology}

\subsubsection{Developers' view}

There are CCTV installations at $\mathrm{S}$ tower, which was and is the only silver town to have them and, presumably, it has a connection to real-time health checks for remote medical support. CCTV in individual units at $\mathrm{S}$ tower caused a controversial issue regarding privacy. This is an important issue not only for the older generation, but also for younger generations. $\mathrm{S}$ tower developers installed CCTVs in individual units as a care-related system to provide extra care services to support elderly patients who have 
difficulty maintaining independent living. There was an expectation that even though the elderly moving into silver towns retained their living without any medical assistance, they would eventually require extra care as they aged.

\subsubsection{Failure of experiment}

Despite the developer providing a blueprint to support the idea, there were no severe medical issues among the current residents. The developers placed themselves into the dilemma that the health condition which is required of the residents to live in silver towns became an obstacle. The seniors were healthy enough to maintain independent living, and using CCTVs inside units for emergency care did not make sense for the elderly residents. Many residents had moved into the silver town despite hearing or seeing that there would be CCTV installations inside their personal unit. However, they did not seriously consider this at the beginning because they did not pay full attention to smart technology systems. Further, residents who faced difficulties with their movements and required help from a personal carer did not agree with the installation of a camera in the domestic area.

There is another reason that the cameras could not operate successfully. S tower residents were not pleased to have CCTV in their unit; thus, later versions of silver towns generally did not install the cameras. In particular, GY tower included ICUs in the same location, but in a different building in which it applied all other supporting technologies and a special care unit team, such as nursing and emergency call systems, a monitor with a nursing call function, movement detection sensors and portable emergency pagers based on RF technology; however, CCTV was not applied because of privacy issues.

The initial concept of the use of CCTVs in bedrooms, living rooms and bathrooms as a support system failed. The interviews and surveys demonstrated that the 
majority of S tower interviewees did not agree to have the CCTV inside, and it has not appeared in any other silver town developments. Further, the survey analysis found a higher awareness of CCTV at S tower compared with other silver town perception rates. This implies that more attention is paid to CCTV by S tower residents because they have them in their individual space. However, a satisfaction rate of around $40 \%$ was not as high as for other silver towns; that is, other silver town respondents showed very high satisfaction, which was over four out of five ratings. It is presumed that respondents were uncomfortable seeing cameras in their private area.

\subsubsection{Not always wrong but some helpful}

Although invasion of privacy was a significant concern, other interviewees believed that CCTVs located in units do not need to be considered a harmful device because single-living dwellers and those who need extra care require the support of CCTV. A few interviewees who currently live alone shared that when they had faced an emergency but were not close to the nursing and emergency call system or the portable emergency pager, they could not rely on movement detection sensors, which require at least 15 minutes of no movement to detect an emergency. Those 15 minutes would be critical moments for the elderly because they were in a significant amount of pain and needed to receive prompt treatment. They imagined that they might have received an instant response and medical treatment if CCTV had been installed in their unit.

\subsubsection{Still uninstalled}

Further, site observations verified that there was still a CCTV monitor in the nursing unit, but it was not in operation, and even if the monitor was turned on, there were no clear images on the CCTV monitors. Despite this failure, CCTVs in the domestic area at $\mathrm{S}$ tower have not been removed. Inside CCTVs were also not active, but the cameras and CCTV monitors were still in place in the individual units and in the 
nursing unit. In addition, the developers confirmed that they would not have a case to operate individual units' CCTVs for any other reasons. However, some interviewees believed that they were still operational and were surveying their private life and taking photos. These residents covered the cameras with plastic bags or paper. Hence, some residents complained that they were not comfortable living with the suspicion; therefore, their concerns must be addressed.

\subsubsection{Next challenge}

Other silver town residents' reactions when they heard about the inside CCTVs at $\mathrm{S}$ tower were instantaneous. They did not agree to having CCTVs in their individual units because of privacy concerns, even though they had the same health-related concerns (i.e., what they would do if there was a medical emergency). Therefore, developers need to consider incorporating an ICU facility as part of silver town developments, or they should at least be affiliated with an ICU service provider to support senior residents' concerns. An alternative would be to use a wireless system such as a tracking device to monitor the elderly residents' movements in real time. This would provide mental comfort to the elderly and would be effective for seniors who would not need to move to a special care unit.

\subsubsection{Indoor air quality—inactive technology}

\subsubsection{To get better air quality}

Urban and semi-urban styles of selected silver towns have corridor access, which represents weak circulation of natural air; therefore, it is important to have a mechanical ventilation system. Semi-urban towers have more windows in public halls and corridors than urban towers, and they introduce reasonable air quality in public areas. However, seniors living in both types of silver towns are not satisfied with the current natural ventilation in individual units. 
There are air inlets and outlets in each unit, and supplied air should pass through an air filter installed in individual unit to filter micro dust and polluted air. However, few people have received this service. One interviewee said that she was curious about the machine in the terrace area and asked for an explanation from a staff member. She then had better knowledge of its operation. As a result, during the interview, the resident demonstrated how it works. Another interviewee showed how they hang a few polyester films on each inlet to check whether there is air supply. These examples demonstrate the demand for improved air quality.

\subsubsection{Next challenge}

Older-generation residents do not like to spend their own money to buy additional technology; however, some interviewees had purchased an air purifier as an additional appliance to produce better-quality air in their unit. Further, air pollution has become a more serious social issue because of the Asian Dust phenomenon, yellow dust and fine particulate matter. These represent the importance of air quality in silver towns and the demand for technology to improve air quality in both urban and semi-urban environments for the elderly. To provide better air quality in silver towns, developers should consider changing the type of building from corridor access to a terraced building, or introducing advanced smart technology to resolve the matter.

\subsubsection{Monitor-inactive technology}

\subsubsection{Overlap of work}

Monitors located in living rooms are used in units to conduct visual and vocal checks of visitors, and even the most recent version of the installation has an additional function to contact nurses directly in an emergency as an alternative usage of the nursing and emergency call system. In contrast, an additional nursing call causes a conflict between the call on the monitor and the other nursing and emergency call 
system due to its location and function. There are only two nursing and emergency call systems installed in the living room; therefore, if two different types of emergency calls are located close together, it decreases the effectiveness and efficiency either side of the call system. Further, without regular usage of the emergency call system, if it is installed as a precaution, the allocation of the nursing and emergency call system or the monitor needs to be considered to increase the scope.

\subsubsection{Digital monitor to analogue}

GH tower has installed an analogue monitor that does not have a visual screen, even though it is a later version of the silver town. The tower has a reception area at the entrance of the building, similar to all other silver towns, and residents and visitors must pass through this point. The staff are confident of their security work at the reception. Thus, this reception service and the lack of use of the monitor by the elderly mean that a digital monitor is not required in silver towns. It is debated whether smart technology can replace human services, which the elderly residents are highly satisfied with.

\subsubsection{Other introduced technology}

GH tower provides a remote control for lights so residents can switch lights on and off from a remote location; however, it only works for turning off lights in the main bedroom at night, and residents rarely use this service. Interestingly, as an alternative

device in the future, one interviewee expressed that voice recognition technology would be more convenient because it only requires a vocal order rather than a physical machine, and the elderly already have other controllers for the TV and the cooling system.

In addition, the thermostat has developed from analogue to digital to provide a precise temperature setting. However, the thermostat is also rarely used because the 
elderly set the temperature once in the summer and once in the winter, and then they do not change it at all to reduce their energy bill.

For all controllers mentioned above, a mobile phone or tablet has been used as a platform in recently built apartments to control lights, heating and cooling, as well as other domestic appliances. These technology platforms will be the next model for the elderly-only environment, as the current older generations are still afraid of dealing with technology.

\subsection{Usage Patterns and Acceptance of Smart Technologies}

\subsubsection{Non-use but demands for new technologies}

The older generation are not familiar with modern technology and supporting smart technologies because the systems are not in general apartments or detached houses. In addition, in terms of senior-centred smart technologies, only those with a particular purpose are applied in silver towns to support independent living, even though smart technologies are not as advanced as those used in general apartments. Therefore, the elderly are pleased to have all supporting systems, which are mostly connected to safety and security issues. The embedded systems overcome one of the residents' biggest concerns related to health.

These aspects demonstrate that there is relatively high awareness of both active and inactive technology. There are questions regarding whether active and advertised technologies support seniors' independent living. This is because usage rates are not significant because of the good health of elderly residents. The systems are not in use and then these become supporting systems but many seniors demand smart technology based on their experience, even if they do not use it on a daily basis. 


\subsubsection{In-use and not-in-use technologies}

In terms of usage, two smart systems have $0 \%$ or $100 \%$ use. Frequency of use is closer to $0 \%$ on medical support or emergency-related systems because of the good health of the elderly. Security-related systems such as the card key have almost $100 \%$ usage. In one sense, care-related systems have one clear function - to create an alarm in an emergency_ — while the card key can be used in many different facilities in silver towns. For instance, it provides access to silver town facilities such as the meal service system, it connects to the electricity supply and it provides the medical history of residents in a medical emergency situation.

Multi-function systems can be divided into everyday use and non-use. Everyday systems (e.g., card key) have a clearer purpose, so they are likely to have higher awareness among elderly users. However, smart systems that are used less often result in misunderstandings. For example, many residents believed that portable emergency pagers included a tracking function because the wireless device provided their location when they activated it in an emergency situation by pressing the button.

When people speak about many purposes in one technology, they draw the image of complication or confusion and the pager indicates a case of not being difficult to use but of being confused by its other conceptual function. To avoid confusion, it is important to provide correct information and thorough, consistent instruction rather than relying on modern technology development or advanced smart systems.

Hence, if a system has multi-functions in a simplified form of use (e.g., card key) and it does not require complicated instructions but delivers useful information to provide better-quality services, it would be an ideal system for the elderly.

Some technologies require pressing a button or pulling a string to activate them, whereas others do not require any action to operate. For both types of technologies, 
interviewees and survey respondents showed high perception because all technology fits the senior residents' concerns. Conversely, the survey results showed slight differences in the satisfaction rate for push-pull types of technology because these types of systems are more visually located and require action to activate, which increases awareness.

However, considering the satisfaction rate for portable emergency pagers, which is in the category of care-related smart systems, it shows a lower percentage of satisfaction than other push-pull technology. Information and interview analysis data indicated that the level of satisfaction would be relatively influenced by other aspects, as well as whether the technology was in use and whether it provided benefits.

Therefore, the developers need to consider smart systems that are easy to use when they integrate smart systems into silver towns.

\subsubsection{Active and inactive technologies}

The technologies applied in silver towns can be active or not in operation. The nursing and emergency call system, movement detection sensor, portable emergency pager, CCTV and card key are known as active systems. All of these systems were highly perceived by the elderly and generally showed a high satisfaction rate regardless of whether they were in use.

In contrast, there are systems - only in S tower - that worked at the beginning of silver town service, but that are not currently in active mode. In addition, remote inspection systems embedded in other silver towns are ready to be used, but they create an extra workload from the developers' point of view; thus, they are currently inactive.

The real-time health-check system is based on the Internet connection, which enables elderly residents to receive a medical consultation at their unit. However, the fact that the elderly need to use a computer but prefer face-to-face conversation left the system as an experimental one. The condition that every silver town runs an on-site 
clinic service and is affiliated with a general hospital within walking distance meets with seniors' concerns. That is, there was a misunderstanding of elderly demands.

CCTVs inside units offer an extra care service for the elderly, but the senior residents were against the system because of an invasion of privacy. Hence, it created an issue through the lack of understanding of its purpose and residents' privacy concerns.

Moreover, many seniors who were sensitive about their financial status wanted to conduct a visual inspection of the energy meters; therefore, from the staff members' perspective, the remote inspection system was pointless because it caused extra work. Thus, the system is only used for reference.

There are a number of technologies in silver towns, but the elderly make them active or inactive according to their concerns and preferences, regardless of their awareness of smart systems. Each technology has a different or similar purpose, but one common reason for all applied smart technologies is to support the elderly; thus, it illustrates residents' increased perception and satisfaction.

\subsubsection{Technology or human-based service}

When the elderly select silver towns as their next dwelling place, one reason is that they feel they are in the last chapter of their life. When they feel like they have settled down, it means that they do not want to move to another place.

When smart technology does not meet with seniors' expectations, or high demands combine with seniors' character and preference, it could be replaced with a human-based service. This has been illustrated in terms of the light controller and remote inspection systems, which can be conducted by the elderly residents or staff members. Further, the use of smart technology has resulted in the need for additional human services (e.g., battery change and card key renewal, which seem to have shared roles between smart technology and human services). 
Even though seniors receive additional technology support, there is no method to prevent aging, which comes with physical and mental degeneration. There were a few negative perceptions regarding smart technology as an obstacle that increases seniors' deterioration. A few residents believed that technology makes life easier and more convenient, but that it reduces opportunities to undertake physical exercise, which is required for the older generation to maintain a certain amount of movement and slow down degeneration. Even if supporting technologies make significant improvements, they cannot replace human-based services.

\subsubsection{Preference for active technology}

Elderly interviewees and survey respondents expressed an interest in supporting technology. Satisfaction and perception rates were high enough to understand that the medical-, emergency- and security-related systems are essential and desired in silver towns by the current elderly residents, regardless of whether the systems are frequently used and whether they are active.

Some technologies do not require any kind of physical contact, but they indicate significant awareness and satisfaction rates because they are in accordance with seniors' major concerns, such as emergency and security issues. In addition, these substantial responses also reflect that elderly residents have received benefits from some noncontact technologies, either directly or indirectly. Conversely, systems that fit with seniors' high concerns and do nothing but operate for 24 hours each day demonstrate high perception but a low satisfaction rate. This is because the systems have not provided any beneficial work; however, even if the system is related to emergency alerts, it produces a high satisfaction rate. Moreover, high satisfaction rates are shown on advertised but non-active technologies, which indicate that technologies that receive considerable attention from elderly residents possibly cause increased perception and 
satisfaction when they meet with residents' concerns. However, they would not be selected as the most wanted or necessary smart systems because they are inactive.

It can be questioned whether the technologies in frequent use are preferable or the most wanted, or whether technologies that are more reliable and have high perception and satisfaction are more suitable for the elderly living environment. That is, it asks whether the card key that is in daily use is more necessary than the emergency contact system, which is currently rarely used. The survey results indicated that there is similar awareness, but that the satisfaction level is a little higher with everyday systems because of received benefits, whereas the interviewees had significant perception of both technologies, but the nursing and emergency call system was slightly more necessary in silver towns because of future health concerns. No system was $100 \%$. The emergency call system, although rarely used, provides comfort to residents who might need it in the future. However, residents can use their card key to access facilities and have a more comfortable and convenient life. In addition, the system rarely malfunctions, and residents can make few mistakes.

From the research analysis, in terms of technology preference, current seniors indicated care-related systems and security as their priority, followed by environmentcontrol-related systems.

Highly preferred technology from current residents would represent the system that needs to be applied in future silver towns with improvement. It is neither responsible nor the sole answer because people in following generations may indicate slightly different perspectives with other experiences regarding modern technology and lifestyle preferences in terms of living environment embedded with smart technology. It is expected that current elderly concerns will remain a major concern for prospective 
customers, but the level of interest and demands on environment-control-related systems could vary depending on the next customers' desired quality of lifestyle.

Given that the elderly living environment in the future will be closely associated with smart technology, it is important to obtain information from current silver town residents to assist with further developments of supporting smart systems embedded in silver towns. Understanding current elderly users' experiences will have a significant effect on future silver town developments in terms of the living environment and technologies.

\subsection{Usage Patterns and Design Changes in Space}

\subsubsection{Extending spatial layout}

The individual design of silver towns shows that there is not a particular physical change or specific point for elderly living but they are similar to general apartments. This is because the units and communal spaces are planned first, and then smart technology is applied; thus, there are often many elderly-centred design aspects because it is an elderly-only living environment.

However, use and possession of smart technology systems brings significant psychological stability, which was emphasised by most interviewees. In terms of mental relief, as many interviewees stated, it is a very important aspect when selecting a silver town, even though there may be confusion resulting from unfamiliarity with smart systems.

Nursing and emergency call systems and movement detection sensors unified physically divided unit spaces to become one large personal space in terms of psychological area. Elderly residents feel much safer than in their previous dwelling because the emergency contact system provides an immediate response and professional treatment. 
Regarding extending space by using smart technology, portable emergency pagers enhance elderly residents' space both mentally and physically. The pager creates a wider area as an active space for elderly residents; thus, the wireless pager can be a medium to link private and communal areas in silver towns. However, the nursing and emergency call system, movement detection sensor and portable emergency pager are rarely used because of the good health of the elderly.

Further, the card key system is used throughout silver towns for many different purposes, but it combines many different facilities in one place for the elderly. The residents use it in their individual unit and for meal services and other facilities. The system not only gives seniors accessibility, but also provides advanced support services by connecting them to the staff or nursing unit to receive customised medical information and therefore proper support and treatment. Therefore, the card key system connects elderly residents and silver town spaces to enlarge their active area.

\subsubsection{Unit size and interference}

The trend in unit size in general apartments around the time that silver towns were developed was towards larger apartments. Apartment complexes were popular at the time, although medium- and smaller-sized apartments became preferable because of changes in family size. Unit sizes in silver towns are generally smaller than the residents' previous dwelling spaces, although there is a variety of unit sizes to choose from in recent silver towns. All interviewees stated that they wanted to downsize their living space as they grew older; and this is not an issue when moving into silver towns. However, in one sense, the elderly were being forced to downsize their living space. For instance, in terms of the unit size of silver towns, in general, urban-style silver towns provide smaller units than semi-urban silver towns, except for some penthouse-style 
units in urban-style towers. $\mathrm{S}$ tower provided the smallest units $\left(26.6 \mathrm{~m}^{2}\right)$, with the largest unit size at only $53.1 \mathrm{~m}^{2}$.

Problems were inevitable between households and smart systems, even though the silver town development was sold off the plan so the elderly would have a sense of how they had to downsize their living space. Photos of an S tower resident's unit showed that there was a significant gap between their unit size and their possessions. Residents brought too many household belongings from their previous dwelling and added more goods after moving in. Thus, the household belongings interfered with technology such as the nursing and emergency call system in the living room and bedroom, as well as the monitor in the living room. Forced downsizing by developers resulted in elderly residents having difficulty coping with technology systems, even if the elderly live in medium- and slightly larger-sized individual units in other towers. Other silver town cases are not as bad as $\mathrm{S}$ tower; however, there are still conflicts between many household objects and supporting technology systems.

Elderly residents had not previously experienced supporting technology in their unit and building; therefore, they may have had lower awareness than they indicated in the interviews and surveys. Both research analysis results showed a significantly high perception of applied smart technologies, although in many cases the seniors did not consider the systems as part of the design aspect.

This illustrates that it would influence lower concern with smart systems because there is no use for supporting technology, so the residents do not care about interference regardless of the design concept. This was shown in the observations of the nursing and emergency call systems, which were hidden by plants or other objects. As an alternative technology, some interviewees expressed a desire for a wireless device that was easier to carry (i.e., lighter and smaller). This would make it possible to prevent 
conflicts between household goods and smart systems, and it would provide a wide range of unit designs in terms of spatial layout and effective usage of space.

However, the application of wireless systems such as portable emergency pagers, which were not used as often as other systems and were returned to the developer in one silver town, demonstrates that wireless devices would not completely resolve the issues. However, they would improve them.

\subsubsection{Proper allocation of technology}

The elderly independently chose to move into a silver town. They inspected and visited a silver town's display house to obtain knowledge of what the silver town looked like. They also received information regarding smart systems that would support their living. Thus, technology is unlikely to be understood by the seniors without the lived experience of the new paradigm of the elderly-only environment and full understanding of how the smart systems work for.

Interferences between households and smart systems, which occur in many individual units, are shown in photos that reflect the perspectives of developers and seniors (e.g., a bed hiding an activation switch for a smart system).

Developers must understand the elderly usage of space and include technology systems as design aspects in the initial unit plan rather than grumbling that the interferences are caused by elderly residents' carelessness.

Further, based on photos of individual units, supporting systems are located next to other switches, such as lights and thermostat. This implies that technology systems were not considered as part of the design. The developer thought that this would increase visibility and effectiveness, but in fact it causes a false alarm and becomes a burden. Thus, developers must find a better way of dealing with seniors' circumstances to avoid confusion. 


\subsubsection{Elderly-friendly design}

Apart from smart technology, because silver towns are only for elderly residents, there are some detailed design aspects. For example, bathroom basins are adjustable to the resident's height, and a folding chair is placed next to the entrance to provide a temporary sitting area to assist the residents with bending forward. In addition, wheelchair accessibility is essential not only for seniors having difficulty walking, but also for emergency circumstances. Further, the floor is flat and a lack of door sills removes any obstacles.

Some design aspects for the elderly are not deemed to be only for seniors, but also for general use in apartments and detached houses. Therefore, it can be said that there is no distinction on unit design for the elderly-only living environment, and this increases considerably the condition where silver town developments are initiated as luring elderly customers with supporting technology.

Silver town developments are still in the early stage of progress and in the evaluation stage for prospective customers and others. Thus, more attention must be paid to facilities and services rather than smart technologies.

\subsection{Other Concerns}

\subsubsection{Limited income}

Another concern relates to the expense of silver towns for people on a middleclass income, even though the prices are improving. Older people have a limited income source because of limited economic activity opportunities. Although the elderly decide to move into silver towns without any financial difficulties at the beginning, it is difficult to make an investment by improving the living environment.

In particular, investing in additional smart systems is a difficult decision if there is no clear benefit from the system, even if it corresponds with seniors' concerns. This 
was explored in the interviews, where the interviewees expressed high satisfaction with current active technologies, but did not accept adding more technologies to their current environment.

\subsubsection{Other interests}

The image of silver towns being for wealthy residents has a negative effect on silver town development. Thus, the development requires the application of advanced smart systems to support a higher level of independent living. Further, it must target middle-class seniors to increase the size of the silver town market and deliver opportunities to many other elderly people who want to choose a silver town for their next dwelling environment.

Current silver town residents are healthier now than when they moved into silver towns; however, the elderly residents have aged and face deterioration. Therefore, silver towns include extra care units, or nursing homes, for older-aged adults as part of their development. Some interviewees' spouses had difficulty maintaining independent living and required intensive care. Including the selected silver towns for the research and other existing towers, few silver towns provide intensive care facilities for elderly residents who require extra care. As illustrated by GY tower's ICU, the unit also has a similar level of active technology to other units, with an extra medical care facility; however, it has a limited number of units. Thus, the upcoming generation of silver towns must consider a balance between the improved application of technologies to support independent living in the elderly living environment to meet with seniors' character and preferences.

\subsection{Discussion}

The number of technologies demonstrated has decreased from those advertised to the active technologies. This reflects the elderly perspective that their understanding 
and patterns of use of smart technology are closely related to their medical, safety and security concerns. In addition, these considerations need to be adapted during the design of silver towns rather than forcing the elderly to use developers' applied technologies.

The gap between elderly residents and developers regarding intended purposes of smart technologies shows obstacles and self-alterations that are caused by seniors because of different perception, satisfaction and usage patterns. For example, the interference between the nursing and emergency call system and furniture allocation showed how the technology placement and design of the elderly space needs to be attached to seniors' use of their environment. Further, self-alteration was evident in movement detection sensors, the nursing and emergency call system and portable emergency pagers, which present different types of conflicts between smart systems and the elderly. It showed the importance of understanding seniors' patterns of use and the current level of smart technologies that are required to improve the design of silver towns. Moreover, although smart systems provide extra care, seniors' privacy and preferences are more important than medical or health-related support from smart technologies (e.g., CCTVs inside units and real-time health-check system). These early experiments reflect that the design of silver towns' integrated smart technology must be understood from the seniors' perspective.

Further, usage patterns of smart technologies derived from elderly residents' demands, preferences and conditions classified the technologies by operation and activation. For instance, health- and security-related systems are mostly in active mode because they directly meet the older generation's concerns. Additionally, the good health of the elderly and their preferences determine whether active systems are used, despite care-related systems being closely related to seniors' largest concern. For instance, the nursing and emergency call system is often neglected by interference from 
furniture, and portable emergency pagers are left in units because the elderly find them unnecessary and inconvenient. Conversely, active technologies are also categorised by elderly involvement. This shows the positive integration of smart technology, and if there is more contact or information regarding smart technologies, there is high awareness and satisfaction with smart systems from elderly residents. These usage patterns show that seniors' preferences should be prioritised over all smart technologies in silver towns.

Even if there are differences in the usage of smart technologies, elderly residents selected the most necessary system (i.e., nursing and emergency call system) because it is closely connected to health and emergency issues. Meanwhile, the highest satisfaction and frequency rates from the survey respondents were with the multi-functional card key, which works throughout silver town. Further, when asked whether they wanted more smart technology systems in silver towns, they felt positive towards technology but want it to be easy to use and to have no effect on their financial status. This showed the status of the design of current silver towns and their effects on the future design of silver towns integrated with smart technology.

Despite seniors' high perceptions and usage of smart technologies in silver towns, there were few changes in the physical layout of the towers resulting from technology use compared with general apartments. However, the application of smart technologies influenced the design of units, despite limiting seniors' allocation of their belongings in individual units. This suggests that the elderly perspective should be considered from the start because smart technologies in silver towns are inevitable. More importantly, there are clear changes in the use of the towers because of the possession and use of smart technologies. Psychological stability has a significant effect on usage of silver towns, regardless of whether the technology is in use. The placement 
of movement detection sensors and nursing and emergency call systems assure elderly residents that they can receive an immediate emergency response in their individual unit. This in turns extends their boundaries throughout the silver town. Further, although the pager system is not in use, the tangible benefits of portable emergency pagers based on RFID, multi-purpose card keys and improved CCTV coverage enables senior residents to feel safe and secure throughout the silver towns. In addition, mental stability derived from the use of smart technologies made the silver towns more active.

Overall, the research analysis indicates that the understanding of the elderly's perspective regarding smart technology embedded in silver town has made changes in the patterns of design and usage of silver town. Patterns of design and use of silver town integrated with smart technology are affected by two aspects. One initiates from elderly demands which often are demonstrated in high awareness and satisfaction in health- and security-related technology. In addition, the elderly residents' preference or condition which is shown in frequency of use of card-key technology provides a different way of perception. The other aspect is that the changes in silver town design already made by the developers due to the application of smart technology combines the different standpoint of elderly perception and usage of the unit layout and the technology. It illustrates that there need to be further changes in the design of silver town with supporting technology. Especially, seniors' psychological stability which is derived from the possessing or the increasing use of technology increases use of silver town actively and it indicates the development requirement in the designing of silver town with smart technology.

\subsection{Conclusion}

This chapter examined the findings and issues regarding technology applied in silver towns and the silver town living environment from the elderly perspective, as 
well as compared with the developers' perspective. Developers' advertised technologies include active technologies in selected silver towns. Applied technology extends to the senior residents' usage of smart systems. The target system is not limited to when it is active, but it includes inactive technologies to explore a wider range of perceptions. Through this, it provides an understanding of how the older generation living in selected silver towns perceive and associate with the systems in their living environment. Moreover, seniors' understanding, frequency of use and satisfaction demonstrated that there are concurrences of existing acceptance criteria, as well as a number of new factors and aspects to be considered. This understanding shows the influences on spatial layout and design changes resulting from the use of embedded technologies.

Chapter 8 summarises the research, explains this study's contribution to the literature and makes suggestions for future research. It begins by outlining the importance of the research and presenting the key findings relating to the research questions. It then outlines this study's contributions to the same or similar fields of research regarding the elderly living environment integrated with smart supporting technology. Lastly, it presents the outcomes and discussion issues that could be extended to the range of possible studies for further research work which need to be followed. 


\section{Chapter 8: Conclusion}

\subsection{Introduction}

The previous chapters examined aging population issues and the importance of the research. Further, they presented significant findings derived from the analysis of interviews, surveys and on-site observations regarding emerging patterns in the design and use of elderly-only buildings integrated with supporting technology systems from the elderly point of view. That is, they provided an understanding of the perspective of elderly residents who choose silver towns as their living environment in relation to their technology experiences. In this study, advertised technology by the silver town developers was narrowed down to applied technology, which is categorised by purpose, and active and inactive technologies. Further, this study examined the elderly perception, usage, satisfaction and interaction with applied technology, and how applied smart technology influences the silver town living environment—especially changes in layout.

This chapter explains the significance of the research and summarises the key findings. Moreover, contributions to the existing literature are outlined, followed by the limitations of this study.

\subsection{Importance of the Research}

Every country around the world is facing a rapid increase in the elderly population. In particular, Korea is already an aging society and, compared with other countries, it will become an aged society within a considerably short period of time. In addition, maintaining independent living among the elderly is a major social issue.

Thus, the new paradigm of elderly-only living environments, or silver towns, has recently emerged in Korea based on one of Korea's strengths, which is 
developments in IT. Silver towns in high-rise buildings include all facilities required by seniors, and they are integrated with smart technology to support independent living.

Previous research has been limited to examining smart homes and introducing technology enabling aging in the home based on theory, aging-friendly design and experiments with technology from the developers' perspective. Further, existing research on silver towns has covered a limited area because of difficulties accessing silver towns and their residents. The existing research has been limited to the design of the silver town, design of its public areas, the prediction of prospective customers' preferences and drawing attention to experimental technology from the developers' perspective.

This study is the first to explore the experiences of elderly residents in relation to emerging silver towns integrated with smart technology systems using intensive interviews, surveys and site observations. Smart technologies need to be part of the design of the elderly living environment. Therefore, it is important to understand current residents' perceptions of, and interactions with, supporting smart technology applied in their living environment for further development. This will provide an understanding of how senior residents comprehend, use and accompany applied smart technology as support systems and changes in silver town spaces influenced by their possessions and use of technology.

\subsection{Findings}

1. Silver towns are elderly-only living spaces, so it is important to comprehend the senior residents' characters to explore the perception of the elderly regarding smart technology in silver towns using intensive interviews, surveys and observations. There is a ten-year gap between when the first ( $\mathrm{S}$ tower) and last (GY tower) towers were built; however, the average age of all silver town residents is around the mid-70s. 
Moreover, the beginning of each silver town service and the average dwelling period of respondents reminds us of the older generation's character - once they feel like settling down in one place, they do not often change their living area. Further, silver town residents had a higher education level than that of the aged population in the rest of Korea.

2. Smart technologies applied in silver towns are relatively new in the elderlyonly living environment, even though the elderly are relatively positive and friendly towards these technologies, because the systems are not integrated into general apartments and detached houses. The systems are embedded to support senior residents' independent living; thus, the elderly were not familiar with smart systems when they moved in, but they slowly began to understand their purpose and necessity, and to appreciate them.

3. The interviews, surveys and observations show a decline in the number of technologies in silver towns, including advertised technology by developers, applied technology by selected silver town developers, and active technology from the elderly residents' perspective. This shows that there is a gap between intended purpose and usage by senior residents.

4. Each active and selective inactive technology is examined to understand and determine the differences regarding intended purpose and usage patterns from the elderly perspective. In general, there are high levels of awareness and satisfaction regarding active and limitedly inactive systems, but only the card key system shows an almost perfect usage rate. Some inactive technologies (e.g., CCTV inside units, realtime health checks and remote inspection systems) are experimental systems that are installed but are not in operation. CCTVs were installed in personal spaces for carerelated reasons, but elderly residents objected because of a lack of privacy, and real- 
time health check is embedded as offering convenience but complicated usage combined with the seniors' character and the duplicated role of the on-site clinic has led to non-usage.

5. Active technologies can be divided into those in use and those that are not in use based on elderly usage patterns. Care-related systems are mostly not in use, despite being closely related to health and emergency concerns, because most elderly residents do not have difficulties with their health and mobility. These systems are installed as a precautionary measure by developers. Health status also creates a barrier to using a portable emergency pager, and additional factors that cause residents to avoid using them include size, weight, battery change and inconvenience. As a result, many residents at GY tower returned their pager to the provider. Further, many interviewees modified the systems; for example, they knotted a string attached to the nursing and emergency call system because of its sensitivity, which caused false alarms, and they covered the movement detection sensor with paper because the flashing lights annoyed them. Further, they felt that they did not need the systems because of their healthy status. In contrast, security-related systems — specifically the card key system — are actively used because of accessibility in relation to the meal service and other facilities in silver towns. In terms of the card key's multiple functions, it creates confusion for a few systems; for example, portable emergency pagers are understood to be tracking systems because of their wireless nature, and movement detection sensors are believed to be CCTV, and vice versa, because of their location and automatic operation.

6. Another classification of active systems regarding their operation method is that some systems, such as the nursing and emergency call system, portable emergency pager and card key, require the press or pull method to send an emergency alarm, and others, such as movement detection sensor and CCTV, do not need the resident to do 
anything. Both systems' satisfaction rates vary, but there is a slight difference in awareness in which the systems with contact show higher figures. This is because the systems not only need an extra action to operate but also have a visibility regarding location.

7. The most necessary smart systems chosen by elderly interviewees are carerelated systems — specifically, the nursing and emergency call system—because They are directly related to emergency health situations and provide mental safety. Conversely, the most satisfactory technology was the security-related systemspecifically, the card key system- - because the residents used the card key every day and everywhere in the silver town (i.e., it had the highest frequency rate), and it provided direct benefits.

8. The elderly indicated that they were interested in using more technology in the future - especially technology that is smaller, lighter, easier and more convenient (e.g., an advanced wireless system without extra requirements, such as a combination of a portable emergency pager and a tracking system). Further, the perception of control over technology is embedded in the suggestion to modulate or manage it. However, the negatives of advanced technology systems in silver towns include financial concerns and the complicated image of smart technology.

9. Based on the interviews and site observations, the individual unit plans show few differences in terms of physical design and size. It is understood that the silver town design is not based on smart technology; that is, units and communal spaces are designed first, and then smart systems are applied. Thus, it is difficult to find significant design differences with general apartments. Unit sizes - especially in S tower-are much smaller than general apartments, and the elderly initially wanted a large-sized unit when S tower was developed; however, once they were settled, they changed their 
mind. Since GS tower was built, other selected silver towns have supplied diverse unit sizes to meet the demands of the elderly. Moving into smaller sized spaces and the many new technology systems combined with the seniors' healthy condition, causes interferences and self-modification of supporting technology to set up their own version of an optimal living environment. This shows the different considerations between household and furniture allocation by the elderly, and technology allocation by the developers.

10. Most technology that supports elderly living is relatively new, although smart technologies applied in general apartments have shown advanced development. This is because smart technologies in general apartments do not have to meet seniors' needs or concerns. Initially, residents in silver towns were unfamiliar with the smart systems, but they started to perceive that the technologies could support their independent living. This has provided high levels of awareness, satisfaction and psychological stability. Care-related systems, such as nursing and emergency call systems and movement detection sensors, combine the seniors' each individual unit space divided by walls to a whole one space because a number of systems are spread out around the unit. Further, wireless portable emergency pagers and card keys extend the elderly space from their personal unit to the entire silver town, which conveys mental stability in terms of security. However, these systems, excluding card keys, are currently not used by elderly residents with a medical condition or other burdens; thus, advantages have been provided to influence changes in spatial perception but mental relief has been the only merit for the elderly so far.

11. The research demonstrates emerging patterns of use and design of silver towns integrated with smart technology from the elderly perspective. There are two aspects which have caused changes in the patterns. Elderly demands and preferences 
regarding usage patterns of technology are one and the other is the benefits, especially mental stability, from possessing and using applied technology. These results require further development in regard to the design and usage of silver town with smart technology.

\subsection{Contributions to Knowledge and Practice}

There are a number of studies on the acceptance of technologies that develop an understanding of individuals' intentions, perceptions and behaviours to the use of technology. However, this research deals with a unique living environment and circumstance in Korea in which the elderly move to a new elderly-centred living place to maintain independent living and cohabit with those of a similar age group.

Developers have integrated smart technologies into the silver towns for the elderly to use as support systems. The research presents, for the first time, the elderly perspective of the smart technologies that support their independent living. It illustrates how their perceptions, acceptance and frequency of use make some changes in silver towns. That is, the new and unique elderly-only living environment is explored in relation to the fields of architecture and other research fields.

This study also contributes to other countries by presenting a new type of elderly-only living environment integrated with smart technology. Smart technology could be applied in a similar or different manner according to different circumstances, preference, demands and cultural backgrounds.

Previous research used a number of existing criteria in technology acceptance; however, this research has discovered additional factors to consider in the new living environment. These include other co-residents, in which the elderly person has indirect experiences with or is affected by other residents, and against elderly character and preference. Even though there are supportive technologies, the elderly prefer to follow 
their old habits or character unless technology overrides them. There are expectations and demands that there are more direct or indirect experiences via personal experience, Internet and media; that is, there are higher expectations regarding technology development.

Silver towns are a new phenomenon in the elderly-only living environment. Thus, they have been a research target in terms of social welfare, architecture and IT; however, until now, the elderly residents and silver towns have not been opened to the public. In this study, intensive interviews and surveys targeted the seniors, and site observations of personal units enabled the researcher to find gaps between the silver town developers' perspective and that of the elderly to understand applied technology and silver towns from both perspectives. In addition, it offers gaps between technology developers' understanding and current silver town users' comprehension regarding smart technology supporting elderly independent living.

There have been difficulties in further developing silver towns because of restricted information regarding silver towns and a lack of information regarding elderly residents' perspectives of silver towns integrated with smart technology. Thus, the research findings demonstrate significant considerations and targets for the next silver town development for existing as well as prospective developers.

Further, smart systems in silver towns are relatively less advanced than those in general apartments, but they are for elderly-only living environments, and many more smart technologies can be applied to fulfil seniors' demands. This research offers design guidelines to architects and designers. The study gives data in terms of elderly concerns and preference as guidelines to policy makers working with the government and seniorrelated smart technology developers. 
In addition, there has not been a method to find and gather information regarding silver town experience. The research provides information for prospective customers to choose an optimal silver town from information regarding current silver town and residents' perspectives in terms of living environment and smart technology.

\subsection{Future Research}

This research examines representative silver town cases in chronological sequence, and a higher number of interviewees than expected participated in the study. However, there were limitations in terms of inviting diverse interviewees with different experiences of living and using smart technology at different levels from other silver towns because of limited accessibility. These competitive circumstances limit research regarding silver town and its environment. In addition, the continuous development of silver towns produces the latest version of silver towns on a nationwide scale and it provides various approaches to comprehend this trend. Thus, more studies should examine the elderly perspective in different types of silver towns integrated with various smart technologies. In the meantime, having the extensive interviews lead a study, as a ethnography-based research, regarding users' experience of smart silver towns or smart technologies to comprehend the distinctive character of them. Additionally, research should continue into the middle-aged population's preferences as prospective customers to understand their demands and needs in relation to smart supporting systems.

It is certain that there is more advanced technology applied in general apartments for different purposes but the pace of silver town development is far behind and insufficient to accommodate the aged population, despite high demands. However, silver towns are in continuous development and application of smart technologies in silver towns are advancing, and it shows that aging in place is in progress in high-rise type living environments. Thus, another aspect is to compare the level of smart 
technology in general apartments to support the elderly with the level of applied supporting technology in silver towns. Moreover, as explained, silver towns are a new and unique elderly-only living environments. Thus, based on the evidence from additional data collection, these provide emerging patterns of silver town and building environment, as a grounded theory-based research, and comparisons could be made between silver towns and low-rise retirement or assisted living environments integrated with smart technology.

The research was begun with my parents who are similar to silver town residents' age. Neither of them have any problems maintaining independent living but they do have medical issues. For example, there is no difficulty in mobility but they do have concerns about their medical conditions. In addition, they are able to use a computer for the Internet and video chatting as well as a mobile phone in their 60s and 70 s but they are still afraid of using modern technology. Thus, the study was initiated to understand the conditions of the elderly, their concerns, their needs and desires in regard to a living environment which is elderly focused and is integrated with smart technology. The understanding of the elderly experience and preference in terms of smart technology integrated in unique and elderly-only living environments leads to further development in various ways. Especially, it is important to develop sustainability of elderly-centred living and the application of user-centred technology for supporting independent living. 


\section{Bibliography}

1. Hahn, J 1998, Residential differentiation and the structure of housing provision: a case study of Seoul, Korea, 1960-1990, doctoral thesis, University of Wisconsin-Madison.

2. Kim, J \& Choe, S 1997, Seoul: the making of a metropolis, John Wiley \& Sons, England.

3. Korea National Statistical Office 2007, Statistics on the aged, viewed July 2008 http://www.nso.go.kr/eng2006/e01__0000/e01b_0000/e01ba_0000/e01ba_00 00.html.

4. Choi, U \& Lee, S 2006, 'A case study on the spatial organization in public areas of silver town', Journal of the Korean Housing Association, vol. 17, no. 2, p. 151 .

5. Korea National Statistical Office 2006, Open 2008: result of the 2005 population and housing census, http://www.nso.go.kr/eng2006/e01 0000/e01b_0000/e01ba_0000/e01ba_00 00.html.

6. Yun, K, Lee, H \& Lim, S 2002, The growth of broadband internet connections in South Korea: contributing factors, working paper, Asia/Pacific Research Center, Stanford University.

7. Kim, Y 2007, 'Understanding of U-CITY', Construction Engineering/Ssang Yong, vol. 45, winter, pp. 25-28.

8. Korean Communications Commission, Dynamic IT Korea, viewed August 2008, http://www.dynamicitkorea.org/policy/itKorea.jsp. 
9. 'The core strategy of IT-839 is making "ubiquitous" environment' 2006, Digital Daily—Internet News, 2 August, viewed June 2008, http://www.ddaily.co.kr/news/news_view.php?uid=7702.

10. Yun, K, Lee, H \& Lim, S 2002, The growth of broadband internet connections in South Korea: contributing factors, working paper, Asia/Pacific Research Center, Stanford University.

11. Korean Association of Senior Industry, viewed July 2008, http://www.kasinet.or.kr.

12. Korea Institute for Health and Social Affairs, viewed August 2008, http://www.kihasa.re.kr/html/jsp/.

13. 'Silver town' n.d., Terminology Dictionary of Urban Planning of Seoul, viewed June 2017, http://terms.naver.com/entry.nhn?docId=1826417\&cid=42151\&categoryId=42 151.

14. 'Elderly' n.d., Oxford Living Dictionary, viewed June 2015, https://en.oxforddictionaries.com/definition/elderly.

15. 'Elderly' n.d., Mirriam-Webster, viewed June 2015, https://www.merriam-webster.com/dictionary/elderly.

16. 'Elderly' n.d., Mirriam-Webster, viewed June 2015, https://www.merriam-webster.com/thesaurus/elderly.

17. 'Enforcement regulation of the elderly welfare act' viewed Aug. 2017, http://www.law.go.kr/lsInfoP.do?1siSeq=178901\#0000

18. 'Smart Technology’ n.d., IGI Global, viewed June 2017, https://www.igiglobal.com/dictionary/smart-technology/38186. 
19. 'Smart system' 2017, Wikipedia, The Free Encyclopedia, viewed June 2017, https://en.wikipedia.org/wiki/Smart_system.

20. 'The core strategy of IT-839 is making “ubiquitous" environment' 2006, Digital Daily—Internet News, 2 August, viewed June 2008, http://www.ddaily.co.kr/news/news_view.php?uid=7702.

21. Kim, Y 2007, 'Understanding of U-CITY', Construction Engineering/Ssang Yong, vol. 45, winter, pp. 25-28.

22. Yun, K, Lee, H \& Lim, S 2002, The growth of broadband internet connections in South Korea: contributing factors, working paper, Asia/Pacific Research Center, Stanford University.

23. Korea National Statistical Office 2007, Statistics on the aged, viewed July 2010, http://www.nso.go.kr.

24. Choi, U \& Lee, S 2006, 'A case study on the spatial organization in public areas of silver town', Journal of the Korean Housing Association, vol. 17, no. 2, p. 151 .

25. He, W, Goodkind, D \& Kowa, P 2016, An aging world: 2015-international population reports, United States Census Bureau, Washington DC.

26. He, W, Goodkind, D \& Kowa, P 2016, An aging world: 2015-international population reports, United States Census Bureau, Washington DC.

27. Korea National Statistical Office 2011, Future population prospects: 2010 2060.

28. Korea National Statistical Office 2011, Future population prospects: 2010 2060.

29. He, W, Goodkind, D \& Kowa, P 2016, An aging world: 2015-international population reports, United States Census Bureau, Washington DC. 
30. United Nations, Department of Economic and Social Affairs, Population Division 2015, World population prospects: The 2010 revision—key findings and advance tables. United Nations, NY.

31. Korea National Statistical Office 2011, Future population prospects: 2010 2060.

32. United Nations, Department of Economic and Social Affairs, Population Division 2015, World population prospects: the 2010 revision—key findings and advance tables. United Nations, NY.

33. Korean Statistical Information Service, Future Population Prospect 2013-2040, viewed august 2016, http://kosis.kr/statHtml/statHtml.do?orgId=101\&tblId=DT_1BPB002\&vw_cd= MT_OTITLE\&list_id=MT_CTITLE_E_3\&scrId=\&seqNo=\&lang_mode=ko\& obj_var_id=\&itm_id=\&conn_path=E1\#.

34. Yun, K, Lee, H \& Lim, S 2002, The growth of broadband internet connections in South Korea: contributing factors, working paper, Asia/Pacific Research Center, Stanford University.

35. eMarketer 2007, Internet users and penetration in select countries in the AsiaPacific Region, 2005-2011, viewed August 2008, http://www.emarketer.com/SiteSearch.aspx?pageNum=15\&arg=Korea.

36. Internet World Stats 2016, Top 20 countries with the highest number of internet users, viewed November 2016, http://www.internetworldstats.com/top20.htm.

37. Internet World Stats 2016, Top 20 countries with the highest number of internet users, viewed November 2016, http://www.internetworldstats.com/top20.htm. 
38. Akamai 2017, Q1 2017 state of the internet, viewed June 2017, https://www.akamai.com/us/en/about/our-thinking/state-of-the-internetreport/global-state-of-the-internet-security-ddos-attack-reports.jsp.

39. Korea Statistical Information Service 2016, Personal computer possession rate by household ages, viewed March 2016, http://kosis.kr/.

40. Ministry of Science, ICT and Future Planning and Korea Internet \& Security Agency 2015, Survey on internet usage, viewed March 2016, http://www.index.go.kr/potal/main/EachDtlPageDetail.do?idx_cd=1345.

41. National IT Industry Promotion Agency, U-IT839 Strategy, viewed May 2015, https://www.nipa.kr/cyber/historySub.it?value=history_2001_5.

42. Korean Communications Commission, Dynamic IT Korea, viewed August 2008, http://www.dynamicitkorea.org/policy/itKorea.jsp.

43. Futurize Korea 2008, Ubiquitous dream hall, viewed 2008, http://futurize.tistory.com/80.

44. Futurize Korea 2008, Ubiquitous dream hall closed, viewed 2008, http://futurize.tistory.com/191.

45. Korea Ubiquitous City Association, Concept of U-City, viewed September 2015, http://www.ucta.or.kr/en/ucity/concept.php.

46. Kim, Y 2007, 'Understanding of U-City', Construction Engineering/Ssang Yong, vol. 45, winter, pp. 25-28.

47. Uhm, J 2006, 'U-City strategy: discourses and visions for the realization of ubiquitous future city: from ideas to cases', in 2006 U-City International Symposium Proceedings, Housing and Urban Research Institute, pp. 186-196. 
48. Gyeonggi-do, Seongnam-si, Korea Land Corporation, Korea National Housing Corporation 2006, The construction scheme of U-City in Seongnam and Pankyo: summary of researches.

49. Pajuunjeong U-City, U-City exhibition center, viewed 2015, http://ucity.paju.go.kr/public/promote.html.

50. Ubiquitous Journal 2013, 'Opening of U-City control center at city of Osan' Ubiquitous Journal web log post, 30 December, viewed 2014, http://blog.naver.com/ubsmart/90187400853.

51. Seongnam City, Seongnam U-City control center, viewed 2016, http://www.seongnam.go.kr/city/1000477/10349/contents.do.

52. Ministry of Land, Infrastructure and Transport 2016, Card news-leading the world by smart city, viewed August 2016, http://www.molit.go.kr/USR/NEWS/m_35045/dtl.jsp?lcmspage=1\&id=950778 73.

53. Songdo IBD, Smart city plan, viewed December 2010, http://songdoibd.tistory.com/1081.

54. 'Incheon Songdo, smart city connected to ICT' 2017, SBS CNBC, 31 January, viewed February 2017, http://sbscnbc.sbs.co.kr/read.jsp?pmArticleId=10000844956.

55. Gwangmyeong City, Smart city strategy, viewed June 2017, http://www.gm.go.kr/pt/user/bbs/BD_selectBbs.do?q_bbsCode=2045\&q_bbsctt $\mathrm{Sn}=20170613142614327$

56. 'Sejong city to K-smart city' 2017, Inews365, 2 February, viewed March 2017, http://www.inews365.com/news/article.html?no=480997. 
57. Busan IT Industry Promotion Agency, Global smart city, viewed August 2016, http://k-smartcity.kr/english/index.php.

58. Woo, JS 2017, 'Exporting Korea's smart city plan to India', MKNews, 7 April, viewed April 2017, http://news.mk.co.kr/newsRead.php?year=2017\&no=237281.

59. Song, J 2017, 'Korea's smart city, exporting to Kuwait...construction begins in 2019', Weeklytoday, 4 April, viewed April 2017, http://www.weeklytoday.com/news/articleView.html?idxno=55548.

60. Dream Home-LG, viewed September 2015, http://www.lghomnet.co.kr/.

61. Lee, S 2016, 'Dongtan Daewoo Prugio's city officetel apply SKT smart home service', Edaily, 10 October, viewed November 2016, http://www.edaily.co.kr/news/NewsRead.edy?SCD=JD31\&newsid=019975266 $12811608 \& \mathrm{DCD}=\mathrm{A} 00403 \&$ OutLnkChk $=\mathrm{Y}$.

62. SK Telecom, Smart home by SK telecom-smart apartment, viewed January 2017, https://www.sktsmarthome.com/html/apartment.html.

63. Cho, J \& Kim, M 2006, 'Study on space composition analysis of the local old age experience hall', Proceedings of Korean Institute of Interior Design, vol. 8, no. 1 , pp. $173-178$.

64. Lee, Y \& Suh, H 2005, 'A study on space formation of the senior simulation center', Proceedings of Korean Institute of Interior Design, vol. 14, no. 3, pp. $156-164$.

65. Miraeseum Seongnam Senior Complex 2008, Miraeseum - Seongnam Senior Complex, viewed 2010, http://www.miraeseum.or.kr/.

66. Z-Works, viewed May 2016, http://z-works.co.jp/index_en.html. 
67. MashableAustralia 2015, Japan's NTT to put home care robot's in the home of the elderly, viewed October 2015, http://mashable.com/2015/07/29/japanhome-care-robot/\#wxqAizE55kqK.

68. Aware Home, viewed September 2015, http://awarehome.imtc.gatech.edu/.

69. MIT PlaceLab, viewed September 2015, http://web.mit.edu/cron/group/house_n/placelab.html.

70. Oatfield Estates - Elite Care Corporation, viewed September 2015, http://www.elitecare.com/.

71. INTEGER Project, viewed February 2015, http://www.integerasia.org.

72. Kim, J, Kim, JK 1995, 'A study on typological analysis of traditional urban housing', Proceedings of the Architectural Institute of Korea, vol. 11 (12), pp. 23-29.

73. Song, I 2002, 'Traditional urban housing vs multi-family housing', Architecture and Culture, November, pp. 120-122.

74. Kim, Y \& Cho, S 2008, 'A study on the change process of unit plan multi complex housing', Proceedings of the Architectural Institute of Korea, vol. 24, no. 2 , pp. 253-260.

75. Yoo, J 2004, 'A study on the transforming characteristics of the housing plan types in modernizing period of Korea', Proceedings of the Architectural Institute of Korea, vol. 20, no. 10, pp. 59-66.

76. Kim, S \& Kim, S 1993, 'A study on the changes of apartment housing plan in Korea', Proceedings of the Architectural Institute of Korea, vol. 13, no. 2, p. 113. 
77. Park, I 2008, 'The development of house through apartment', Herald Media, 14 August, viewed October 2008, http://www.heraldbiz.com/SITE/data/html_dir/2008/08/14/200808140082.asp.

78. Kim, J \& Choi, C 2007, 'A study on the change of area division in accordance with each room of the unit plan of apartment—-focused on the public housing size below in Seoul', Proceedings of the Architectural Institute of Korea, vol. 23, no. 5, p. 159 .

79. Shin, J, Suh, K, Heo, J, Kim, H \& Kim, C 2002, 'A study on the unit plan characteristics of the recent super-high-rise-apartment', Proceedings of the Architectural Institute of Korea, vol. 18, no. 8, pp. 11-22.

80. Kim, J \& Choe, S 1997, Seoul: the making of a metropolis, John Wiley \& Sons, England.

81. Kang, J 2005, 'Mystery of "the republic of apartments", The Hankyoreh, 2 Decmeber, viewed October 2008, http://www.hani.co.kr/section021128000/2005/12/021128000200512210590007.html.

82. Kim, S 2006, 'Time of life, face of time', Heungkuk, viewed October 2008, <http://www.hungkuk.co.kr/>.

83. Korea National Statistical Office 2007, Statistics on the aged, viewed July 2007, http://www.nso.go.kr/.

84. 'Why are Koreans so addicted to apartment?' 2007, Chosun Ilbo, 24 April, viewed November 2008, http://english.chosun.com/w21data/html/news/200704/200704240024.html.

85. Statistics Korea 2016, Result of the 2015 population and housing census, viewed January 2017 , 
http://www.kostat.go.kr/portal/korea/kor_nw/2/1/index.board?bmode=read\&aS eq $=356061$.

86. Yoo, J \& Cho, S 2001, 'The characteristics and the influences of standard urban housing in Korea between the 1950's and the early 1980's', Proceedings of the Architectural Institute of Korea, vol. 17, no. 12.

87. Choi, J, Cho, H, Park, I \& Park, Y 2004, 'A spatial analysis of the apartment unit plans from 1966 to 2002 in Seoul', Proceedings of the Architectural Institute of Korea 2004, vol. 20, no. 6, p. 159.

88. Ko, Y, Lee, S, Lee, K \& Kim, Y 2003, 'A study of transformation tendency of an apartment unit plan after the enforcement of price deregulation', Proceedings of the Architectural Institute of Korea, vol. 23, no. 2, pp. 79-82.

89. Ko, Y, Lee, S, Lee, K \& Kim, Y 2003, 'A study of transformation tendency of an apartment unit plan after the enforcement of price deregulation', Proceedings of the Architectural Institute of Korea, vol. 23, no. 2, pp. 79-82.

90. Oh, H \& Kim, D 2001, 'A study on space composition and the trend for interior design of the luxurious apartment', Proceedings of the Architectural Institute of Korea, vol. 27, p. 114.

91. Shim, W, Kang, S \& Cho, J 2000, 'A comparative analysis on housing unit plans of Korea, China and Japan', Proceedings of the Architectural Institute of Korea, vol. 16, no. 11.

92. Lee, K, Park, S \& Lee, H 2005, 'An analysis of the space size in the apartment unit plan', Proceedings of the Korean Institute of Interior Design, vol. 7, no. 2, pp. 52-55.

93. Korean Statistical Information Service (KOSIS) 2016, Number of houses and distribution rate of house, updated, viewed 2016, http://kosis.kr/. 
94. 'Why are Koreans so addicted to apartment?' 2007, Chosun Ilbo, 24 April, viewed November 2008, http://english.chosun.com/w21data/html/news/200704/200704240024.html.

95. Ministry of Land, Infrastructure and Transport, Korean Statistical Information Service 2015, Current status of number of floors of apartment, viewed December 2015, http://kosis.kr/.

96. Kim, C \& Park, Y 2007, 'Demand of the old life preparation for following in the thread silver town of the specialist group analysis', Korean Institute of Culture Architecture Journal, vol. 18, p. 45.

97. Choe, E 1970, 'Current and future prospects on problems of aging in the Republic of Korea', in Population aging: review of emerging issues, United Nations Economic and Social Commission for Asia and the Pacific, Bangkok.

98. Choi, J 1970, 'Comparative study on the traditional families in Korea, Japan and China', in R Hill \& R Koeing (eds), Families in East and West, Mouton, Paris pp. 202-210.

99. Sung, K 1995, 'Measures and dimensions of filial piety in Korea', Gerontologist, vol. 35, no. 2, pp. 240-247.

100. Kim, I 1999, 'Population aging in Korea', Journal of Sociology \& Social Welfare, vol. 26, no. 1, pp. 101-123.

101. Ministry of Health and Welfare \& Korean Statistical Information Service, The research on current condition of the elderly, viewed October 2016, http://stat.mohw.go.kr/, http://kosis.kr/.

102. 'Change of method of approach in terms of policy is important to promote silver industry', Newstomato, viewed September 2016, http://www.newstomato.com/ReadNews.aspx?no=691973. 
103. Ministry of Health and Welfare, Estimate of silver industry, viewed July 2016, http://stat.mohw.go.kr/.

104. 'It is now spending money for myself...5060, becoming major consumers' 2013, Senior Chosun, 19 June, viewed July 2014, http://senior.chosun.com/site/data/html_dir/2013/06/19/2013061900913.html. 105. inistry of Health, Welfare and Family Affairs, Social welfare services, viewed June 2008, http://english.mw.go.kr/.

106. Seoul Seniors Tower, viewed August 2008, http://www.sst.co.kr/eng.

107. Ministry of Health and Welfare \& Korean Statistical Information Service, The research on current condition of the elderly, viewed October 2016, http://stat.mohw.go.kr/, http://kosis.kr/.

108. Kwon, JT 2015, 'An analysis of the current situation and development trends of housing for the elderly (silver town)', Master's thesis, Semyung University, Jecheon.

109. 'GS E\&C Corporation announce launching a silver town building, the one would be a role model for senior housing' 2016, Bridgenews, viewed November 2016, http://www.viva100.com/main/view.php?key=20161031010008576.

110. 'Lotte hotel conclude memorandum of understanding (MOU) with Bobath Memorial Hospital' 2016, Herald Corporation, viewed November 2016, <http://news.heraldcorp.com/view.php?ud=20161104000017>.

111. Banham, R 1984, The architecture of the well-tempered environments, University of Chicago Press, Chicago.

112. Silverstone, R \& Hirsch, E (eds) 2003, Consuming technologies—media and information in domestic spaces, Routledge, London. 
113. Harper, R (ed.) 2003, Inside the smart home, Springer, London.

114. Aldrich, F 2003, 'Smart homes: past, present and future', in R Harper (ed.), Inside the smart home, Springer, London, pp. 17-39.

115. Kim, J \& Choe, S 1997, Seoul: the making of a metropolis, John Wiley \& Sons, London. Valérie, G \& Kil, H (ed.) 2007, The republic of apartments, Humanitas, Seoul.

116. Demiris, G, Rantz, M, Aud, M, Marek, K, Tyrer, H, Skubic, M \& Hussam, A 2004, 'Older adults' attitudes towards and perceptions of "smart home" technologies: a pilot study', Journal of Medical Informatics and the Internet in Medicine, vol. 29, no. 2, pp. 87-94.

117. Kim, M, Lee, J \& Lee, Y 2007, 'A study of elderly preference on living arrangement using small group workshop method', Proceedings of the Architectural Institute of Korea, vol. 7, no. 1, pp. 311-317.

118. Lee, C 2014, 'A survey on residential environment's improvement plan of silver town by means of applying ubiquitous systems', Proceedings of Korea Society of Geothermal Energy Engineers, vol. 10, no. 4, pp. 8-14.

119. Hwang, J 2015, 'An analysis of the research and policy on the smart home design for the elderly based on the u-healthcare', Proceedings of the Architectural Institute of Korea, vol. 31, no. 4, pp. 53-60.

120. Kim, M \& Lee, Y 2007, 'Preference of consumers after late 40's for development future home network services', Proceedings of Korea Institute of Ecological Architecture and Environment, vol. 7, no. 2, pp. 47-55.

121. Ha, J \& Kwak, J 2007, ‘A research on the service environment evaluation elements for development of the silver town', Journal of the Korean Housing Association, vol. 18, no. 5, pp. 143-150. 
122. Chai, S 2013, A study on the preference determinants of consumers for silver town, Doctoral thesis, Hoseo University, Cheonan.

123. Kang, N 2012, 'Determinants of choosing to live in silver town for supply of dwelling environments of elder', Proceedings of Korea Institute of Ecological Architecture and Environment, vol. 12, no. 2, pp. 103-110.

124. Kim, M, Won, Y \& Lee, J 2014, 'A study of the elderly housing type development plan considering the preconsumer housing characteristic-focused on Seoul metropolitan area', Journal of the Korea Academia-Industrial Cooperation Society, vol. 15, no. 5, pp. 2844-2858.

125. Kim, J, Kim, S, Kim, J \& Jang, J 2016, 'A study on preference characteristic of silver town and inclination to move in (실버타운 선호특성과 입소의향에 대한 연구)', Journal of the Korean Urban Management Association, vol. 29, no. 2, pp. 1-23.

126. Kwon, JH, Park, SH \& Kim, EJ 2016, 'A study on the characteristics of location factors of urban silver town - focused on the urban silver town in the Seoul metropolitan area', Proceeding of the Korean Housing Association, vol. 28, no. 1, pp. 101-105.

127. Park, SY 2015, A strategy to invigorate attraction of silver town, Policy Note No. 449, pp. 1-12, Research Institute for Gangwon.

128. Seo, Y \& Kim, M 2006, 'A study on the paid residential space for the elder from a marketing perspective', Proceedings of Korean Institute of Interior Design, vol. 8, no. 2, pp. 74-80.

129. Won, NK 2013, A study of decision factors of intension to move in silver town — focus on the preliminary silvers and preliminary seniors residing in 
Seoul and Kyoungki area, Master's thesis, Graduate School of Public Policy, Hanyang University, Seoul.

130. Kwon, JT 2015, An analysis of the current situation and development trends of housing for elderly (SilverTown), Master's thesis, Semyung University, Jecheon.

131. Song, N \& Nam, K 2011, 'A study on the smart design in public space of urban type silver town - focusing on the lifestyle of active seniors', Proceedings of Korea Digital Design Council, vol. 11, no. 3, pp. 164-172.

132. Song, N 2011, A study on the design of the smart silver town in urban type for active senior, Master's thesis, Hanyang University, Seoul.

133. Lim, E \& Hwang, Y 2011, 'A study on the planning and design characteristics of public space in urban silver town', Proceedings of Korean Space Design Association, vol. 5, no. 5, pp. 65-73.

134. Lee, H, Yoon, H \& Kim, Y 2007, 'A study on senior residences in a u-city', Bulletin of Japanese Society for the Science of Design, pp. 150-151.

135. Choi, Y, Park, B \& Choi, Y 2010, 'Design and implementation of location based silver town u-service system', Proceedings of Korean Society for Internet Information, vol. 11, no. 3, pp. 53-63.

136. Choi, M, Lee, J \& Joe, I 2012, 'Design and implementation of the agingfriendly telemedicine system based on cps for silver town', Proceedings of the Korean Institute of Communications and Information Sciences, vol. 37C, no. 8, pp. 690-696.

137. Jeoung, Y, Na, S, Park, J \& Rhee, E 2006, 'A study on the resident's needs for planning sustainable ubiquitous apartment houses', Proceedings of the Architectural Institute of Korea, vol. 6, no. 2, pp. 73-80. 
138. Oh, C \& Lee, H 2006, 'Space design of digital home from the perspective of digital life style', Journal of Asia Interior Design Institute Association, vol. 6, pp. $48-56$.

139. Lee, J \& Nam, K 2015, ‘An analysis of smart home technology applied cases based on IoT (Internet of Things) — focused on major domestic apartment brand model houses', Proceedings of Korean Institute of Interior Design, vol. 18, no. 39, pp. 234-237.

140. Ahn, M 2004, Older people's attitude toward residential technology: the role of technology in aging in place, Doctoral thesis, Faculty of Virginia Polytechnic Institute and State University, VA.

141. Mynatt, E, Rowan, J, Jacobs, A \& Craighill, S 2001, 'Digital family portraits: supporting peace of mind for extended family members', Proceedings of SIGCHI 2001 Conference on Human Factors in Computing Systems, vol. 3, no. 1, pp. 333-340.

142. Blanson Henkemans, O, Caine, K, Rogers, W, Fisk, A, Neerincx, M \& de Ruyter, B 2007, 'Medical monitoring for independent living: user-centered design of smart home technologies for older adults', Proceedings of the Med-eTel Conference for eHealth, Telemedicine and Health Information and Communication Technologies, pp. 368-373.

143. Helal, S, Mann, W, El-Zabadani, H, King, J, Kaddoura, Y \& Jansen, E 2005, 'The Gator Tech smart house: a programmable pervasive space', IEEE Computer Society, vol. 38, no. 3, pp. 64-74.

144. Oatfield Estates-Elite Care Corporation, viewed September 2008, http://www.elitecare.com/. 
145. Supportive Technology and Design for Healthy Aging Conference, University of Washington, 11-12 May 2007, http://www.aia.org/SiteObjects/files/Supportive\%20Tech\%20Handouts.pdf.

146. Davis, FD 1986, A technology acceptance model for empirically testing new end-user information systems: theory and results, unpublished doctoral thesis, Sloan School of Management, Massachusetts Institute of Technology.

147. Davis, FD 1989, Perceived usefulness, perceived ease of use, and user acceptance of information technology, MIS Quarterly, vol. 13, no. 3, pp. 319340.

148. Fishbein, M \& Ajzen, I 1975, Belief, attitude, intention and behavior: an introduction to theory and research reading, Addison-Wesley, MA.

149. Venkatesh, V \& Davis, FD 2000, 'A theoretical extension of the technology acceptance model: four longitudinal field studies', Management Science, vol. 46, no. 2, pp. 186-204.

150. Bagozzi, RP 2007, 'The legacy of the technology acceptance model and a proposal for a paradigm shift', Journal of the Association for Information Systems, vol. 8, no. 4, pp. 244-254.

151. Venkatesh, V, Morris, MG, Davis, GB \& Davis, FD 2003, 'User acceptance of information technology: toward a unified view', MIS Quarterly, vol. 27, no. 3, pp. $425-478$.

152. Chen, K \& Chan, A 2014, 'Gerontechnology acceptance by elderly Hong Kong Chinese: a senior technology acceptance model (STAM)', Ergonomics, vol. 57, no. 5 , pp. 635-652.

153. Mishra, BH 2015, Attitude of senior citizens towards smart home technologies: literature review, degree thesis, Human Ageing and Elderly Service, ARCADA. 
154. Weegh, H \& Kampel, M 2015, 'Acceptance criteria of ambient assistant living technologies', Studies in Health Technology and Informatics, vol. 217, pp. 857864.

155. Evans, SJ 1991, 'Good survey guide’, BMJ, vol. 302, pp. 302-303.

156. Fincham, JE 2008, 'Response rates and responsiveness for surveys, standards, and the journal', American Journal of Pharmaceutical Education, vol. 72, no. 2, pp. 1-3.

157. Holbrook, A, Krosnick, J \& Pfent, A 2007, 'The causes and consequences of response rates in surveys by the news media and government contractor survey research firms', in JM Lepkowski, NC Tucker, JM Brick, ED De Leeuw, L Japec, PJ Lavrakas, MW Link \& RL Sangster (eds), Advances in telephone survey methodology, Wiley, New York, pp. 499-678,

158. Mason, M 2010, 'Sample size and saturation in PhD studies using qualitative interviews', Forum: qualitative social research, vol. 11, no. 3, http://www.qualitative-research.net/index.php/fqs/article/view/1428/3027.

159. Bryman, A 2012, Social research methods $-4^{\text {th }}$ edition, Oxford University Press, United Kingdom.

160. Statistics Korea 2017, An analysis of character and changes in different lifetime stages, viewed May 2017, http://kostat.go.kr/portal/korea/index.action.

161. Consumer Injury Surveillance System of Korea Consumer Agency 2013, An analysis of safety accident of the elderly, viewed April 2017, http://www.ciss.go.kr/www/index.do. 


\section{Appendices}

\section{Appendix 1. Interview Questions for Elderly—English}

\section{Smart Silver Towns: Prospects and Challenges}

$\underline{\text { Introducing Me and Research Aims }}$

My name is Mr Sung Jun Kim and PhD candidate in Faculty of Architecture, Building and Planning at The University of Melbourne. The aim of the research is to investigate changes in design and patterns of use in silver towns integrated with smart technologies from the perspective of aged residents.

The purpose of this interview is to understand in detail your awareness and usage of smart technologies, and also which smart technologies work or not. More importantly, we would like to understand the reasons for using or not using smart technologies based on your experiences and opinions. The interview will allow us to highlight changes in the aged living and space usage patterns due to smart technologies as perceived by the elderly residents. Additionally, we want to know what you may find more desirable in future developments.

Your cooperation and willingness to share time and information are much appreciated. Thank you very much.

Opening Questions

1. Please tell me your name, age, flat number and name of silver town.

2. How long have you lived here?

3. Is there any reason that you have decided to move in silver town? If you have, could you briefly tell me about the reasons? 


\section{$\underline{\text { Transition Question }}$}

4. At one time, we lived without Internet, cell phone or even computer. Now we use smart technology on a daily basis at home and work. How do you feel about these changes?

\section{$\underline{\text { Key Questions }}$}

5. Are you aware of smart technologies embedded in your place? (Presenting list)

\begin{tabular}{|c|c|c|}
\hline Location & Purpose & Technology systems applied in Silver towns \\
\hline \multirow{3}{*}{$\begin{array}{l}\text { Technology in } \\
\text { Individual Living Unit }\end{array}$} & Care & $\begin{array}{l}* \text { Real-time health check system } \\
* \text { Nursing \& emergency call system } \\
* \text { Movement detection sensor } \\
* \text { Tracking system } \\
* \text { Portable emergency pager }\end{array}$ \\
\hline & $\begin{array}{l}\text { Environment } \\
\text { control }\end{array}$ & $\begin{array}{l}* \text { Indoor air quality control system } \\
* \text { Lighting control/energy saving } \\
* \text { Elevator call system } \\
* \text { Remote inspection }\end{array}$ \\
\hline & Security & $\begin{array}{l}* \text { Monitoring system } \\
* \text { Card key system }\end{array}$ \\
\hline $\begin{array}{l}\text { Technology in } \\
\text { Communal Facilities }\end{array}$ & - & $\begin{array}{l}* \text { CCTV } \\
* \text { Movement detection sensor } \\
* \text { Parking control }\end{array}$ \\
\hline
\end{tabular}

6. Do you know the locations of technologies that you are aware of?

If yes, could you show me where it is?

7. Do you know how to use those technologies that you are aware of?

If yes, could you briefly explain how does it operate and how did you learn to use them?

8. Which technology is the most preferred and useful?

9. Why do you think it is the most preferred and useful technology? 
10. Which technology is the least preferred and useful?

11. Why do you think it is the least preferred and useful technology?

12. Could you find any differences in space structure between previous and current living space?

If yes, tell me about the differences. In addition, if these changes have been created due to the usage of smart technology, tell me about more details.

13. Have there been any changes in the usage of living spaces due to availability of smart technology?

If yes, please give details of these changes?

(Providing some examples of changes in the usage of living space and space structure)

14. Development of technology applied in silver towns is remarkable. How do you think of more and more technology application in silver town as well as changes in your living environment caused by technology usage?

\section{Ending Questions}

15. If you have a chance to give advice to the designers and developers involved in development of the aged living environment, what advice would you give them in terms of technology?

16. What kind of technology will be needed in the elderly living space for future development?

Thank you very much for your time. 


\section{Appendix 2. Interview Questions for Elderly-Korean}

\section{스마트 실버타운: 향후 전망과 도전}

\section{개인 및 연구 목적 소개}

안녕하십니까? 인터뷰에 참석해 주셔서 감사 드립니다.

제 이름은 김성준 입니다. 중앙대학교 건축학과 건축환경 연구실에서 석사과정을 마치고 현재는 호주 엘버른 대학교 건축학과 (Faculty of Architecture, Building \& Planning, The University of Melbourne) 박사과정에 있습니다.

본 연구는 실버타운에 적용되어 있는 스마트 기술들이 노인들의 생활환경과 생활공간 이용에 어떤 영향을 미치고 어떤 변화를 가져왔는지 노인들의 관점에서 알아보기 위한 것입니다.

본 인터뷰의 목적은 첫째, 노인들의 생활공간에 적용된 스마트 기술에 대한 노인들의 인지상태를 파악하고 기술 사용여부와 그 이유에 대해 알아보는 것입니다. 둘째, 스마트 기술 사용으로 노인들의 생활공간에서 발생된 변화와 생활공간 이용 패턴에 대해 알아보는 것입니다. 또한 노인들의 생활공간에 스마트 기술 적용의 발전 방향에 대해서도 알아보고자 합니다.

인터뷰에 참여하여 주셔서 대단히 감사 드립니다.

\section{Opening Questions}

1. 귀하의 이름과 나이 그리고 주소를 말씀해 주십시오.

2. 귀하께서는 실버타운에 거주 하신지 얼마나 되셨는지 말씀해 주십시오.

3. 귀하께서 실버타운에 입주하신 이유가 있으시면 말씀해 주십시오.

\section{Transition Question}


4. 과거에는 휴대용 무선전화기나 컴퓨터가 없이도 생활하였습니다. 하지만 현재는 많은 스마트 기술을 집과 직장에서 사용하며 생활하고 있습니다. 이러한 변화에 대하여 어떻게 생각하시는지 개인의 느낌이나 의견을 말씀해 주십시오. (스마트 기술에 관한 기본 개념 및 예를 설명한다.)

\section{Key Questions}

5. 아래에 나열된 스마트 기술들이 현재 거주하고 계신 생활공간에 적용되어 있는 것을 알고 계시는지요?

\begin{tabular}{|c|c|c|}
\hline 구분 & 목적 & 실버타운에 적용된 스마트 기술 \\
\hline \multirow{3}{*}{$\begin{array}{l}\text { 개인 } \\
\text { 생활공간에 } \\
\text { 적용된 기술 }\end{array}$} & 건강한 생활 & $\begin{array}{l}\text { * 실시간 건강검진 시스템 } \\
\text { * 응급호출 시스템 } \\
\text { * 무선 위치 확인 시스템 } \\
\text { * 무선 응급 호출기 } \\
\text { * 무 동작 감지 센서 }\end{array}$ \\
\hline & $\begin{array}{l}\text { 생활환경 } \\
\text { 관리 }\end{array}$ & $\begin{array}{l}\text { * 실내환경 자동제어 시스템 } \\
\text { * 에너지 절약 (전등 조절 등) 관련 시스템 } \\
\text { * 엘리베이터 호출 시스템 } \\
\text { * 자동 검침 (가스, 전기 등) 시스템 }\end{array}$ \\
\hline & 안전한 생활 & $\begin{array}{l}\text { * 실내환경 자동제어 시스템 } \\
\text { * 카드 키 시스템 }\end{array}$ \\
\hline $\begin{array}{l}\text { 부대시설에 } \\
\text { 적용된 기술 }\end{array}$ & - & $\begin{array}{l}\text { * CCTV 시스템 } \\
\text { * 동작 감지 센서 } \\
\text { * 주차관리/상태 확인 시스템 }\end{array}$ \\
\hline
\end{tabular}

6. 생활공간에 적용된 스마트 기술들의 위치를 알고 계십니까? 알고 계시다면 위치를 말씀해 주십시오. 
7. 생활공간에 적용된 스마트 기술들의 사용방법에 대하여 알고 계십니까? 알고 계시면 간단하게 사용방법과 사용방법을 익히신 경로에 관하여 말씀해 주십시오.

8. 적용된 기술 중에 어떠한 기술을 가장 선호하시며, 유용하다고 생각하시는지 말씀해 주십시오.

9. 8 번의 기술을 선택하신 이유를 말씀해 주십시오.

10. 적용된 기술 중에 어떠한 기술을 가장 덜 선호하시며, 필요하지 않다고 생각하시는지 말씀해 주십시오.

11. 10 번의 기술을 선택하신 이유를 말씀해 주십시오.

12. 기존 거주지의 생활공간과 현재 생활공간을 비교했을 때, 생활 공간 구조에 다른 점이 있다면 무엇인지 말씀해 주십시오. 그리고, 말씀하신 변화 중에 스마트 기술의 사용으로 인한 구조 변화가 있다면 말씀해 주십시오.

13. 적용된 스마트 기술 사용으로 인해 생활공간 사용에 변화가 생긴 것이 있다면 말씀해 주십시오.

(구조변화와 생활공간 사용의 변화에 대한 구체적인 예를 제시하여 이해를 쉽도록 한다.)

14. 실버타운에 적용된 스마트 기술을 보면, 예전과 비교하여 많은 변화가 있음을 알 수 있습니다. 이처럼 스마트 기술의 실버타운 적용이 다양해지는 것과 이로 인해 생기는 생활환경의 변화에 대해서는 어떻게 생각하시는지 말씀해 주십시오. 


\section{Ending Questions}

15. 만약, 귀하의 말씀이 노인 생활환경 개발에 반영된다면, 스마트 기술 적용에 관하여 디자이너와 개발자들에게 하고 싶으신 말씀을 해 주십시오.

16. 향후 스마트 기술을 적용한 노인 생활환경 개발에 있어서 적용되는 것이 바람직하다고 생각되는 스마트 기술이 있으면 말씀해 주십시오.

이상입니다. 인터뷰에 참여해 주셔서 대단히 감사 드립니다. 귀하의 건강과 댁내 평안을 기원합니다. 


\section{Appendix 3. Interview Questions for Developers-English}

\section{Smart Silver Towns: Prospects and Challenges}

$\underline{\text { Introducing Me and Research Aims }}$

My name is Mr Sung Jun Kim and PhD candidate in Faculty of Architecture, Building and Planning at The University of Melbourne. The aim of the research is to investigate changes in design and patterns of use in silver towns integrated with smart technologies from the perspective of aged residents.

The purpose of the interview is to identify and examine range of smart technologies introduced in the silver town. We are interested to understand operation and locations of smart technologies in silver town as well as any other relevant views about smart technologies in the elderly living environment. Additionally, we request copies of building layouts (i.e. drawings including site plans, unit plans, and other relevant details) and other supporting materials such as photographs which will help us understand and describe better integration of technologies in silver town.

Your cooperation and willingness to share time and information are much appreciated.

Thank you very much.

Opening Questions

1. Please tell me your name, formal position and the company name that manages the silver town project.

\section{$\underline{\text { Key Questions }}$}

2. Please tell me about specific smart technologies applied in silver town.

3. Where are these technologies located in the silver town?

4. What are the reasons for selecting these technologies in silver town? 
5. How does the technology operate?

6. What are the reasons for locating technology in specific spaces in silver town?

7. Has the integration of technology in living environments required changes to unit and silver town layouts? If yes, in what ways?

\section{Ending Questions}

8. If you have a chance to give advice to the designers and developers involved in development of the aged living environment, what advice would you give them in terms of technology?

9. What kind of technology will be needed in the elderly living space for future development?

\section{$\underline{\text { Requesting Data }}$}

10. We would like to obtain copies of building layouts (i.e. drawings including site plans, unit plans), applied technology details and other supporting materials such as photographs to help us understand and describe better integration of technologies in silver towns. From where can I obtain copies of these drawings?

Thank you very much for your time. 


\section{Appendix 4. Interview Questions for Developers—Korean}

\section{스마트 실버타운: 향후 전망과 도전}

\section{개인 및 연구 목적 소개}

안녕하십니까? 인터뷰에 참석하여 주셔서 감사 드립니다.

제 이름은 김성준 입니다. 중앙대학교 건축학과 건축환경 연구실에서 석사과정을 마치고 현재는 호주에 있는 엘번대학교 (The University of Melbourne) 건축학과에서 박사과정을 진행하고 있습니다.

본 연구의 목적은 노인들의 관점에서, 실버타운에 적용되어 있는 스마트 기술들이 노인들에 미친 영향으로 인하여 노인들의 생활환경과 생활공간 이용에 어떠한 변화를 가져왔는지를 알아보는 연구입니다.

본 인터뷰의 목적은 다음과 같습니다.

우선, 실버타운에 적용된 스마트 기술을 알아봅니다. 그리고 적용된 기술들의

작동방법과 설치위치, 노인환경에 적용한 이유에 대하여 알아보는 것을 목적으로 하고 있습니다.

또한, 본 연구를 위하여 건물의 설계도 및 관련 도면과 사진들 그리고 실버타운에 적용된 기술의 이해를 도울 수 있는 시스템 관련 자료와 사진들 제공을 부탁 드리는데 있습니다.

인터뷰에 참여해 주셔서 대단히 감사 드립니다.

\section{Opening Questions}

1. 귀하의 이름과 현재 직위 그리고 근무지를 말씀해주시고, 실버타운 개발에 참여하신 타운 이름을 말씀해 주십시오..

\section{Key Questions}


2. 현재 실버타운에 적용되어 있는 스마트 기술에 관하여 말씀해 주십시오.

3. 실버타운에 적용되어 있는 스마트 기술의 위치를 말씀해 주십시오.

4. 말씀하신 스마트 기술을 실버타운에 적용하신 이유가 있으면 말씀해 주십시오.

5. 각 스마트 기술이 어떻게 작동하는지 말씀해 주십시오.

6. 각 스마트 기술을 실버타운의 일정한 장소에 적용하신 이유를 말씀해 주십시오.

7. 이전과 비교하여, 실버타운에 스마트 기술 적용으로 인하여 노인들의 개별 생활공간 계획이나 공용공간 계획에 있어서 변화가 생긴 것이 있다면 말씀해 주십시오.

\section{Ending Questions}

8. 만약, 귀하의 말씀이 노인 생활환경 개발에 반영된다면, 스마트 기술 적용에 관하여 디자이너와 개발자들에게 하고 싶으신 말씀을 해 주십시오.

9. 향후 스마트 기술을 적용한 노인 생활환경 개발에 있어서 이러한 기술은 향후 적용되는 것이 바람직하다고 생각되는 기술이 있으면 말씀해 주십시오.

\section{Requesting Data}

10. 본 연구를 위하여 건물의 설계도 및 관련 도면과 사진들 그리고 실버타운에 적용된 기술의 이해를 도울 수 있는 시스템 관련 자료와 
사진들 제공을 부탁 드립니다. 제공해주신 자료는 본 연구를 위한 목적으로만 사용될 것 입니다.

자료제공 및 인터뷰에 참여해 주심을 다시 한번 감사 드립니다. 


\section{Appendix 5. Survey Questionnaires for Elderly_English}

\section{Smart Silver Towns: Prospects and Challenges}

The survey includes questions about the range of applied smart technology in silver town and will solicit information about your preferences for the technologies in the living environment. The aim of the survey is to investigate the elderly preferences for the use of technologies in their living environment.

It will be highly appreciated if your responses can be returned in the included envelope to Manhyeon Doosan Weve Apt., Sanghyeon-2 dong,Suji-gu,Yongin-si, Gyeonggi-do, Korea, 448-516 or Mr Sung Jun Kim, PhD candidate <s.kim5@pgrad.unimelb.edu.au>.

Your cooperation and willingness to share time and information are much appreciated.

Thank you very much.

\section{Name:}

\section{Contact number:}

Unit number / Silver town name:

* Please mark circle $(O)$ in each question*

\section{QUESTIONS}

\section{'Care'-related technology}

Q1. Are you aware of 'real-time health check system' in your place? (circle) Yes No

Q2. Do you know where it is? If yes, could you write us the location? 
Q3. How often do you use 'real-time health check system'? (circle)
A. Often
B. Neither often nor none
C. None

Q4. Are you satisfied with 'real-time health check system'? (circle)
A. Satisfied
B. Neither satisfied nor dissatisfied
C. Dissatisfied

Q5. Are you aware of 'nursing \& emergency call system' in your place? (circle) Yes No

Q6. Do you know where it is? If yes, could you write us the location?

Q7. How often do you use 'nursing \& emergency call system'? (circle)
A. Often
B. Neither often nor none
C. None

Q8. Are you satisfied with 'nursing \& emergency call system'? (circle)
A. Satisfied
B. Neither satisfied nor dissatisfied
C. Dissatisfied

Q9. Are you aware of 'tracking system' in your place? (circle) Yes No

Q10. Do you know where it is? If yes, could you write us the location?

Q11. How often do you use 'tracking system'? (circle)
A. Often
B. Neither often nor none
C. None 
Q12. Are you satisfied with 'tracking system'? (circle)
A. Satisfied
B. Neither satisfied nor dissatisfied
C. Dissatisfied

Q13. Are you aware of 'portable emergency pager' in your place? (circle) Yes No

Q14. Do you know where it is? If yes, could you write us the location?

Q15. How often do you use 'portable emergency pager'? (circle)
A. Often
B. Neither often nor none
C. None

Q16. Are you satisfied with 'portable emergency pager'? (circle)
A. Satisfied
B. Neither satisfied nor dissatisfied
C. Dissatisfied

Q17. Are you aware of 'movement detection sensor' in your place? (circle) Yes No

Q18. Do you know where it is? If yes, could you write us the location?

Q19. How often do you use 'movement detection sensor'? (circle)
A. Often
B. Neither often nor none
C. None

Q20. Are you satisfied with 'movement detection sensor'? (circle)
A. Satisfied
B. Neither satisfied nor dissatisfied
C. Dissatisfied 
Q21. Could you tell me about your preferences of among 'care'-related technology? [Number 1 (the most preferred) 5 (the least preferred)]
A. Real-time health check system
B. Nursing \& emergency call system
C. Tracking system
D. Portable emergency pager
E. Movement detection sensor

\section{'Environmental-control'-related technology}

Q22. Are you aware of 'indoor air quality control system' in your place? (circle) Yes No

Q23. Do you know where it is? If yes, could you write us the location?

Q24. How often do you use 'indoor air quality control system'? (circle)
A. Often
B. Neither often nor none
C. None

Q25. Are you satisfied with 'indoor air quality control system'? (circle)
A. Satisfied
B. Neither satisfied nor dissatisfied
C. Dissatisfied

Q26. Are you aware of 'home network system' in your place? (circle) Yes No

Q27. Do you know where it is? If yes, could you write us the location?

Q28. How often do you use 'home network system'? (circle)
A. Often
B. Neither often nor none
C. None 
Q29. Are you satisfied with 'home network system'? (circle)
A. Satisfied
B. Neither satisfied nor dissatisfied
C. Dissatisfied

Q30. Are you aware of 'light control/energy-saving system' in your place? (circle) Yes No

Q31. Do you know where it is? If yes, could you write us the location?

Q32. How often do you use 'light control/energy-saving system'? (circle)
A. Often
B. Neither often nor none
C. None

Q33. Are you satisfied with 'light control/energy-saving system'? (circle)
A. Satisfied
B. Neither satisfied nor dissatisfied
C. Dissatisfied

Q34. Are you aware of 'elevator call system' in your place? (circle) Yes No

Q35. Do you know where it is? If yes, could you write us the location?

Q36. How often do you use 'elevator call system'? (circle)
A. Often
B. Neither often nor none
C. None

Q37. Are you satisfied with 'elevator call system'? (circle)
A. Satisfied
B. Neither satisfied nor dissatisfied
C. Dissatisfied 
Q38. Are you aware of 'remote inspection system' in your place? (circle)

Yes

No

Q39. Do you know where it is? If yes, could you write us the location?

Q40. How often do you use 'remote inspection system'? (circle)
A. Often
B. Neither often nor none
C. None

Q41. Are you satisfied with 'remote inspection system'? (circle)
A. Satisfied
B. Neither satisfied nor dissatisfied
C. Dissatisfied

Q42. Could you tell me about your preferences of among 'environmental-control'related technology? [Number 1 (the most preferred) 5 (the least preferred)]
A. Indoor air quality control system
B. Home network system
C. Lighting control/energy-saving system
D. Elevator call system
E. Remote inspection system

\section{'Security'-related technology}

Q43. Are you aware of 'monitoring system' in your place? (circle) Yes No

Q44. Do you know where it is? If yes, could you write us the location?

Q45. How often do you use 'monitoring system'? (circle)
A. Often
B. Neither often nor none
C. None 
Q46. Are you satisfied with 'monitoring system'? (circle)
A. Satisfied
B. Neither satisfied nor dissatisfied
C. Dissatisfied

Q47. Are you aware of 'card key system' in your place? (circle) Yes No

Q48. Do you know where it is? If yes, could you write us the location?

Q49. How often do you use 'card key system'? (circle)
A. Often
B. Neither often nor none
C. None

Q50. Are you satisfied with 'card key system'? (circle)
A. Satisfied
B. Neither satisfied nor dissatisfied
C. Dissatisfied

Q51. Could you tell me about your preferences of among 'security'-related technology? [Number 1 (the most preferred) 2 (the least preferred)]
a. Monitoring system
b. Card key system

\section{'Technologies in communal facilities' in silver town}

Q52. Are you aware of 'CCTV system' in silver town?

Yes No

Q53. Do you know where it is? If yes, could you write us the location?

Q54. How often do you use 'CCTV system'?
A. Often
B. Neither often nor none 
C. None

Q55. Are you satisfied with 'CCTV system'?
A. Satisfied
B. Neither satisfied nor dissatisfied
C. Dissatisfied

Q56. Are you aware of 'movement detection sensors' in silver town?

Yes No

Q57. Do you know where it is? If yes, could you write us the location?

Q58. How often do you use 'movement detection sensors'?
A. Often
B. Neither often nor none
C. None

Q59. Are you satisfied with 'movement detection sensors'?
A. Satisfied
B. Neither satisfied nor dissatisfied
C. Dissatisfied

Q60. Are you aware of 'parking control system' in silver town?

Yes No

Q61. Do you know where it is? If yes, could you write us the location?

Q62. How often do you use 'parking control system'?
A. Often
B. Neither often nor none
C. None

Q63. Are you satisfied with 'parking control system'?
A. Satisfied
B. Neither satisfied nor dissatisfied
C. Dissatisfied 
Q64. Could you tell me about your preferences of among 'technologies in communal facilities' in silver town? [Number 1 (the most preferred) 3 (the least preferred)]
A. CCTV system
B. Movement detection sensors
C. Parking control system

\section{DEMOGRAPHICS}

D1. How long have you lived in silver town?

D2. What is your age category?
A. Between 60 and 65
B. Between 66 and 70
C. Between 71 and 75
D. Between 76 and 80
E. Between 81 and 85
F. Over 86

D3. What is your gender?

Female Male

D4. Do you live alone or with your spouse?

Live alone With spouse

D5. Could you tell me about your educational background? Please circle your highest educational qualification in the following list.
A. None, High school incomplete (grade 10-12)
B. High school graduate
C. College degree incomplete - University graduate incomplete (Bachelor degree)
D. University graduate
E. Post-graduate degree or professional schooling or higher 
D6. Could you tell me about your monthly income statue? What is your (if you live with spouse, include spouse's income) average monthly income from all sources after taxes?
A. Less than 2,000,000
B. $2,000,001$ to $3,000,000$
C. $3,000,001$ to $4,000,000$
D. 4 4,000,001 to W 5,000,000
E. W 5,000,001 to W 6,000,000
F. W 6,000,001 to $7,000,000$
G. W 7,000,001 or more 


\section{Appendix 6. Survey Questionnaires for Elderly_Korean}

스마트 실버타운: 향후 전망과 도전

본 설문은 여러분께서 거주하시는 실버타운에서 사용되는 기술에 관한 여러분의 선호도를 조사하는 것을 목적으로 하고 있습니다.

설문지의 내용은 실버타운에 적용되어 있는 스마트 기술에 관한 것과 제시된 기술에 관한 여러분들의 선호경향을 알아보도록 작성되어 있습니다.

예를 들면, 1 . 건강검진 등 여러분의 건강한 생활에 관련된 기술 항목, 2. 에너지 절약 및 가전제품 제어 등 생활환경 관리에 관련된 기술 항목, 3. 보안 등 안전한 생활에 관련된 기술 항목, 4. 부대시설에 관련된 기술 항목, 5. 여러분의 간단한 개인 정보에 관련된 항목 등으로 나누어져 있습니다.

본 설문조사를 허락해 주심을 감사 드리며 설문은 작성 후 함께 동봉되어 있는 봉투에 넣어 아래 주소로 보내주시면 논문을 위하여 소중하게 사용하도록 하겠습니다. 보내주실 주소는 우편번호 448-516, 경기도 용인시 수지구 상현 2 동 만현마을 두산 위브 아파트 802 동 802 호이며 받는 사람은 김성준 입니다.

또는 전자메일을 사용하셔도 되며, 주소는 <s.kim5@pgrad.unimelb.edu.au> 입니다. 본 설문조사에 참여해 주셔서 대단히 감사합니다.

성명:

전화번호 / 이메일:

주소:

* 모든 문항에 해당되는 곳에 $\mathrm{O}$ 표시를 해주십시오. 


\section{'건강한 생활' 관련 기술에 관한 질문입니다.}

Q65. 귀하)께서는 '실시간 건강 검진 시스템’(여러분의 건강상태를 실시간으로 검사해주는 시스템입니다.) 이 본인의 생활 공간에 있는 것을 알고 계십니까?

예 아니오

Q66.만약 알고 계시다면 설치된 장소를 적어주십시오.

Q67. ‘실시간 건강 검진 시스템’ 사용빈도에 관한 질문입니다. 얼마나 자주 사용하십니까?
A. 자주사용 한다
B. A 도 C도 아니다
C. 전혀 사용하지 않는다

Q68. '실시간 건강 검진 시스템’에 만족하십니까?
A. 만족한다
B. A 도 C도 아니다
C. 만족하지 못한다

Q69.귀하는 ‘응급 호출 시스템’(응급 상황 시에 도움을 요청할 수 있는 시스템입니다.) 이 본인의 생활 공간에 있는 것을 알고 계십니까?

예 아니오

Q70.만약 알고 계시다면 설치된 장소를 적어주십시오.

Q71. ‘응급 호출 시스템’ 사용빈도에 관한 질문입니다. 얼마나 자주 사용하십니까?
A. 자주사용 한다
B. A 도 C도 아니다
C. 전혀 사용하지 않는다 
Q72. '응급 호출 시스템’에 만족하십니까?
A. 만족한다
B. A 도 C도 아니다
C. 만족하지 못한다

Q73.귀하께서는 '무선 위치 확인 시스템’(유사시에 여러분의 위치를 가족들이나 관리자들이 무선으로 확인할 수 있는 시스템입니다.) 이 본인의 생활 공간에 있는 것을 알고 계십니까?

예

아니오

Q74.만약 알고 계시다면 설치된 장소를 적어주십시오.

Q75. ‘무선 위치 확인 시스템’ 사용빈도에 관한 질문입니다. 얼마나 자주 사용하십니까?
A. 자주사용 한다
B. A 도 C도 아니다
C. 전혀 사용하지 않는다

Q76. ‘무선 위치 확인 시스템’에 만족하십니까?
A. 만족한다
B. A 도 C 도 아니다
C. 만족하지 못한다

Q77. 귀하)ㅔㅔ서는 '무선 응급 호출기'(응급상황 시에 여러분)께서 도움을 요청할 수 있는 휴대용 응급 호출기 입니다.) 가 본인의 생활 공간에 있는 것을 알고 계십니까?

예

아니오

Q78. 만약 알고 계시다면 설치된 장소를 적어주십시오.

Q79. '무선 응급 호출기’ 사용빈도에 관한 질문입니다. 얼마나 자주 사용하십니까?
A. 자주사용 한다
B. A 도 C도 아니다
C. 전혀 사용하지 않는다 
Q80. ‘무선 응급 호출기’에 만족하십니까?
A. 만족한다
B. A 도 C도 아니다
C. 만족하지 못한다

Q81.귀하께서는 ‘무 동작 감지센서’(유사시를 대비하여 여러분의 움직임에 이상이 있는지 감지해 주는 센서입니다.) 가 본인의 생활 공간에 있는 것을 알고 계십니까?

예

$$
\text { 아니오 }
$$

Q82.만약 알고 계시다면 설치된 장소를 적어주십시오.

Q83. ‘무 동작 감지센서’ 사용빈도에 관한 질문입니다. 얼마나 자주 사용하십니까?
A. 자주사용 한다
B. A 도 C도 아니다
C. 전혀 사용하지 않는다

Q84. '무 동작 감지센서’에 만족하십니까?
A. 만족한다
B. A 도 C도 아니다
C. 만족하지 못한다

Q85.지금까지 '건강한 생활'에 관련된 기술에 관한 질운이었습니다. 이 기술에 관한 귀하의 선호도를 숫자 1 부터 5 를 사용하여 표시해 주십시오. [1. 가장 선호함 2. 선호함 3. 보통 4. 선호하지 않음 5. 가장 선호하지 않음]
F. (
) 실시간 건강 검진 시스템
G. (
) 응급 호출 시스템
H. (
) 무선 위치 확인 시스템
I. (
) 무선 응급 호출기
J. (
) 무 동작 감지센서

'생활환경 관리' 관련 기술에 관한 질문입니다. 
Q86. 귀하)께서는 '실내환경 자동제어 시스템'(실내의 공기환경 조절, 온도조절 등 실내환경을 여러분이 본인의 쾌정 정도에 맞추어 조절 할 수 있는 시스템입니다.) 이 본인의 생활 공간에 있는 것을 알고 계십니까?

예

아니오

Q87.만약 알고 계시다면 설치된 장소를 적어주십시오.

Q88. '실내환경 자동제어 시스템' 사용빈도에 관한 질문입니다. 얼마나 자주 사용하십니까?
A. 자주사용 한다
B. A 도 C도 아니다
C. 전혀 사용하지 않는다

Q89. ‘실내환경 자동제어 시스템’에 만족하십니까?
A. 만족한다
B. A 도 C도 아니다
C. 만족하지 못한다

Q90.귀하)ㅔㅔ서는 '홈 네트워크 시스템'(여러분의 집안에 있는 가전제품들 (TV, 홈 시어터, 냉장고 등)을 편하게 조절할 수 있도록 되어 있는 시스템입니다.)이 본인의 생활 공간에 있는 것을 알고 계십니까?

예

아니오

Q91.만약 알고 계시다면 설치된 장소를 적어주십시오.

Q92. ‘홈 네트워크 시스템’ 사용빈도에 관한 질문입니다. 얼마나 자주 사용하십니까?
A. 자주사용 한다
B. A 도 C도 아니다
C. 전혀 사용하지 않는다

Q93. '홈 네트워크 시스템’에 만족하십니까?
A. 만족한다
B. A 도 C도 아니다
C. 만족하지 못한다 
Q94.귀하)ㅔㅔ서는 '에너지 절약 (전등 조절 등) 관련 시스템'(여러분의 생활 환경에서 불필요한 에너지 낭비를 줄이기 위해서 전등이나 전기기구를 부재 시 최소한의 에너지만 사용하도록 조절하는 등의 시스템)이 본인의 생활 공간에 있는 것을 알고 계십니까?

예 아니오

Q95. 만약 알고 계시다면 설치된 장소를 적어주십시오.

Q96. ‘에너지 절약 (전등 조절 등) 관련 시스템’ 사용빈도에 관한 질문입니다. 얼마나 자주 사용하십니까?
A. 자주사용 한다
B. A 도 C도 아니다
C. 전혀 사용하지 않는다

Q97. ‘에너지 절약 (전등 조절 등) 관련 시스템’에 만족하십니까?
A. 만족한다
B. A 도 C도 아니다
C. 만족하지 못한다

Q98. 귀하께서는 ‘엘리베이터 호출 시스템’(여러분이 필요 시에 생활공간에서 엘리베이터를 여러분이 계신 층으로 이동, 대기시킬 수 있는 시스템입니다.) 이 본인의 생활 공간에 있는 것을 알고 계십니까?

예 아니오

Q99.만약 알고 계시다면 설치된 장소를 적어주십시오.

Q100. ‘엘리베이터 호출 시스템’ 사용빈도에 관한 질문입니다. 얼마나 자주 사용하십니까?
A. 자주사용 한다
B. A 도 C도 아니다
C. 전혀 사용하지 않는다

Q101. '엘리베이터 호출 시스템’에 만족하십니까?
A. 만족한다 


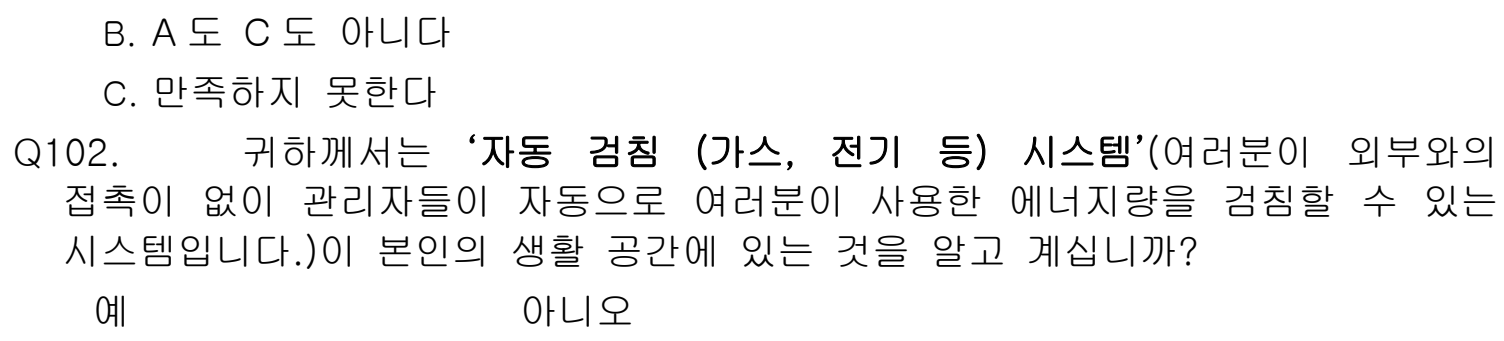

Q103. 만약 알고 계시다면 설치된 장소를 적어주십시오.

Q104. ‘자동 검침 (가스, 전기 등) 시스템’ 사용빈도에 관한 질문입니다. 얼마나 자주 사용하십니까?
A. 자주사용 한다
B. A 도 C도 아니다
C. 전혀 사용하지 않는다

Q105. ‘자동 검침 (가스, 전기 등) 시스템’에 만족하십니까?
A. 만족한다
B. A 도 C도 아니다
C. 만족하지 못한다

Q106. 지금까지 ‘생활환경 관리’에 관련된 기술에 관한 질문이었습니다. 이 기술에 관한 귀하의 선호도를 숫자 1 부터 5 를 사용하여 표시해 주십시오. [1. 가장 선호함 2. 선호함 3. 보통 4. 선호하지 않음 5. 가장 선호하지 않음]
A. (
) 실내환경 자동제어 시스템
B. (
) 홈 네트워크 시스템
C. (
) 에너지 절약 (전등 조절 등) 관련 시스템
D. (
) 엘리베이터 호출 시스템
E. (
) 자동 검침 (가스, 전기 등) 시스템
'안전한 생활' 관련 기술에 관한 질운입니다.

Q107. 귀하)ㅔㅔ서는 ‘모니터 (부재 중 및 방문자 확인 등) 시스템’(여러분이 실내에서 방문자 확인 또는 부재중에도 방문자를 기록하여 확인할 수 있는 시스템입니다.)이 본인의 생활 공간에 있는 것을 알고 계십니까?

예

아니오 
Q108. 만약 알고 계시다면 설치된 장소를 적어주십시오.

Q109. '모니터 (부재 중 및 방문자 확인 등) 시스템’ 사용빈도에 관한 질문입니다. 얼마나 자주 사용하십니까?
A. 자주사용 한다
B. A 도 C도 아니다
C. 전혀 사용하지 않는다

Q110. '모니터 (부재 중 및 방문자 확인 등) 시스템’에 만족하십니까?
A. 만족한다
B. A 도 C도 아니다
C. 만족하지 못한다

Q111. 귀하)ㅔㅔ서는 ‘카드 키 시스템’(여러분이 출입문을 열쇠 없이 맞춤형 카드를 이용하여 출입할 수 있도록 되어 있는 시스템입니다.) 이 본인의 생활 공간에 있는 것을 알고 계십니까?

예

아니오

Q112. 만약 알고 계시다면 설치된 장소를 적어주십시오.

Q113. ‘카드 키 시스템’ 사용빈도에 관한 질문입니다. 얼마나 자주 사용하십니까?
A. 자주사용 한다
B. A 도 C도 아니다
C. 전혀 사용하지 않는다

Q114. ‘카드 키 시스템’에 만족하십니까?
A. 만족한다
B. A 도 C도 아니다
C. 만족하지 못한다

Q115. 지금까지 '안전한 생활’에 관련된 기술에 관한 질문이었습니다. 이 기술에 관한 귀하의 선호도를 숫자 1 부터 2 를 사용하여 표시해 주십시오. [1. 선호함 2. 선호하지 않음]
A. (
) 실내환경 자동제어 시스템 

B. (
) 홈 네트워크 시스템

\section{‘부대시설에 적용된 기술’에 관한 질문입니다.}

Q116. 귀하)ㅔㅔ서는 'CCTV 시스템'(여러분의 안전을 위해 위험 또는 응급상황에 대한 신속한 대응을 위해 설치된 카메라 시스템입니다.) 이 본인의 생활 공간에 있는 것을 알고 계십니까?

예

아니오

Q117. 만약 알고 계시다면 설치된 장소를 적어주십시오.

Q118. ‘CCTV 시스템’ 사용빈도에 관한 질문입니다. 얼마나 자주 사용하십니까?
A. 자주사용 한다
B. A 도 C도 아니다
C. 전혀 사용하지 않는다

Q119. ‘CCTV 시스템’에 만족하십니까?
A. 만족한다
B. A 도 C도 아니다
C. 만족하지 못한다

Q120. 귀하)ㅔㅔ서는 '동작감지 센서’(유사시를 대비하여 부대시설에도 적용되어 여러분의 움직임에 이상이 있는지 감지해 주는 센서입니다.)이 본인의 생활 공간에 있는 것을 알고 계십니까?

예

아니오

Q121. 만약 알고 계시다면 설치된 장소를 적어주십시오.

Q122. ‘동작감지 센서' 사용빈도에 관한 질문입니다. 얼마나 자주 사용하십니까?
A. 자주사용 한다 


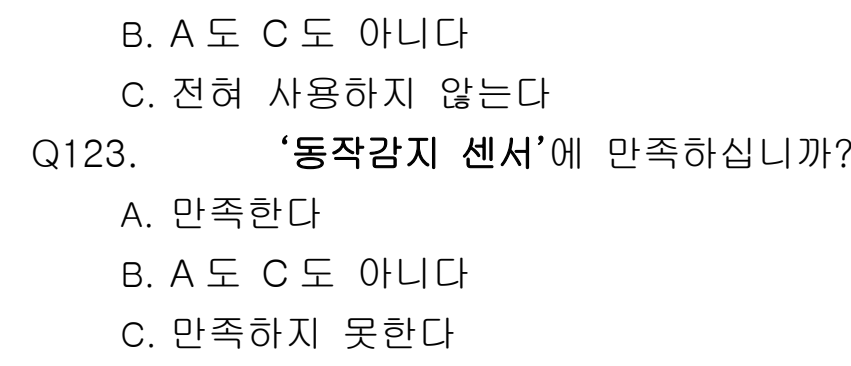

Q124. 귀하)ㅔㅔ서는 “주차관리/상태 확인 시스템’(여러분의 생활공간에서 주차장의 빈공간 유무 및 주차상태를 확인할 수 있는 시스템입니다.) 이 본인의 생활 공간에 있는 것을 알고 계십니까?

예

아니오

Q125. 만약 알고 계시다면 설치된 장소를 적어주십시오.

Q126. '주차관리/상태 확인 시스템’ 사용빈도에 관한 질문입니다. 얼마나 자주 사용하십니까?
A. 자주사용 한다
B. A 도 C도 아니다
C. 전혀 사용하지 않는다

Q127.

‘주차관리/상태 확인 시스템’에 만족하십니까? (O 표시를 해주십시오)
A. 만족한다
B. A 도 C도 아니다
C. 만족하지 못한다

Q128. 지금까지 ‘부대시설에 적용된 기술’에 관련된 기술에 관한 질문이었습니다. 이 기술에 관한 귀하의 선호도를 숫자 1 부터 3 를 사용하여 표시해 주십시오. [1. 선호함 2. 보통 3. 선호하지 않음]
A. (
) CCTV 시스템
B. (
) 동작감지 센서
C. (
) 주차관리/상태 확인 시스템 
D7. 귀하께서 실버타운에 거주하신 기간은 얼마나 되십니까?

년 개월

D8. 귀하의 연령대 및 성별에 관하여 말씀하여 주십시오.

G. 60 세에서 65 세

H. 66 세에서 70 세

I. 71 세에서 75 세

J. 76 세에서 80 세

K. 81 세에서 85 세

L. 86 세 이상

D9. 본인의 성별을 말씀해 주십시오.

(남 / 여)

D10.현재의 거주 상태를 말씀해 주십시오.

(1 인 거주 / 배우자와 함)께 거주)

D11. 귀하의 교육 정도 (최종학력)을 말씀해 주십시오. (O 표시를 해주십시오)
A. 고등학교 중퇴
B. 고등학교 졸업
C. 전문대학 중퇴 - 대학교 중퇴
D. 대학교 졸업
E. 대학원 중퇴 - 대학원 졸업 (석사, 박사과정 또는 전문대학원(법, 의학))- 이상

D12. 귀하의 평균 월 수입 (세금을 제한 후)에 관하여 말씀해 주십시오. (만약 배우자의 수입이 있다, 포함하여 말씀해 주십시오).

H. $\# 2,000,000$ 이하

I. \# 2,000,001 이상 \# 3,000,000

J. $\# 3,000,001$ 이상 $\$ 4,000,000$

K. \# 4,000,001 이상 \# 5,000,000

L. \# 5,000,001 이상 \# 6,000,000

M. $* 6,000,001$ 이상 $\# 7,000,000$

N. $\# 7,000,001$ 이상

O. 모름 
** 설문조사에 참여해 주셔서 대단히 감사 드립니다. ** 


\section{University Library}

\section{- M I I N E R VA \\ A gateway to Melbourne's research publications}

Minerva Access is the Institutional Repository of The University of Melbourne

Author/s:

Kim, Sung Jun

Title:

Smart silver towns: prospects and challenges

Date:

2017

Persistent Link:

http://hdl.handle.net/11343/215895

Terms and Conditions:

Terms and Conditions: Copyright in works deposited in Minerva Access is retained by the copyright owner. The work may not be altered without permission from the copyright owner. Readers may only download, print and save electronic copies of whole works for their own personal non-commercial use. Any use that exceeds these limits requires permission from the copyright owner. Attribution is essential when quoting or paraphrasing from these works. 